Intravenous magnesium sulphate and sotalol for prevention of atrial fibrillation after coronary artery bypass surgery: a systematic review and economic evaluation

J Shepherd, J Jones, GK Frampton, Ł Tanajewski, $D$ Turner and A Price

June 2008

Health Technology Assessment NHS R\&D HTA Programme www.hta.ac.uk

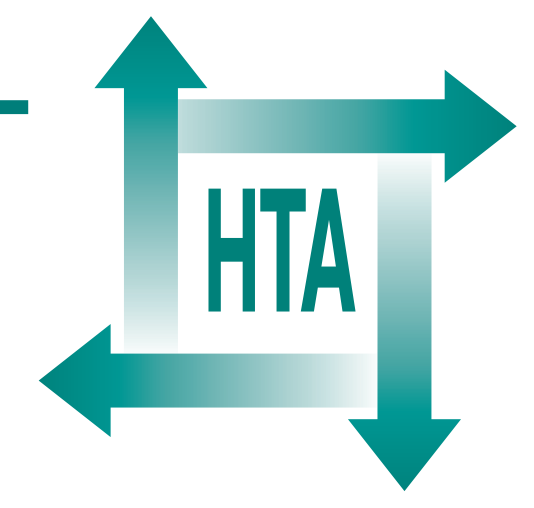




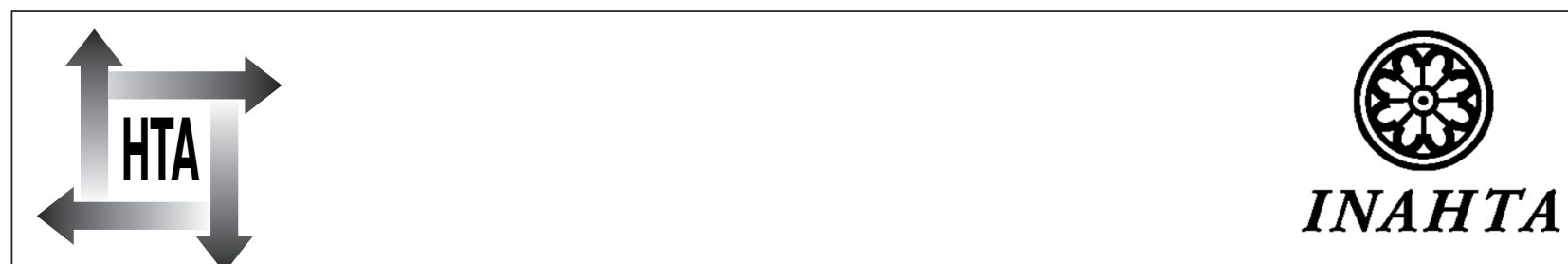

How to obtain copies of this and other HTA Programme reports.

An electronic version of this publication, in Adobe Acrobat format, is available for downloading free of charge for personal use from the HTA website (http://www.hta.ac.uk). A fully searchable CD-ROM is also available (see below).

Printed copies of HTA monographs cost $£ 20$ each (post and packing free in the UK) to both public and private sector purchasers from our Despatch Agents.

Non-UK purchasers will have to pay a small fee for post and packing. For European countries the cost is $£ 2$ per monograph and for the rest of the world $£ 3$ per monograph.

You can order HTA monographs from our Despatch Agents:

- fax (with credit card or official purchase order)

- post (with credit card or official purchase order or cheque)

- phone during office hours (credit card only).

Additionally the HTA website allows you either to pay securely by credit card or to print out your order and then post or fax it.

\section{Contact details are as follows:}

HTA Despatch

c/o Direct Mail Works Ltd

4 Oakwood Business Centre

Downley, HAVANT PO9 2NP, UK
Email: orders@hta.ac.uk

Tel: 02392492000

Fax: 02392478555

Fax from outside the UK: +442392478555

$\mathrm{NHS}$ libraries can subscribe free of charge. Public libraries can subscribe at a very reduced cost of $£ 100$ for each volume (normally comprising 30-40 titles). The commercial subscription rate is $£ 300$ per volume. Please see our website for details. Subscriptions can only be purchased for the current or forthcoming volume.

\section{Payment methods}

Paying by cheque

If you pay by cheque, the cheque must be in pounds sterling, made payable to Direct Mail Works Ltd and drawn on a bank with a UK address.

Paying by credit card

The following cards are accepted by phone, fax, post or via the website ordering pages: Delta, Eurocard, Mastercard, Solo, Switch and Visa. We advise against sending credit card details in a plain email.

Paying by official purchase order

You can post or fax these, but they must be from public bodies (i.e. NHS or universities) within the UK. We cannot at present accept purchase orders from commercial companies or from outside the UK.

\section{How do I get a copy of HTA on CD?}

Please use the form on the HTA website (www.hta.ac.uk/htacd.htm). Or contact Direct Mail Works (see contact details above) by email, post, fax or phone. HTA on CD is currently free of charge worldwide.

The website also provides information about the HTA Programme and lists the membership of the various committees. 


\title{
Intravenous magnesium sulphate and sotalol for prevention of atrial fibrillation after coronary artery bypass surgery: a systematic review and economic evaluation
}

\author{
J Shepherd, ${ }^{*}$ J Jones, GK Frampton, $Ł$ Tanajewski, ${ }^{\dagger}$ \\ D Turner and A Price
}

Southampton Health Technology Assessments Centre (SHTAC),

University of Southampton, UK

* Corresponding author

† Present address: Department of Health Technology Assessment, The Agency for Health

Technology Assessment in Poland (AHTAPol), Poland

Declared competing interests of authors: none

Published June 2008

This report should be referenced as follows:

Shepherd J, Jones J, Frampton GK, Tanajewski Ł, Turner D, Price A. Intravenous magnesium sulphate and sotalol for prevention of atrial fibrillation after coronary artery bypass surgery: a systematic review and economic evaluation. Health Technol Assess 2008; 12(28).

Health Technology Assessment is indexed and abstracted in Index Medicus/MEDLINE, Excerpta Medica/EMBASE and Science Citation Index Expanded (SciSearch ${ }^{\circledR}$ ) and Current Contents ${ }^{\circledR} /$ Clinical Medicine. 


\section{NIHR Health Technology Assessment Programme}

$\mathrm{T}$ he Health Technology Assessment (HTA) Programme, part of the National Institute for Health Research (NIHR), was set up in 1993. It produces high-quality research information on the effectiveness, costs and broader impact of health technologies for those who use, manage and provide care in the NHS. 'Health technologies' are broadly defined as all interventions used to promote health, prevent and treat disease, and improve rehabilitation and long-term care.

The research findings from the HTA Programme directly influence decision-making bodies such as the National Institute for Health and Clinical Excellence (NICE) and the National Screening Committee (NSC). HTA findings also help to improve the quality of clinical practice in the NHS indirectly in that they form a key component of the 'National Knowledge Service'.

The HTA Programme is needs-led in that it fills gaps in the evidence needed by the NHS. There are three routes to the start of projects.

First is the commissioned route. Suggestions for research are actively sought from people working in the NHS, the public and consumer groups and professional bodies such as royal colleges and NHS trusts. These suggestions are carefully prioritised by panels of independent experts (including NHS service users). The HTA Programme then commissions the research by competitive tender.

Secondly, the HTA Programme provides grants for clinical trials for researchers who identify research questions. These are assessed for importance to patients and the NHS, and scientific rigour.

Thirdly, through its Technology Assessment Report (TAR) call-off contract, the HTA Programme commissions bespoke reports, principally for NICE, but also for other policy-makers. TARs bring together evidence on the value of specific technologies.

Some HTA research projects, including TARs, may take only months, others need several years. They can cost from as little as $£ 40,000$ to over $£ 1$ million, and may involve synthesising existing evidence, undertaking a trial, or other research collecting new data to answer a research problem.

The final reports from HTA projects are peer-reviewed by a number of independent expert referees before publication in the widely read journal series Health Technology Assessment.

\section{Criteria for inclusion in the HTA journal series}

Reports are published in the HTA journal series if (1) they have resulted from work for the HTA Programme, and (2) they are of a sufficiently high scientific quality as assessed by the referees and editors.

Reviews in Health Technology Assessment are termed 'systematic' when the account of the search, appraisal and synthesis methods (to minimise biases and random errors) would, in theory, permit the replication of the review by others.

The research reported in this issue of the journal was commissioned by the HTA Programme as project number 07/18/01. The contractual start date was in April 2007. The draft report began editorial review in August 2007 and was accepted for publication in February 2008. As the funder, by devising a

commissioning brief, the HTA Programme specified the research question and study design. The authors have been wholly responsible for all data collection, analysis and interpretation, and for writing up their work. The HTA editors and publisher have tried to ensure the accuracy of the authors' report and would like to thank the referees for their constructive comments on the draft document. However, they do not accept liability for damages or losses arising from material published in this report.

The views expressed in this publication are those of the authors and not necessarily those of the HTA Programme or the Department of Health.

Editor-in-Chief:

Series Editors:

Programme Managers:
Professor Tom Walley

Dr Aileen Clarke, Dr Peter Davidson, Dr Chris Hyde, Dr John Powell, Dr Rob Riemsma and Professor Ken Stein

Sarah Llewellyn Lloyd, Stephen Lemon, Kate Rodger,

Stephanie Russell and Pauline Swinburne

ISSN $1366-5278$

\section{(C) Queen's Printer and Controller of HMSO 2008}

This monograph may be freely reproduced for the purposes of private research and study and may be included in professional journals provided that suitable acknowledgement is made and the reproduction is not associated with any form of advertising.

Applications for commercial reproduction should be addressed to: NCCHTA, Alpha House, Enterprise Road, Southampton Science Park, Chilworth, Southampton SOI6 7NS, UK. 


\title{
Abstract
}

\section{Intravenous magnesium sulphate and sotalol for prevention of atrial fibrillation after coronary artery bypass surgery: a systematic review and economic evaluation}

\author{
J Shepherd, ${ }^{*}$ J Jones, GK Frampton, $Ł$ Tanajewski, ${ }^{\dagger} D$ Turner and A Price
}

\author{
Southampton Health Technology Assessments Centre (SHTAC), University of Southampton, UK \\ * Corresponding author \\ † Present address: Department of Health Technology Assessment, The Agency for Health Technology Assessment \\ in Poland (AHTAPol), Poland
}

\begin{abstract}
Objectives: To assess the clinical and costeffectiveness of magnesium sulphate compared with sotalol, and to assess the clinical effectiveness of magnesium sulphate compared with placebo in the prevention of atrial fibrillation (AF) in patients who have had a coronary artery bypass graft (CABG). Data sources: Major electronic databases were searched from December 2003 to May 2007.
\end{abstract}

Review methods: Selected studies were assessed, subjected to data extraction using a standard template and quality assessment using published criteria.

A simple short-term economic model was developed, informed by a systematic review of economic evaluations and populated with data from a review of costing/resource-use studies and other published studies. The cost-effectiveness of magnesium sulphate as prophylaxis was estimated for a set of base-case assumptions and the robustness of these results was assessed using deterministic and probabilistic sensitivity analysis.

Results: Twenty-two papers met the inclusion criteria reporting 15 trials which all compared magnesium sulphate with placebo or control. They ranged in size from 15 to 176 patients randomised, and were conducted in Europe, the USA and Canada. The standard of reporting was generally poor, with details of key methodological attributes difficult to elucidate. No trials were identified that specifically aimed to compare magnesium sulphate with sotalol. Of 1070 patients in the pooled magnesium group, 230 (21\%) developed postoperative AF, compared with 307 of I03I (30\%) patients in the placebo or (control) group. Meta-analysis using a fixed-effects model generated a pooled odds ratio (OR) that was significantly less than I. $0[\mathrm{OR}=0.65,95 \%$ confidence interval $(\mathrm{Cl}) 0.53$ to 0.79 , test for overall effect $p<0.000 I]$, but with statistically significant heterogeneity $\left(I^{2}=63.4 \%\right.$, $p=0.0005)$. Two randomised controlled trials (RCTs) were notable as they had relatively lower ORs in favour of magnesium sulphate. When these were removed from the analyses the pooled OR remained statistically significant, but heterogeneity no longer remained significant. These two studies tended to impart a highly significant reduction in the odds of $\mathrm{AF}$ to whichever subgroup they were analysed in. When studies were ordered by total duration of prophylaxis, an apparent relationship between duration and odds of AF was evident, with decreasing odds of AF as duration of prophylaxis increased. This was confirmed by linear regression analysis $\left(R^{2}=0.743, p<0.001\right)$. When the data were grouped into three classes according to duration, a statistically significant intervention effect was only present for the longest duration $(O R=0.12$, $95 \% \mathrm{Cl} 0.06$ to $0.23, p=0.0000 \mathrm{I})$. Statistically significant intervention effects were associated with the initiation of prophylaxis 12 hours or more before surgery (OR $0.26 ; 95 \% \mathrm{Cl} 0.16$ to 0.44 , test for overall effect $p=0.0000 \mathrm{I}$, fixed-effects model) and less than 12 hours before surgery or during the surgery itself (OR $=0.73,95 \% \mathrm{Cl} 0.56$ to 0.97 , test for overall effect $p=0.03$, fixed-effects model), but not when prophylaxis was initiated at the end of surgery or postsurgery $(\mathrm{OR}=0.85,95 \% \mathrm{Cl} 0.59, \mathrm{I} .22, p=0.37$, fixed-effects model). When studies were ordered by total dose of intravenous magnesium sulphate $(<25 \mathrm{~g})$, the odds of AF were independent of the dose. A notable exception was that for a total dose of $9 \mathrm{~g}$ magnesium sulphate; here the odds of AF were significantly reduced relative to the control group, although this may be explained by the fact that these studies had excluded patients who were on antiarrhythmic drugs and so may have been at higher risk of AF. Sixty-three potentially relevant references about cost-effectiveness were identified, but no 
economic evaluations of intravenous magnesium alone as prophylaxis against $A F$ following $C A B G$, compared with sotalol as prophylaxis or no prophylaxis, were identified. Studies reporting resource use by patients with $A F$ following $C A B G$ suggest that while $A F$ significantly increased inpatient stays, by up to 2.3 days in the intensive care unit (ICU) and 3.4 days on the ward, differences in length of stay and costs between patients receiving prophylaxis and those not receiving prophylaxis were not statistically significant. In the base-case analysis, magnesium sulphate prophylaxis resulted in $0.08 \mathrm{I}$ fewer cases of $A F$ at an incremental cost of $\notin 2.55$. The incremental cost-effectiveness ratio (ICER) was $t 32$ per AF case avoided. The estimated difference in average length of stay between the prophylaxis and no-prophylaxis strategies was only 0.24 days, despite a large assumed difference of 3 days for patients experiencing $A F$ in each group ( $I$ extra day in the ICU and 2 extra days on the ward). In a deterministic sensitivity analysis the greatest variation in ICERs was observed for input parameters relating to the baseline risk of $A F$ following CABG and the effectiveness of prophylaxis, cost of prophylaxis and the resource consequences of postoperative AF. The largest ICER (£2092) in the sensitivity analysis was associated with increasing the length of patients' preoperative stay. In the base case it was assumed that admission routines would be identical under both strategies. However, patients receiving prophylaxis by intravenous infusion may have longer preoperative stays. In a probabilistic analysis the majority of the simulations were associated with improved outcomes (in this case fewer cases of AF), but also higher costs. Prophylaxis was the dominant strategy (better outcome at lower cost) in about $41 \%$ of the simulations using the base-case assumptions. Under an alternative scenario where patients receiving prophylaxis are admitted for longer before their operation, to receive their initial infusion, the proportion of simulations where prophylaxis dominates fell to around $5 \%$. The probability of being cost-effective was $99 \%$ at a willingness to pay (WTP) threshold of $£ 2000$ per AF case avoided and $100 \%$ at a WTP threshold of $£ 5000$ per AF case avoided under the base-case assumptions. Under the alternative scenario of longer preoperative stays the probability of being cost-effective at these two threshold values fell to $48 \%$ and $93 \%$, respectively. It is unclear what the appropriate decision threshold should be, given that this model used intermediate rather than final outcomes.

Conclusions: No RCTs were identified that specifically aimed to compare intravenous magnesium with sotalol as prophylaxis for $A F$ in patients undergoing $C A B G$. Intravenous magnesium, compared with placebo or control, is effective in preventing postoperative AF, as confirmed by a statistically significant intervention effect based on pooled analysis of 15 RCTs. It was also found that $A F$ was less likely to occur when a longer duration of prophylaxis was used, and the earlier that prophylaxis is started; however, this finding was associated with two RCTs that had more favourable results than the other trials. No clear relationship between dose and AF was observed, although a lower constant dose rate was associated with the lowest odds of AF. Further research should investigate the relationship between dose, dose rate, duration of prophylaxis, timing of initiation of therapy and patient characteristics, such as degree of risk for AF. This will provide stronger evidence for the optimum delivery of intravenous magnesium in patients undergoing CABG. In the base-case analysis in the economic model, magnesium sulphate prophylaxis reduced the number of postoperative AF cases at a modest increase in cost. The results of the economic analysis are highly sensitive to variation in certain key parameters. Prophylaxis is less likely to be a cost-effective option if it requires changes in admission routines that result in longer preoperative stays than would be the case without prophylaxis. 


\section{Contents}

Glossary and list of abbreviations

\section{Executive summary}

I Aim of the review

2 Background

Description of the underlying health problem

Current service provision

Description of the intervention

3 Methods of assessing clinical

\section{effectiveness}

Inclusion and exclusion criteria

Search strategy

Study inclusion

Data extraction

Quality assessment

Data synthesis

4 Clinical effectiveness results

Quantity and quality of research available

Systematic reviews

Characteristics of the included RCTs

Assessment of effectiveness

5 Economic analysis

Methods for economic analysis

Results of the systematic review of

economic evaluations

SHTAC economic model methods

Results of the economic model

6 Discussion

Clinical effectiveness

Cost-effectiveness vii

ix

1

3

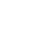

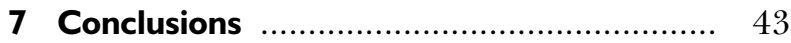

Acknowledgements ............................. 45

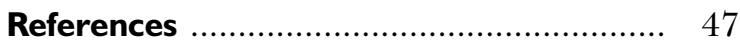

Appendix I Search strategy for RCTs and systematic reviews

Appendix 2 Decision tree for screening abstracts and full papers

Appendix 3 Data extraction templates for the 15 RCTs included in this review

Appendix 4 Studies screened and included in the current review

Appendix 5 Detection and definitions of atrial fibrillation given in the included RCTs

Appendix 6 Exclusion criteria reported for the selection of patients in RCTs

Appendix 7 Search strategy for economic evaluations

Appendix 8 Inclusion criteria for economic review

Health Technology Assessment reports published to date

\section{Health Technology Assessment}

Programme 



\section{Glossary and list of abbreviations}

Technical terms and abbreviations are used throughout this report. The meaning is usually clear from the context, but a glossary is provided for the non-specialist reader. In some cases, usage differs in the literature, but the term has a constant meaning throughout this review.

\section{Glossary}

Atrial arrhythmia Altered atrial rhythm (includes atrial fibrillation, atrial flutter and atrial tachycardia).

Atrial fibrillation Uncoordinated atrial pulsation.

Atrial flutter Increased but coordinated atrial pulsation.

Atrial tachycardia Increased atrial beat rate.

F waves (ECG) Regular, rapid atrial waves indicative of atrial flutter.

Left ventricular ejection fraction The fraction of blood pumped out of a ventricle with each heart beat; one of the most important predictors of prognosis.

P wave (ECG) The wave of depolarisation that spreads from the sinoatrial node throughout the atria.
PQ interval (ECG) The time between the beginning of atrial depolarisation and the beginning of ventricular depolarisation.

QRS complex (ECG) Deflections in the tracing comprising the $\mathrm{Q}, \mathrm{R}$ and $\mathrm{S}$ waves indicating currents generated when the ventricles depolarise before their contraction.

QT interval The time between the start of the $Q$ wave and the end of the $T$ wave in the heart's electrical cycle.

Supraventricular arrhythmia A rhythmic abnormality of the heart caused by impulses originating above the ventricles, e.g. in the atrioventricular (sinoatrial) node; may be synonymous with atrial arrhythmia. 


\section{List of abbreviations}

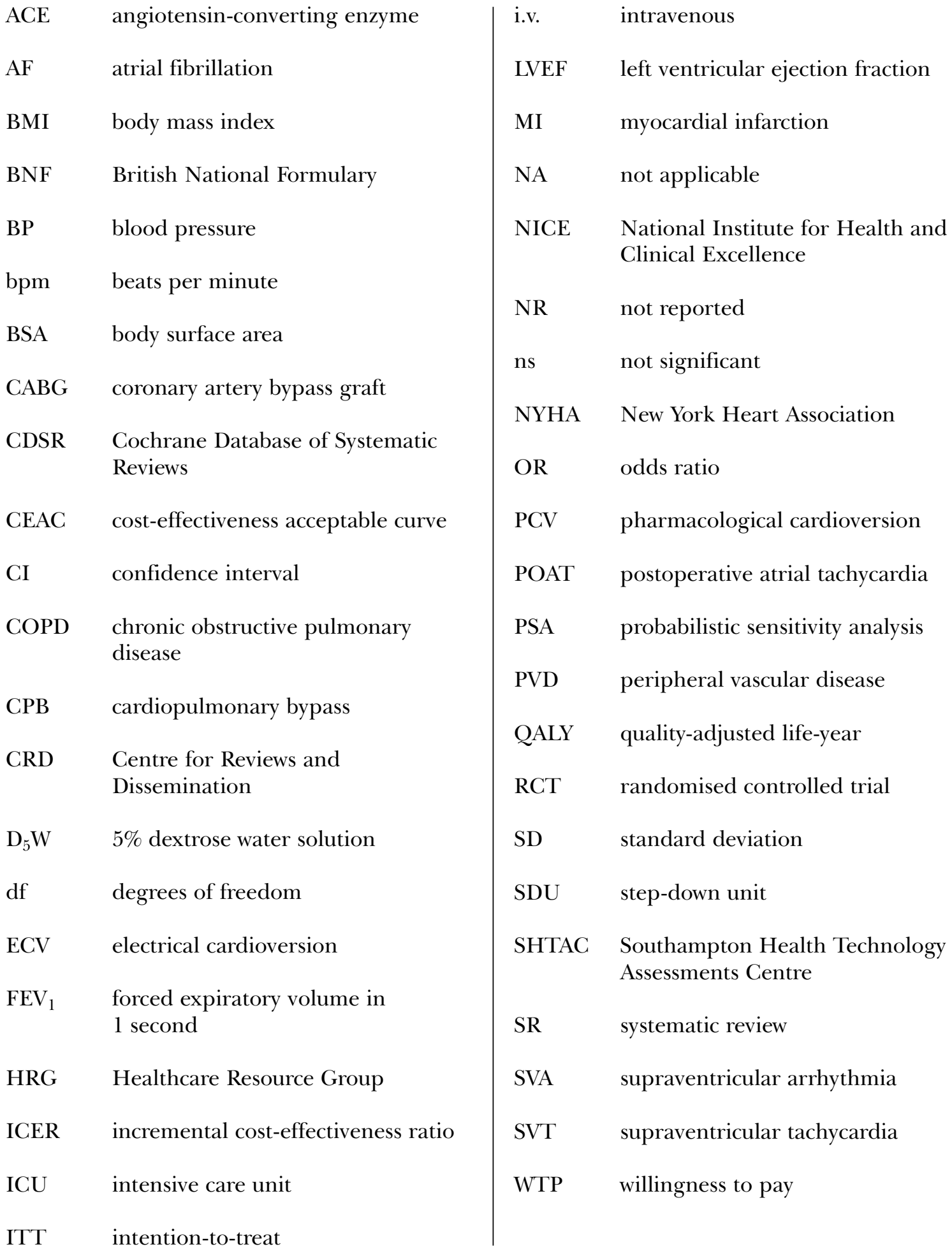

All abbreviations that have been used in this report are listed here unless the abbreviation is well known (e.g. NHS), or it has been used only once, or it is a non-standard abbreviation used only in figures/tables/appendices in which case the abbreviation is defined in the figure legend or at the end of the table. 


\section{. \\ Executive summary}

\section{Background}

Atrial fibrillation (AF) is a supraventricular arrhythmia characterised by abnormal heart rhythm, with symptoms such as palpitations and nausea. It is one of the most common complications after coronary artery bypass graft (CABG) and $20-40 \%$ of patients experience AF following cardiac or thoracic surgery. AF increases the risk of mortality and morbidity from stroke, heart failure, myocardial infarction and thromboembolism. This can result in prolonged hospitalisation, hospital readmission, excess utilisation of hospital resources and increased health service costs. Risk factors include advanced age (particularly over the age of 50), previous history of AF, male gender, hypertension, diabetes, smoking, myocardial infarction and valvular heart disease.

Clinical guidelines recommend that $\beta$-blockers are used routinely as first choice for the prophylaxis of $\mathrm{AF}$ in all patients undergoing cardiac surgery. It is also recommended that sotalol hydrochloride, a $\beta$-blocker with class III antiarrhythmic activity, is used. Magnesium may also be given to patients undergoing cardiothoracic surgery to reduce hypomagnesaemia, a common occurrence following this kind of surgery. However, it is not a first line choice for prophylaxis and it is not known to what extent it is used in current practice.

\section{Objective}

The aim of this research is to conduct a systematic review and economic evaluation of the clinical and cost-effectiveness of magnesium sulphate compared with sotalol, and to assess the clinical effectiveness of magnesium sulphate compared with placebo in the prevention of atrial fibrillation in patients who have had a CABG.

\section{Methods}

\section{Methods for assessing clinical effectiveness}

A systematic review was conducted to compare intravenous magnesium sulphate with placebo (or control), and intravenous magnesium sulphate with sotalol given as prophylaxis before the onset of $\mathrm{AF}$, in patients over 18 years, undergoing elective isolated CABG. Studies of other magnesium compounds (e.g. chloride, hydroxide or unspecified) were excluded. The primary outcome was incidence of postoperative AF. Supraventricular arrhythmias other than AF (e.g. tachycardias and atrial flutter) and all other nonatrial arrhythmias were excluded. Patient length of postoperative stay and the total length of hospital stay were additional outcomes.

A comprehensive search strategy was developed to identify relevant randomised controlled trials (RCTs) and systematic reviews. As this systematic review updates a previous published systematic review the searches were limited to studies published after the cut-off date for literature searching in that review (December 2003). The strategy was applied to ten general and specialist health and biomedical databases. Titles and abstracts were screened systematically against the inclusion criteria and full papers were ordered for further investigation. All included trials were subjected to data extraction using a standard template and quality assessment using published criteria. Data were analysed by narrative synthesis and quantitative meta-analysis, with sensitivity analyses where necessary. A priori defined subgroup analyses were performed to assess the effects of different delivery strategies for intravenous magnesium, including different total doses, timing of the initiation of prophylaxis and total duration of prophylaxis.

\section{Methods for assessing cost-effectiveness}

A systematic literature search was undertaken to identify economic evaluations of intravenous magnesium sulphate alone as prophylaxis against AF following CABG compared with sotalol as prophylaxis or no prophylaxis. A secondary aim of this review was to identify economic evaluations of other agents used for prophylaxis against postoperative $\mathrm{AF}$ or studies that reported cost/resource-use differences for patients undergoing $\mathrm{CABG}$ who developed AF. The purpose of reviewing these studies was to identify the scope and methods adopted in previous economic evaluations of prophylaxis against postoperative 
$\mathrm{AF}$ and to identify the impact of postoperative $\mathrm{AF}$ on patients' resource use, which would inform the development of an economic model.

A comprehensive search strategy was developed to identify relevant economic evaluations and costing studies. The strategy was applied to a number of general and specialist health and biomedical databases. Titles and abstracts were screened against the inclusion criteria and full papers were ordered for further investigation. Included studies were discussed in a narrative review.

A simple short-term economic model was developed, informed by the systematic review of economic evaluations and populated with data from the review of costing/resource-use studies and other published studies. The cost-effectiveness of magnesium sulphate as prophylaxis was estimated for a set of base-case assumptions and the robustness of these results was assessed using deterministic and probabilistic sensitivity analysis.

\section{Results of the assessment of clinical effectiveness}

The review identified 206 potentially relevant references. Of these, 22 papers met the inclusion criteria, comprising 17 papers that reported parallel-group RCTs (15 RCTs altogether) and five systematic reviews.

Of the 15 trials included, all compared magnesium sulphate with placebo or control. No trials were identified that specifically aimed to compare magnesium sulphate with sotalol. The 15 trials ranged in size from 15 to 176 patients randomised, and were conducted in Europe, the USA and Canada. The standard of reporting was generally poor, with details of key methodological attributes (e.g. method of randomisation and concealment of allocation) difficult to elucidate.

Of 1070 patients in the pooled magnesium group, $230(21 \%)$ developed postoperative AF, compared with 307 of $1031(30 \%)$ patients in the placebo or (control) group. Meta-analysis using a fixed-effects model generated a pooled odds ratio (OR) that was significantly less than $1.0[\mathrm{OR}=0.65,95 \%$ confidence interval (CI) 0.53 to 0.79 , test for overall effect $p<0.0001]$, but with statistically significant heterogeneity $\left(I^{2}=63.4 \%, p=0.0005\right)$. Two RCTs were notable as they had relatively lower ORs in favour of magnesium sulphate. When these were removed from the analyses the pooled OR remained statistically significant, but heterogeneity no longer remained significant. These two studies tended to impart a highly significant reduction in the odds of AF to whichever subgroup they were analysed in.

When studies were ordered by total duration of prophylaxis, an apparent relationship between duration and odds of $\mathrm{AF}$ was evident, with decreasing odds of $\mathrm{AF}$ as duration of prophylaxis increased. This was confirmed by linear regression analysis $\left(R^{2}=0.743, p<0.001\right)$. When the data were grouped into three classes according to whether duration of prophylaxis was 1 day or less, 2-4 days, or 5 days or greater, a statistically significant intervention effect was only present for the longest duration group $(\mathrm{OR}=0.12,95 \% \mathrm{CI}$ 0.06 to $0.23, p=0.00001$ ).

Statistically significant intervention effects were associated with the initiation of prophylaxis 12 hours or more before surgery (OR 0.26 ; $95 \%$ CI 0.16 to 0.44 , test for overall effect $p=0.00001$, fixed-effects model) and less than 12 hours before surgery or during the surgery itself $(\mathrm{OR}=0.73,95 \%$ CI 0.56 to 0.97 , test for overall effect $p=0.03$, fixed-effects model), but not when prophylaxis was initiated at the end of surgery or postsurgery $(\mathrm{OR}=0.85,95 \%$ CI 0.59 , $1.22, p=0.37$, fixed-effects model).

When studies were ordered by total dose of intravenous magnesium sulphate $(<25 \mathrm{~g})$, the odds of $\mathrm{AF}$ were independent of the dose. $\mathrm{A}$ notable exception was that for a total dose of $9 \mathrm{~g}$ magnesium sulphate, the odds of AF were significantly reduced relative to the control group, based on three studies that used this dose, including the two RCTs mentioned above that appeared to contribute to heterogeneity. This may be explained by the fact that each had excluded patients who were on antiarrhythmic drugs. They may have been at higher risk of AF compared with patients in other studies and, if so, might have benefited more from prophylactic magnesium. Within the subgroup of eight studies that maintained a constant dose rate there appears to be a relationship between the dose rate of magnesium sulphate and the odds of AF, with the largest prophylactic effects being seen at the lowest dose rates.

\section{Results of the assessment of cost-effectiveness}

Sixty-three potentially relevant references were found. No economic evaluations of intravenous 
magnesium alone as prophylaxis against $\mathrm{AF}$ following $\mathrm{CABG}$, compared with sotalol as prophylaxis or no prophylaxis, were identified. Four studies were included in the secondary review. One of the included studies was a report of an economic evaluation of oral amiodarone for prophylaxis against AF following CABG. The evaluation suggested that the principal determinant of the cost-effectiveness of prophylaxis against AF is likely to be the length of stay in the intensive care unit (ICU) and on hospital wards. A simple economic model, using a decision tree, was constructed. A flow diagram developed from this decision tree was assessed for its relevance to $\mathrm{UK}$ clinical practice and applicability to modelling the cost-effectiveness of magnesium sulphate prophylaxis. The diagram was taken to be a reasonable representation of current practice for patients developing AF following $\mathrm{CABG}$, subject to modifications that would make it more consistent with current UK and European clinical guidelines.

Studies reporting resource use by patients with AF following $\mathrm{CABG}$ suggest that, while AF significantly increased inpatient stays, by up to 2.3 days in the ICU and 3.4 days on the ward, differences in length of stay and costs between patients receiving prophylaxis and those not receiving prophylaxis were not statistically significant. The lack of significant findings, with respect to differences in length of stay or cost, may reflect clinical trials being powered to detect differences in clinical outcome and not differences in resource use. However, the lack of significant differences may also reflect the fact that, since postoperative AF affects a minority of patients (albeit a large minority), the difference in resource use between patients with and without AF may be diluted when looking at mean values across a cohort of patients.

A simple economic model was developed to estimate the cost-effectiveness of magnesium sulphate prophylaxis against AF following CABG. This was populated with data on the baseline risk of $\mathrm{AF}$ following $\mathrm{CABG}$ and the relative risk of $\mathrm{AF}$ with magnesium sulphate prophylaxis from the meta-analysis, along with cost and resource-use data from published sources. In the base-case analysis, magnesium sulphate prophylaxis resulted in 0.081 fewer cases of AF at an incremental cost of $£ 2.55$. That is, the cost of prophylaxis was slightly higher than the expected savings due to reduced ICU and ward stays resulting from the reduction in AF cases. The incremental costeffectiveness ratio (ICER) was $£ 32$ per AF case avoided. The estimated difference in average length of stay between the prophylaxis and noprophylaxis strategies was only 0.24 days, despite a large assumed difference of 3 days for patients experiencing AF in each group (1 extra day in the ICU and 2 extra days on the ward). In the deterministic sensitivity analysis the greatest variation in ICERs was observed for input parameters relating to the baseline risk of $\mathrm{AF}$ following $\mathrm{CABG}$ and the effectiveness of prophylaxis, the cost of prophylaxis and the resource consequences of postoperative AF. The largest ICER (£2092) in the sensitivity analysis was associated with increasing the length of patients' preoperative stay. In the base case it was assumed that admission routines would be identical under both strategies. However, patients receiving prophylaxis by intravenous infusion may have longer preoperative stays.

In the probabilistic analysis the majority of the simulations were associated with improved outcomes (in this case fewer cases of AF), but also higher costs. Prophylaxis was the dominant strategy (better outcome at lower cost) in about $41 \%$ of the simulations using the base-case assumptions. Under an alternative scenario where patients receiving prophylaxis are admitted for longer before their operation, to receive their initial infusion, the proportion of simulations where prophylaxis dominates falls to around $5 \%$. Analysis using an acceptability curve showed that the probability of magnesium sulphate prophylaxis being cost-effective, compared with surgery with no prophylaxis, increases with willingness to pay (WTP) for a unit of outcome. The probability of being cost-effective was $99 \%$ at a WTP threshold of $£ 2000$ per AF case avoided and $100 \%$ at a WTP threshold of $£ 5000$ per AF case avoided under the base-case assumptions. Under the alternative scenario of longer preoperative stays the probability of being cost-effective at these two threshold values fell to $48 \%$ and $93 \%$, respectively. It is unclear what the appropriate decision threshold should be, given that this model used intermediate rather than final outcomes.

\section{Conclusions}

No RCTs were identified that specifically aimed to compare intravenous magnesium with sotalol as prophylaxis for AF in patients undergoing CABG. Such a comparison does not appear to be clinically meaningful. Intravenous magnesium, compared with placebo or control, is effective in preventing postoperative $\mathrm{AF}$, as confirmed by a statistically 
significant intervention effect based on pooled analysis of 15 RCTs. It was also found that AF was less likely to occur when a longer duration of prophylaxis was used, and the earlier that prophylaxis is started; however, this finding was associated with two RCTs that had more favourable results than the other trials, but with no clear explanation as to why. No clear relationship between dose and AF was observed, although a lower constant dose rate was associated with the lowest odds of AF.

In the base-case analysis in the economic model, magnesium sulphate prophylaxis reduced the number of postoperative AF cases at a modest increase in cost. The results of the economic analysis are highly sensitive to variation in certain key parameters. Prophylaxis is less likely to be a cost-effective option if it requires changes in admission routines that result in longer preoperative stays than would be the case without prophylaxis.

\section{Recommendations for further research}

Further research should investigate the relationship between dose, dose rate, duration of prophylaxis, timing of initiation of therapy and patient characteristics, such as degree of risk for AF. This will provide stronger evidence for the optimum delivery of intravenous magnesium in patients undergoing CABG. 


\section{Chapter I}

\section{Aim of the review}

The aim of this research is to conduct a

systematic review and economic evaluation of the clinical effectiveness and cost-effectiveness of magnesium sulphate compared with sotalol, and to assess the clinical effectiveness of magnesium sulphate compared with placebo in the prevention of atrial fibrillation $(\mathrm{AF})$ in patients who have had a coronary artery bypass graft (CABG). 



\section{Chapter 2 Background}

\section{Description of the underlying health problem}

$\mathrm{AF}$ is a supraventricular arrhythmia characterised by uncoordinated atrial activation with consequent deterioration of atrial mechanical function, and is one of the most common complications after CABG. Between 20 and $40 \%$ of patients experience AF following cardiac or thoracic surgery. ${ }^{1}$ AF usually occurs early in the postoperative period, with $70 \%$ of events developing within 4 days. However, AF sometimes occurs after discharge. ${ }^{2}$

During an episode of AF patients can experience symptoms such as palpitations, nausea and malaise. The management of AF aims to restore sinus rhythm through pharmacological or electrical cardioversion, and to reduce the risk of thromboembolism with the use of antithrombotic drugs (e.g. warfarin or aspirin). Rate control is another management goal, with the use of drugs such as digoxin (for non-acute episodes), $\beta$-blockers and rate-limiting calcium antagonists. Rate control has been shown to be as effective as rhythm control. ${ }^{3}$

AF increases the risk of mortality and morbidity from stroke, heart failure, myocardial infarction, thromboembolism and bleeding from anticoagulation. ${ }^{1}$ This results in prolonged hospitalisation, hospital readmission, excess utilisation of hospital resources and increased health service costs. ${ }^{2}$ Consequently, primary prevention of AF after CABG is of great importance.

The exact cause of AF after CABG is thought to be multifactorial. Risk factors include advanced age (particularly over the age of 50), previous history of AF, male gender, hypertension, diabetes, smoking, myocardial infarction and valvular heart disease. ${ }^{3}$ Magnesium is essential to the functioning of the cardiovascular system and patients with cardiac problems often exhibit abnormal magnesium metabolism. Cardiac surgical procedures may also cause rapid and acute changes in magnesium status.
Approximately 23,000 CABG operations are performed annually in England. ${ }^{4}$ For adults undergoing elective CABG the procedure may be on- or off-pump (i.e. the patient's circulation is, or is not, diverted through a pump oxygenator machine). During surgery the heart is beating when a patient is off-pump and can be either be beating or artificially stopped when the patient is on-pump.

$\mathrm{AF}$ is detected in an ECG by the presence of rapid oscillations or fibrillatory waves that vary in size, shape and timing. A distinction is made between AF and atrial flutter, the latter being a more organised arrhythmia characterised by a sawtooth pattern of regular atrial flutter waves in the ECG.

\section{Current service provision}

European clinical guidelines recommend that $\beta$-blockers are used routinely as first choice for the prophylaxis of $\mathrm{AF}$ in all patients undergoing cardiac surgery. ${ }^{1} \beta$-blockers act as antiarrhythmic drugs principally by attenuating the effects of the sympathetic system on automaticity and conductivity within the heart. ${ }^{5}$ Commonly used $\beta$-blockers include metoprolol, bisoprolol and atenolol. Amiodarone, a class III antiarrhythmic drug, is recommended for all patients undergoing cardiac surgery in whom $\beta$-blocker therapy is not possible.

In 2006 the National Institute for Health and Clinical Excellence (NICE) issued a clinical guideline on the management of $\mathrm{AF}^{6}$ In terms of prophylaxis of postoperative $\mathrm{AF}$ it recommends that one of the following drugs be used: amiodarone, a $\beta$-blocker, sotalol (class III $\beta$-blocker), or a rate-limiting calcium antagonist (e.g. verapamil or diltiazem). In addition, patients undergoing cardiac surgery on pre-existing $\beta$-blocker therapy should continue with this unless contraindications develop (e.g. bradycardia or hypotension). However, the role of magnesium was not assessed and therefore it is not covered by their recommendations. 


\section{Description of the intervention}

Magnesium may be given to patients undergoing cardiothoracic surgery to reduce

hypomagnesaemia, a common occurrence following this kind of surgery. Magnesium may exhibit antiarrhythmic activity through a number of mechanisms including inhibiting L-type calcium channels, which reduces sinus node rate firing. ${ }^{7}$ However, the mechanisms are not fully understood. ${ }^{8}$ Magnesium is not a first line choice for prophylaxis of $\mathrm{AF}$ and there appear to be few data on the extent to which it is used in current practice.

Magnesium may be used in combination with other drugs such as $\beta$-blockers (e.g. bisoprolol or sotalol). ${ }^{9}$ The drug is usually administered intravenously at a dose of $1-4 \mathrm{~g}$ in $10-20 \%$ solution at a rate not exceeding $1.5 \mathrm{ml}$ of $10 \%$ solution, or equivalent per minute, or intravenous infusion of $4 \mathrm{~g}$ in $250 \mathrm{ml}$ of $5 \%$ dextrose at a rate not exceeding $3 \mathrm{ml}$ per minute. It may also be given as an intravenous bolus, intramuscularly or orally in the form of magnesium

glycerophosphate. Prophylaxis with magnesium can begin before, during or after cardiothoracic surgery. The duration of prophylaxis varies from a matter of hours to several days.

Magnesium is well tolerated by patients and is unlikely to cause drug reactions such as plaques associated with antiarrhythmic agent use and the side-effects of drowsiness and lethargy from using $\beta$-blockers. However, it has wide effects on basic biological mechanisms and is unlikely to be particularly targeted in action.

Sotalol hydrochloride (Beta-cardone ${ }^{\circledR}$, Celltech; Sotacor ${ }^{\circledR}$; Bristol-Myers Squibb; non-proprietary) is a non-selective $\beta$-blocker with class III antiarrhythmic activity, used in the prophylaxis of paroxysmal supraventricular arrhythmias. By blocking the potassium channels, sotalol prolongs repolarisation, therefore lengthening the QT interval and decreasing automaticity.

Sotalol has an appreciable class III action only at high doses (240-480 mg per day). At low doses commonly prescribed in the UK (80-160 mg per day) the main antiarrhythmic effect is its class II (i.e. $\beta$-blocker) action. Side-effects may include ventricular proarrhythmias. ${ }^{2}$ It is available orally for prophylaxis at a dose of $80 \mathrm{mg}$ daily in one or two divided doses, increased gradually at intervals of 2-3 days to a usual dose of $160-320 \mathrm{mg}$ daily in two divided doses. ${ }^{5}$ Sotalol via injection is not recommended routinely for prophylaxis. No estimates of the extent to which it is currently used were available, but expert opinion suggests that most clinicians use $\beta$-blockers other than sotalol. 


\section{Chapter 3}

\section{Methods of assessing clinical effectiveness}

\author{
Asstematic review was conducted according to \\ the scope and methods outlined in the \\ protocol issued in March 2007 (based on the HTA \\ commissioning brief).
}

\section{Inclusion and exclusion criteria}

\section{Populations}

For studies to be included, patients had to be aged over 18 years, undergoing elective isolated CABG (either on-pump or off-pump, with any number of grafts or any conduit type). Studies were excluded if patients received other concomitant surgical procedures (e.g. valvular operations), unless the proportion of patients undergoing isolated CABG was also clearly documented. Studies in which methods of detecting AF were not specified, in which patients had a history of AF or history of AF was not reported, and/or studies in which length of follow-up was not reported were included in this review if they met the other inclusion criteria.

\section{Interventions}

Studies using intravenously administered magnesium sulphate alone, as either a bolus or a continuous infusion of clearly specified dosage and duration, given as prophylaxis before the onset of AF, were included. Studies of other magnesium compounds (e.g. chloride, hydroxide or unspecified) were excluded. Studies in which patients received other drugs (e.g. $\beta$-blockers) were included in this review only if the drugs were administered as usual patient care and did not differ between the randomised study groups.

\section{Comparators}

The study compared:

- intravenous magnesium sulphate versus different administration strategies of intravenous magnesium sulphate

- intravenous magnesium sulphate versus placebo/control

- intravenous magnesium sulphate versus sotalol.

\section{Outcomes}

The primary outcome was incidence of AF after CABG. Supraventricular arrhythmias other than

\begin{abstract}
$\mathrm{AF}$ (e.g. tachycardias and atrial flutter) and all
\end{abstract} other non-atrial arrhythmias were excluded.

\section{Study types}

Randomised controlled trials (RCTs) were included. Systematic reviews were identified for context, but their results were not extracted and their methodological quality was not appraised.

\section{Search strategy}

A comprehensive search strategy was developed to identify RCTs and systematic reviews that have investigated the effects of prophylactic intravenous magnesium sulphate on AF after CABG. The search strategy (Appendix 1) aimed to identify systematically all relevant studies that met the inclusion criteria reported above. As the current review provides an update to a previous systematic review by Alghamdi and colleagues ${ }^{10}$ (as requested in the HTA commissioning brief), the searches for intravenous magnesium versus placebo/control were limited to studies published after 2003 (the cut-off date for literature searching in Alghamdi's systematic review being December 2003). No date restriction was applied to searches for sotalol studies.

The search strategy was applied to the following general and specialist health and biomedical databases (Appendix 1): Cochrane Library (2007 Issue 2), Ovid MEDLINE ${ }^{\circledR}$ (1950 to May 2007 week 1), Ovid MEDLINE ${ }^{\circledR}$ In-process and Other Non-indexed Citations, EMBASE (1980 to 2007 week 19), Database of Abstracts of Reviews of Effectiveness (DARE), Health Technology Assessment (HTA) Database, Centre for Reviews and Dissemination (CRD) database, National Research Register (NRR), Current Controlled Trials, including the Medical Research Council (MRC) Trials Database (controlled-trials.com) and Clinical Trials (clinicaltrials.gov). Each database was searched once, during 14-17 May 2007.

\section{Study inclusion}

All references identified by the literature searches were imported into a Reference Manager 
bibliographic database. After duplicate references had been deleted from the database, the title and (where available) abstract of each reference were screened systematically against the inclusion criteria reported above, to assess the relevance of the study for inclusion in the review. This initial screening step was carried out by a reviewer using a standard decision tree (Appendix 2). Cases of uncertainty were resolved by discussion with a second reviewer. For those references that did not fulfil the inclusion criteria (owing to inappropriate population, study design, intervention or outcome) the reason for exclusion was recorded. Full papers for those references that appeared relevant on the basis of title and (where available) abstract were retrieved. Full papers were checked for their relevance using the same decision tree independently by two independent reviewers. Any disagreements between the reviewers were resolved by discussion and, if necessary, consultation with a third reviewer. Reasons for excluding papers at this stage were also recorded. Reference lists of relevant systematic reviews that were identified using the search strategy were checked for additional relevant literature not identified in the systematic searches.

\section{Data extraction}

Data were extracted from the included studies using a predesigned and piloted data extraction template to report the study design, patient populations, interventions, outcomes, analyses and any study limitations (Appendix 3). Data were extracted for incidence of $\mathrm{AF}$ and other relevant $\mathrm{AF}$ outcomes (e.g. time to onset of AF). If available, data on the patients' length of stay in the intensive care unit (ICU), postoperative stay and total hospital stay were also extracted. Data from each study were extracted by one reviewer and checked by a second reviewer. Any disagreements were resolved by consensus, if necessary involving a third reviewer.

\section{Quality assessment}

The methodological quality of each of the included studies was assessed systematically according to guidelines provided by the NHS CRD. ${ }^{11}$ Study quality was assessed independently by two reviewers and reported in Table 2 for each of seven criteria [randomisation, treatment allocation concealment, homogeneity of patient populations, blinding of outcome assessors, presentation of outcome data, intention-to-treat analysis (ITT), and description of withdrawals and dropouts]. Any disagreements in quality classification were resolved by consensus, if necessary involving a third reviewer.

\section{Data synthesis}

Two forms of synthesis were conducted, a narrative synthesis and quantitative meta-analysis. Both forms of analysis were conducted according to standard principles, and using accepted methods. ${ }^{11,12}$ The key characteristics of the included studies (e.g. details of the study populations, intervention characteristics and outcomes measured) and the results (e.g. incidence of AF, length of hospital stay and adverse events) were summarised narratively and tabulated.

The feasibility and appropriateness of metaanalysis were considered once narrative synthesis had been completed. Meta-analysis to quantify the effects of prophylaxis on incidence of $\mathrm{AF}$ was performed using Cochrane Review Manager Software (RevMan, version 4.2). A similar approach to meta-analysis used by Alghamdi and colleagues was followed here. ${ }^{10}$ The proportion of patients experiencing $\mathrm{AF}$ in the intervention and comparator groups and the total number of patients in each study group were entered into RevMan. Data for the ITT population were entered where available; however, in the majority of studies it was not clear whether a true ITT analysis had been performed owing to poor reporting. Study authors were not routinely contacted to supply missing data or to clarify their analysis (with the exception of Nurözler and colleagues, ${ }^{25}$ see section 'Subgroup analyses: dose', p. 19).

A fixed-effects analysis was performed, with random-effects analysis reserved for cases where statistical heterogeneity could not be explained. Heterogeneity was defined by a statistically significant $\chi^{2}$ test $(p>0.10)$ and quantified by the $I^{2}$ statistic, where a figure greater than $50 \%$ indicates substantial heterogeneity. ${ }^{12}$

Sensitivity analyses were performed in cases of statistical heterogeneity (e.g. based on study methodological quality). Subgroup analyses were performed to assess the effects of different delivery strategies for intravenous magnesium, including different total doses, timing of the initiation of prophylaxis and total duration of prophylaxis. These subgroups were defined $a$ priori 
in the research protocol, based on the HTA commissioning brief for this assessment which requested analysis of optimal delivery strategies. For each subgroup, trials were assigned to mutually exclusive categories for analysis. (The categories themselves were not defined in the protocol, but were devised by the authors during the course of the systematic review.) For the total duration of infusion the categories were: 1 day or less, 2-4 days, and 5 days or more. The studies were also ordered by duration, from shortest to longest. For timing of the initiation of prophylaxis the categories were: 12 hours or more presurgery, less than 12 hours presurgery or during surgery, and termination of surgery or immediately

postsurgery. The total dose of magnesium was not split into separate subgroups as it was considered that defining subgroups on the basis of dose thresholds would be an arbitrary process. Expert clinical opinion suggested that there is no consensus over high or low dose thresholds. Alternatively, all doses were displayed graphically in a forest plot from lowest to highest to permit examination of the relationship between dose and odds of AF. A fourth delivery strategy specified in the research protocol, bolus versus intravenous infusion, was not assessed as only two trials were included that reported administering magnesium via bolus.

Effect measures were expressed as the odds ratio (OR) with $95 \%$ confidence intervals (CIs). 



\section{Chapter 4}

\section{Clinical effectiveness results}

\section{Quantity and quality of research available}

The search strategy (Appendix 1), together with the previous systematic review by Alghamdi and colleagues, ${ }^{10}$ yielded 204 potentially relevant references. Two additional relevant references ${ }^{13,14}$ were identified during checking of the reference lists of the retrieved systematic reviews. Of these initial 206 papers, 158 were excluded on screening of titles and abstracts and a further 26 were subsequently excluded on screening of the full papers (Appendix 4). The remaining 22 papers that met the inclusion criteria for this review comprised 17 that reported parallel-group RCTs (15 trials altogether $)^{13-29}$ and five systematic reviews. ${ }^{7-10,30}$

\section{Systematic reviews}

As mentioned earlier, the current systematic review updates a systematic review published by Alghamdi and colleagues (2005). ${ }^{10}$ The inclusion criteria for the current review were based on those used by Alghamdi and colleagues. ${ }^{10}$ Seven of the eight studies included in that systematic review are included here. (NB. The additional study ${ }^{31}$ appears to have been erroneously included by Alghamdi and colleagues; it evaluated magnesium chloride, yet their inclusion criteria specified only magnesium sulphate, hence it is not included in the current report.) Note that of the additional eight studies included here, three were new studies ${ }^{16,22,29}$ published since Alghamdi and colleagues' review, and five were studies published before 2003, of which two were not found by Alghamdi and colleagues but identified by the present authors' search of reference lists of other systematic reviews ${ }^{13,14}$ and three were studies that Alghamdi and colleagues excluded. ${ }^{15,24,26}$ Of these three exclusions, two were rejected because the primary outcome measure was a broader measure of arrhythmia including other forms of arrhythmia as well as AF (e.g. atrial flutter or atrial tachycardia). ${ }^{15,24}$ However, these studies are included in the current report as it was discernible from the published papers that the proportion of arrhythmic events that were AF was relatively high (e.g. greater than $90 \%)$. The third study ${ }^{26}$ was excluded by Alghamdi and colleagues because their inclusion criteria prohibited studies in which patients had a prior history of AF. However, it is included in the current review as that particular study excluded patients with chronic AF, and the proportion of patients in the trial with previous non-chronic AF was relatively low (less than 10\%). It should be pointed out that some of the studies included here and in the review by Alghamdi and colleagues ${ }^{10}$ did not report whether or not patients had experienced previous AF, and consequently it cannot be guaranteed that all patients in these trials were being treated for first occurrence of $\mathrm{AF}$.

Four other relevant published systematic reviews were identified from the literature search. ${ }^{7-9,30}$ The systematic reviews varied slightly in terms of inclusion criteria and when they were conducted, meaning that each contained a different set of studies. The systematic reviews with the highest degree of overlap with the current systematic review were by Burgess and colleagues (2006), ${ }^{30}$ Miller and colleagues $(2005)^{7}$ and Shiga and colleagues (2004), ${ }^{8}$ which included up to 11 of the 15 studies included here. These reviews included other studies that are excluded from the current review, reflecting differences in inclusion criteria. For example, some of the reviews included studies of magnesium chloride.

One of the key differences between the current review and the five published systematic reviews is that none of those reviews specifically aimed to assess the role of delivery characteristics in the effectiveness of magnesium prophylaxis, with the exceptions of Henyan and colleagues ${ }^{9}$ and Miller and colleagues, ${ }^{7}$ who performed subgroup analyses based on dose and timing of the initiation of therapy. Another key difference is that none of the five published systematic reviews aimed to assess the effectiveness of magnesium sulphate compared with sotalol. The systematic review by Burgess and colleagues ${ }^{30}$ also included a set of studies comparing sotalol to placebo, and a Cochrane systematic review has also compared sotalol with placebo; ${ }^{32}$ however, such a comparison is outside the scope of the current review. 
In summary, this systematic review updates and expands a previous review by Alghamdi and colleagues, ${ }^{10}$ adding in three newly published RCTs and a further five older RCTs that were not previously included. There is some degree of overlap with other published systematic reviews, but none specifically aimed to assess the role of intravenous magnesium delivery or to compare intravenous magnesium with sotalol.

\section{Characteristics of the included RCTs}

Most of the trials included in the current report were conducted in Turkey (five trials ${ }^{14,17,18,23,25,27}$ ) and the USA (four trials ${ }^{15,16,19,22}$ ), with single trials also in Canada, ${ }^{24}$ Finland, ${ }^{26}$ Israel $^{13}$ and Switzerland $^{28}$ The number of patients randomised to each intervention ranged from 15 to 176

(Table 1). In nine trials the comparator was explicitly reported as a placebo group, whereas in six trials it was referred to as a control group. One of the trials, by Forlani and colleagues, ${ }^{20,21}$ compared magnesium and sotalol in combination with a control group, and against magnesium alone and sotalol alone (Table 1). According to the authors the study was not designed to compare magnesium against sotalol directly, and no statistical tests were reported for the comparison of the two drugs.

The standard of reporting in these trials was generally poor. In the majority of studies the adequacy of randomisation, concealment of treatment allocation, blinding of assessors and analysis of missing data could not be elucidated (Table 2). Although most of the studies reported baseline characteristics of their patient populations, the quantity of information given and whether differences between groups were tested statistically were highly variable among the studies. None of the studies reported the ethnic or socio-demographic status of their recruited patients. Reporting of the methods of detecting $\mathrm{AF}$ and the definitions of AF used in the studies were variable (Appendix 5).

\section{Assessment of effectiveness}

\section{Incidence of AF}

As mentioned earlier, only one RCT included both a sotalol and an intravenous magnesium arm. ${ }^{20,21}$ However, the trial was designed to compare the clinical efficacy of combined sotalol and

TABLE I Characteristics of I5 RCTs that met the criteria for inclusion in this review

\begin{tabular}{|c|c|c|c|c|c|c|c|c|c|}
\hline \multirow[t]{3}{*}{ Study } & \multirow[t]{3}{*}{ Population } & \multirow[t]{3}{*}{ Intervention } & \multirow[t]{3}{*}{$\mathbf{N}$} & \multirow[t]{3}{*}{ Comparator } & \multirow[t]{3}{*}{$\mathbf{N}$} & \multicolumn{4}{|c|}{ Outcomes } \\
\hline & & & & & & \multirow[t]{2}{*}{ AF } & \multicolumn{3}{|c|}{ Length of stay } \\
\hline & & & & & & & ICU & Postop. & Hospital \\
\hline Bert et al., 2001 ${ }^{15}$ & $C A B G+V$ & $\mathrm{Mg}$ & 63 & Control & 60 & $(\checkmark)$ & & & $\checkmark$ \\
\hline Bhudia et al., $2006^{16}$ & $C A B G+V$ & $\mathrm{Mg}$ & 174 & Placebo & 176 & 1 & $\checkmark$ & $\checkmark$ & $\checkmark$ \\
\hline Caspi et al., $1995^{13}$ & $\mathrm{CABG}^{a}$ & $\mathrm{Mg}$ & 50 & Placebo & 48 & $\checkmark$ & & & \\
\hline $\begin{array}{l}\text { Dagdelen et al., 2002, }{ }^{17} \\
2003^{18}\end{array}$ & CABG & $\mathrm{Mg}$ & 93 & Control & 55 & $\checkmark$ & & & \\
\hline Fanning et al., $1991^{19}$ & CABG & $\mathrm{Mg}$ & 49 & Placebo & 50 & $(\checkmark)$ & & & \\
\hline \multirow{3}{*}{$\begin{array}{l}\text { Forlani et al., 2002, } \\
\qquad 2003^{21}\end{array}$} & CABG & $\mathrm{Mg}$ & 54 & Control & 50 & 1 & & $\checkmark$ & \\
\hline & & Sotalol & 51 & & & & & & \\
\hline & & Mg + sotalol & 52 & & & & & & \\
\hline Hazelrigg et al., $2004^{22}$ & CABG & $\mathrm{Mg}$ & 105 & Control & 97 & $\checkmark$ & $\checkmark$ & & $\checkmark$ \\
\hline Kaplan et al., $2003^{23}$ & CABG & $\mathrm{Mg}$ & 100 & Placebo & 100 & $\checkmark$ & $\checkmark$ & & $\checkmark$ \\
\hline Karmy-Jones et al., $1995^{24}$ & $C A B G+V$ & $\mathrm{Mg}$ & 46 & Placebo & 54 & $(\checkmark)$ & $\checkmark$ & & $\checkmark$ \\
\hline Nurözler et al., $1996^{25}$ & CABG & $\mathrm{Mg}^{b}$ & 25 & Placebo & 25 & 1 & & & \\
\hline Parikka et al., $1993^{26}$ & CABG & $\mathrm{Mg}$ & 69 & Placebo & 71 & $\checkmark$ & & & \\
\hline Toraman et al., $200 \mathrm{I}^{27}$ & CABG & $\mathrm{Mg}$ & 100 & Control & 100 & $\checkmark$ & $\checkmark$ & $\checkmark$ & \\
\hline Treggiari-Venzi et al., $2000^{28}$ & CABG & $\mathrm{Mg}$ & 49 & Placebo & 53 & $\checkmark$ & $\checkmark$ & & \\
\hline Yilmaz et al., $2000^{14}$ & $\mathrm{CABG}^{a}$ & $\mathrm{Mg}^{\mathrm{c}}$ & 15 & Control & 15 & $\checkmark$ & & & \\
\hline Zangrillo et al., $2005^{29}$ & CABG & $\mathrm{Mg}$ & 80 & Placebo & 80 & $\checkmark$ & $\checkmark$ & & $\checkmark$ \\
\hline \multicolumn{10}{|c|}{$\begin{array}{l}\text { Unless stated otherwise, CABG was isolated ( }{ }^{a} \text { not reported whether CABG was isolated). } \\
\text { Hospital, total hospital time; ICU, time in intensive care unit; } M g \text {, magnesium sulphate given by intravenous delivery } \\
\text { ('bunclear whether all magnesium administered was given as sulphate; }{ }^{b} \text { not reported whether delivery was intravenous); } \\
\text { Postop, total postoperative time; } V \text {, valvular surgery; } \checkmark \text {, directly reported; }(\mathcal{V}) \text {, inferred indirectly. }\end{array}$} \\
\hline
\end{tabular}


TABLE 2 Quality of the RCTs assessed systematically according to the criteria of the NHS CRD

\begin{tabular}{|c|c|c|c|c|c|c|c|}
\hline Study & $\begin{array}{l}\text { Randomi- } \\
\text { sation }\end{array}$ & $\begin{array}{l}\text { Conceal- } \\
\text { ment of } \\
\text { allocation }\end{array}$ & $\begin{array}{l}\text { Baseline } \\
\text { charac- } \\
\text { teristics }\end{array}$ & $\begin{array}{l}\text { Blinding of } \\
\text { assessors }\end{array}$ & $\begin{array}{c}\text { Primary } \\
\text { outcome } \\
\text { data }\end{array}$ & $\begin{array}{c}\text { ITT } \\
\text { analysis }\end{array}$ & $\begin{array}{l}\text { Missing } \\
\text { values }\end{array}$ \\
\hline Bert et al., 2001 ${ }^{15}$ & Adequate & Unknown & Reported & Adequate & Adequate & Inadequate & Partial \\
\hline Bhudia et al., $2006^{16}$ & Unknown & Adequate & Reported & Unknown & Adequate & Inadequate & Unknown \\
\hline Caspi et al., $1995^{13}$ & Unknown & Unknown & Reported & Adequate & Partial & Inadequate & Unknown \\
\hline $\begin{array}{l}\text { Dagdelen et al., 2002, }{ }^{17} \\
2003^{18}\end{array}$ & Unknown & Unknown & Reported & Adequate & Adequate & Inadequate & Unknown \\
\hline Fanning et al., $\left.199\right|^{19}$ & Unknown & Unknown & Reported & Unknown & Adequate & Inadequate & Unknown \\
\hline Forlani et al., $2002,{ }^{20} 2003^{21}$ & Adequate & Unknown & Reported & Unknown & Adequate & Inadequate & Inadequate \\
\hline Hazelrigg et al., $2004^{22}$ & Inadequate & Inadequate & Reported & Inadequate & Partial & Inadequate & Inadequate \\
\hline Kaplan et al., $2003^{23}$ & Inadequate & Inadequate & Reported & Inadequate & Adequate & Inadequate & Inadequate \\
\hline Karmy-Jones et al., $1995^{24}$ & Unknown & Unknown & Reported & Adequate & Partial & Inadequate & Unknown \\
\hline Nurözler et al., $1996^{25}$ & Unknown & Unknown & Reported & Unknown & Adequate & Inadequate & Unknown \\
\hline Parikka et al., $1993^{26}$ & Unknown & Unknown & Reported & Unknown & Adequate & Inadequate & Adequate \\
\hline Toraman et al., 200I ${ }^{27}$ & Inadequate & Inadequate & Reported & Adequate & Adequate & Inadequate & Inadequate \\
\hline Treggiari-Venzi et al., $2000^{28}$ & Partial & Adequate & Reported & Unknown & Adequate & Inadequate & Inadequate \\
\hline Yilmaz et al., $2000^{14}$ & Unknown & Unknown & Unknown & Unknown & Adequate & Inadequate & Unknown \\
\hline Zangrillo et al., $2005^{29}$ & Adequate & Unknown & Reported & Inadequate & Adequate & Adequate & Adequate \\
\hline Overall (modal class) & Unknown & Unknown & Reported & Unknown & Adequate & Inadequate & Unknown \\
\hline
\end{tabular}

intravenous magnesium against the two agents separately, and against a control. No statistical tests were performed for the comparison between sotalol and intravenous magnesium. In the study postoperative AF occurred in $12 \%$ of patients receiving sotalol and in $15 \%$ of patients receiving magnesium.

No RCTs were identified that compared different delivery strategies of intravenous magnesium. The remainder of this section therefore focuses on the results of the RCTs that compared intravenous magnesium with placebo or control.

Of 1070 patients in the pooled magnesium group, $230(21 \%)$ developed postoperative AF, compared with 307 of $1031(30 \%)$ patients in the control (or placebo) group. Figure 1 shows the forest plot of the meta-analysis of all 15 RCTs on the incidence of AF. Initial analysis using a fixed-effect model gave a pooled OR significantly less than 1.0 $(\mathrm{OR}=0.65,95 \%$ CI 0.53 to 0.79 , test for overall effect $p<0001$ ), but with statistically significant heterogeneity $\left(I^{2}=63.4 \%, p=0.0005\right)$.

All individual studies with an OR that was significantly different from 1.0, and those with an OR bordering on significance (whose CI only just included 1.0) were in favour of magnesium sulphate. The overall effect favouring magnesium was driven by a relatively small proportion of the studies, with the majority (nine out of 15) exhibiting ORs very close to 1.0. Two RCTs, by Dagdelen and colleagues (2002) ${ }^{17}$ and Toraman and colleagues (2001), ${ }^{27}$ are notable as they had lower ORs in favour of magnesium sulphate than all the other studies.

\section{Sensitivity analyses}

Sensitivity analyses were performed to explore the likely reasons for heterogeneity. When the analysis was restricted to the two RCTs that were judged to have adequately concealed random allocation ${ }^{16,28}$ (Table 2), the intervention effect was no longer statistically significant $(\mathrm{OR}=0.84,95 \%$ CI 0.57 to 1.26 , test for overall effect $p=0.40$ ), although heterogeneity was absent $\left(I^{2}=0 \%\right)$ and no longer significant $(p=0.92)$. A similar pattern was evident when analyses were restricted to the three RCTs whose randomisation procedures were judged to be adequate ${ }^{15,20,21,29}$ (Table 2) or the five RCTs whose blinding was considered adequate $^{13,15,17,18,24,27}$ (forest plots not shown). Given that the number of studies meeting the criteria of methodological adequacy for these attributes was comparatively low, these results should be interpreted with caution.

In a meta-analysis of eight RCTs, which included seven of the RCTs included in the current report, Alghamdi and colleagues ${ }^{10}$ also identified a statistically significant intervention effect and statistically significant heterogeneity. When their analysis was restricted to the six highest quality studies scored using the Van Tulder methodological quality assessment scale, their intervention effect remained statistically significant, but heterogeneity was reduced and no longer statistically significant. The two studies that were excluded were Dagdelen $(2002)^{17}$ and Toraman (2001). ${ }^{27}$ These two trials 
TABLE 3 Dosage and duration of magnesium sulphate administration in the intervention group (indicated only where this differed from the control or placebo comparator group)

\begin{tabular}{|c|c|c|c|c|c|}
\hline Study & $\begin{array}{l}\text { Method of } \\
\text { delivery }\end{array}$ & Time & $\begin{array}{l}\mathrm{MgSO}_{4} \text { dose or } \\
\text { concentration }\end{array}$ & Carrier & Duration \\
\hline \multirow[t]{4}{*}{ Bert et al., 200। ${ }^{15}$} & i.v. infusion & $\begin{array}{l}\text { I. After termination } \\
\text { of CPB }\end{array}$ & $2 \mathrm{~g}$ & $\begin{array}{l}50 \mathrm{ml} \text { normal } \\
\text { saline }\end{array}$ & 30 minutes \\
\hline & & 2. On arrival in ICU & $2 \mathrm{~g}$ & $\begin{array}{l}50 \mathrm{ml} \text { normal } \\
\text { saline }\end{array}$ & 30 minutes \\
\hline & & $\begin{array}{l}\text { 3. Each morning for } \\
\text { first } 4 \text { days } \\
\text { postsurgery }\end{array}$ & $2 \mathrm{~g} \times 4$ & $\begin{array}{l}50 \mathrm{ml} \text { normal } \\
\text { saline } \times 4\end{array}$ & $\begin{array}{l}30 \text { minutes } \\
\times 4\end{array}$ \\
\hline & & Overall total & $12 \mathrm{~g}$ & $\begin{array}{l}300 \mathrm{ml} \text { normal } \\
\text { saline }\end{array}$ & 3 h in 5 days \\
\hline \multirow[t]{4}{*}{ Bhudia et al., $2006^{16}$} & CPB circuit & I. During CPB & 3.6 to $4.8 \mathrm{mg} \mathrm{dl}^{-1}$ & - & - \\
\hline & i.v. & $\begin{array}{l}\text { 2. During anaesthesia } \\
\text { induction }\end{array}$ & $0.78 \mathrm{~g}(32 \mathrm{mmol})$ & $\begin{array}{l}100 \mathrm{ml} \text { normal } \\
\text { saline }\end{array}$ & 15 minutes \\
\hline & & $\begin{array}{l}\text { 3. After anaesthesia } \\
\text { induction }\end{array}$ & $3.16 \mathrm{~g}(130 \mathrm{mmol})$ & $\begin{array}{l}100 \mathrm{ml} \text { normal } \\
\text { saline }\end{array}$ & $24 \mathrm{~h}$ \\
\hline & & Overall total & $\begin{array}{l}3.94 \mathrm{~g}(162 \mathrm{mmol}) \\
+ \text { CPB conc. }\end{array}$ & $\begin{array}{l}200 \mathrm{ml} \text { normal } \\
\text { saline }+ \\
\text { CPB prime }\end{array}$ & $24.25 h$ \\
\hline \multirow[t]{3}{*}{ Caspi et al., $1995^{13}$} & $\begin{array}{l}\text { i.v. via } \\
\text { syringe pump }\end{array}$ & $\begin{array}{l}\text { I. During interval } \\
\text { between induction } \\
\text { of anaesthesia and } \\
\text { aortic cross-clamp }\end{array}$ & $16 \mathrm{mmol}$ & $20 \mathrm{ml}$ saline & - \\
\hline & i.v. & $\begin{array}{l}\text { 2. After release of } \\
\text { cross-clamp }\end{array}$ & $32 \mathrm{mmol}$ & $20 \mathrm{ml}$ saline & $24 \mathrm{~h}$ \\
\hline & & Overall total & $48 \mathrm{mmol}$ & $40 \mathrm{ml}$ saline & $\sim 24 h$ \\
\hline \multirow[t]{4}{*}{$\begin{array}{l}\text { Dagdelen et al., 2002, }{ }^{17} \\
2003^{18}\end{array}$} & i.v. infusion & I. I day presurgery & $1.5 \mathrm{~g}$ & $\begin{array}{l}100 \mathrm{ml} 0.9 \mathrm{NaCl} \\
\text { solution } \\
\left(25 \mathrm{ml} \mathrm{h}^{-1}\right)\end{array}$ & I day \\
\hline & & 2. Just after surgery & $1.5 \mathrm{~g}$ & $\begin{array}{l}100 \mathrm{ml} 0.9 \mathrm{NaCl} \\
\text { solution } \\
\left(25 \mathrm{ml} \mathrm{h}^{-1}\right)\end{array}$ & I day \\
\hline & & $\begin{array}{l}\text { 3. Once daily for } \\
4 \text { days postsurgery }\end{array}$ & $1.5 \mathrm{~g} \times 4$ & $\begin{array}{l}100 \mathrm{ml} 0.9 \mathrm{NaCl} \\
\text { solution } \\
\left(25 \mathrm{ml} \mathrm{h}^{-1}\right) \times 4\end{array}$ & 4 days \\
\hline & & Overall total & $9 g$ & $\begin{array}{l}600 \mathrm{ml} 0.9 \mathrm{NaCl} \\
\text { solution }\end{array}$ & 6 days \\
\hline \multirow[t]{3}{*}{ Fanning et al., $\left.199\right|^{19}$} & i.v. infusion & I. First $24 \mathrm{~h}$ postsurgery & $\begin{array}{l}40 \mathrm{mEq}^{-1} \text { at } \\
100 \mathrm{ml} \mathrm{h}^{-1} \\
\text { (total } 96 \mathrm{mEq} \text { at } \\
4 \mathrm{mEq} \mathrm{h}^{-1} \text { ) }\end{array}$ & $\begin{array}{l}5 \% \text { dextrose in } \\
\text { water }+20 \mathrm{mEq} \\
\text { potassium } \\
\text { chloride } \mathrm{I}^{-1} \text { at } \\
100 \mathrm{ml} \mathrm{h}^{-1}\end{array}$ & I day \\
\hline & & $\begin{array}{l}\text { 2. Next } 72 \mathrm{~h} \text { postsurgery } \\
(25-96 \mathrm{~h})\end{array}$ & $\begin{array}{l}40 \mathrm{mEq}^{-1} \text { at } \\
25 \mathrm{ml} \mathrm{h}^{-1} \\
\text { (total } 72 \mathrm{mEq} \text { at } \\
\left(\mathrm{mEq} \mathrm{h}^{-1} \text { ) }\right.\end{array}$ & $\begin{array}{l}5 \% \text { dextrose in } \\
\text { water }+20 \mathrm{mEq} \\
\text { potassium } \\
\text { chloride } \mathrm{L}^{-1} \text { at } \\
25 \mathrm{~mL} \mathrm{~h}^{-1}\end{array}$ & 3 days \\
\hline & & Overall total & $168 \mathrm{mEq}$ & $\begin{array}{l}5 \% \text { dextrose in } \\
\text { water }+80 \mathrm{mEq} \\
\text { potassium chloride }\end{array}$ & 4 days \\
\hline
\end{tabular}


TABLE 3 Dosage and duration of magnesium sulphate administration in the intervention group (indicated only where this differed from the control or placebo comparator group) (cont'd)

\begin{tabular}{|c|c|c|c|c|c|}
\hline Study & $\begin{array}{l}\text { Method of } \\
\text { delivery }\end{array}$ & Time & $\begin{array}{l}\mathrm{MgSO}_{4} \text { dose or } \\
\text { concentration }\end{array}$ & Carrier & Duration \\
\hline \multirow{2}{*}{$\begin{array}{l}\text { Forlani et al., 2002, } \\
2003^{21} \\
\text { Magnesium group }\end{array}$} & i.v. & $\begin{array}{l}\text { From just before CPB } \\
\text { until } 5 \text { days postsurgery }\end{array}$ & $\begin{array}{l}1.5 \mathrm{~g}(12 \mathrm{mEq}) \\
\mathrm{day}^{-1} \times 6\end{array}$ & NR & 6 days \\
\hline & & Overall total & $9 \mathrm{~g}(72 \mathrm{mEq})$ & - & 6 days \\
\hline \multirow{2}{*}{$\begin{array}{l}\text { Forlani et al., } 2002,{ }^{20} \\
2003^{21} \\
\text { Magnesium + sotalol } \\
\text { group }\end{array}$} & $\begin{array}{l}\text { i.v. } \\
\text { magnesium }+ \\
\text { oral sotalol }\end{array}$ & $\begin{array}{l}\text { From just before CPB } \\
\text { until } 5 \text { days postsurgery }\end{array}$ & $\begin{array}{l}\text { As above plus } \\
\text { sotalol } 80 \mathrm{mg} \text { orally } \\
\text { twice daily }\end{array}$ & NR & 6 days \\
\hline & & Overall total & $\begin{array}{l}9 \mathrm{~g}(72 \mathrm{mEq}) \\
\mathrm{MgSO}_{4}+960 \mathrm{mg} \\
\text { sotalol }\end{array}$ & - & 6 days $^{\mathrm{a}}$ \\
\hline \multirow[t]{3}{*}{ Hazelrigg et al., $2004^{22}$} & $\begin{array}{l}\text { Bolus (no } \\
\text { other details) }\end{array}$ & $\begin{array}{l}\text { I. } 30 \text { minutes before } \\
\text { CPB }\end{array}$ & $\begin{array}{l}80 \mathrm{mg} \mathrm{kg}^{-1} \text { (ideal } \\
\text { body weight) }\end{array}$ & $100 \mathrm{ml}$ of $\mathrm{D}_{5} \mathrm{~W}$ & 30 minutes \\
\hline & $\begin{array}{l}\text { i.v. drip } \\
\text { infusion }\end{array}$ & 2. Subsequent $48 \mathrm{~h}$ & $\begin{array}{l}8 \mathrm{mg} \mathrm{kg}^{-1} \text { (ideal } \\
\text { body weight) } \mathrm{h}^{-1}\end{array}$ & $100 \mathrm{ml}$ of $D_{5} W$ & $48 \mathrm{~h}$ \\
\hline & & Overall total & $\begin{array}{l}464 \mathrm{mg} \mathrm{kg}^{-1} \\
\text { (ideal body weight) }\end{array}$ & $200 \mathrm{~mL}$ of $D_{5} \mathrm{~W}$ & $48.5 h$ \\
\hline \multirow[t]{5}{*}{ Kaplan et al., $2003^{23}$} & i.v. infusion & I. $12 \mathrm{~h}$ presurgery & $\begin{array}{l}3 \mathrm{~g}(24.34 \mathrm{mEq}) \text { at } \\
50 \mathrm{ml} \mathrm{h}^{-1}\end{array}$ & $\begin{array}{l}100 \mathrm{ml}^{\text {saline at }} \\
50 \mathrm{ml} \mathrm{h}^{-1}\end{array}$ & $2 \mathrm{~h}$ \\
\hline & & $\begin{array}{l}\text { 2. After termination of } \\
\text { CPB or anastomosis } \\
\text { of last graft }\end{array}$ & $\begin{array}{l}3 \mathrm{~g}(24.34 \mathrm{mEq}) \text { at } \\
50 \mathrm{ml} \mathrm{h}^{-1}\end{array}$ & $\begin{array}{l}100 \mathrm{ml}^{-1} \text { aline at } \\
50 \mathrm{ml} \mathrm{h}^{-1}\end{array}$ & $2 \mathrm{~h}$ \\
\hline & & $\begin{array}{l}\text { 3. First postsurgery } \\
\text { dose in ICU }\end{array}$ & $\begin{array}{l}3 \mathrm{~g}(24.34 \mathrm{mEq}) \text { at } \\
50 \mathrm{ml} \mathrm{h}^{-1}\end{array}$ & $\begin{array}{l}100 \mathrm{ml}^{\text {saline at }} \\
50 \mathrm{ml} \mathrm{h}^{-1}\end{array}$ & $2 \mathrm{~h}$ \\
\hline & & 4. I-3 days postsurgery & $\begin{array}{l}3 \mathrm{~g}(24.34 \mathrm{mEq}) \text { at } \\
50 \mathrm{ml} \mathrm{h}^{-1} \text { daily } \times 3\end{array}$ & $\begin{array}{l}100 \mathrm{ml}^{\text {saline at }} \\
50 \mathrm{ml} \mathrm{h}^{-1}\end{array}$ & $2 \mathrm{~h} \times 3$ \\
\hline & & Overall total & $18 \mathrm{~g}(146.04 \mathrm{mEq})$ & $600 \mathrm{ml}$ saline & $\begin{array}{l}12 \mathrm{~h} \text { in } \\
4.5 \text { days }\end{array}$ \\
\hline \multirow{3}{*}{$\begin{array}{l}\text { Karmy-Jones et al., } \\
1995^{24}\end{array}$} & i.v. & I. At termination of CPB & $2.4 \mathrm{~g}(19.2 \mathrm{mEq})$ & $50 \mathrm{~mL}$ of $\mathrm{D}_{5} \mathrm{~W}$ & 20 minutes \\
\hline & & $\begin{array}{l}\text { 2. Every } 4 \mathrm{~h} \text { for a } \\
\text { further five doses }\end{array}$ & $\begin{array}{l}2.4 \mathrm{~g}(19.2 \mathrm{mEq}) \\
\times 5\end{array}$ & $50 \mathrm{ml}$ of $D_{5} W$ & 100 minutes \\
\hline & & Overall total & $14.4 \mathrm{~g}(1 / 5 \mathrm{mEq})$ & $100 \mathrm{~mL}$ of $D_{5} \mathrm{~W}$ & $2 h$ in $20.3 h$ \\
\hline \multirow[t]{4}{*}{ Nurözler et al., $1996^{25}$} & i.v. infusion & I. In cardioplegia ${ }^{b}$ & $16 \mathrm{mmol} \mathrm{I}^{-1 b}$ & NR & NR \\
\hline & & 2. First postoperative day & 100 mEq & $\begin{array}{l}1000 \mathrm{ml} \text { of } \\
\mathrm{D}_{5} \mathrm{~W} \text { day }\end{array}$ & I day \\
\hline & & $\begin{array}{l}\text { 3. Postoperative } \\
\text { days } 2-5\end{array}$ & $25 \mathrm{mEq}$ day $^{-1} \times 4$ & $\begin{array}{l}1000 \mathrm{ml} \text { of } \\
\mathrm{D}_{5} \mathrm{~W} \mathrm{day}^{-1} \times 4\end{array}$ & 4 days \\
\hline & & Overall total & $200 \mathrm{mEq}$ & 5 litres of $D_{5} W$ & 5 days \\
\hline \multirow[t]{3}{*}{ Parikka et al., $1993^{26}$} & i.v. infusion & $\begin{array}{l}\text { I. First } 24 \mathrm{~h} \text { after } \\
\text { surgery (started } \\
\text { within } 2 \mathrm{~h} \text { of } \\
\text { operation) }\end{array}$ & $40 \mathrm{mmol}$ & $\begin{array}{l}\text { I litre of } 5 \% \\
\text { glucose solution }\end{array}$ & I day \\
\hline & & $\begin{array}{l}\text { 2. Next } 24 \mathrm{~h} \text { after } \\
\text { surgery }\end{array}$ & $30 \mathrm{mmol}$ & $\begin{array}{l}500 \mathrm{ml} \text { of } 5 \% \\
\text { glucose solution }\end{array}$ & I day \\
\hline & & Overall total & $70 \mathrm{mmol}$ & $\begin{array}{l}\text { l.5 I of } 5 \% \text { glucose } \\
\text { solution }\end{array}$ & 2 days \\
\hline
\end{tabular}


TABLE 3 Dosage and duration of magnesium sulphate administration in the intervention group (indicated only where this differed from the control or placebo comparator group) (cont'd)

\begin{tabular}{|c|c|c|c|c|c|}
\hline Study & $\begin{array}{l}\text { Method of } \\
\text { delivery }\end{array}$ & Time & $\begin{array}{l}\mathrm{MgSO}_{4} \text { dose or } \\
\text { concentration }\end{array}$ & Carrier & Duration \\
\hline \multirow[t]{4}{*}{ Toraman et al., $200 \mathrm{I}^{27}$} & i.v. infusion & I. One day presurgery & $6 \mathrm{mmol}$ & $\begin{array}{l}\mathrm{l} 00 \mathrm{ml} 0.9 \% \\
\mathrm{NaCl}\left(25 \mathrm{ml} \mathrm{h}^{-1}\right)\end{array}$ & I day \\
\hline & & 2. Just after $\mathrm{CPB}$ & $6 \mathrm{mmol}$ & $\begin{array}{l}100 \mathrm{ml} 0.9 \% \\
\mathrm{NaCl}\left(25 \mathrm{ml} \mathrm{h}^{-1}\right)\end{array}$ & I day \\
\hline & & $\begin{array}{l}\text { 3. Once daily for } 4 \text { days } \\
\text { postsurgery }\end{array}$ & $6 \mathrm{mmol} \times 4$ & $\begin{array}{l}\mathrm{l} 00 \mathrm{ml} 0.9 \% \\
\mathrm{NaCl}\left(25 \mathrm{ml} \mathrm{h}^{-1}\right) \\
\times 4\end{array}$ & 4 days \\
\hline & & Overall total & $36 \mathrm{mmol}$ & $600 \mathrm{ml} 0.9 \% \mathrm{NaCl}$ & 6 days \\
\hline \multirow[t]{2}{*}{$\begin{array}{l}\text { Treggiari-Venzi et al., } \\
2000^{28}\end{array}$} & i.v. infusion & $\begin{array}{l}\text { For } 72 \mathrm{~h} \text {, starting } \\
\text { within I h of arrival } \\
\text { in ICU }\end{array}$ & $\begin{array}{l}4 \mathrm{~g}(16 \mathrm{mmol}) \\
(32 \mathrm{mEq}) \mathrm{day}^{-1} \\
\times 3\end{array}$ & $\mathrm{NR}^{c}$ & 3 days \\
\hline & & Overall total & $\begin{array}{l}12 \mathrm{~g}(48 \mathrm{mmol}) \\
(96 \mathrm{mEq})\end{array}$ & - & 3 days \\
\hline \multirow[t]{2}{*}{ Yilmaz et al., $2000^{14}$} & $\begin{array}{l}\text { Bolus (no } \\
\text { other details) }\end{array}$ & At initiation of $\mathrm{CPB}^{d}$ & $\begin{array}{l}0.4 \mathrm{mmol} \mathrm{kg-1} \\
(15 \%)^{\mathrm{e}}\end{array}$ & NR & NR \\
\hline & & Overall total & $\begin{array}{l}0.4 \mathrm{mmol} \mathrm{kg}{ }^{-1} \\
(15 \%)^{\mathrm{e}}\end{array}$ & - & - \\
\hline \multirow[t]{2}{*}{ Zangrillo et al., $2005^{29}$} & Infusion & $\begin{array}{l}\text { For } 30 \text { minutes } \\
\text { immediately after } \\
\text { central venous } \\
\text { cannulation }\end{array}$ & $2.5 \mathrm{~g}(20 \mathrm{mEq})^{f}$ & $\begin{array}{l}100 \mathrm{ml} \text { of } \\
\text { normal saline }\end{array}$ & 30 minutes \\
\hline & & Overall total & $2.5 \mathrm{~g}(20 \mathrm{mEq})$ & $\begin{array}{l}100 \mathrm{ml} \text { of normal } \\
\text { saline }\end{array}$ & 30 minutes \\
\hline \multicolumn{6}{|c|}{ 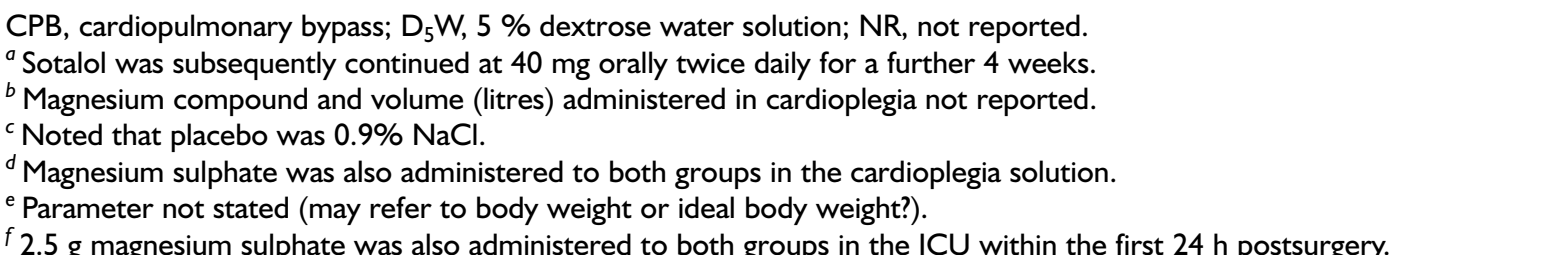 } \\
\hline
\end{tabular}

were conducted by the same team of investigators and appear to be similar in many intervention and study design characteristics.

In the current meta-analysis quality scores were not assigned to studies as this is not recommended practice. ${ }^{33}$ Critical appraisal of the various aspects of the methodological quality of these two RCTs (Table 2) concluded that, in terms of key methodological attributes such as method of randomisation or concealment of allocation, either they were inadequate or details were not reported clearly enough to allow an informed judgement to be made (although it should be noted that these two studies are not atypical, as standards of reporting were generally poor in most trials). From visual inspection of Figure 1 these two studies appeared to contribute to the statistical them from the analysis meant that heterogeneity was no longer statistically significant $(p=0.35$, $I^{2}=9.4 \%$, but increased the pooled OR to 0.78 and widened the CIs (95\% CI 0.63 to 0.97 ), although a statistically significant intervention effect remained $(p=0.02)$. The analyses presented in the next section illustrate that these two trials appear to be different from the other trials in all subgroup analyses.

\section{Subgroup analyses: total duration of prophylaxis}

The total duration of magnesium sulphate prophylaxis ranged from 30 minutes to 6 days $(0.5$ to 144 hours) (Table 3). When studies were ordered by duration of prophylaxis, an apparent relationship between duration of prophylaxis and odds of AF was evident, with decreasing odds of $\mathrm{AF}$ as duration of prophylaxis is increased 
(Figure 2). Note that the forest plot displaying this relationship includes all studies except for one by Yilmaz and colleagues ${ }^{14}$ (for which the duration of prophylaxis was not reported), and consequently the heterogeneity and overall effect are similar to those reported above in Figure 1. As noted above, two studies, by Dagdelen ${ }^{17,18}$ and Toraman ${ }^{27}$ warrant careful consideration because they appear to influence strongly the overall pattern in the forest plot. Both these studies excluded patients on $\beta$-blockers and might therefore have analysed populations who were at relatively high risk of AF, who might have been more likely to respond to prophylaxis for AF. A third study that warrants consideration is by Nurözler and colleagues ${ }^{25}$ In their study, the full dose and duration of magnesium sulphate administration are uncertain; as well as giving magnesium intravenously it appears to have been applied in the cardioplegia solution used during surgery, with unspecified details of dose (Table 3). Omitting these three studies from the meta-analysis subgroup would result in a forest plot that still appears to support the relationship between duration of prophylaxis and odds of AF (Figure 3). Excluding these studies also considerably reduces the heterogeneity of the overall effect $\left(I^{2}=5.8 \%, p=0.39\right.$, fixed-effects model).

The relationship between the duration of prophylaxis and the odds of AF appears approximately linear, irrespective of whether the $\mathrm{OR}$ is plotted on an arithmetic (Figure 4) or a logarithmic scale. A linear metaregression with ln OR as the dependent variable (random-effects least-squares model in which studies are weighted according to the inter-trial and intra-trial variances) based on 14 studies (omitting only the study by Yilmaz, ${ }^{14}$ which did not report duration) would confirm the linear relationship $\left(R^{2}=0.743\right.$, $p<0.001)$. The linear relationship would still be supported by this model if a further three studies by Dagdelen, ${ }^{17,18}$ Nurözler ${ }^{25}$ and Toraman ${ }^{27}$ (discussed above) were excluded $\left(R^{2}=0.704\right.$, $p=0.001)$.

It is difficult to determine how (or indeed whether) the studies should be grouped for analysing effects of prophylaxis duration on odds of AF. If the data are grouped into three classes

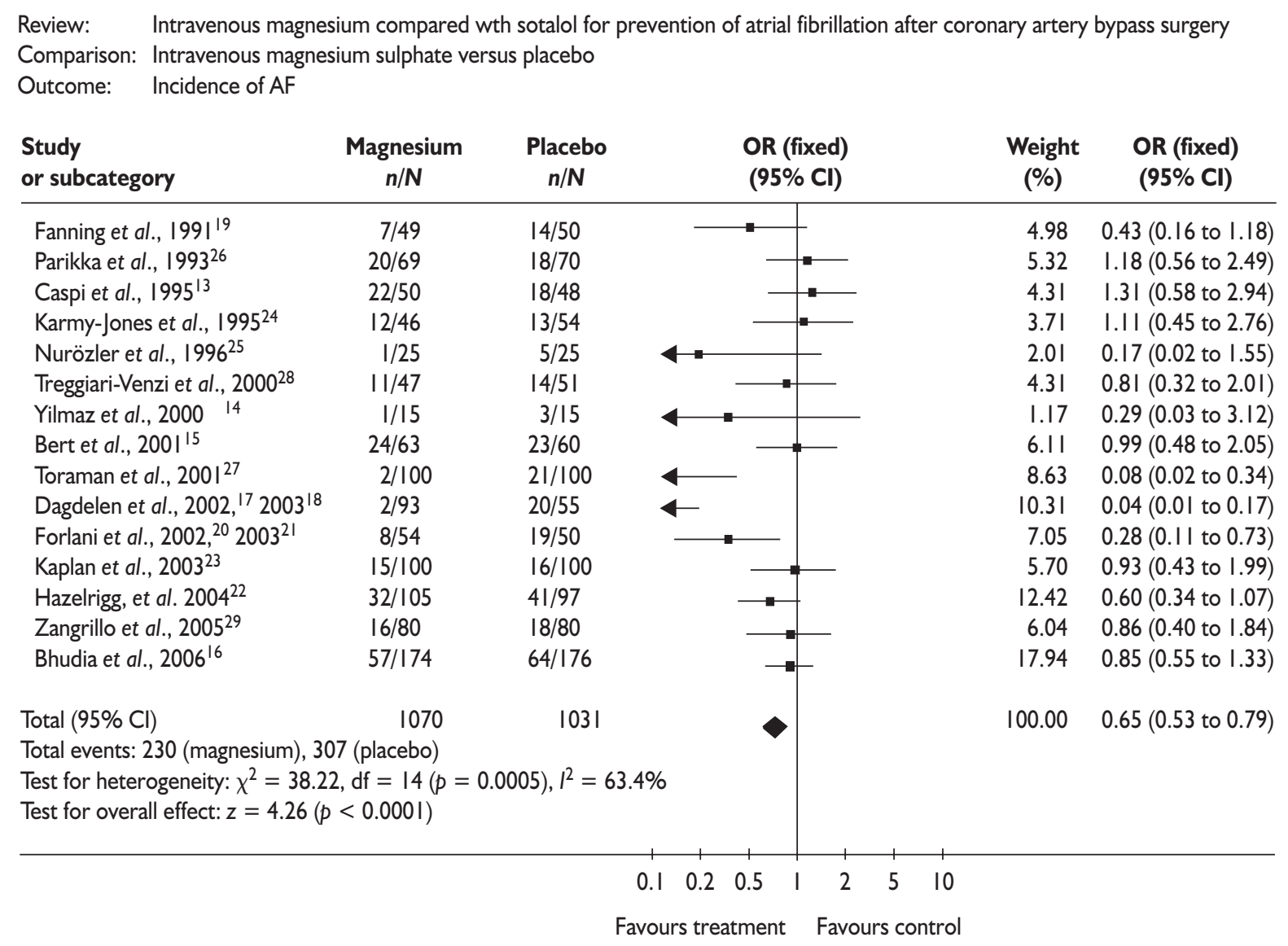




\begin{tabular}{|c|c|c|c|c|c|c|}
\hline $\begin{array}{ll}\text { Review: } & \text { Intravenous magne } \\
\text { Comparison: } & \text { Intravenous magne } \\
\text { Outcome: } & \text { Incidence of AF (ra }\end{array}$ & $\begin{array}{l}\text { ium compared } \\
\text { ium sulphate ve } \\
\text { ked by total } d u\end{array}$ & $\begin{array}{l}\text { i sotalol for } \\
\text { us placebo } \\
\text { ion) }\end{array}$ & vention of atrial fib & fter coron & ary artery bypass surg & \\
\hline $\begin{array}{l}\text { Study } \\
\text { or subcategory }\end{array}$ & $\begin{array}{l}\text { Magnesium } \\
n / N\end{array}$ & $\begin{array}{c}\text { Placebo } \\
n / N\end{array}$ & $\begin{array}{l}\text { OR (random) } \\
(95 \% \mathrm{Cl})\end{array}$ & $\begin{array}{l}\text { Weight } \\
(\%)\end{array}$ & $\begin{array}{l}\text { OR (random) } \\
(95 \% \mathrm{Cl})\end{array}$ & Order \\
\hline Zangrillo et al., $2005^{29}$ & $16 / 80$ & $18 / 80$ & & 8.23 & $0.86(0.40$ to 1.84$)$ & I \\
\hline Karmy-Jones et al., $1995^{24}$ & $12 / 46$ & $13 / 54$ & & 7.24 & I.II (0.45 to 2.76$)$ & 2 \\
\hline Bert et al., 200 $\mathrm{I}^{15}$ & $24 / 63$ & $23 / 60$ & & 8.44 & $0.99(0.48$ to 2.05$)$ & 3 \\
\hline Kaplan et al., $2003^{23}$ & $15 / 100$ & $16 / 100$ & & 8.17 & $0.93(0.43$ to 1.99$)$ & 12 \\
\hline Caspi et al., $1995^{13}$ & $22 / 50$ & $18 / 48$ & & 7.89 & I.3I (0.58 to 2.94$)$ & 24 \\
\hline Bhudia et al., $2006^{16}$ & $57 / 174$ & $64 / 176$ & & 10.41 & 0.85 (0.55 to 1.33$)$ & 25 \\
\hline Parikka et al., $1993^{26}$ & $20 / 69$ & $18 / 70$ & & 8.31 & $1.18(0.56$ to 2.49$)$ & 48 \\
\hline Hazelrigg et al., $2004^{22}$ & $32 / 105$ & $4 I / 97$ & -1 & 9.48 & $0.60(0.34$ to 1.07$)$ & 49 \\
\hline Treggiari-Venzi et al., $2000^{28}$ & $\mathrm{II} / 47$ & $|4 / 5|$ & $\rightarrow$ & 7.20 & $0.81(0.32$ to 2.01$)$ & 72 \\
\hline Fanning et al., $\left.199\right|^{19}$ & $7 / 49$ & $14 / 50$ & $\rightarrow$ & 6.60 & $0.43(0.16$ to 1.18$)$ & 96 \\
\hline Nurözler et al., $1996^{25}$ & $1 / 25$ & $5 / 25$ & $\longrightarrow$ & 2.41 & $0.17(0.02$ to 1.55$)$ & 120 \\
\hline Dagdelen, 2002 et al., ${ }^{17} 2003^{18}$ & $2 / 93$ & $20 / 55$ & $\longrightarrow$ & 4.26 & $0.04(0.01$ to 0.17$)$ & 144 \\
\hline Forlani et al., $2002,{ }^{20} 2003^{21}$ & $8 / 54$ & $19 / 50$ & $\square$ & 7.01 & $0.28(0.11$ to 0.73$)$ & 144 \\
\hline Toraman et al., 200। ${ }^{27}$ & $2 / 100$ & $21 / 100$ & $\longrightarrow-$ & 4.35 & 0.08 (0.02 to 0.34$)$ & 144 \\
\hline Total $(95 \% \mathrm{Cl})$ & 1055 & 1016 & & 100.00 & $0.6 \mathrm{I}(0.4 \mathrm{I}$ to 0.90$)$ & \\
\hline \multicolumn{7}{|c|}{$\begin{array}{l}\text { Total events: } 229 \text { (magnesium), } 304 \text { (placebo) } \\
\text { Test for heterogeneity: } \chi^{2}=37.65, \mathrm{df}=13(p=0.0003), I^{2}=65.5 \% \\
\text { Test for overall effect: } z=2.5 \mathrm{I}(p=0.0 \mathrm{I})\end{array}$} \\
\hline \multicolumn{7}{|c|}{$\begin{array}{lllllll}0.001 & 0.01 & 0.1 & 1 & 10 & 100 & 1000\end{array}$} \\
\hline \multicolumn{7}{|c|}{ Favours treatment Favours control } \\
\hline
\end{tabular}

FIGURE 2 Studies ordered by duration of magnesium sulphate intervention (random-effects model). The data column 'Order' shows the duration of intervention (hours, rounded to the nearest I hour).

Review: Intravenous magnesium compared wth sotalol for prevention of atrial fibrillation after coronary artery bypass surgery

Comparison: Intravenous magnesium sulphate versus placebo

Outcome: Incidence of AF (ranked by total duration)

\begin{tabular}{|c|c|c|c|c|c|c|}
\hline $\begin{array}{l}\text { Study } \\
\text { or subcategory }\end{array}$ & $\begin{array}{l}\text { Magnesium } \\
n / N\end{array}$ & $\begin{array}{c}\text { Placebo } \\
n / N\end{array}$ & $\begin{array}{l}\text { OR (fixed) } \\
(95 \% \mathrm{Cl})\end{array}$ & $\begin{array}{l}\text { Weight } \\
(\%)\end{array}$ & $\begin{array}{l}\text { OR (fixed) } \\
(95 \% \mathrm{Cl})\end{array}$ & Order \\
\hline Zangrillo et al., $2005^{29}$ & $16 / 80$ & $18 / 80$ & \begin{tabular}{l|l}
- \\
-
\end{tabular} & 7.75 & 0.86 (0.40 to I.84) & I \\
\hline Karmy-Jones et al., $1995^{24}$ & $12 / 46$ & $13 / 54$ & 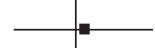 & 4.76 & I.II (0.45 to 2.76$)$ & 2 \\
\hline Bert et al., 200। ${ }^{15}$ & $24 / 63$ & $23 / 60$ & 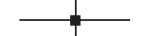 & 7.85 & 0.99 (0.48 to 2.05$)$ & 3 \\
\hline Kaplan et al., $2003^{23}$ & $15 / 100$ & $16 / 100$ & 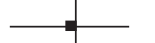 & 7.32 & 0.93 (0.43 to I.99) & 12 \\
\hline Caspi et al., $1995^{13}$ & $22 / 50$ & $18 / 48$ & 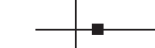 & 5.54 & 1.31 (0.58 to 2.94$)$ & 24 \\
\hline Bhudia et al., $2006^{16}$ & $57 / 174$ & $64 / 176$ & $\rightarrow-$ & 23.03 & 0.85 (0.55 to I.33) & 25 \\
\hline Parikka et al., $1993^{26}$ & $20 / 69$ & $18 / 70$ & 1. & 6.83 & 1.18 (0.56 to 2.49$)$ & 48 \\
\hline Hazelrigg et al., $2004^{22}$ & $32 / 105$ & $4 \mathrm{I} / 97$ & 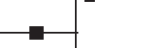 & 15.95 & $0.60(0.34$ to 1.07$)$ & 49 \\
\hline Treggiari-Venzi et al., $2000^{28}$ & II/47 & $|4 / 5|$ & $\rightarrow$ & 5.54 & 0.81 ( 0.32 to 2.01$)$ & 72 \\
\hline Fanning et al., $|99|^{19}$ & $7 / 49$ & $14 / 50$ & & 6.39 & $0.43(0.16$ to 1.18$)$ & 96 \\
\hline Forlani et al., $2002,{ }^{20} 2003^{21}$ & $8 / 54$ & $19 / 50$ & & 9.05 & $0.28(0.11$ to 0.73$)$ & 144 \\
\hline Total $(95 \% \mathrm{Cl})$ & 837 & 836 & & 100.00 & $0.8 \mathrm{I}(0.65$ to $\mathrm{I} .00)$ & \\
\hline \multicolumn{7}{|c|}{$\begin{array}{l}\text { Total events: } 224 \text { (magnesium), } 258 \text { (placebo) } \\
\text { Test for heterogeneity: } \chi^{2}=10.61, \mathrm{df}=10(p=0.39), 1^{2}=5.8 \% \\
\text { Test for overall effect: } z=1.95(p=0.05)\end{array}$} \\
\hline
\end{tabular}

FIGURE 3 Studies ordered by duration of magnesium sulphate intervention, excluding studies by Dagdelen et al., ${ }^{17,18}$ Nurözler et al. ${ }^{25}$ and Toraman et al. ${ }^{27}$ (fixed-effects model; other details as in Figure 2) 


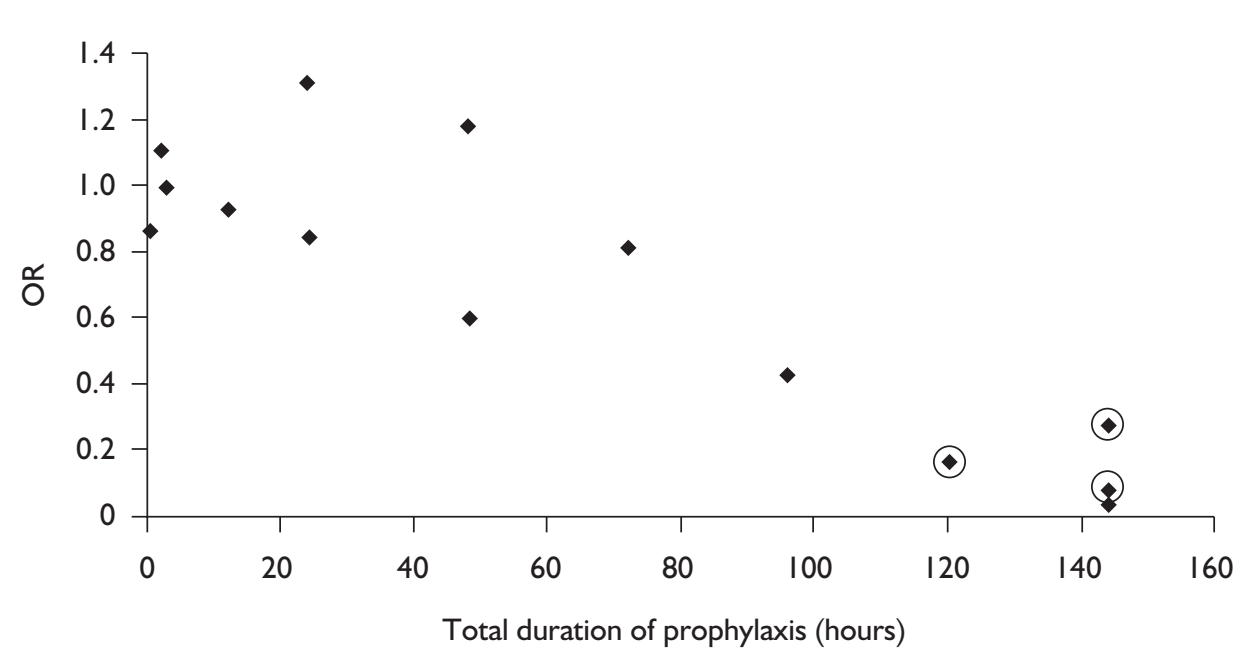

FIGURE 4 Relationship between the duration of magnesium sulphate prophylaxis and the odds of AF. Studies by Dagdelen, ${ }^{17,18}$ Nurözler ${ }^{25}$ and Toraman ${ }^{27}$ are encircled; a study by Yilmaz ${ }^{14}$ is omitted (see text).

according to whether duration of prophylaxis was 1 day or less, 2-4 days, or 5 days or greater, a statistically significant intervention effect is only present for the longest duration group $(\mathrm{OR}=$ $0.12,95 \%$ CI 0.06 to 0.23 , test for overall effect $p=0.00001$ ) (forest plot not shown). In this subgroup heterogeneity is not statistically significant $(p=0.12)$, although the $I^{2}$ value $(48 \%)$, is just below the suggested threshold of substantial heterogeneity (50\%). ${ }^{12}$ The effect for a duration of 5 days or greater would remain statistically significant after excluding the trials by Toraman ${ }^{27}$ and Dagdelen ${ }^{17,18}$ (data not shown).

\section{Subgroup analyses: timing of initiation of prophylaxis}

Most of the studies did not report the exact timing of the start of magnesium prophylaxis, but the studies can be grouped according to whether prophylaxis commenced 12 hours or more presurgery (Figure 5), within 12 hours of surgery (including during surgery itself) (Figure 6) or at the termination of surgery or immediately postsurgery (Figure 7). For the first two subgroups there was a statistically significant intervention effect, while in the third there was no significant effect.

Review: Intravenous magnesium compared wth sotalol for prevention of atrial fibrillation after coronary artery bypass surgery

Comparison: Intravenous magnesium sulphate versus placebo

Outcome: Incidence of AF: timing - initiation of therapy $\geqslant 12$ hours presurgery

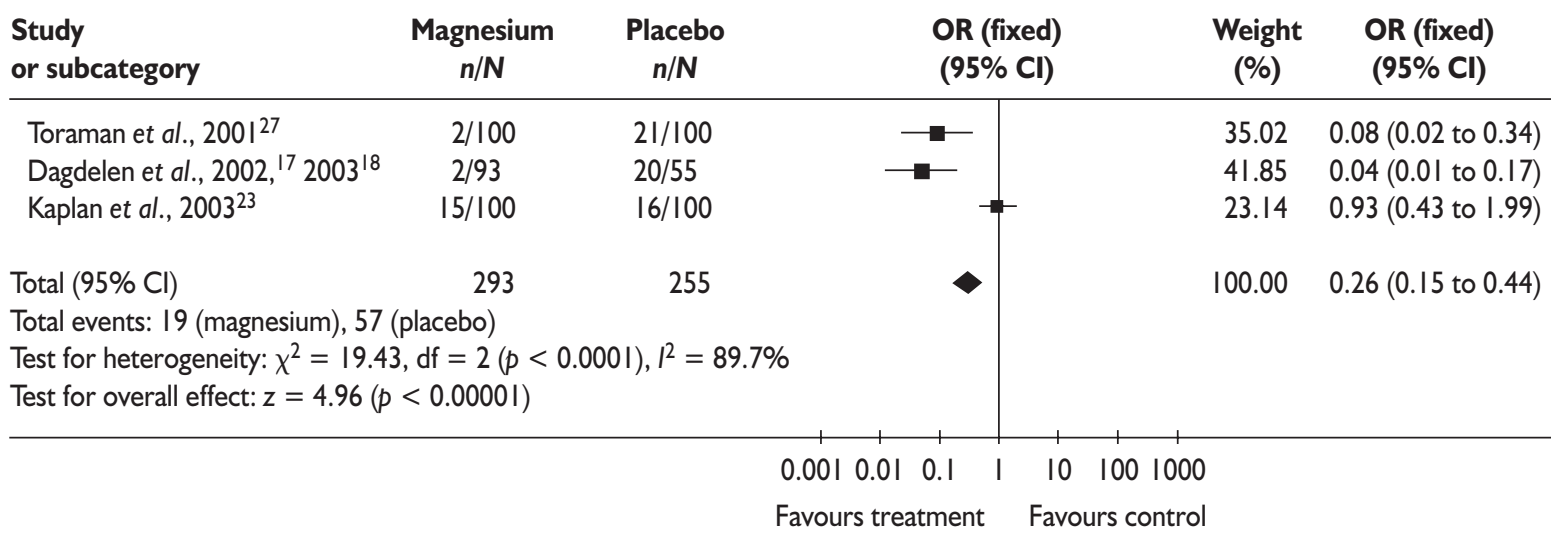


Review: Intravenous magnesium compared wth sotalol for prevention of atrial fibrillation after coronary artery bypass surgery

Comparison: Intravenous magnesium sulphate versus placebo

Outcome: Incidence of AF: timing - initiation of therapy $<12$ hours presurgery/during surgery

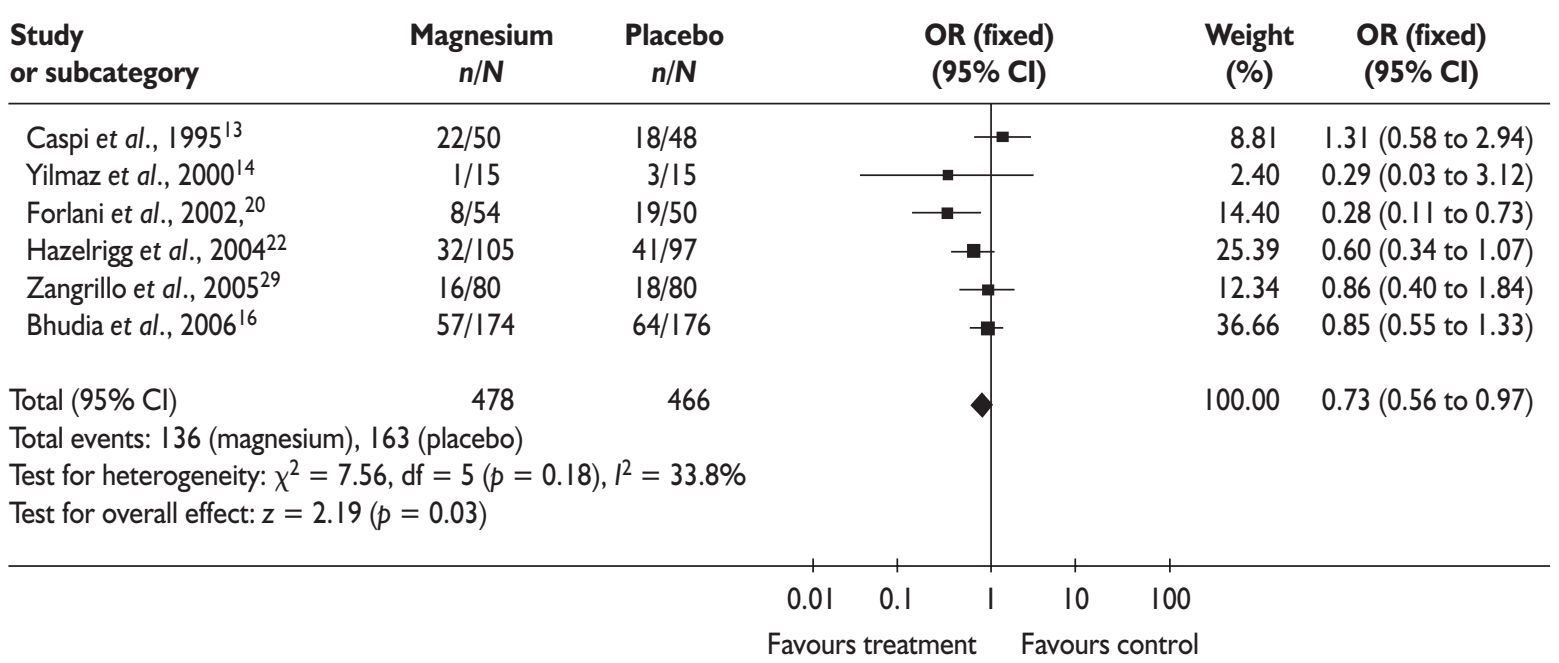

FIGURE 6 Subgroup analysis: timing of initiation of prophylaxis (less than 12 hours presurgery or during surgery) (fixed-effects model)

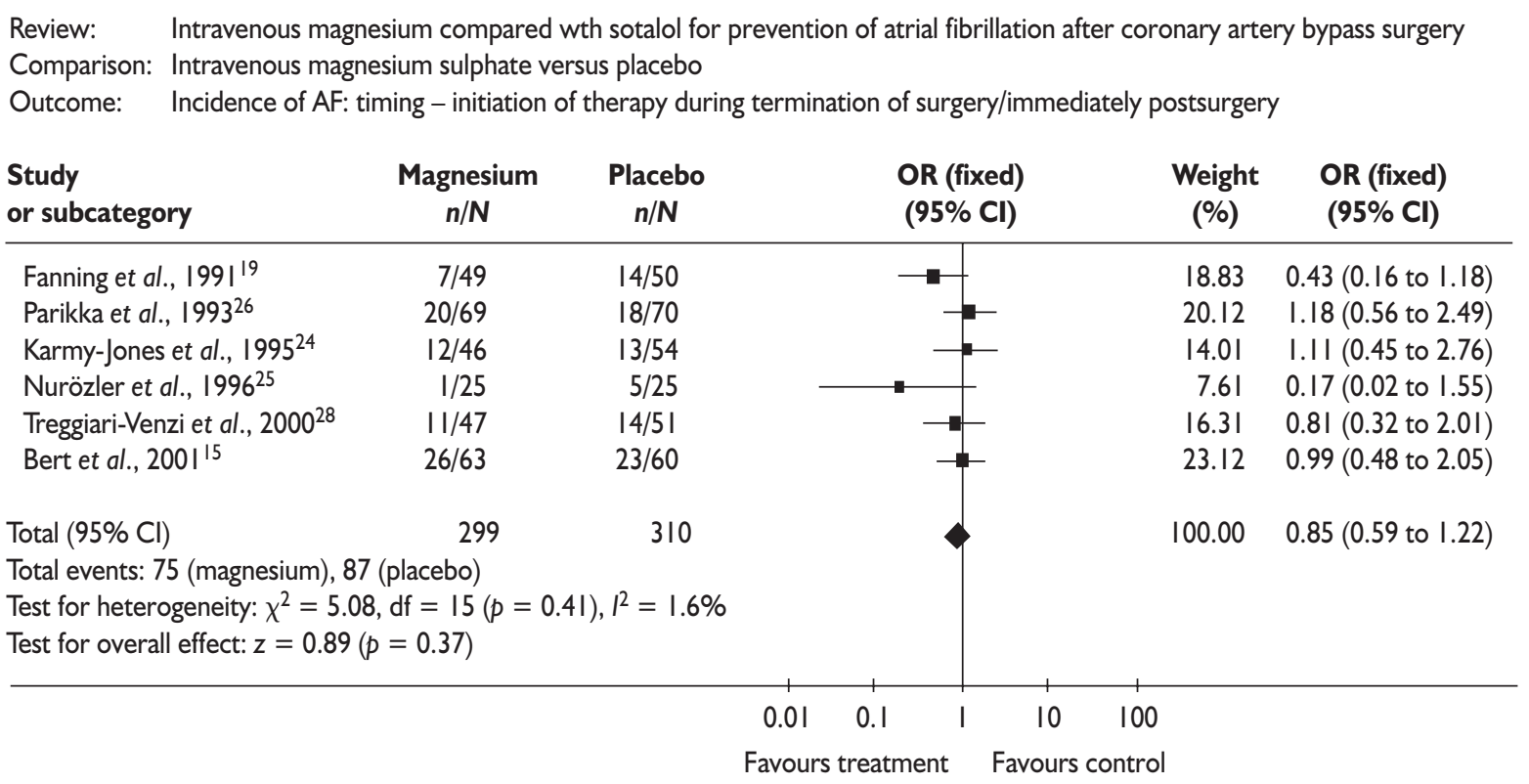

FIGURE 7 Subgroup analysis: timing of initiation of prophylaxis (at termination of surgery or immediately postsurgery) (fixed-effects model)

For the subgroup of studies that initiated prophylaxis 12 hours or more before surgery the OR was 0.26 (95\% CI 0.15 to 0.44 , test for overall effect $p=0.00001$, fixed-effects model) (Figure 5). However, there was statistically significant heterogeneity $\left(I^{2}=89.7 \%, p<0.0001\right)$. This is
Toraman $^{27}$ and Dagdelen ${ }^{17,18}$ trials, compared with the trial by Kaplan and colleagues. ${ }^{23}$ When a random-effects model was used the OR was reduced to 0.15 , but the CIs included 1.0 (95\% CI 0.02 to 1.38 , test for overall effect $=0.09$ ) and the effect was therefore no longer statistically significant. 
For studies that initiated prophylaxis less than 12 hours before surgery or during the surgery itself, there was a significant intervention effect $(\mathrm{OR}=0.73,95 \%$ CI 0.56 to $0.97, p=0.03$, fixedeffects model) without statistically significant heterogeneity $\left(I^{2}=33.8 \%, p=0.18\right)$ (Figure 6).

The subgroup of studies that initiated prophylaxis at the end of surgery or postsurgery was not associated with a significant intervention effect $(\mathrm{OR}=0.85,95 \%$ CI 0.59 to $1.22, p=0.37$, fixedeffects model); heterogeneity was also not statistically significant in this subgroup $\left(I^{2}=1.6 \%\right.$, $p=0.41)$ (Figure 7).

\section{Subgroup analyses: dose}

In eight of the 15 trials the dose of magnesium sulphate was reported in grams. In five trials the dose in grams was converted by the reviewers from millimoles or milliequivalents, by assuming $1 \mathrm{~g} \equiv 4 \mathrm{mmol} \equiv 8 \mathrm{mEq}$ of magnesium sulphate (based on a conversion formula provided by Shiga and colleagues ${ }^{8}$ ). The total dose of magnesium sulphate administered in 13 of the trials ranged from 2.5 to $25 \mathrm{~g}$ (Table 3). In the remaining two trials, total doses of magnesium sulphate were given per kilogram of unspecified ideal body weight $^{22}$ or per an unspecified parameter, ${ }^{14}$ precluding them from meta-analysis.

The dose-response relationship has not previously been characterised for effects of magnesium sulphate on AF. Meta-analysis (Figure 8) shows that for total doses of magnesium sulphate less than $21 \mathrm{~g}$, the odds of AF were independent of the dose. A notable exception is that for a total dose of $9 \mathrm{~g}$ magnesium sulphate the odds of AF were significantly reduced relative to the control group $(\mathrm{OR}=0.12$, test for overall effect $p<0.00001$, heterogeneity $p=0.06)$. Previous studies have identified serum magnesium concentration as a predictor of AF, but it is unclear why a profound prophylactic effect of magnesium sulphate would be found only at a total dose of $9 \mathrm{~g}$. It is notable that the three studies that administered magnesium sulphate at the total dose of $9 \mathrm{~g}$ (Dagdelen, ${ }^{17.18}$ Forlani $^{20,21}$ and Toraman ${ }^{27}$ ) had each excluded patients who were on antiarrhythmic drugs (Appendix 6). As mentioned previously, the patients included in these studies might have been at higher risk of $\mathrm{AF}$ compared with patients in other studies and, if so, might have benefited more from prophylactic magnesium. The studies by Dagdelen ${ }^{17,18}$ and Toraman ${ }^{27}$ in particular tend to impart a highly significant reduction in the odds of AF to whichever subgroup these studies are analysed in (see above).
If the study by Nurözler and colleagues ${ }^{25}$ is included in the meta-analysis, the forest plot (Figure 8) would suggest a possible dose-response relationship, as the highest doses tested (21 and $25 \mathrm{~g}$ ) are associated with a reduction in the odds of AF, although for these individual doses the CIs of the OR include $1(p>0.05)$. Repeating the meta-analysis with the two highest doses grouped together $(n=2)$ would yield a significant OR for this high-dose $(\geqslant 21 \mathrm{~g})$ group $(\mathrm{OR}=0.35,95 \% \mathrm{CI}$ 0.14 to 0.88 , test for overall effect $p=0.02$, heterogeneity $p=0.45$; forest plot not shown). The Nurözler and colleagues study is problematic, however, because in addition to the total of 200 mEq magnesium sulphate that they administered intravenously, they gave an unspecified dose of an unspecified magnesium compound only to the intervention group, during cardioplegia. This effectively confounds their intravenous magnesium sulphate dose with an unknown variable. Excluding the Nurözler and colleagues data from the forest plot is therefore advisable unless the details of how magnesium was administered in cardioplegia can be clarified. (The authors were contacted during preparation of the current review, but no response was received at the time of submission of this report.) Excluding the Nurözler and colleagues study would weaken the support for a dose-response relationship.

A potential limitation of comparing studies in terms of the total magnesium sulphate dose administered is that total dosage does not take into account the dose rate, which may have clinical relevance. An analysis of whether the dose rate of magnesium sulphate affects the incidence of AF was possible for eight trials in which the dose rate was kept constant (Table 4). In the remaining seven trials either the dose rates were varied during the course of a study, or they were unclear $^{13,14,16,19,22,25,26}$ (Table 3).

Within the subgroup of eight studies that maintained a constant dose rate there appears to be a relationship between the dose rate of magnesium sulphate and the odds of AF, with the largest prophylactic effects being at the lowest dose rates (Figure 9). In the forest plot the dose rates $\left(\mathrm{mg} \mathrm{hour}^{-1}\right)$ are ordered from lowest $\left(62.5 \mathrm{mg} \mathrm{hour}^{-1}\right)$ to highest $\left(7200 \mathrm{mg} \mathrm{hour}^{-1}\right)$. The forest plot illustrates a large and statistically significant degree of heterogeneity $\left(I^{2}=76.6 \%\right.$, $p=0.0001$, random-effects model). It is notable that two studies that appear influential in this relationship (by Dagdelen ${ }^{17,18}$ and Toraman ${ }^{27}$ ) have been highlighted previously in terms of their low ORs and possibly atypical patient populations 
Review: Intravenous magnesium compared wth sotalol for prevention of atrial fibrillation after coronary artery bypass surgery

Comparison: Intravenous magnesium sulphate versus placebo

Outcome: Incidence of AF (in dosage subgroups)

Study

or subcategory

$2.5 \mathrm{~g}$

Zangrillo et al., $2005^{29}$

Subtotal $(95 \% \mathrm{Cl})$

Test for overall effect: $z=0.39(p=0.70)$

$3 \mathrm{~g}$

Kaplan et al., $2003^{23}$

Subtotal $(95 \% \mathrm{Cl})$

Test for overall effect: $z=0.20(p=0.85)$

$3.94 \mathrm{~g}$

Bhudia et al., $2006^{16}$

Subtotal $(95 \% \mathrm{Cl})$

Test for overall effect: $z=0.7 \mathrm{I}(p=0.48)$

$4.4 \mathrm{~g}$

Karmy-Jones et al., $1995^{24}$

Subtotal $(95 \% \mathrm{Cl})$

Test for overall effect: $z=0.23(p=0.82)$

$9 \mathrm{~g}$

Toraman et al., 2001 27

Dagdelen et al., 2002,17 $2003^{18}$

Forlani et al., 2002, ${ }^{20} 2003^{21}$

Subtotal $(95 \% \mathrm{Cl})$

Total events: 12 (magnesium), 60 (placebo)

Test for heterogeneity: $\chi^{2}=5.79, \mathrm{df}=2(p=0.06), I^{2}=65.4 \%$

Test for overall effect: $z=6.26(p<0.0000 \mathrm{I})$

$12 \mathrm{~g}$

Fanning et al., $1991^{19}$

$57 / 174$
174

$64 / 176$

$\begin{array}{rr}5 / 100 & 16 / 100 \\ 100 & 100\end{array}$

Placebo

OR (fixed)

$(95 \% \mathrm{Cl})$

Weight

(\%)

OR (fixed)

$(95 \% \mathrm{Cl})$

$16 / 80$

80

$18 / 80$

80

6.99

6.990 .86 ( 0.40 to 1.84$)$

$6.60 \quad 0.93(0.43$ to 1.99$)$

6.600 .93 (0.43 to 1.99$)$

$\begin{array}{rr}12 / 46 & 13 / 54 \\ 46 & 54\end{array}$

$3 / 54$

54

$\begin{array}{ll}2 / 100 & 21 / 100 \\ 2 / 93 & 20 / 55 \\ 8 / 54 & 19 / 50\end{array}$

247

$19 / 50$
205

$20.76 \quad 0.85(0.55$ to 1.33$)$

$20.76 \quad 0.85$ (0.55 to I.33)

$4.29 \quad \mathrm{I} . \mathrm{II}(0.45$ to 2.76$)$

4.29 I.II (0.45 to 2.76$)$

$9.98 \quad 0.08(0.02$ to 0.34$)$

$\begin{array}{ll}11.98 & 0.04(0.01 \text { to } 0.17)\end{array}$

$8.15 \quad 0.28(0.11$ to 0.73$)$

$30.07 \quad 0.12(0.06$ to 0.23$)$
Caspi et al., $1995^{13}$

Treggiari-Venzi et al., $2000^{28}$

Bert et al., 200। ${ }^{15}$

Subtotal $(95 \% \mathrm{Cl})$

Total events: 57 (magnesium), 55 (placebo)

Test for heterogeneity: $\chi^{2}=0.62, \mathrm{df}=2(p=0.73), I^{2}=0 \%$

Test for overall effect: $z=0.13(p=0.90)$

$17.5 \mathrm{~g}$

Parikka et al., $1993^{26}$

Subtotal $(95 \% \mathrm{Cl})$

Test for overall effect: $z=0.43(p=0.67)$

$21 \mathrm{~g}$

Subtotal $(95 \% \mathrm{Cl})$

Test for overall effect: $z=1.64(p=0.10)$

$25 \mathrm{~g}$

Nurözler et al., $1996^{25}$

Subtotal $(95 \% \mathrm{Cl})$

Test for overall effect: $z=1.58(p=0.1 \mathrm{I})$

Total $(95 \% \mathrm{Cl})$

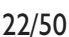

11/47

$24 / 63$

Total events: 197 (magnesium), 263 (placebo)

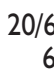

69

69

$18 / 70$

70

$18 / 48$

$|4 / 5|$

$23 / 60$
159

160

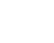

Test for heterogeneity: $\chi^{2}=37.36, \mathrm{df}=12(p$

Test for overall effect: $z=3.8 \mathrm{I}(p=0.000 \mathrm{I})$

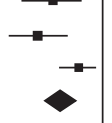

4.99

4.99

7.08

17.06

0.81 ( 0.32 to 2.01$)$

0.99 (0.48 to 2.05$)$

I.03 (0.65 to I.64)
I.3I (0.58 to 2.94$)$ 
TABLE 4 Studies in which the dose rate of magnesium sulphate was kept constant

\begin{tabular}{|c|c|c|c|c|c|}
\hline & Dose rate reported & $\begin{array}{l}\text { Dose rate } \\
\left(\mathrm{mg} \mathrm{h}^{-1}\right)\end{array}$ & $\begin{array}{l}\text { Total time } \\
\text { (h) }\end{array}$ & $\begin{array}{l}\text { Total dose } \\
\text { (g) }\end{array}$ & i.v. carrier \\
\hline Bert et al., 2001 ${ }^{15}$ & $2 \mathrm{~g}$ in 30 minutes & 4000 & 3 & 12 & $50 \mathrm{ml}$ saline \\
\hline $\begin{array}{l}\text { Dagdelen et al., 2002, }{ }^{17} \\
2003^{18}\end{array}$ & $1.5 \mathrm{~g} \mathrm{day}^{-1}$ & 62.5 & 144 (= 6 days) & 9 & $100 \mathrm{ml}$ saline \\
\hline $\begin{array}{l}\text { Forlani et al., } 2002,{ }^{20} \\
\qquad 2003^{21}\end{array}$ & $1.5 \mathrm{~g} \mathrm{day}^{-1}$ & 62.5 & 144 (= 6 days $)$ & 9 & NR \\
\hline Kaplan et al., $2003^{23}$ & $3 \mathrm{~g}$ in $2 \mathrm{~h}$ & 1500 & 12 & 18 & $100 \mathrm{ml}$ saline \\
\hline Karmy-Jones et al., $1995^{24}$ & $2.4 \mathrm{~g}$ in 20 minutes & 7200 & 2 & 14.4 & $50 \mathrm{ml}$ dextrose water \\
\hline Toraman et al., $200 \mathrm{I}^{27}$ & $6 \mathrm{mmol}(\equiv \mathrm{I} .5 \mathrm{~g}) \mathrm{day}^{-1}$ & 62.5 & 144 (= 6 days $)$ & 9 & $100 \mathrm{ml}$ saline \\
\hline $\begin{array}{l}\text { Treggiari-Venzi et al., } \\
2000^{28}\end{array}$ & $4 \mathrm{~g} \mathrm{day}^{-1}$ & 167 & 72 (= 3 days $)$ & 12 & NR \\
\hline Zangrillo et al., $2005^{29}$ & $2.5 \mathrm{~g}$ in 30 minutes & 5000 & 0.5 & 2.5 & $100 \mathrm{ml}$ saline \\
\hline
\end{tabular}

Review: Intravenous magnesium compared wth sotalol for prevention of atrial fibrillation after coronary artery bypass surgery

Comparison: Intravenous magnesium sulphate versus placebo

Outcome: Incidence of AF (dose rate in $\mathrm{mg}$ per hour)

\begin{tabular}{|c|c|c|c|c|c|c|}
\hline $\begin{array}{l}\text { Study } \\
\text { or subcategory }\end{array}$ & $\begin{array}{l}\text { Magnesium } \\
n / N\end{array}$ & $\begin{array}{c}\text { Placebo } \\
n / N\end{array}$ & $\begin{array}{c}\text { OR (random) } \\
(95 \% \mathrm{Cl})\end{array}$ & $\begin{array}{l}\text { Weight } \\
(\%)\end{array}$ & $\begin{array}{c}\text { OR (random) } \\
(95 \% \mathrm{Cl})\end{array}$ & Order \\
\hline Dagdelen et al., 2002,, $2003^{18}$ & $2 / 93$ & $20 / 55$ & $\longrightarrow-$ & 9.31 & $0.04(0.01$ to 0.17$)$ & 62 \\
\hline Forlani et al., $2002,{ }^{20} 2003^{21}$ & $8 / 54$ & $19 / 50$ & $\rightarrow-$ & 12.83 & $0.28(0.1$ I to 0.73$)$ & 62 \\
\hline Toraman et al., $200 \mathrm{I}^{27}$ & $2 / 100$ & $21 / 100$ & $\longrightarrow$ & 9.45 & $0.08(0.02$ to 0.34$)$ & 62 \\
\hline Treggiari-Venzi et al., $2000^{28}$ & $11 / 47$ & $|4 / 5|$ & $\rightarrow$ & 13.03 & $0.8 \mathrm{I}(0.32$ to $2.0 \mathrm{I})$ & 167 \\
\hline Kaplan et al., $2003^{23}$ & $15 / 100$ & $16 / 100$ & $\rightarrow$ & 14.00 & 0.93 (0.43 to I.99) & 1500 \\
\hline Bert et al., $2001^{15}$ & $24 / 63$ & $23 / 60$ & - & 14.25 & 0.99 (0.48 to 2.05$)$ & 4000 \\
\hline Zangrillo et al., $2005^{29}$ & $16 / 80$ & $18 / 80$ & $\rightarrow$ & 14.05 & $0.86(0.40$ to 1.84$)$ & 5000 \\
\hline Karmy-Jones et al., $1995^{24}$ & $12 / 46$ & $13 / 54$ & $\rightarrow$ & 13.08 & I.II (0.45 to 2.76$)$ & 7200 \\
\hline Total $(95 \% \mathrm{Cl})$ & 583 & 550 & & 100.00 & $0.47(0.24$ to 0.93$)$ & \\
\hline
\end{tabular}

Total events: 90 (magnesium), 144 (placebo)

Test for heterogeneity: $\chi^{2}=29.87, \mathrm{df}=7(p=0.000 \mathrm{I}), 1^{2}=76.6 \%$

Test for overall effect: $z=2.17(p=0.03)$

$0.0010 .010 .1 \quad 1 \quad 10 \quad 1001000$

Favours treatment Favours control

FIGURE 9 Subgroup analysis: all studies that maintained a constant dose rate (random-effects model). Studies are ordered from lowest dose rate (top) to highest (bottom). Order: dose rate in $\mathrm{mg} \mathrm{h}^{-1}$.

(see above). Excluding these two trials from the sub-group reduces the heterogeneity to a nonsignificant level $\left(I^{2}=11.6 \%, p=0.34\right.$, fixedeffects model), but also weakens the evidence for an effect of dose rate, with only one out of the remaining six studies exhibiting an OR that is clearly and significantly different from 1.0

(Figure 10).

\section{Adverse events}

Studies varied in whether they reported adverse events, and how such events were reported; for example, in some cases, AF was reported as an adverse event. Ten of the 15 studies mentioned whether mortality differed between the magnesium sulphate and control (or placebo) groups (Table 5). Overall, numbers of deaths were too low for differences to attain statistical significance.

Potentially adverse events that were reported included a wide range of electrocardiological conditions (e.g. ventricular tachycardia, ischaemia, other arrhythmias), haemodynamic changes (e.g. altered blood pressure) and biochemical events (e.g. changes in serum electrolytes and creatinine 
Review: Intravenous magnesium compared wth sotalol for prevention of atrial fibrillation after coronary artery bypass surgery

Comparison: Intravenous magnesium sulphate versus placebo

Outcome: Incidence of AF (dose rate in $\mathrm{mg}$ per hour)

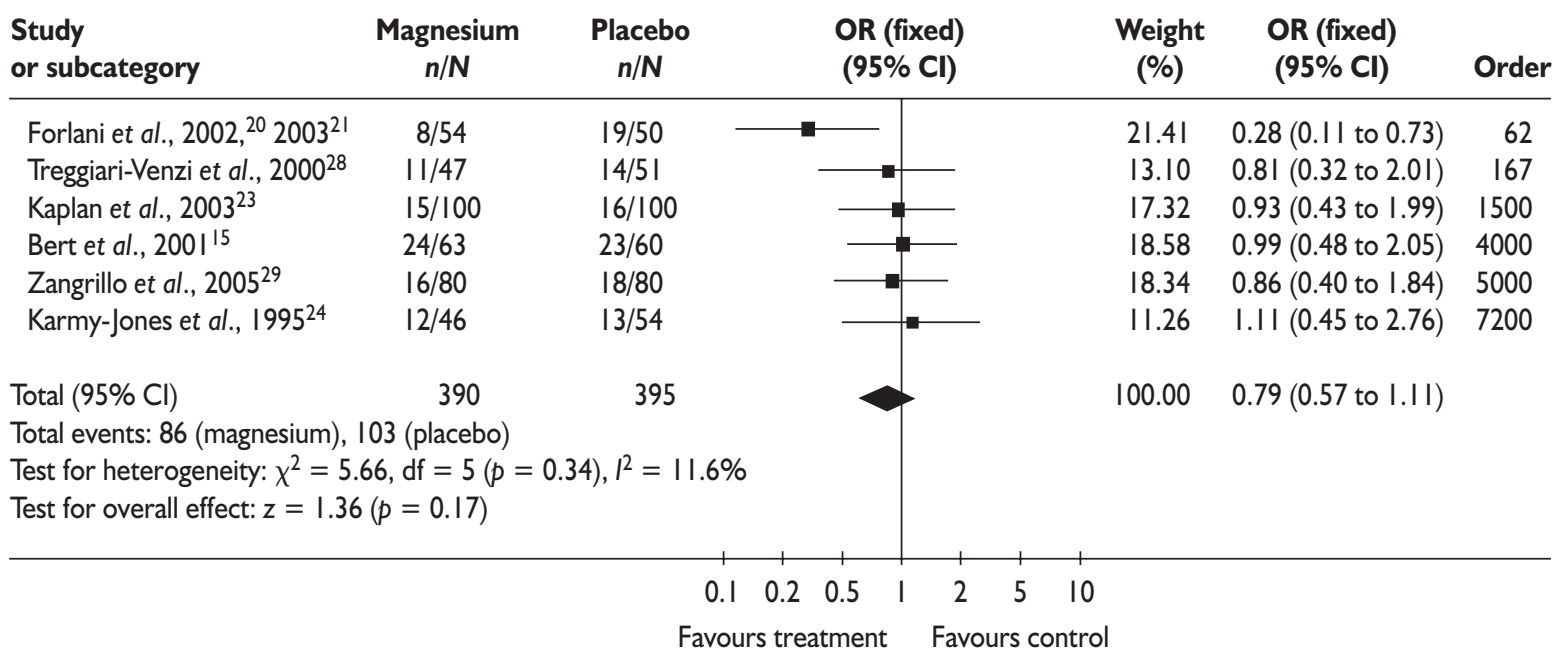

FIGURE 10 Subgroup analysis: studies that maintained a constant dose rate, excluding those by Dagdelen et al. ${ }^{17,18}$ and Toraman et al. ${ }^{27}$ (fixed-effects model). Studies are ordered from lowest dose rate (top) to highest (bottom). Order: dose rate in $\mathrm{mg} \mathrm{h}^{-1}$.

TABLE 5 Summary of mortality reported in patients receiving magnesium sulphate compared with control (or placebo) patients

\begin{tabular}{|c|c|c|}
\hline Study & Postoperative in-study mortality (n) & $\begin{array}{l}\text { Mortality reported after discharge } \\
\text { or main follow-up ( } n)\end{array}$ \\
\hline Bert et al., $200 \mathrm{I}^{15}$ & $0 \mathrm{Mg}, 0$ control & NR \\
\hline Bhudia et al., $2006^{16}$ & I Mg, I placebo & I Mg, 4 placebo $(p=0.2)$ \\
\hline Caspi et al., $1995^{13}$ & I $\mathrm{Mg}, 0$ placebo & $N R$ \\
\hline Dagdelen et al., $2002,,^{17} 2003^{18}$ & NR & NR \\
\hline Fanning et al., $\left.199\right|^{19}$ & $0 \mathrm{Mg}$, I placebo & NR \\
\hline Forlani et al., $2002,{ }^{20} 2003^{21}$ & $\mathrm{I} \mathrm{Mg}, 0$ control & NR \\
\hline Hazelrigg et al., $2004^{22}$ & $\mathrm{I} \mathrm{Mg}, 2$ control & NR \\
\hline Kaplan et al., $2003^{23}$ & I Mg, I placebo & NR \\
\hline Karmy-Jones et al., $1995^{24}$ & $0 \mathrm{Mg}, 2$ placebo & NR \\
\hline Nurözler et al., $1996^{25}$ & $N R$ & NR \\
\hline Parikka et al., $1993^{26}$ & NR & (group not specified) \\
\hline Toraman et al., 2001 27 & NR & NR \\
\hline Treggiari-Venzi et al., $2000^{28}$ & $0 \mathrm{Mg}, 0$ placebo (inferred) & $0 \mathrm{Mg}$, I placebo \\
\hline Yilmaz et al., $2000^{14}$ & NR & $N R$ \\
\hline Zangrillo et al., $2005^{29}$ & $0 \mathrm{Mg}, 0$ placebo & NR \\
\hline
\end{tabular}

kinase concentrations). One study, by Hazelrigg and colleagues, ${ }^{22}$ reported a statistically significant, but not clinically significant, lower arterial pressure in magnesium-treated patients immediately after surgery (no $p$-value reported). They also reported a significantly greater excretion $(p<0.001)$ of magnesium and calcium over a 24-hour period in the magnesium sulphatetreated patients, but the timing relative to surgery was unclear. In all other studies where adverse events differed significantly between the groups, it was the magnesium sulphate group that had the more favourable incidence (or concentration). 


\section{Chapter 5}

\section{Economic analysis}

$\mathrm{T}$ he aim of this section is to assess the costeffectiveness of intravenous magnesium sulphate alone as prophylaxis against AF following CABG compared with no prophylaxis. The economic analysis comprises:

- a systematic review of the literature on the costeffectiveness of intravenous magnesium sulphate alone as prophylaxis against $\mathrm{AF}$ following $\mathrm{CABG}$

- identification of appropriate methods to model the cost-effectiveness of prophylaxis against AF following $\mathrm{CABG}$

- identification of key resource-use differences between post-CABG patients with and without $\mathrm{AF}$

- presentation of the economic model and costeffectiveness evaluation.

\section{Methods for economic analysis}

A systematic literature search was undertaken to identify economic evaluations comparing intravenous magnesium sulphate as prophylaxis against AF following CABG compared with sotalol or no prophylaxis. The details of the search strategy are documented in Appendix 7.

Titles and abstracts of studies identified by the search strategy were assessed for potential eligibility by three health economists independently. The inclusion criteria for the review are documented in Appendix 8. Economic evaluations were eligible for inclusion if they reported the cost-effectiveness of intravenous magnesium sulphate alone as prophylaxis against AF following CABG compared with sotalol as prophylaxis or compared with no prophylaxis. Studies reporting the economic evaluation of other agents for prophylaxis against AF following $\mathrm{CABG}$, and studies reporting costs or resource use associated with postoperative AF and its management were included in a secondary review. The purpose of the secondary review was to identify appropriate methods for modelling the cost-effectiveness of prophylaxis against AF following $\mathrm{CABG}$, and key resource-use differences between post-CABG patients with and without AF.
On the basis of the secondary review a short-term economic model was developed to assess the costeffectiveness of magnesium sulphate prophylaxis against AF following CABG. The model needed to take account of any additional resource use by patients with AF, including the costs of managing postoperative AF during the patient's admission. The outcome used in the economic analysis was cases of AF avoided. Long-term modelling to estimate gains in life expectancy or qualityadjusted life expectancy was not attempted.

\section{Results of the systematic review of economic evaluations}

Tailored searches, using the terms reported in Appendix 7, were applied to specialist health, biomedical and health economic databases: Ovid MEDLINE $^{\circledR}$ (1950 to May week 12007$)$, EMBASE (1980 to 2007 week 19), Ovid MEDLINE InProcess and Other Non-Indexed Citations (14 May, 2007), and NHS EED and Econlit. A total of 63 references was downloaded into a Reference Manager bibliographic database. References were coded according to whether they were identified by drug-specific filters (eight magnesium studies and 55 sotalol studies were coded). None of these studies met the prespecified criteria for inclusion in the primary review of economic evaluations of intravenous magnesium sulphate alone as prophylaxis against AF following CABG compared with sotalol as prophylaxis or no prophylaxis.

On initial assessment of title and abstract, 49 references were excluded from the review, while two references were included in the secondary review. The remaining 12 references were classified as unclear on screening of title and abstract.

The 12 references classified as unclear on screening of title and abstract were reassessed once the full papers were retrieved. Of these, two were included in the secondary review (one was an economic evaluation of another agent for prophylaxis against $\mathrm{AF}$ following $\mathrm{CABG}$, and the other was a meta-analysis reporting resource-use differences) and all other references were excluded. 


\section{Summary}

- Sixty-three references were identified by the literature search. No studies met the inclusion criteria for the primary review of economic evaluations of intravenous magnesium sulphate as prophylaxis against AF following CABG compared with sotalol as prophylaxis or no prophylaxis.

- Four of the 63 references were included in a secondary review of economic evaluation of other agents for prophylaxis against $\mathrm{AF}$ following $\mathrm{CABG}$, and studies reporting costs or resource use associated with postoperative $\mathrm{AF}$ and its management.

\section{Secondary review of economic evaluations}

Since no studies met the inclusion criteria for the primary review, a review was conducted of papers that reported economic evaluations of other agents used for prophylaxis against postoperative $\mathrm{AF}$, or papers that reported cost/resource-use differences for patients undergoing CABG who developed AF. Of the four included studies, one is an economic evaluation of oral amiodarone for prophylaxis, ${ }^{34}$ two are reviews of clinical trials ${ }^{35,36}$ that also reported economic outcomes (including trials of amiodarone and sotalol) and one is a clinical trial report ${ }^{28}$ (including amiodarone, magnesium sulphate and placebo) that reported resource use for patients receiving prophylaxis and for patients with or without AF. The review is broken down into a discussion of:

- the scope of analysis and methods adopted in previous economic evaluation of prophylaxis against postoperative AF

- resource-use differences for patients with and without AF reported in the included studies.

\section{Scope and methodology of economic evaluations}

Reddy and colleagues ${ }^{34}$ developed a simple decision-tree model to assess the cost-effectiveness of amiodarone as prophylaxis against $\mathrm{AF}$ for patients undergoing CABG. The proportions of patients developing AF with or without prophylaxis (31.2\% and $25.5 \%$, respectively) were taken from a controlled trial. ${ }^{37}$ Other data used to populate the model were taken from published literature and a clinical database at the Hartford Hospital Cardiology Department. The time-frame for the model was the initial hospitalisation for cardiac surgery, and outcomes were expressed as costs to discharge and AF events occurring during hospital stay following
Patients who did not develop AF simply accrued costs associated with oral amiodarone prophylaxis (if in the intervention group) and hospital stay, in the ICU and the cardiac step-down unit (SDU). Costs of hospitalisation were based on length of stay in the ICU and SDU, estimated from the literature (the paper contains no information on how these length of stay estimates were derived, other than giving reference to source papers), and unit costs (cost per day) estimated from the local hospital cost database. Cost per day was $32 \%$ higher for ICU than for SDU. The same unit costs were applied for patients with and without AF. However, ICU costs were $43 \%$ higher and SDU costs $54 \%$ higher for patients developing AF, owing to the longer lengths of stay (4.32 versus 3.02 days in the ICU and 5.7 versus 3.7 days in SDU).

It was assumed that AF developed on the second day after surgery; therefore, this was the date on which treatment for AF would start. All patients with $\mathrm{AF}$ were assumed to be treated with digoxin, with an initial loading dose and subsequent daily maintenance doses. Patients with AF of greater than 48 hours' duration were also treated with anticoagulants, receiving 2 days of heparin and 8 days of warfarin. Patients received two activated partial thromboplastin (aPTT) tests per day while on heparin and one international normalised ratio (INR) per day while on warfarin. The proportion of patients with AF lasting for more than 48 hours was taken from the hospital cardiology department's clinical database and was estimated at $16.7 \%$.

In addition to costs of hospitalisation and drug treatments for AF, patients may require rhythm control (using electrical or pharmacological cardioversion) or rate control (using drugs such as digoxin). The proportion of patients with AF following $\mathrm{CABG}$ who spontaneously convert to normal sinus rhythm (33\%) and the proportion requiring electrical cardioversion (13\%) were taken from the literature. ${ }^{38}$ The proportion receiving rate control, which was assumed to continue until discharge from hospital, was the complement of these two proportions (i.e. 54\%). The proportion of patients having successful electrical cardioversion or successful pharmacological cardioversion, which was assumed to follow unsuccessful electrical cardioversion, was also taken from the literature.

The flow of patients implied by the model adopted by Reddy and colleagues ${ }^{34}$ appears to be a reasonable representation of current practice for 
patients developing AF following CABG, subject to modifications that would make it more consistent with current clinical guidelines related to England and Wales ${ }^{6}$ and Europe. ${ }^{1}$

The model appears to have been evaluated using Monte Carlo simulation. It is difficult to assess the validity of this approach as only the central estimates (with minima and maxima) for parameter values adopted in the model are reported, with no information on how values were selected in any given simulation or whether distributions were assigned to parameters. The base-case results are presented as average cost per AF case avoided for each strategy rather than an incremental analysis for the prophylaxis strategy compared with no prophylaxis. However, the analysis shows that the most influential variables were the cost of hospitalisations and the frequency of AF. The dominant effect of hospital costs is not surprising given the unit costs of US\$1080 and $\$ 1420$ for step-down care and ICU bed days, compared with $\$ 64$ for prophylaxis with oral amiodarone or $\$ 152$ for electrical cardioversion.

\section{Resource-use differences, with and without AF}

Treggiari-Venzi and colleagues ${ }^{28}$ suggest that prophylaxis with either amiodarone or magnesium sulphate will not be cost-effective since the proportion of patients developing AF with prophylaxis is not significantly different, at the $5 \%$ level, from placebo [placebo $27 \%$ versus magnesium sulphate $23 \%(p=0.82)$ and amiodarone $14 \%(p=0.14)]$. They support their argument with a brief analysis which suggests that length of stay in ICU will be longer with amiodarone prophylaxis than without. This is based on the observation that, while patients in the trial who developed postoperative AF had a median length of ICU stay 2 days longer than those without AF (median 5 versus 3 days), patients receiving amiodarone had a median length of ICU stay 1 day longer than placebo patients (median 4 versus 3 days). With an avoidable risk of AF with amiodarone prophylaxis calculated as $13 \%(27-14 \%)$ they estimate that routine amiodarone prophylaxis for all patients undergoing CABG would be associated with an extra 740 days in the ICU for every 1000 patients compared with no prophylaxis (Table 6).

In effect, Treggiari-Venzi and colleagues ${ }^{28}$ argue, on the basis of the comparison of oral amiodarone prophylaxis against placebo, that prophylaxis against postoperative AF is dominated by the no-prophylaxis option (with symptomatic management of $\mathrm{AF}$ ) and therefore no consideration of the cost of prophylaxis was required. They reinforced this conclusion by stating that the oral amiodarone group experienced a higher adverse event rate than did placebo patients, which "may be attributable to the study drug". The same does not apply for magnesium sulphate prophylaxis which, while not having a statistically significant effect on the occurrence of postoperative AF, could save 80 days of ICU stay using a similar analysis as reported for oral amiodarone (Table 6), which was not reported by Treggiari-Venzi and colleagues. ${ }^{28}$ TreggiariVenzi and colleagues ${ }^{28}$ did not report length of stay on ward following discharge from ICU or total hospital stay, whereas other studies have suggested that AF may increase ward stay as well as ICU stay.

Reddy and colleagues ${ }^{35}$ reviewed six trials of amiodarone (either oral or intravenous) and one trial of sotalol as prophylaxis against AF following CABG. The main economic outcomes reported were length of stay (reported for all trials and given as total hospital stay or broken down by ICU and ward stay) and hospital costs (reported in five of the amiodarone trials). Trials included in the review typically reported length of stay for each arm of the trial (prophylaxis versus placebo) and do not indicate the difference in length of stay for patients with and without AF. Reddy and colleagues $^{35}$ reviews additional studies that reported length of stay for patients with AF,

TABLE 6 Days in ICU with and without prophylaxis (from Treggiari-Venzi and colleagues ${ }^{28}$ )

\begin{tabular}{|lccc|}
\hline & \multicolumn{3}{c|}{ Days in ICU for cohort of 1000 patients } \\
\cline { 2 - 4 } Prophylaxis type & With AF $^{a}$ & Without AF $^{b}$ & Total \\
\hline Oral amiodarone & 840 & 3440 & 4280 \\
None & 1350 & 2190 & 3540 \\
Magnesium sulphate & 1150 & 2310 & 3460 \\
\hline a Length of stay $\times$ probability of AF $\times 1000$. & & & \\
$b$ Length of stay $\times(I-$ probability of AF $) \times 1000$. & & & \\
\end{tabular}


suggesting that AF may increase total stay by between $3.2^{39}$ and $6^{40}$ days. Breaking this down by ICU and ward stay, one study showed that AF increased ICU stay by 2.3 days (5.7 versus 3.4 days) and ward stay by 3.4 days (10.9 versus 7.5 days). ${ }^{41}$ In the clinical trials of prophylaxis against postoperative $\mathrm{AF}$, while all studies reported a lower average length of stay for patients receiving prophylaxis (and five of the studies showing a significant decrease in the proportion of patients with $\mathrm{AF}$ ), only one study reported a statistically significant reduction in length of stay. ${ }^{38}$ This may be a reflection of the trials being underpowered to show significant differences in resource use, since they will typically be powered only to detect differences in clinical outcome. The lack of significant differences may also reflect the fact that, while it may substantially increase length of stay in the ICU or on the ward for some patients, postoperative AF only affects a minority of patients, so the effect of this difference is diluted when looking at mean length of stay across a cohort of patients. Among those studies that reported costs, only one study reported a statistically significant difference ${ }^{38}$ (with lower costs for patients receiving prophylaxis). The results with respect to cost were less consistent, with two studies reporting lower costs for placebo patients.

Zimmer and colleagues ${ }^{36}$ included similar studies to those reviewed by Reddy and colleagues ${ }^{35}$ in their meta-analysis. This included meta-analysis of the effect of amiodarone or sotalol prophylaxis on length of hospital stay and on hospital costs.

\section{Summary}

A simple decision tree can be used to estimate the short-term cost-effectiveness of magnesium sulphate prophylaxis against AF following CABG. The form of the analysis in this report will be costeffectiveness analysis with AF events avoided as the outcome measure.

The principal determinant of the cost-effectiveness of prophylaxis against $\mathrm{AF}$ following $\mathrm{CABG}$ is likely to be length of stay in the ICU and on hospital wards.
The structure presented by Reddy and colleagues $^{34}$ is reasonable, but requires some modification to make it consistent with current clinical guidelines relevant to the NHS.

The economic analysis will need to examine potential resource differences that may be associated with statistically non-significant differences in outcome, particularly in terms of length of stay.

A comparison of the cost-effectiveness of prophylaxis with intravenous magnesium sulphate compared with sotalol will not be performed. No RCTs or economic evaluations of this comparison were identified in the present systematic review, and expert clinical opinion suggests that it is not a clinically meaningful comparison.

\section{SHTAC economic model methods}

\section{Estimation of net benefits (taking account of disbenefits)}

The outcome of interest in the economic model in this report is the proportion of patients experiencing AF following $\mathrm{CABG}$, with or without prophylaxis with magnesium sulphate; or, alternatively, the number of patients experiencing $\mathrm{AF}$ in a given patient cohort, for example 1000 patients. The pooled risk ratio derived in the meta-analysis (estimated as a relative risk, rather than OR as presented in 'Incidence of AF', p. 10) will be applied to the estimated baseline proportion of patients experiencing AF following CABG with prophylaxis. This will provide an estimate of the proportion of AF cases averted by prophylaxis with magnesium sulphate.

As reported in 'Description of the underlying health problem' (p. 3), the typical range reported for $\mathrm{AF}$ following $\mathrm{CABG}$, without prophylaxis, is between 20 and $40 \%$ of patients. For the economic model a point estimate of $30 \%$, which is the average across the placebo arms from trials included in the meta-analysis, will be used. Table 7

TABLE 7 Baseline risk of AF following CABG and relative risk with magnesium sulphate prophylaxis: inputs to economic model

\begin{tabular}{|lccc|}
\hline & $\begin{array}{c}\text { Point estimate } \\
\text { Limit/maximum }\end{array}$ & $\begin{array}{c}\text { Lower confidence } \\
\text { Limit/minimum }\end{array}$ & Upper confidence \\
\hline Relative risk of AF with magnesium sulphate prophylaxis & 0.73 & $0.63^{a}$ & $0.84^{a}$ \\
Baseline risk of AF following CABG & 0.30 & 0.20 & 0.40 \\
\hline a $95 \%$ confidence interval. & & & \\
\hline
\end{tabular}


summarises the point estimates and confidence limits/ranges used in the analysis.

Applying 27\% risk reduction to the baseline estimate of risk of AF following CABG produces an estimate of the proportion of patients receiving prophylaxis who experience AF of $21.9 \%$. In terms of the estimated 23,000 operations performed annually in England (see 'Description of underlying health problem', p. 3) this would translate to 1863 fewer patients experiencing AF following $\mathrm{CABG}$, if all patients were assumed to be eligible for prophylaxis. In resource terms, assuming that patients with AF stay in the ICU 1 day longer than those without AF, this could result in the avoidance of 1836 ICU days attributable to AF following CABG.

There would be additional resource savings in terms of avoided drug treatments for AF, reduced requirements for anticoagulation and associated tests, and averted cardioversions as the number of patients with AF is reduced. Treatments for AF are not without complications, so a reduced risk of $\mathrm{AF}$ following $\mathrm{CABG}$ may not only reduce the potential morbidity burden in terms of $\mathrm{AF}$ and consequent risk of stroke and other conditions (discussed in 'Description of underlying health problem', p. 3), but also avoid morbidity of adverse events associated with AF treatment (not quantified in the model).

As discussed earlier, a short-term model was adopted that only estimates the reduction in the proportion of patients experiencing $\mathrm{AF}$ and resource use up to hospital discharge.

\section{Estimation of net costs}

The net costs of consumables for providing magnesium sulphate prophylaxis are calculated as $£ 9.84$ per infusion. These are based on unit costs of $£ 2.91$ for a 2-ml ampoule of magnesium sulphate (which corresponds to $4 \mathrm{mmol}$ of magnesium sulphate) and £2.01 for a 50 -ml ampoule of sodium chloride intravenous infusion solution $(0.9 \% \mathrm{NaCl})$. Unit costs are taken from the British National Formulary (BNF), No. 53 (March 2007). ${ }^{5}$ A range of concentrations has been adopted in clinical trials: the European Association of Cardiothoracic Surgeons guidelines recommend a 6 -mmol infusion in $100 \mathrm{ml} 0.9 \%$ $\mathrm{NaCl}$ solution at a rate of $25 \mathrm{ml}$ per hour. ${ }^{1}$ The recommended regimen is to provide one infusion on the day before surgery, one just after bypass and an infusion once daily for 4 days postoperatively. If the typical length of stay in the ICU following surgery is 1-2 days, it can be assumed that three of the infusions occur alongside usual care and would not require any additional set-up time or monitoring. However, the preoperative and two of the postoperative infusions would take place on the wards and would have additional staff costs for set-up and monitoring.

To estimate the staff costs associated with providing magnesium sulphate prophylaxis by intravenous infusion, it was assumed that 10 minutes of doctor time would be required to initiate and terminate the infusion. In addition, 10 minutes of nurse time would be required each hour of the infusion for patient monitoring. If the infusion occurs at a rate of $25 \mathrm{ml}$ per hour, this implies that each infusion takes 4 hours. Using hourly costs for a specialist registrar and for nurse staff on a 24-hour ward (Unit Costs of Health and Social Care, $2006^{42}$ ) gives a cost of $£ 11.33$ for medical staff and $£ 14.67$ for nursing staff per infusion (Table 8). Following the recommended regimen of six infusions and assuming that three of these occur in settings where additional costs for initiating and monitoring infusions would be minimal, the total net cost of providing magnesium sulphate prophylaxis by intravenous infusion was estimated at $£ 137.04$.

TABLE 8 Unit costs applied in the economic model ( $€$ )

\begin{tabular}{|c|c|c|c|}
\hline & Point estimate & Lower limit & Upper limit \\
\hline Magnesium sulphate (per infusion) & 9.84 & & \\
\hline Medical staff cost (per infusion) & 11.33 & 5.67 & 17.00 \\
\hline Nurse staff cost (per infusion) & 14.67 & 7.33 & 22.00 \\
\hline CABG (excluding critical care costs) ${ }^{a}$ & 8172 & & \\
\hline Coronary intensive care (per day) ${ }^{b}$ & 925 & 693 & 1196 \\
\hline CABG - excess bed days ${ }^{a}$ & 334 & 231 & 369 \\
\hline \multicolumn{4}{|c|}{$\begin{array}{l}\text { Lower and upper limit are based on variation of } \pm 50 \% \text { unless otherwise stated. } \\
\left.{ }^{a} \text { HRG - E04: coronary bypass; elective inpatient. (NHS Reference Costs } 2005 / 06^{43}\right) \text {. } \\
{ }^{b} \text { HRG - CC6L2: cardiac intensive care unit - level } 2 \text { care (NHS Reference Costs } 2005 / 06^{43} \text { ). } \\
\text { For NHS reference costs the lower and upper limits are the lower and upper quartiles. }\end{array}$} \\
\hline
\end{tabular}


Unit costs for the coronary artery bypass admission, cost per bed day in coronary intensive care and costs for additional bed days associated with postoperative $\mathrm{AF}$ were taken from NHS Reference Costs $(2005 / 06) .{ }^{43}$ The elective inpatient cost for Healthcare Resonance Group (HRG) E04 (coronary bypass) was taken as the unit cost for the coronary artery bypass admission; this excludes costs associated with critical care. The cost for postoperative intensive care was taken as level 2 care in the cardiac intensive care unit (HRG CC6L2). The Intensive Care Society defines level 2 care as being for "patients requiring more detailed observation or intervention, single failing organ system or postoperative care, and higher levels of care." ${ }^{44}$ The excess bed-day cost for HRG E04 was taken as the unit cost for additional bed days associated with postoperative AF. Reference costs, along with the lower and upper quartiles, are reported in Table 8.

To estimate the cost of a typical CABG admission, using NHS Reference Costs, an estimate of ICU use must be added. The Bristol Royal Infirmary Cardiac services, adult cardiac surgery audit report ${ }^{45}$ reported a mean cardiac ICU stay between 1.7 and 2.3 days, with a median of 1 day. This analysis assumes a normal postoperative ICU stay of 1 day. Since this estimate is common to all patients in the model (as is the cost of CABG), it has no impact on the cost-effectiveness estimates, only on total cost. Using these assumptions an uncomplicated
CABG admission may be expected to cost $£ 9097$ using the unit costs adopted for this analysis.

The greatest anticipated savings from the use of prophylaxis against AF following CABG are likely to be a reduction in the proportion of patients having longer stays in the ICU and a reduction in the proportion of patients having longer overall stays. Using the $27 \%$ risk reduction discussed in the previous section would suggest eight fewer patients experiencing AF per 100 operations. To estimate the additional inpatient resource use associated with postoperative $\mathrm{AF}$, studies reporting additional ICU and ward stays associated with postoperative AF were briefly reviewed. These studies were selected from the list of references identified by the search for economic evaluations and costing studies of magnesium sulphate and sotalol as prophylaxis against AF following $\mathrm{CABG}$ reported in the section 'Results of the systematic review of economic evaluations' (p. 23). Additional studies were identified from the reference lists of included papers.

Where studies have reported length of stay in ICU following $\mathrm{CABG}$ and postoperative length of stay for patients with and without postoperative AF, they have consistently shown longer stays for patients with postoperative $\mathrm{AF}$ (Table 9), although the difference is not always shown to be statistically significant at the $5 \%$ level. The range for extra time spent in the ICU is between 8 hours and 2.3 days

TABLE 9 Estimated increase in length of stay, by location of care, associated with patients with AF after CABG

\begin{tabular}{|c|c|c|c|}
\hline \multirow[b]{2}{*}{ Study } & \multicolumn{3}{|c|}{ Length of stay } \\
\hline & ICU (days) & Ward (days) & Overall (days) \\
\hline Creswell et al., 199341 & 2.3 & 3.4 & \\
\hline Mendes et al., $1995^{46}$ & & & 1.7 \\
\hline Mathew et al., $1996^{47}$ & 0.54 & 2 & \\
\hline Aranki et al., $1996^{40}$ & & & $4.9^{a}$ \\
\hline Kowey et al., $1997^{48}$ & & & $3^{b}$ \\
\hline Almassi et al., $1997^{49}$ & $1.6^{b}$ & & $3^{b}$ \\
\hline Zaman et al., $1997^{50}$ & & & I.I \\
\hline Borzak et al., $1998^{51}$ & I & & $2.9^{a}$ \\
\hline Tamis and Steinberg, $2000^{39}$ & & & 3.2 \\
\hline Treggiari-Venzi et al., $2000^{28}$ & $2^{b}$ & & \\
\hline Zaman et al., $2000^{52}$ & & & 1.9 \\
\hline Kim et al., $2001^{53}$ & & & $1.2^{a}$ \\
\hline Hravnak et al., $2002^{54}$ & & & 1.4 \\
\hline Thompson et al., $2002^{55}$ & & & 5.5 \\
\hline Tamis-Holland et al., $2006^{56}$ & & $1.1^{a}$ & \\
\hline Hosokawa et al., $2007^{57}$ & 0.33 & & 3 \\
\hline
\end{tabular}


and for extra days spent on the ward range the range is 1.1-3.4 days. The range for overall postoperative stay is $1.1-5.5$ days. These values are similar to those adopted by Reddy and colleagues ${ }^{34}$ in their economic evaluation of amiodarone prophylaxis, where the base-case estimates were 1.3 additional days in the ICU (range 1.3-1.85) and 2 additional days on the ward (range 0-5.95) associated with postoperative AF.

Postoperative $\mathrm{AF}$ is associated with patient factors (such as age) that may also be associated with longer inpatient stays. For example, the Society for Cardiothoracic Surgery's National Adult Surgical Database Report $(2000 / 01)^{58}$ reported average postoperative stays between 6 and 10 days, with older patients having the longer average length of stay. Therefore, the unadjusted lengths of stay reported in Table 9 may overestimate the effect of AF on postoperative length of stay. Those studies that have sought to control for confounding factors ${ }^{40,51,53,56}$ have typically shown that the effect of $\mathrm{AF}$ alone is reduced, but that differences between patients with and without $\mathrm{AF}$ remain significant. Variables that were found to be significant confounders, and included in the adjustments, are patient sex, ${ }^{40,51,53}$ age ${ }^{40,51,53,56}$ postoperative complications, ${ }^{40,56}$ preoperative unstable angina ${ }^{53}$ and digoxin use before surgery ${ }^{56}$ On the basis of these studies it was assumed that postoperative AF results in 1 additional day in the ICU (range 0-2) and 2 additional days on the ward (range 0-4) (Table 10).

The additional cost per 100 patients undergoing CABG, with a $30 \%$ baseline risk of postoperative $\mathrm{AF}$ and using the unit costs in Table 8 , would be $£ 47,785$ if overall stay were increased by 3 days for patients experiencing AF following CABG (1 extra day in the ICU and 2 extra days on the ward). If prophylaxis with magnesium sulphate is associated with a relative risk of postoperative $\mathrm{AF}$ of 0.73 , the reduction in costs associated with extra bed days due to $\mathrm{AF}$ could be $£ 12,902$ per 100 patients.

Costs of drugs used for pharmacological cardioversion (PCV) are based on an assumed body weight of $84 \mathrm{~kg}$ for a male patient undergoing CABG. This was derived from the distribution of body surface area (BSA) reported in the Society for Cardiothoracic Surgery's National Adult Surgical Database Report (2003), ${ }^{59}$ which has a mean of approximately $2.00 \mathrm{~m}^{2}$. Using the equation reported to derive BSA [see equation (1)] and an assumed average height of $175 \mathrm{~cm}\left(5^{\prime} 10^{\prime \prime}\right)$, the patient weight associated with a BSA of 2.00 can be estimated. A range for body weight was calculated using heights of 170 and $180 \mathrm{~cm}$, giving a weight range of $80-89 \mathrm{~kg}$.

$$
\mathrm{BSA}=7.184 \times 10^{-3} \times m^{0.425} \times h^{0.725}
$$

where $m$ is weight $(\mathrm{kg})$ and $h$ is height $(\mathrm{cm})$.

Using a dosing protocol for amiodarone of a loading dose of $5 \mathrm{mg} / \mathrm{kg}^{-1}$ for 30 minutes as intravenous infusion, followed by $25 \mathrm{mg}$ per hour for 24 hours and continuing treatment for 24 hours after cardioversion, gives a consumables cost of $£ 40.88$ for the loading dose and 48 hours of treatment (assuming that cardioversion occurs with 24 hours) (Table 11). This excludes staff costs for initiation of the intravenous infusions and for patient monitoring, as it was assumed that the majority of PCV will be initiated in the ICU. The reported effectiveness of amiodarone, for cardioversion, ranges from 77 to $93 \%$ of patients with postoperative AF converting to sinus rhythm at 24 hours. ${ }^{1}$

An alternative strategy for PCV was costed, using sotalol with a loading dose of $1 \mathrm{mg} \mathrm{kg}^{-1}$, followed by $0.2 \mathrm{mg} \mathrm{kg}^{-1}$ for 12 hours as an intravenous infusion. If cardioversion occurs patients receive a maintenance dose of $160 \mathrm{mg}$ oral sotalol, taken twice daily, for 2 weeks. The estimated consumables cost of this strategy was £20.11 for intravenous infusions and $£ 3.55$ for oral drugs, giving a total cost of £23.66 (Table 11). The reported effectiveness of sotalol, for cardioversion, ranges from 85 to $100 \%$ of patients with postoperative $\mathrm{AF}$ converting to sinus rhythm at 24 hours, ${ }^{1}$ although these values were derived from small studies.

TABLE IO Lengths of stay with and without postoperative AF used in the model

\begin{tabular}{|lccc|}
\hline & Point estimate & Lower limit & Upper limit \\
\hline CABG, excluding ICU, without AF & 7 & & \\
ICU stay, without AF & 1 & 0 & 2 \\
Additional ICU days with AF & 1 & 0 & 4 \\
Additional ward days with AF & 2 & 0
\end{tabular}


TABLE II Costs for treating AF: cardioversion or rate control $(E)$

\begin{tabular}{|lcrr|}
\hline & Point estimate & Lower limit & Upper limit \\
\hline Amiodarone - PCV & 40.88 & 20.44 & 61.32 \\
Sotalol -PCV & 23.66 & 11.83 & 35.49 \\
Direct current cardioversion & 117 & 58.50 & 175.50 \\
Digoxin - rate control & 14.41 & 7.21 & 21.62 \\
Anticoagulation & 22.84 & 21.62 & 34.26 \\
\hline Lower and upper limit are based on variation of $\pm 50 \%$ unless otherwise stated. & & \\
\end{tabular}

Costs for electrical cardioversion (ECV) were taken from Buxton and colleagues. ${ }^{60}$ This gave a cost of $£ 100$ at 2001 prices, which was updated to 2005/06 prices using the Hospital and Community Health Services Pay and Prices Index. ${ }^{42}$ Similarly, costs of anticoagulation were taken from Reddy and colleagues. ${ }^{34}$ Costs for warfarin and heparin reported in 1998 US dollars were converted to UK pounds using 1998 purchasing power parities $^{61}$ and then updated to $2005 / 06$ prices using the Hospital and Community Health Services Pay and Prices Index. ${ }^{42}$ Patients who did not convert to sinus rhythm within 48 hours received 2 days of intravenous heparin and 8 days of warfarin.

Rate control was costed using digoxin with a loading dose of $0.5 \mathrm{mg}$ followed by $0.25 \mathrm{mg}$ per 2 hours up to a maximum of $1.5 \mathrm{mg}$. This was followed by an oral maintenance dose of $0.25 \mathrm{mg}$ daily. The estimated consumables cost of the intravenous loading dose was $£ 13.74$ and oral maintenance dosing was costed at $£ 0.08$ per day (based on a unit cost of $£ 2.35$ per packet of $28 \times 250-\mu \mathrm{g}$ tablets) ${ }^{5}$

\section{Estimation of cost-effectiveness Model structure}

Figure 11 illustrates the model developed to estimate the cost-effectiveness of intravenous magnesium as prophylaxis against AF following CABG. The rounded rectangles (CABG and Discharge) indicate the "start" and "end" states. The non-rounded rectangles are "outcomes":

- presence or absence of postoperative AF

- success or failure of rhythm or rate control.

The diamonds indicate "decisions":

- whether patients spontaneously revert to sinus rhythm (effectively a decision not to initiate treatment for $\mathrm{AF}$, and observe)

- choice of rhythm or rate control (and choice of electrical or pharmacological rhythm control).
The flowchart allows for patients with AF, who fail to convert spontaneously to sinus rhythm, to receive pharmacological rate control rather than electrical or pharmacological rhythm control. It also allows for patients who fail PCV to move directly to rate control rather than ECV. The flow chart was converted to a decision tree (Figure 12) to perform the cost-effectiveness analysis.

\section{Model inputs}

Table 7 lists the point estimates (with lower and upper limits) for key parameters related to the baseline risk of AF following $\mathrm{CABG}$ and the relative risk of $\mathrm{AF}$ with magnesium sulphate prophylaxis used in the base-case analysis and in the deterministic sensitivity analyses. Tables 8 and 11 report the point estimates (with lower and upper limits) for unit costs used in the model, while Table 10 reports the point estimates (with lower and upper limits) for length of stay, with and without postoperative AF, used in the basecase analysis and in the deterministic sensitivity analyses.

Table 12 reports all parameter inputs to the model, with their point estimates along with the distribution types (and distribution parameters) applied in the probabilistic sensitivity analysis (PSA).

\section{Methods}

The decision tree can be used to estimate the costeffectiveness, in terms of incremental cost per AF case avoided with magnesium sulphate prophylaxis compared with no prophylaxis. In addition to reporting the incremental costs and incremental effectiveness, the average length of stay for the prophylaxis and no-prophylaxis options is reported, as well as the average additional ICU and ward days under each option. Key areas of uncertainty in the model are examined using deterministic and probabilistic sensitivity analyses.

Deterministic sensitivity analysis is used to address particular areas of uncertainty in the model related to: 


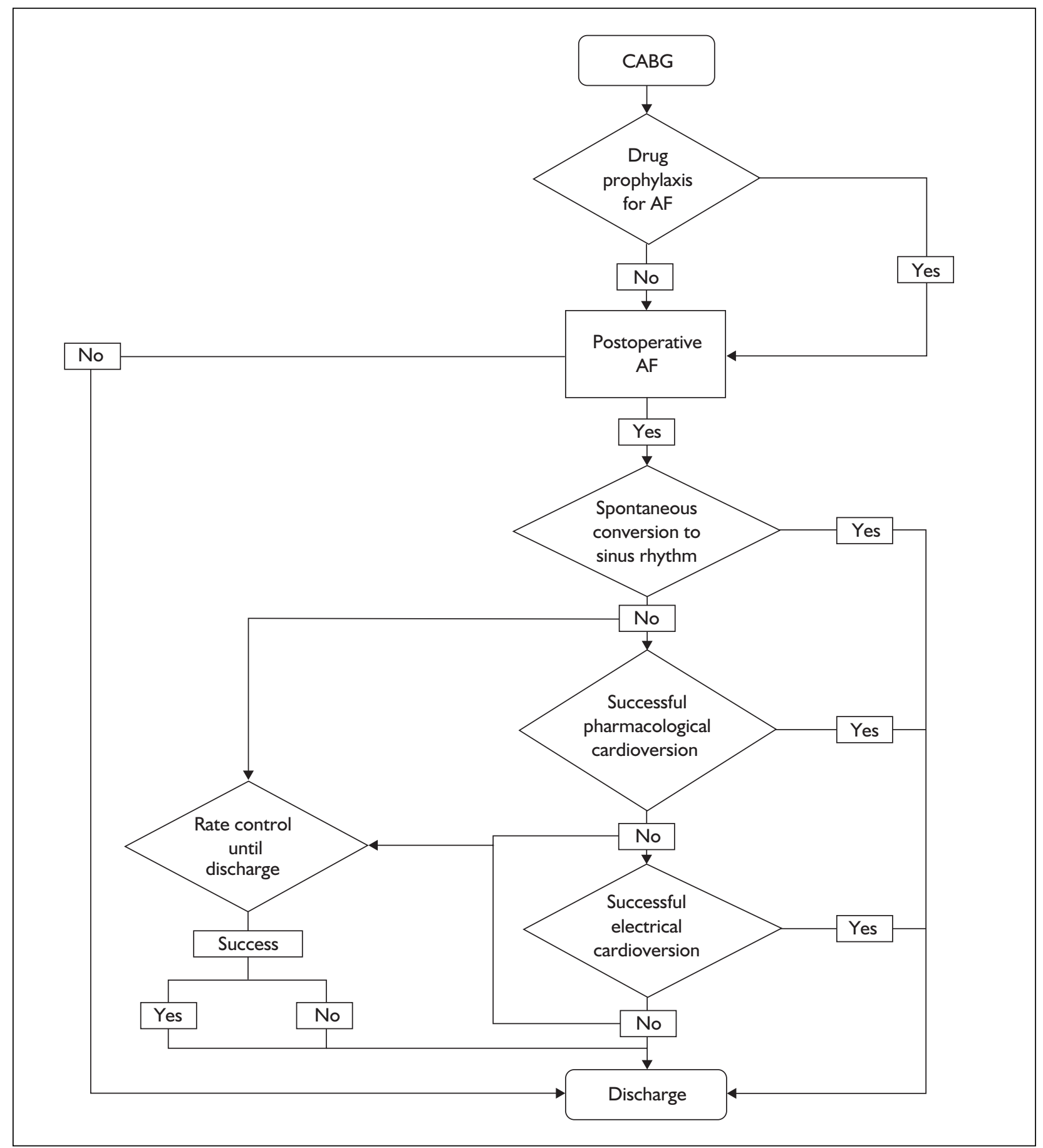

FIGURE II Flowchart for drug prophylaxis for, and management of, AF following CABG

- model structure

- methodological assumptions

- parameters around which there is considerable uncertainty or that may be expected, a priori, to have disproportionate impact on study results.

The purpose of this analysis is to identify clearly the impact of this uncertainty and to test the robustness of the cost-effectiveness results to variation in structural assumptions and parameter inputs.

Parameter uncertainty is addressed using PSA. Probability distributions are assigned to the point estimates used in the base-case analysis, using the point estimates and ranges listed in Tables 7 , 8,10 and 11 . Table 12 reports the variables included in the PSA, the form of distribution 


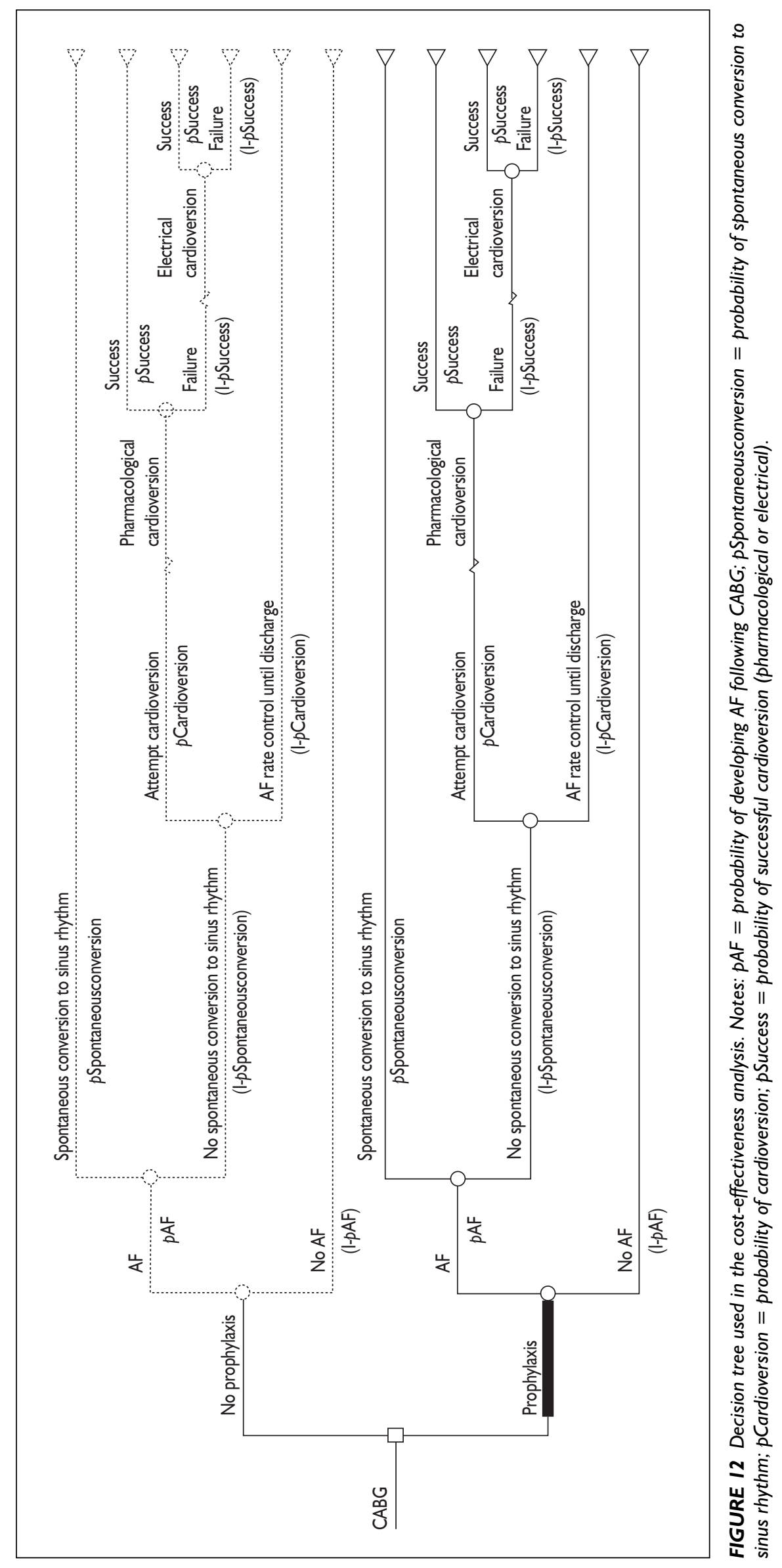


TABLE I2 Parameter input values in the economic model

\begin{tabular}{|c|c|c|}
\hline Parameter & $\begin{array}{c}\text { Point } \\
\text { estimate }\end{array}$ & $\begin{array}{c}\text { Distribution } \\
\text { (parameters of distribution) }\end{array}$ \\
\hline \multicolumn{3}{|l|}{ Probabilities } \\
\hline Baseline risk of $A F$ following $C A B G$ & 0.30 & $\begin{array}{c}\text { Beta } \\
\alpha=59.8621 ; \beta=139.6782\end{array}$ \\
\hline Relative risk of $\mathrm{AF}$ with magnesium sulphate prophylaxis & 0.73 & $\mu=\ln (0.73) ; \sigma=0.0734$ \\
\hline Probability of spontaneous conversion to sinus rhythm ${ }^{34,38}$ & 0.35 & $\begin{array}{c}\text { Beta } \\
n=40 ; r=14\end{array}$ \\
\hline Probability of cardioversion ${ }^{34,38}$ & 0.60 & $n=40 ; r=24$ \\
\hline Probability of successful PCV 62,63 & 0.736 & $n=72 ; r=53$ \\
\hline Probability of successful ECV following unsuccessful PCV 62,63 & 0.842 & $n=19 ; r=16$ \\
\hline \multicolumn{3}{|l|}{ Additional resource use associated with $A F$} \\
\hline Additional days in ICU due to postoperative AF & 1 & $\begin{array}{c}\text { Gamma } \\
\alpha=6.1117 ; \beta=0.1636\end{array}$ \\
\hline Additional days on ward due to postoperative AF & 2 & $\begin{array}{c}\text { Gamma } \\
\alpha=9.5495 ; \beta=0.2094\end{array}$ \\
\hline \multicolumn{3}{|l|}{ Costs } \\
\hline Magnesium sulphate prophylaxis & 137.04 & \\
\hline Rate control - digoxin & $|4.4|$ & \\
\hline PCV with amiodarone & 40.88 & \\
\hline PCV with sotalol & 23.66 & \\
\hline Anticoagulation - heparin and warfarin & 22.84 & \\
\hline Cost of ECV & 117 & \\
\hline Cost of CABG admission & 8172 & \\
\hline Coronary intensive care (per bed day) & 925 & $\begin{array}{c}\text { Gamma } \\
\alpha=88.7514 ; \beta=3.7613\end{array}$ \\
\hline Hospital ward (cost per excess bed day) & 344 & $\begin{array}{c}\text { Gamma } \\
\alpha=52.1459 ; \beta=17.7421\end{array}$ \\
\hline
\end{tabular}

used for sampling and the parameters of the distribution.

\section{Results of the economic model}

\section{Base-case results}

The base-case results of the analysis are reported in Table 13. Costs under the strategy of providing magnesium sulphate as prophylaxis against postoperative AF are slightly higher than with no prophylaxis (£2.55). Prophylaxis is associated with a reduction in the proportion of patients experiencing AF following CABG (0.081), giving an incremental cost-effectiveness ratio (ICER) of $£ 32$ per AF case avoided.
To identify which factors have contributed most to these results, Table 14 reports the average total inpatient stay estimated for each strategy and the average number of additional ICU and ward days associated with AF for each strategy.

As with the studies investigating the effect of prophylaxis on hospital stay (reviewed in the section 'Secondary review of economic evaluations', p. 24), there was only a small difference in length of stay (in the ICU or on the ward) between the prophylaxis and no-prophylaxis strategies (8.66 and 8.90, respectively), despite large assumed differences in length of stay for patients with and without postoperative AF (average of 11 versus 8 days, respectively). This 
TABLE 13 Base-case results of economic analysis

\begin{tabular}{|lccccc|}
\hline Strategy & Cost $(\boldsymbol{\epsilon})$ & $\begin{array}{c}\text { Incremental } \\
\text { cost }(\boldsymbol{\epsilon})\end{array}$ & AF cases & $\begin{array}{c}\text { AF cases } \\
\text { avoided }\end{array}$ & $\begin{array}{c}\text { Incremental cost per } \\
\text { AF case avoided }(\boldsymbol{\epsilon})\end{array}$ \\
\hline $\begin{array}{l}\text { No prophylaxis } \\
\text { Prophylaxis }\end{array}$ & 9595 & & 0.300 & & \\
\hline
\end{tabular}

TABLE I4 Estimated total stays for CABG patients and additional days due to AF

\begin{tabular}{|lcccc|}
\hline Strategy & Total stay (days) & Additional ICU days & Additional ward days & Costs of inpatient days ( $\boldsymbol{\epsilon}$ ) \\
\hline No prophylaxis & 8.90 & 0.30 & 0.60 & 9581 \\
Prophylaxis & 8.66 & 0.22 & 0.44 & 9450 \\
\hline
\end{tabular}

analysis assumes that admission routines would be identical for patients under both the noprophylaxis and prophylaxis strategies.

\section{Deterministic sensitivity analysis}

A sensitivity analysis was conducted to consider the effect of uncertainty around model structure and variation in model parameters. The method adopted was univariate sensitivity analysis; that is, varying one parameter at a time, leaving all other variables unchanged. This is to highlight the impact, if any, of each selected parameter alone on the cost-effectiveness results.

Table 15 reports the results of the sensitivity analysis. The table is divided to distinguish between analyses undertaken due to uncertainties over parameters related to:

- the risk of postoperative AF and effectiveness of magnesium sulphate prophylaxis

- the cost of prophylaxis

- resource consequences of postoperative AF

- resources used in the management of postoperative AF.

Table 15 shows large variations in cost-effectiveness estimates relating to uncertainty over both the baseline risk and relative risk of postoperative AF with magnesium sulphate prophylaxis. At the upper limit of baseline risk of AF (40\%) the prophylaxis option dominates, providing better outcome at lower cost. At the lower limit incremental cost is positive, the prophylaxis option costs more than no prophylaxis and the incremental effectiveness is reduced, leading to a substantial increase in ICER. This is further illustrated in Figure 13.

Variation in the relative risk of AF with prophylaxis dominating at the lower limit (larger treatment effect). At the upper limit the prophylaxis option has positive incremental cost and reduced incremental effect, leading to a large increase in ICER. This is further illustrated in Figure 14.

The cost-effectiveness estimates also seem to be highly sensitive to the overall cost of prophylaxis, and to variation in components of the cost of prophylaxis. Varying the total cost of prophylaxis by plus or minus $50 \%$ shows wide variation, from a situation where prophylaxis dominates (at lower cost of prophylaxis) to an increase in ICER equivalent to that for the lower limit in baseline risk of AF. Varying assumptions over staff inputs to initiate intravenous infusions and patient monitoring show large variations in ICER. A strategy where nurses initiate and terminate intravenous infusions (labelled "no medical input" in Table 15) reduces the cost for the prophylaxis option below the cost for no prophylaxis, using all other base-case assumptions, causing prophylaxis to be dominant.

It is possible that the prophylaxis option may increase preoperative length of stay, since one recommended regimen for magnesium sulphate includes an infusion on the day before surgery. If patients having prophylaxis stay on average half a day longer than those without prophylaxis the incremental cost increases by almost $£ 167$ and the ICER increases to $£ 2092$ per AF case avoided. This is the largest ICER for any option included in the one-way sensitivity analyses.

Considering the resource consequences of AF, the ICERs are highly sensitive to assumptions over the number of additional ICU days due to $\mathrm{AF}$, and to a lesser extent the number of additional ward days. The range of ICERs was 
TABLE I5 Univariate sensitivity analysis

\begin{tabular}{|c|c|c|c|c|c|}
\hline Variable (base case) & $\begin{array}{l}\text { Lower limit } \\
\text { Upper limit }\end{array}$ & $\begin{array}{l}\text { Incremental } \\
\text { cost }(E)\end{array}$ & $\begin{array}{l}\text { Incremental } \\
\text { effectiveness }\end{array}$ & $\begin{array}{l}\text { ICER }(\boldsymbol{E} / \mathrm{AF} \\
\text { case averted) }\end{array}$ & Range \\
\hline \multicolumn{6}{|l|}{ Risk of AF and effectiveness of prophylaxis } \\
\hline Probability of $\mathrm{AF}(0.30)$ & $\begin{array}{l}0.20 \\
0.40\end{array}$ & $\begin{array}{r}47.38 \\
-42.28\end{array}$ & $\begin{array}{l}0.054 \\
0.108\end{array}$ & $\begin{array}{c}877.44 \\
\text { Dominant }\end{array}$ & 1268.89 \\
\hline Relative risk of AF (0.73) & $\begin{array}{l}0.63 \\
0.84\end{array}$ & $\begin{array}{r}-42.28 \\
57.34\end{array}$ & $\begin{array}{l}0.108 \\
0.048\end{array}$ & $\begin{array}{l}\text { Dominant } \\
\text { II } 94.66\end{array}$ & 1620.40 \\
\hline \multicolumn{6}{|l|}{ Cost of prophylaxis } \\
\hline Prophylaxis cost (137.04) & $\begin{array}{r}68.52 \\
205.56\end{array}$ & $\begin{array}{r}-65.97 \\
71.07\end{array}$ & $\begin{array}{l}0.081 \\
0.081\end{array}$ & $\begin{array}{l}\text { Dominant } \\
877.44\end{array}$ & 1691.85 \\
\hline Minutes of doctor time for prophylaxis (20) & $\begin{array}{l}10 \\
30\end{array}$ & $\begin{array}{r}-14.45 \\
19.55\end{array}$ & $\begin{array}{l}0.081 \\
0.081\end{array}$ & $\begin{array}{l}\text { Dominant } \\
241.39\end{array}$ & 419.75 \\
\hline Minutes of nurse time for prophylaxis (40) & $\begin{array}{l}20 \\
60\end{array}$ & $\begin{array}{r}-19.45 \\
24.55\end{array}$ & $\begin{array}{l}0.081 \\
0.081\end{array}$ & $\begin{array}{l}\text { Dominant } \\
303.12\end{array}$ & 543.21 \\
\hline $\begin{array}{l}\text { Nurse initiates infusion and monitors } \\
\text { patient: no medical input }\end{array}$ & $\begin{array}{l}30 \\
60 \\
90\end{array}$ & $\begin{array}{r}-42.45 \\
-9.45 \\
23.55\end{array}$ & $\begin{array}{l}0.08 I \\
0.08 I \\
0.08 I\end{array}$ & $\begin{array}{c}\text { Dominant } \\
\text { Dominant } \\
290.77\end{array}$ & 814.81 \\
\hline $\begin{array}{l}\text { Number of prophylaxis infusions with } \\
\text { additional staff costs (3) }\end{array}$ & 6 & 80.55 & 0.081 & 994.47 & NA \\
\hline Additional preoperative days $(0)$ & 0.50 & 169.46 & 0.081 & 2092.13 & NA \\
\hline \multicolumn{6}{|l|}{ Resource consequences of postoperative AF } \\
\hline Additional ICU days (I) & $\begin{array}{l}0.00 \\
2.00\end{array}$ & $\begin{array}{r}77.48 \\
-72.40\end{array}$ & $\begin{array}{l}0.081 \\
0.081\end{array}$ & $\begin{array}{c}956.59 \\
\text { Dominant }\end{array}$ & 1850.40 \\
\hline Additional ward days (2) & $\begin{array}{l}0.00 \\
4.00\end{array}$ & $\begin{array}{r}56.63 \\
-51.54\end{array}$ & $\begin{array}{l}0.081 \\
0.081\end{array}$ & $\begin{array}{c}699.08 \\
\text { Dominant }\end{array}$ & 1335.37 \\
\hline $\begin{array}{l}\text { Additional bed days for spontaneous } \\
\text { converters ( } 3 \text { ) }\end{array}$ & 0 & 47.70 & 0.081 & 588.92 & NA \\
\hline Cost of ICU bed day (925) & $\begin{array}{r}693.00 \\
1196.00\end{array}$ & $\begin{array}{r}21.36 \\
-19.38\end{array}$ & $\begin{array}{l}0.081 \\
0.081\end{array}$ & $\begin{array}{c}263.66 \\
\text { Dominant }\end{array}$ & 502.94 \\
\hline Cost of excess bed day (344) & $\begin{array}{l}231.00 \\
369.00\end{array}$ & $\begin{array}{l}19.21 \\
-3.15\end{array}$ & $\begin{array}{l}0.08 I \\
0.08 I\end{array}$ & $\begin{array}{c}237.12 \\
\text { Dominant }\end{array}$ & 275.95 \\
\hline \multicolumn{6}{|l|}{ Resources used in managing postoperative $A F$} \\
\hline PCV/ECV attempted $(0.6)$ & $\begin{array}{l}0.30 \\
0.90\end{array}$ & $\begin{array}{l}4.76 \\
0.34\end{array}$ & $\begin{array}{l}0.08 I \\
0.08 I\end{array}$ & $\begin{array}{r}58.79 \\
4.23\end{array}$ & 54.57 \\
\hline Spontaneous conversion $(0.35)$ & $\begin{array}{l}0.175 \\
0.525\end{array}$ & $\begin{array}{l}1.16 \\
3.95\end{array}$ & $\begin{array}{l}0.081 \\
0.081\end{array}$ & $\begin{array}{l}14.30 \\
48.72\end{array}$ & 34.43 \\
\hline Cost of ECV (II7) & $\begin{array}{r}58.50 \\
175.50\end{array}$ & $\begin{array}{l}4.40 \\
0.70\end{array}$ & $\begin{array}{l}0.081 \\
0.08 I\end{array}$ & $\begin{array}{r}54.33 \\
8.70\end{array}$ & 45.63 \\
\hline Cost of amiodarone PCV (40.88) & $\begin{array}{l}20.44 \\
61.32\end{array}$ & $\begin{array}{l}2.72 \\
2.38\end{array}$ & $\begin{array}{l}0.081 \\
0.08 I\end{array}$ & $\begin{array}{l}33.61 \\
29.41\end{array}$ & 4.21 \\
\hline Use sotalol for PCV & 23.66 & 2.70 & 0.081 & 33.28 & NA \\
\hline Cost of sotalol PCV (23.66) & $\begin{array}{l}11.83 \\
35.49\end{array}$ & $\begin{array}{l}2.79 \\
2.60\end{array}$ & $\begin{array}{l}0.081 \\
0.081\end{array}$ & $\begin{array}{l}34.50 \\
32.07\end{array}$ & 2.44 \\
\hline
\end{tabular}

lower for variation in the cost of ICU bed days or of excess ward days.

Tamis-Holland and colleagues ${ }^{56}$ suggest that patients with postoperative AF who spontaneously convert to sinus rhythm do not experience longer stays than do patients without AF. Setting the additional bed days to zero for patients with postoperative AF who spontaneously convert increases the incremental cost of the prophylaxis 


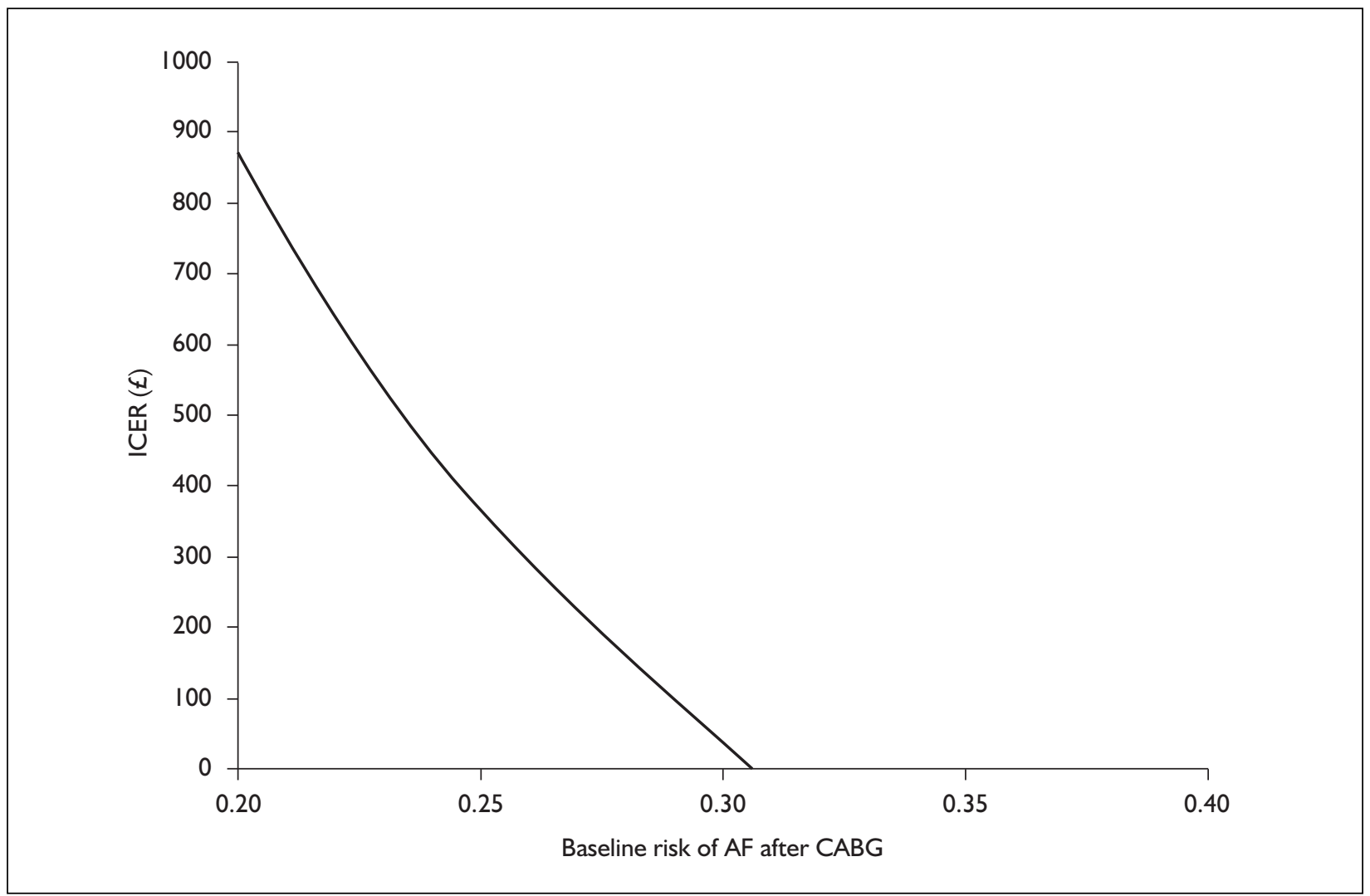

FIGURE I3 Sensitivity analysis on baseline risk of AF following CABG

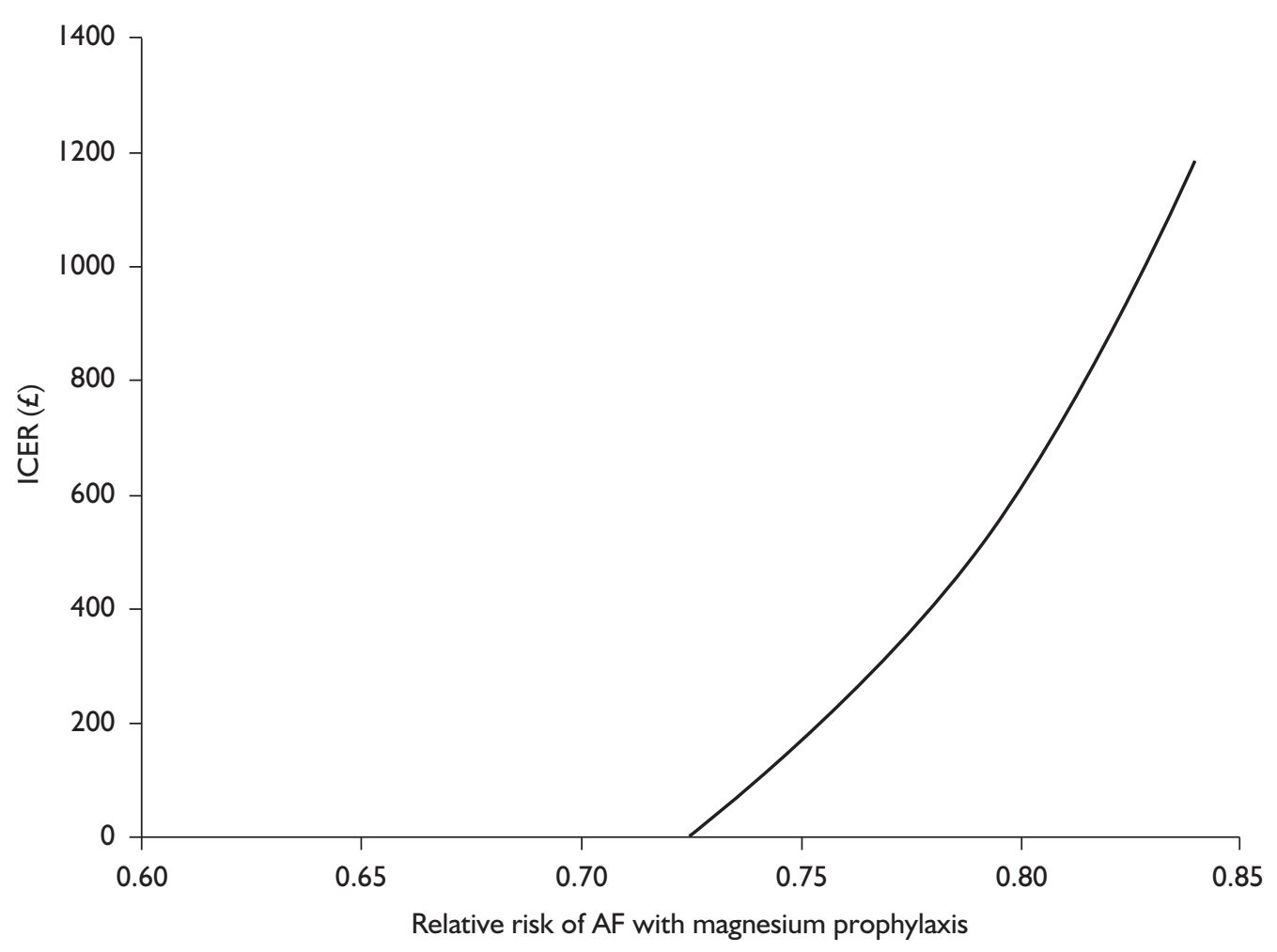

FIGURE I4 Sensitivity analysis on relative risk of AF following CABG with magnesium sulphate prophylaxis 
strategy and increases the ICER to almost $£ 600$ per AF case avoided.

Table 15 shows that the ICERs are largely insensitive to variation in values of parameters related to management of postoperative AF.

\section{Probabilistic sensitivity analysis}

In a PSA of magnesium sulphate prophylaxis, where probabilities of postoperative AF, relative risk of $\mathrm{AF}$ with magnesium sulphate prophylaxis and additional bed days (ward or ICU) associated with $\mathrm{AF}$ were sampled across the distributions described in Table 12, just over half of the simulations are associated with better outcomes (fewer cases of AF), but also increased costs (Figure 15). Many of the simulations (41\%) have negative incremental costs. In this area magnesium sulphate prophylaxis is the dominant strategy, achieving better outcome at lower costs. Simulations where costs for prophylaxis are lower are most likely to be associated with high estimates of additional stay on the ward or in the ICU associated with AF.
In this analysis magnesium sulphate prophylaxis had a probability of being cost-effective (compared with surgery without prophylaxis) of $99 \%$ at a willingness-to-pay (WTP) threshold of £2000 per AF case avoided and $100 \%$ at a WTP threshold of $£ 5000$ per AF case avoided (Figure 16, (CEAC: base-case assumptions).

The base-case analysis assumes identical admission routines for patients under the no-prophylaxis and prophylaxis strategies. An alternative scenario, where patients receiving magnesium sulphate prophylaxis by intravenous infusion are admitted early to receive their initial infusion, was included in the PSA (mean additional stay $=0.5$ days, using a uniform distribution with minimum $=0$ and maximum $=1$ ). The effect of including this assumption in the PSA is to shift the scatter of points on the cost-effectiveness plane (Figure 15) upwards to a mean incremental cost of approximately $£ 170$, so that only around $5 \%$ of simulations have negative incremental costs. This increase in mean incremental costs also changes the location of the cost-effectiveness acceptability

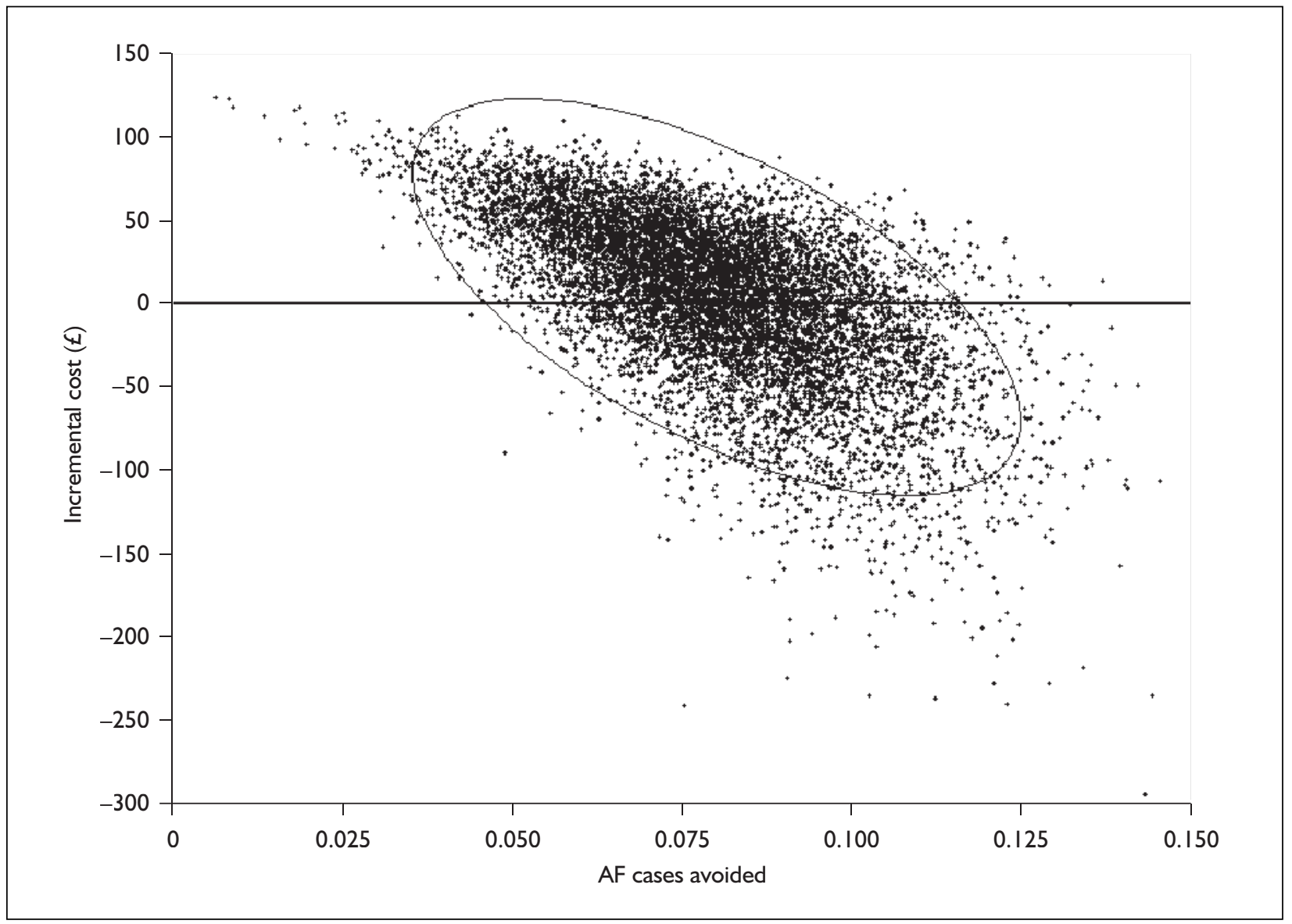

FIGURE I5 Cost-effectiveness plane: incremental cost and AF cases avoided for magnesium sulphate prophylaxis against postoperative AF 


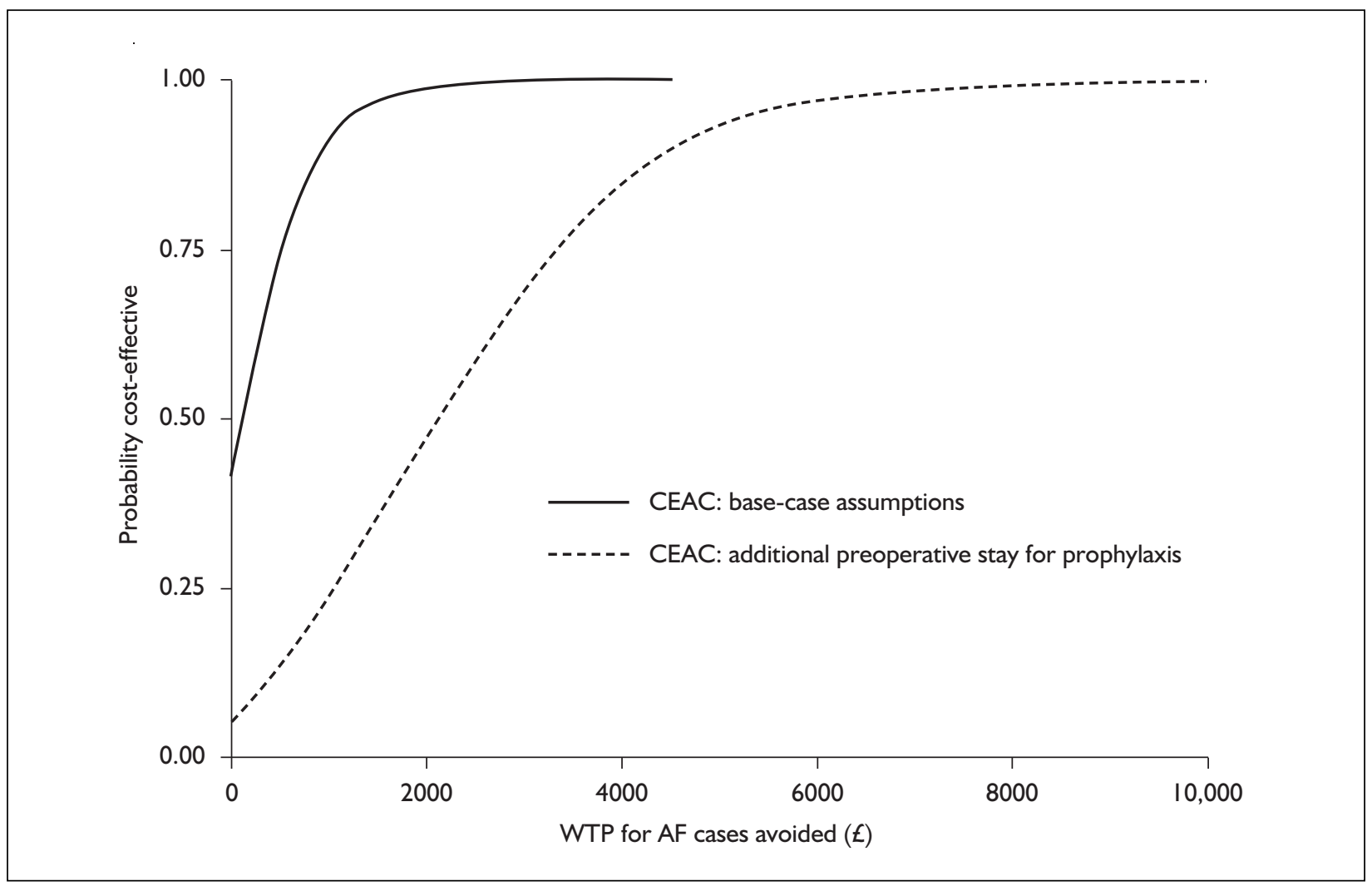

FIGURE I6 CEAC: magnesium sulphate prophylaxis PSA result

curve (CEAC) (Figure 16) and the probability of prophylaxis being cost-effective at each threshold of WTP. Now the probability of magnesium sulphate prophylaxis being cost-effective (compared with surgery without prophylaxis) is $48 \%$ at a WTP threshold of $£ 2000$ per AF case avoided and $93 \%$ at a WTP threshold of $£ 5000$ per AF case avoided.

In reporting this probabilistic analysis, much lower thresholds were used than would commonly be applied in models reporting outcomes in terms of quality-adjusted life-years (QALYs). It is not clear in this model how the avoidance of postoperative AF would translate to final outcomes, such as gains in life expectancy or quality-adjusted life expectancy. The European Association of Cardiothoracic Surgeons guideline ${ }^{1}$ suggests that AF following cardiac surgery doubles the risk of stroke, with a baseline risk of between $1.4 \%^{41}$ and $2.5 \%{ }^{49}$ for patients in sinus rhythm in the studies reviewed. At these levels of risk it is unlikely that the reduction in risk, modelled in this analysis, would translate to substantial gains in life expectancy or quality-adjusted life expectancy. 


\section{Chapter 6 Discussion}

\section{Clinical effectiveness}

This systematic review did not identify any RCTs that aimed to compare intravenous magnesium with sotalol. Expert clinical advice suggests that in practice this would not be a meaningful comparison, as the decision would be more likely to be whether or not to use these (and other) drugs in combination, as opposed to choosing between them. The clinical effectiveness of magnesium sulphate and sotalol combination therapy has been evaluated in RCTs, although it is outside the scope of the current review. ${ }^{20,21,64}$ This would be a worthwhile topic for future evidence synthesis.

This systematic review has updated and expanded the review published by Alghamdi and colleagues in $2005,{ }^{10}$ adding in a further eight RCTs. In that systematic review it was found that intravenous magnesium administered perioperatively to patients undergoing CABG was effective, with a statistically significant intervention effect. The current review comes to a similar conclusion, that intravenous magnesium is associated with a statistically significant reduction in the odds of a postoperative AF.

\section{Effects of total dose, dose rate and duration of magnesium sulphate intervention}

If the studies by Dagdelen and colleagues ${ }^{17,18}$ and Toraman and colleagues ${ }^{27}$ are excluded, the current review would suggest that the total magnesium sulphate dose up to $21 \mathrm{~g}$ is probably not a useful predictor of effects on AF. It should be noted, however, that a robust analysis of total dose should, ideally, include co-variables, but this was not possible owing to the heterogeneity of reporting in the primary studies. The possibility of effects at higher total doses $(>21 \mathrm{~g})$ is unclear owing to ambiguity within the study by Nurözler and colleagues ${ }^{25}$ (25 g total dose), in which confounding of variables might have occurred. Analyses of the duration of prophylaxis and the dose rate suggest that these may be better predictors of effects on $\mathrm{AF}$, but the dose rate and duration of prophylaxis were not generally independent and their relative importance cannot be ascertained from the available trials [only one total dose (12 g) was administered at more than one dose rate]. An hypothesis arising from these findings that may warrant further investigation is that continuous low-dose administration of magnesium sulphate would be more effective for prophylaxis of AF than a similar total dose administered over a shorter period.

Two of the five systematic reviews identified in the searches assessed the influence of total dose of magnesium sulphate on AF. ${ }^{7,9}$ Henyan and colleagues ${ }^{9}$ divided the studies according to whether they administered magnesium sulphate in low doses $(<10 \mathrm{~g})$ or moderate to high doses $(\geqslant 10 \mathrm{~g})$, whereas Miller and colleagues ${ }^{7}$ divided the studies according to whether they administered low doses ( $<35 \mathrm{mmol})$, medium doses $(35-50 \mathrm{mmol})$ or high doses $(>50 \mathrm{mmol})$. These dose subgroups appear to have been defined on an arbitrary basis, and it is unclear whether they have clinical or biochemical relevance. Only one of the subgroups in each review exhibited a significant intervention effect (the low-dose group of Henyan and colleagues ${ }^{9}$ and the medium-dose group of Miller and colleagues $^{7}$ ) and it is notable that the studies by Dagdelen and colleagues ${ }^{17,18}$ and Toraman and colleagues $^{27}$ were in these sub-groups. Given that the studies by Dagdelen ${ }^{17,18}$ and Toraman ${ }^{27}$ differed in other respects besides their dose of magnesium sulphate, the findings that low-dose $\mathrm{e}^{9}$ or medium-dose $\mathrm{e}^{7}$ magnesium sulphate significantly reduced the incidence of $\mathrm{AF}$ appear questionable and are not supported in the current review.

\section{Possible influence of $\beta$-blocker therapy and other factors on effects of magnesium sulphate}

As noted above, the studies by Dagdelen ${ }^{17,18}$ and Toraman $^{27}$ impart a significant intervention effect to almost any subgroup in which the studies are analysed. It is difficult to determine which aspects of these studies drive the significant intervention effect, as the studies differed in several respects from the other studies included in this review. For example, they were the only studies that explicitly excluded patients who were on $\beta$-blockers, and they started prophylactic therapy earlier than most 
other studies, continued prophylaxis over a longer duration and used a lower dose rate than other studies. It is possible that an interaction between these (and possibly other) factors was responsible for the uniquely low ORs reported in these two studies. $\beta$-Blockers prevent the loss of intracellular magnesium and it has been suggested that prophylactic magnesium sulphate may be more effective in patients who are not offered preoperative $\beta$-blockers. ${ }^{22}$ The relative importance of $\beta$-blockers, the time of initiation and the duration of prophylaxis appear to warrant further investigation, given the overall positive results of these studies for prophylaxis of AF.

\section{Heterogeneity of exclusion criteria in the primary studies}

The criteria used to exclude patients from the trials were reported in variable detail, with up to 15 main criteria listed in one study, whereas three of the studies did not report any exclusion criteria (Appendix 6). The selection of exclusion criteria could have an important bearing on the risk classification of the recruited populations. As discussed above, excluding patients who are on antiarrhythmic drugs might have led to the included patients being at higher risk of AF. Conversely, excluding high-risk patients (e.g. those with ventricular dysfunction or history of $\mathrm{AF}$ ) might have led to the included patients being at lower risk of AF. Ideally, meta-analysis should be stratified by patient risk to account for such interpopulation differences. This was not possible, however, as in most cases the exclusion criteria were weakly defined or undefined (e.g. unclear whether supraventricular arrhythmia included $\mathrm{AF})$, and because it is difficult to weigh up objectively the relative importance of individual exclusion criteria in the risk of AF (Appendix 6).

\section{Cost-effectiveness}

The systematic review of economic evaluations did not identify any studies comparing magnesium sulphate prophylaxis with sotalol or with no prophylaxis. It is unlikely that economic evaluations of intravenous magnesium sulphate compared with sotalol have been performed, given the lack of RCT evidence for this comparison. The secondary review of economic evaluations of other agents as prophylaxis for AF found one study of oral amiodarone conducted using a short-term model. Short-term models such as this only follow up patients to discharge from hospital and use intermediate outcomes. It is unclear from the current evidence base how a reduction in postoperative $\mathrm{AF}$ cases relates to changes in final outcomes.

The secondary review suggests that postoperative AF leads to increases in resource use, particularly increased stay in the ICU and on hospital wards. Estimates of the additional resource use associated with postoperative $\mathrm{AF}$ were developed using the results of the literature search. However, the data were not suitable for a quantitative synthesis. The applicability of all the included studies to current UK clinical practice may be questioned as the publication dates of the studies ranged over 14 years. Moreover, the included studies were conducted in a number of countries, which may have significantly different criteria for admission or discharge from the ICU and patterns of postoperative management. Existing UK cardiac surgical databases, such as the Society of Cardiothoracic Surgeons' National Adult Cardiac Surgical Database, could be investigated for suitable data to refine the inputs to the economic model. Such databases could also be used to define current patterns of practice in management of surgical patients and of postsurgical patients with AF.

The analysis presented here suggests that prophylaxis may achieve a reduction in $\mathrm{AF}$ cases at a modest additional cost and that this result is not sensitive to assumptions made regarding the management of postoperative $\mathrm{AF}$, but is sensitive to assumptions over the length of stay for patients with AF. The results were also sensitive to the baseline risk of $\mathrm{AF}$ and to the effectiveness of prophylaxis, as would be expected. The PSA suggests that prophylaxis is most likely to be associated with increased treatment costs, although these may be modest. If intensive care facilities are in short supply it may be reasonable to accept a slight increase in treatment costs to release scarce resources. However, if prophylaxis requires earlier admission of patients than would be the case under the no-prophylaxis option, a more careful evaluation of the relative benefits of increasing ward stays compared with freeing up some intensive care facilities is required.

A key question that is beyond the scope of this report is the extent to which avoiding postoperative $\mathrm{AF}$ cases translates to changes in life expectancy or quality-adjusted life expectancy for patients undergoing coronary artery bypass surgery. Evidence reviewed in the European Association of Cardiothoracic Surgeons guideline ${ }^{1}$ suggests that postoperative $\mathrm{AF}$ is associated with an approximate doubling in the risk of stroke 
following CABG (from 1.4-2.5\% for patients in sinus rhythm to $3.3-5.2 \%$ for patients who experience postoperative AF). Patients experiencing postoperative $\mathrm{AF}$ tend to have higher preoperative risks of stroke, such as older age and hypertension, ${ }^{49}$ although a retrospective study by Stamou and colleagues ${ }^{65}$ demonstrated an independent effect for postoperative $\mathrm{AF}$ on risk of stroke in multivariate analysis $(\mathrm{OR}=1.7,95 \%$ CI 1.4 to 2.2). While the epidemiological evidence is currently insufficient to support the construction of a robust, long-term model of outcomes for patients experiencing postoperative $\mathrm{AF}$, these data suggest that for every 1000 patients undergoing
CABG between one and two strokes could be avoided through the use of magnesium sulphate prophylaxis (by averting 81 cases of postoperative $\mathrm{AF})$. In addition to quality of life impacts resulting from the mortality and morbidity associated with strokes, costs of strokes have been estimated to be between $£ 16,000$ and $£ 91,000$ (2004 prices) depending on severity of stroke and time-horizon; the lower figure is for a mild stroke over 5 years, the higher figure is a lifetime cost for a major ischaemic stroke. ${ }^{66}$ (Costs were reported in US dollars. These have been converted to UK sterling by the authors of this report, using purchasing power parities in the original article ${ }^{66}$.) 



\section{Chapter 7 Conclusions}

$\mathrm{N}$ o RCTs were identified that specifically aimed to compare intravenous magnesium with sotalol as prophylaxis for AF in patients undergoing CABG. Intravenous magnesium, when compared with placebo or control, is effective in preventing postoperative $\mathrm{AF}$, as confirmed by a statistically significant intervention effect based on pooled analysis of 15 RCTs. It was also found that AF was less likely to occur with a longer duration of prophylaxis and when prophylaxis was started earlier, although there were uncertainties associated with the trials in these subgroups. No clear relationship between dose and AF was observed, although a lower constant dose rate was associated with the lowest odds of AF. Further primary research should investigate the relationship between dose, dose rate, duration of prophylaxis, timing of initiation of therapy and patient characteristics, such as degree of risk for AF. This will provide stronger evidence for the optimum delivery of intravenous magnesium in patients undergoing CABG.

In terms of cost-effectiveness, magnesium sulphate prophylaxis can lead to reductions in the number of postoperative AF cases at low or no additional costs, owing to offsetting the additional costs of prophylaxis with reductions in ICU and ward stays as well as avoided costs of managing postoperative AF.

The results of the cost-effectiveness analysis are sensitive to plausible changes in certain assumptions. In particular, the results were sensitive to variation in the baseline risk of $\mathrm{AF}$, the relative risk of postoperative $\mathrm{AF}$ with magnesium sulphate prophylaxis, the cost of prophylaxis (in particular the possibility of a longer preoperative stay to allow for the first infusion to occur on the day before surgery) and the number of additional ICU or ward days associated with AF.

The probabilistic analysis showed that the proportion of simulations where magnesium sulphate prophylaxis was dominant depended on assumptions over the admission routines for patients receiving prophylaxis. If these were the same for both strategies then the proportion of simulations where prophylaxis was dominant was $41 \%$. This reduced to $5 \%$ if it was assumed that patients receiving prophylaxis are admitted, on average, half a day early. The majority of simulations in both scenarios were associated with increased costs. All simulations had positive incremental effectiveness (i.e. magnesium prophylaxis was always effective in reducing the number of AF cases).

The CEAC shows that the probability of prophylaxis being cost-effective increases with increasing WTP for a unit of outcome. It is unclear what the appropriate decision threshold (threshold WTP) should be, with outcome in the model being expressed as AF cases averted. 



\section{Acknowledgements}

$\mathrm{W}$ e are grateful to the following: Professor Gregory Lip, Consultant Cardiologist and Professor of Cardiovascular Medicine at City Hospital in Birmingham for reviewing a draft of the report, Ms Jackie Bryant, Senior Research Fellow, Southampton Health Technology Assessments Centre (SHTAC), Wessex Institute, University of Southampton, for reviewing a draft of the report and for writing the research protocol, Professor Andrew Clegg, Director, SHTAC, Wessex Institute, University of Southampton, for writing the research protocol and Ms Liz Hodson, Information Officer, Wessex Institute, University of Southampton, for retrieving papers for inclusion in the systematic review.

This report was commissioned by the NHS R\&D HTA Programme.

\section{Contribution of authors}

Jonathan Shepherd (Principal Research Fellow) was responsible for project management and report editing; analysis and interpretation of clinical effectiveness studies; screening clinical effectiveness studies for inclusion; and report writing. Alison Price (Information Scientist) carried out the literature search. Geoff Frampton (Research Fellow) did the screening of clinical effectiveness studies for inclusion; data extraction and critical appraisal of clinical effectiveness studies; analysis and interpretation of clinical effectiveness studies; and report writing. Lukasz Tanajewski (Specialist) contributed to the data extraction and critical appraisal of clinical effectiveness studies; analysis and interpretation of clinical effectiveness studies; screening clinical effectiveness studies for inclusion; conception and design of economic model; and analysis and interpretation of results of economic model. Jeremy Jones (Principal Research Fellow) and David Turner (Senior Research Fellow) carried out the screening clinical effectiveness studies for inclusion; conception and design of economic model; analysis and interpretation of results of economic model; and report writing. 



\section{References}

1. Dunning J, Treasure T, Versteegh M, Nashef SA, EACTS Audit and Guidelines Committee.

Guidelines on the prevention and management of de novo atrial fibrillation after cardiac and thoracic surgery [review]. Eur J Cardiothorac Surg 2006; 30:852-72.

2. Shantsila E, Watson T, Lip GY. Atrial fibrillation post-cardiac surgery: changing perspectives [review]. Curr Med Res Opin 2006;22:1437-41.

3. Iqbal MB, Taneja AK, Lip GY, Flather M. Recent developments in atrial fibrillation [review]. BMJ 2005;330:238-43.

4. NHS. Hospital episode statistics. NHS England 2004-05. HES data 2006. URL: http://www.hesonline.nhs.uk. Accessed 28 April 2008.

5. Joint Formulary Committee. British National Formulary, No. 53. London: British Medical Association and Royal Pharmaceutical Society of Great Britain; 2007.

6. National Institute for Health and Clinical Excellence (NICE). The management of atrial fibrillation. NICE Clinical Guideline 36. London: NICE; 2007.

7. Miller S, Crystal E, Garfinkle M, Lau C, Lashevsky I, Connolly SJ. Effects of magnesium on atrial fibrillation after cardiac surgery: a metaanalysis [review]. Heart 2005;91:618-23.

8. Shiga T, Wajima Z, Inoue T, Ogawa R. Magnesium prophylaxis for arrhythmias after cardiac surgery: a meta-analysis of randomized controlled trials. Am J Med 2004;117:325-33.

9. Henyan NN, Gillespie EL, White CM, Kluger J, Coleman CI. Impact of intravenous magnesium on post-cardiothoracic surgery atrial fibrillation and length of hospital stay: a meta-analysis. Ann Thorac Surg 2005;80:2402-6.

10. Alghamdi AA, Al-Radi OO, Latter DA. Intravenous magnesium for prevention of atrial fibrillation after coronary artery bypass surgery: a systematic review and meta-analysis [review].J Card Surg 2005; 20:293-9.

11. NHS Centre for Reviews and Dissemination. Undertaking systematic reviews of research on effectiveness: CRD's guidance for those carrying out or commissioning reviews. 2nd ed. CRD Report No. 4. York: York Publishing Services; 2001.

12. Cochrane handbook for systematic reviews of interventions. Version 4.2.5. URL: http://www.cochrane.org./resources./handbook/. Accessed 28 September 2006.

13. Caspi J, Rudis E, Bar I, Safadi T, Saute M. Effects of magnesium on myocardial function after coronary artery bypass grafting. Ann Thorac Surg 1995;59:942-7.

14. Yilmaz C, Couruh T, Yildiz Y, Macika H, Abay G, Aykac Z. The effect of magnesium sulphate on arrhythmia after coronary artery bypass surgery. Br J Anaesth 2000;84 (Suppl 1):37.

15. Bert AA, Reinert SE, Singh AK. A $\beta$-blocker, not magnesium, is effective prophylaxis for atrial tachyarrhythmias after coronary artery bypass graft surgery. J Cardiothorac Vasc Anesth 2001;15:204-9.

16. Bhudia SK, Cosgrove DM, Naugle RI, Rajeswaran J, Lam BK, Walton E, et al. Magnesium as a neuroprotectant in cardiac surgery: a randomized clinical trial. J Thorac Cardiovasc Surg 2006;131: 853-61.

17. Dagdelen S, Toraman F, Karabulut H, Alhan C. The value of $\mathrm{P}$ dispersion on predicting atrial fibrillation after coronary artery bypass surgery: effect of magnesium on $\mathrm{P}$ dispersion. Ann Noninvasive Electrocardiol 2002;7:211-18.

18. Dagdelen S, Yuce M, Toraman F, Karabulut H, Alhan C. The value of $\mathrm{P}$ dispersion on predicting atrial fibrillation after coronary artery bypass surgery; effect of magnesium on $\mathrm{P}$ dispersion. Card Electrophysiol Rev 2003;7:162-4.

19. Fanning WJ, Thomas CS, Roach A, Tomichek R, Alford WC, Stoney WS. Prophylaxis of atrial fibrillation with magnesium sulfate after coronary artery bypass grafting. Ann Thorac Surg 1991; 52:529-33.

20. Forlani S, De Paulis R, de Notaris S, Nardi P, Tomai F, Proietti I, et al. Combination of sotalol and magnesium prevents atrial fibrillation after coronary artery bypass grafting. Ann Thorac Surg 2002;74:720-6.

21. Forlani S, Moscarelli M, Scafuri A, Pellegrino A, Chiariello L. Combination therapy for prevention of atrial fibrillation after coronary artery bypass surgery: a randomized trial of sotalol and magnesium. Card Electrophysiol Rev 2003;7:168-71.

22. Hazelrigg SR, Boley TM, Cetindag IB, Moulton KP, Trammell GL, Polancic JE, et al. The efficacy of supplemental magnesium in reducing atrial fibrillation after coronary artery bypass grafting. Ann Thorac Surg 2004;77:824-30. 
23. Kaplan M, Kut MS, Icer UA, Demirtas MM. Intravenous magnesium sulfate prophylaxis for atrial fibrillation after coronary artery bypass surgery. J Thorac Cardiovasc Surg 2003;125:344-52.

24. Karmy-Jones R, Hamilton A, Dzavik V, Allegreto M, Finegan BA, Koshal A. Magnesium sulfate prophylaxis after cardiac operations. Ann Thoracic Surg 1995;59:502-7.

25. Nurözler F, Tokgözoglu L, Pasaoglu I, Böke E, Ersoy U, Bozer AY. Atrial fibrillation after coronary artery bypass surgery: predictors and the role of $\mathrm{MgSO}_{4}$ replacement. J Card Surg 1996;11:421-7.

26. Parikka H, Toivonen L, Pellinen T, Verkkala K, Järvinen A, Nieminen MS. The influence of intravenous magnesium sulphate on the occurrence of atrial fibrillation after coronary artery by-pass operation. Eur Heart J 1993;14:251-8.

27. Toraman F, Karabulut EH, Alhan HC, Dagdelen S, Tarcan S. Magnesium infusion dramatically decreases the incidence of atrial fibrillation after coronary artery bypass grafting. Ann Thorac Surg 2001;72:1256-62.

28. Treggiari-Venzi MM, Waeber JL, Perneger TV, Suter PM, Adamec R, Romand JA. Intravenous amiodarone or magnesium sulphate is not costbeneficial prophylaxis for atrial fibrillation after coronary artery bypass surgery. $\mathrm{Br} J$ Anaesth 2000;85:690-5.

29. Zangrillo A, Landoni G, Sparicio D, Pappalardo F, Bove T, Cerchierini E, et al. Perioperative magnesium supplementation to prevent atrial fibrillation after off-pump coronary artery surgery: a randomized controlled study. J Cardiothorac Vasc Anesth 2005;19:723-8.

30. Burgess DC, Kilborn MJ, Keech AC. Interventions for prevention of post-operative atrial fibrillation and its complications after cardiac surgery: a metaanalysis. Eur Heart J 2006;27:2846-57.

31. Colquhoun IW, Berg GA, el-Fiky M, Hurle A, Fell GS, Wheatley DJ. Arrhythmia prophylaxis after coronary artery surgery. A randomized controlled trial of intravenous magnesium chloride. Eur J Cardiothorac Surg 1993;7:520-3.

32. Crystal E, Garfinkle MS, Connolly SS, Ginger TT, Sleik K, Yusuf SS. Interventions for preventing post-operative atrial fibrillation in patients undergoing heart surgery. Cochrane Database Syst Rev (Issue 4) Chichester: John Wiley \& Sons; 2004.

33. Juni P, Witschi A, Bloch R, Egger M. The hazards of scoring the quality of clinical trials for metaanalysis. JAMA 1999;282:1054-60.

34. Reddy P, Richerson M, Freeman-Bosco L, Dunn A, White CM, Chow MSS. Cost-effectiveness of amiodarone for prophylaxis of atrial fibrillation in coronary artery bypass surgery. Am J Health Syst
35. Reddy P. Does prophylaxis against atrial fibrillation after cardiac surgery reduce length of stay or hospital costs? Pharmacotherapy 2001;21:338-44.

36. Zimmer J, Pezzullo J, Choucair W, Southard J, Kokkinos P, Karasik P, et al. Meta-analysis of antiarrhythmic therapy in the prevention of postoperative atrial fibrillation and the effect on hospital length of stay, costs, cerebrovascular accidents, and mortality in patients undergoing cardiac surgery. Am J Cardiol 2003;91:1137-40.

37. Redle JD, Khurana S, Marzan R, Bassett J, Tepe N, Westveer $\mathrm{D}$, et al. Prophylactic low dose amiodarone versus placebo to prevent atrial fibrillation in patients undergoing coronary artery bypass surgery [abstract]. J Am Coll Cardiol 1997;29:289A.

38. Daoud EG, Strickberger A, Ching Man K. Preoperative amiodarone as prophylaxis against atrial fibrillation after heart surgery. $N$ Engl J Med 1997;337:1785-91.

39. Tamis JE, Steinberg JS. Atrial fibrillation independently prolongs hospital stay after coronary artery bypass surgery. Clin Cardiol 2000;23:155-9.

40. Aranki SF, Shaw DP, Adams DG, Rizzo RJ, Couper GS, Van der Vliet M, et al. Predictors of atrial fibrillation after coronary artery surgery: current trends and impact on hospital resources. Circulation 1996;94:390-7.

41. Creswell LL, Schuessler RB, Rosenbloom M, Cox JL. Hazards of postoperative atrial arrhythmias. Ann Thorac Surg 1993;56:539-49.

42. Curtis L, Netten A. Unit costs of health and social care. Canterbury: Personal Social Services Research Unit, University of Kent; 2006.

43. Department of Health (UK). NHS reference costs 2005-06. 2006. URL: http://www.dh.gov.uk/en/ Publicationsandstatistics/Publications/Publications PolicyAndGuidance/DH_062884. Accessed 17 July 2007.

44. Intensive Care Society. What is intensive care? 2007. URL: http://www.ics.ac.uk/patrel/wiic.asp?menuid $=2$. Accessed 17 July 2007.

45. Bryan AJ, Cohen AM, Finch DJ. Cardiac services, adult cardiac surgery audit report, 2005-06. United Bristol Healthcare NHS Trust; 2006.

46. Mendes LA, Connelly GP, McKenney PA, Podrid PJ, Cupples LA, Shemin RJ, et al. Right coronary artery stenosis: an independent predictor of atrial fibrillation after coronary artery bypass surgery. J Am Coll Cardiol 1995;25:198-202.

47. MultiCenter Study of Perioperative Ischemia Research Group. Mathew JP, Parks R, Savino JS, Friedman AS, Koch C, Mangano DT, et al. Atrial fibrillation following coronary artery bypass graft surgery: predictors, outcomes, and resource utilization. JAMA 1996;276:300-6. 
48. Kowey PR, Dalessandro DA, Herbertson R, Briggs B, Wertan MA, Rials SJ, et al. Effectiveness of digitalis with or without acebutolol in preventing atrial arrhythmias after coronary artery surgery. $\mathrm{Am}$ J Cardiol 1997;79:1114-17.

49. Almassi GH, Schowalter T, Nicolosi AC, Aggarwal A, Moritz TE, Henderson WG, et al. Atrial fibrillation after cardiac surgery: a major morbid event? Ann Surg 1997;226:501-11.

50. Zaman AG, Alamgir F, Richens T, Williams R, Rothman MT, Mills PG. The role of signal averaged $\mathrm{P}$ wave duration and serum magnesium as a combined predictor of atrial fibrillation after elective coronary artery bypass surgery. Heart 1997;77:527-31.

51. Borzak S, Tisdale JE, Amin NB, Goldberg AD, Frank D, Padhi ID, et al. Atrial fibrillation after bypass surgery: does the arrhythmia or the characteristics of the patients prolong hospital stay? Chest 1998;113:1489-91.

52. Zaman AG, Archbold RA, Helft G, Paul EA, Curzen NP, Mills PG. Atrial fibrillation after coronary artery bypass surgery: a model for preoperative risk stratification. Circulation 2000;101:1403-8.

53. Kim MH, Deeb GM, Morady F, Bruckman D, Hallock LR, Smith KA, et al. Effect of postoperative atrial fibrillation on length of stay after cardiac surgery (The Postoperative Atrial Fibrillation in Cardiac Surgery study [PACS(2)]. Am J Cardiol 2001;87:881-5.

54. Hravnak M, Hoffman LA, Saul MI, Zullo TG, Whitman GR. Resource utilization related to atrial fibrillation after coronary artery bypass grafting. $A m$ $J$ Crit Care 2002;11:228-38.

55. Thompson AE, Hirsch GM, Pearson GJ. Assessment of new onset postcoronary artery bypass surgery atrial fibrillation: current practice pattern review and the development of treatment guidelines. J Clin Pharm Ther 2002;27:21-37.

56. Tamis-Holland JE, Kowalski M, Rill V, Firoozi K, Steinberg JS. Patterns of atrial fibrillation after coronary artery bypass surgery. Ann Noninvasive Electrocardiol 2006;11:139-44.

57. Hosokawa K, Nakajima Y, Umenai T, Ueno H, Taniguchi S, Matsukawa T, et al. Predictors of atrial fibrillation after off-pump coronary artery bypass graft surgery. Br J Anaesth 2007;98:575-80.

58. Society for Cardiothoracic Surgery of Great Britain and Ireland. National Adult Cardiac Surgical Database 2000-2001. 2002. URL: http://www.scts.org/sections/ audit/Cardiac/index.html. Accessed 6 July 2007.

59. Society for Cardiothoracic Surgery of Great Britain and Ireland. Fifth National Adult Cardiac Surgical Database Report 2003. Improving patient outcomes. URL: http://www.scts.org/sections/audit/ Cardiac/index.html. Accessed 6 July 2007.

60. Buxton M, Caine N, Chase D, Connelly D, Grace A, Jackson $\mathrm{C}$, et al. A review of the evidence on the effects and costs of implantable cardioverter defibrillator therapy in different patient groups, and modelling of cost-effectiveness and cost-utility for these groups in a UK context. Health Technol Assess 2006;10(27).

61. Organisation for Economic Cooperation and Development. Purchasing power parities (PPPS) for OECD countries since 1980 (xls). 2007. URL: http://www.oecd.org/document/47/0,3343,en_2649_ 34357_36202863_1_1_1_1,00.html\# historicalppp. Accessed 28 April 2008.

62. De Paola AA, Figueiredo E, Sesso R, Veloso HH, Nascimento LO. Effectiveness and costs of chemical versus electrical cardioversion of atrial fibrillation Int J Cardiol 2003;88:157-66.

63. National Collaborating Centre for Chronic Conditions. Atrial fibrillation: national clinical guideline for management in primary and secondary care. London: Royal College of Physicians; 2006.

64. El-Essawi A, Khan S, Carstens U, Kutschka I, Falku I, Harringer W. Efficacy of sotalol and magnesium in the prevention of atrial fibrillation following coronary artery bypass surgery. Z Herz, Thorax Gefasschir 2006;20:151-5.

65. Stamou SC, Hill PC, Dangas G, Pfister AJ, Boyce SW, Dullum MKC, et al. Stroke after coronary artery bypass: incidence, predictors, and clinical outcome editorial comment: Incidence, predictors, and clinical outcome. Stroke 2001;32:1508-13.

66. Miller PSJ, Andersson FL, Kalra L. Are cost benefits of anticoagulation for stroke prevention in atrial fibrillation underestimated? Stroke 2005;36:360-6. 



\section{Appendix I}

\section{Search strategy for RCTs and systematic reviews}

\section{Cochrane Library}

2007 (Issue 2)

Searched 14 May 2007

\# 1 MeSH descriptor Coronary Artery Bypass explode all trees

\#2 (CABG or coronary artery bypass graft*):ti,ab

\#3 (coronary artery bypass NEAR/3 surgery):ti,ab

\#4 coronary revascular*:ti,ab

\#5 (\#1 OR \#2 OR \#3 OR \#4)

\#6 MeSH descriptor Magnesium Sulfate explode all trees

\#7 magnesium (sulphate* or sulfate*):ti,ab

\#8 (\#6 OR \#7)

\#9 MeSH descriptor Atrial Fibrillation explode all trees

\#10 (heart NEAR/3 fibrillat*):ti,ab

\#11 (atrial and fibrillat*):ti,ab

\#12 atrial fibrillat*

\#13 (\#9 OR \#10 OR \#11 OR \#12)

\#14 (\#5 AND \#8), from 2004 to 2007

\#15 (\#13 AND \#8), from 2004 to 2007

\#16 (\#14 OR \#15)

\#17 MeSH descriptor Sotalol explode all trees

\#18 sotalol

\#19 (\#17 OR \#18)

\#20 (\#5 OR \#13)

\#21 (\#20 AND \# 19)

\#22 (\#8 AND \#19)

\#23 (\#19 AND \#5)

\section{Number of hits (download file)}

Cochrane Database of Systematic Reviews (CDSR) magnesium: 1

CDSR sotalol: 8

CENTRAL magnesium: 8

CENTRAL magnesium + sotalol: 1

CENTRAL sotalol: 16

\section{Ovid MEDLINE}

1950 to May week 12007

Searched 15 May 2007

1 "Atrial Fibrillation"/ (19465)

2 Atrial Flutter/ (3991)

3 (atrial adj3 fibrillat\$).mp. (25464)

4 (heart adj3 fibrillat\$).mp. (950)

5 atrial fibrillat\$.mp. (25294)
$6 \quad$ (atrium adj3 flutter\$).mp. (23)

7 (atrium adj3 fibrillat $\$ r$ ).mp. (0)

8 (auricular\$ adj3 fibrillat\$).mp. (736)

9 (auricular\$ adj3 flutter\$).mp. (274)

10 Tachycardia Supraventricular/ (3781)

11 or/1-10 (30644)

12 "Coronary Artery Bypass"/ (31512)

13 (CABG or coronary artery bypass graft\$).ti,ab. (16229)

14 (coronary artery bypass adj3 surgery).ti,ab. (7332)

15 (coronary adj3 revasculari\$).ti,ab. (4439)

16 (myocardial adj3 revascular\$).ti,ab. (4063)

17 (coronary adj6 graft).ti,ab. (6832)

18 (coronary adj6 bypass).ti,ab. (26085)

19 (coronary adj6 surgery).ti,ab. (15257)

20 (aortocoronary adj6 bypass).ti,ab. (2453)

21 (valve $\$$ adj6 surgery).ti,ab. (4554)

22 Cardiac Surgical Procedures/ (23335)

23 or/12-22 (71271)

24 MgSO4.mp. (1029)

25 magnesium sulfate/ (3419)

26 magnesium sulfate $\$ . t i, a b .(1735)$

27 exp magnesium compounds/ (10471)

28 magnesium/ (56302)

29 (magnesium and (sulphate $\$$ or sulfate $\$$ )).ti,ab. (3192)

30 magnesium sulphate $\$ . t i, a b .(729)$

31 magnesium sulfate $\$ . t i, a b .(1735)$

32 7487-88-9.rn. (3419)

33 Magnesium Deficiency/ (3387)

34 or/24-33 (67330)

35 3930-20-9.rn. (1695)

36 Sotalol/ (1695)

37 sotalol.ti,ab. (1997)

38 or/35-37 (2418)

3911 and 23 and 34 (48)

4023 and 34 (242)

4111 and $34(151)$

4239 or 40 or $41(345)$

43 limit 42 to (humans and english language and $\mathrm{yr}=" 2004-2007 ")(45)$

44 RANDOMISED CONTROLLED TRIAL.pt. (234701)

45 CONTROLLED CLINICAL TRIAL.pt. (74869)

46 RANDOMISED CONTROLLED TRIALS.sh. (48464)

47 RANDOM ALLOCATION.sh. (57810)

48 DOUBLE BLIND METHOD.sh. (91140)

49 SINGLE BLIND METHOD.sh. (10900) 
50 or/44-49 (397972)

51 CLINICAL TRIAL.pt. (435563)

$52 \exp$ CLINICAL TRIALS/ (190865)

53 (clin\$ adj25 trial\$).ti,ab. (129659)

54 ( (singl\$ or doubl $\$$ or trebl $\$$ or tripl $\$)$ adj25 (blind $\$$ or mask $\$)$ ).ti,ab. (90466)

55 PLACEBOS.sh. (26144)

56 placebo $\$ . t i, a b .(102017)$

57 random $\$ . t i, a b .(370373)$

58 RESEARCH DESIGN.sh. (47354)

59 or/51-58 (843224)

60 COMPARATIVE STUDY.sh. (0)

61 exp Evaluation Studies/ (596080)

62 FOLLOW UP STUDIES.sh. (337594)

63 PROSPECTIVE STUDIES.sh. (220463)

64 (control\$ or prospectiv\$ or volunteer\$).ti,ab. (1775327)

65 or/60-64 (2564190)

66 or/50,59,65 (2918050)

6743 and 66 (32)

68 from 67 keep 1-32 (32)

69 from 68 keep 1-32 (32)

70 (review or review-tutorial or reviewacademic).pt. (1275632)

71 (Medline or medlars or embase).ti,ab,sh. (23800)

72 (scisearch or psychinfo or psycinfo).ti,ab,sh. (1277)

73 (Psychlit or psyclit).ti,ab,sh. (709)

74 cinahl.ti,ab,sh. (2178)

75 ((hand adj59 search\$) or (manual\$ adj9 search\$)).mp. [mp=title, original title, abstract, name of substance word, subject heading word] (3888)

76 (electronic database $\$$ or bibliographic database $\$$ or computeri\# ed database $\$$ or online database $\$$ ).mp. $[\mathrm{mp}=$ title, original title, abstract, name of substance word, subject heading word] (4129)

77 (pooling or pooled or mantel haenszel).mp. $[\mathrm{mp}=$ title, original title, abstract, name of substance word, subject heading word] (25915)

78 (peto or dersimonian or der simonian or fixed effect).mp. [mp=title, original title, abstract, name of substance word, subject heading word] (1092)

7971 or 72 or 73 or 74 or 75 or 76 or 77 or 78 (52839)

8070 and 79 (19955)

81 meta-analysis.pt. (15271)

82 meta-analysis.sh. (7414)

83 (meta-analys\$ or meta analys $\$$ or metaanalys $\$$ ).mp. [ $\mathrm{mp}=$ title, original title, abstract, name of substance word, subject heading word] (27299)

84 (systematic $\$$ adj9 review $\$$ ).mp. [mp $=$ title, original title, abstract, name of substance word, subject heading word] (13485)
85 (systematic $\$$ adj9 overview $\$$ ).mp. $[\mathrm{mp}=$ title, original title, abstract, name of substance word, subject heading word] (416)

86 (quantitativ\$ adj9 review\$).mp. (1754)

87 (quantitativ $\$$ adj9 overview $\$$ ).mp. $[\mathrm{mp}=$ title, original title, abstract, name of substance word, subject heading word] (142)

88 (quantitativ\$ adj9 synthesis\$).mp. (1376)

89 (methodologic\$ adj9 review\$).mp. (2493)

90 (methodologic $\$$ adj9 overview\$).mp. (153)

91 (integrative research review\$ or research integration).mp. (51)

92 or/81-91 (41150)

9380 or $92(53669)$

9443 and $93(6)$

95 from 94 keep 1-6 (6)

9611 or $23(99880)$

$97 \quad 34$ and 38 and 96 (10)

98 from 97 keep 1-10 (10)

9938 and 93 and 96 (27)

100 from 99 keep 1-27 (27)

$101100(27)$

10238 and 66 and 96 (313)

103 limit 102 to (humans and english language) (268)

104103 not $99(246)$

10523 and $104(45)$

106104 not $105(201)$

10723 and 38 and 66 (52)

108 limit 107 to (humans and english language) (51)

10923 and 38 and $92(6)$

110108 not $109(47)$

\section{Number of hits (download file)}

Systematic reviews (SRs) magnesium: 5

SRs magnesium + sotalol: 2

SRs sotalol: 6

RCTs magnesium: 24

RCTs magnesium + sotalol: 10

RCTs sotalol: 47

\section{EMBASE}

1980 to 2007 week 19

Searched 16 May 2007

1 heart atrium fibrillation/ (21875)

2 heart atrium flutter/ (3362)

3 exp Heart Atrium Arrhythmia/ (35266)

4 (atrial adj3 fibrillat\$).mp. (17803)

5 (heart adj3 fibrillat\$).mp. (31983)

6 atrial fibrillat\$.mp. (17577)

7 (atrium adj3 flutter\$).mp. (3380)

8 (atrium adj3 fibrillat\$r).mp. (0)

9 (auricular\$ adj3 fibrillat\$).mp. (108)

10 (auricular\$ adj3 flutter\$).mp. (29) 
11 Supraventricular Tachycardia/ (5812)

12 or/1-11 (47152)

13 coronary artery bypass graft/ (22523)

14 Coronary Artery Bypass Surgery/ (6944)

15 exp coronary artery surgery/ (39530)

16 (CABG or coronary artery bypass graft\$).ti,ab. (14959)

17 (coronary artery bypass adj3 surgery).ti,ab. (6804)

18 (coronary adj3 revasculari\$).ti,ab. (4087)

19 (myocardial adj3 revascular\$).ti,ab. (3015)

20 (coronary adj6 graft).ti,ab. (6026)

21 (coronary adj6 bypass).ti,ab. (23026)

22 (coronary adj6 surgery).ti,ab. (13234)

23 (aortocoronary adj6 bypass).ti,ab. (1469)

24 (valve $\$$ adj6 surgery).ti,ab. (3618)

25 or/13-24 (50320)

26 MgSO4.mp. (1011)

27 magnesium sulfate/ (6009)

28 Magnesium Derivative/ (989)

29 magnesium/ (23019)

30 (magnesium and (sulphate $\$$ or sulfate $\$$ )).ti,ab. (2910)

31 magnesium sulphate\$.ti,ab. (642)

32 magnesium sulfate $\$ . t i, a b$. (1548)

33 7487-88-9.rn. (6022)

34 Magnesium Deficiency/ (1203)

35 or/26-34 (30923)

36 3930-20-9.rn. (7170)

37 Sotalol/ (7144)

38 sotalol.ti,ab. (2048)

39 or/36-38 (7279)

$40 \quad 12$ and 25 and 35 (88)

4125 and 35 (209)

$42 \quad 12$ and 35 (667)

4341 or $42(788)$

44 limit 43 to (humans and english language and $\mathrm{yr}=" 2004-2007 ")(229)$

4512 or $25(95066)$

4635 and 39 and 45 (149)

47 exp Postoperative Complication/ (188542)

48 exp meta analysis/ (30150)

49 meta\#analy\$.ab,sh,ti. (30151)

50 methodologic $\$$ review $\$$. ab,sh,ti. (128)

51 methodologic $\$$ overview\$.ab,sh,ti. (31)

52 (integrative research adj5 review\$).mp. or research integration.ab,ti. $[\mathrm{mp}=$ title, abstract, subject headings, heading word, drug trade name, original title, device manufacturer, drug manufacturer name] (28)

53 quantitat\$ synthesis.ab,sh,ti. (91)

54 quantitat\$ review\$.ab,sh,ti. (260)

55 quantitat\$ overview\$.ab,sh,ti. (60)

56 systematic \$ review\$.ab,sh,ti. (23698)

57 systematic $\$$ overview $\$$. ab,sh,ti. (287)

5848 or 49 or 50 or 51 or 52 or 53 or 54 or 55 or 56 or 57 (43716)
5944 and 58 (28)

60 from 59 keep 1-2,4-5,8-9,12-13,15,17-20,2225,28 (18)

61 randomisation/ (22296)

62 controlled study/ (2402316)

63 single blind procedure/ (6576)

64 placebo/ (98219)

65 double blind procedure/ (63899)

66 clinical trial/ (423526)

67 crossover procedure/ (18621)

68 placebo\$.tw. (98196)

69 blind\$ fashion.tw. (3585)

70 random $\$ . t w .(335411)$

71 clinical trial?.tw. (99670)

72 or/61-71 (2809080)

73 limit 72 to human (1793268)

7444 and 73 (120)

7574 not $59(92)$

76 from 75 keep 5,7,10,16,18,20,22-25,27,30-

$31,33,39-40,43,45,48,50-51,58,60,65,68$ -

$77,80,84,86,88,90-92(41)$

7746 and 58 (18)

$7877 \operatorname{not}(59$ or 75$)(4)$

79 from 78 keep 1-4 (4)

8046 and 73 (69)

81 limit 80 to english language (66)

8281 not $74(34)$

83 from 82 keep 2-4,7,10-12,14-15,17,19-24,26$27,31,34(20)$

$84 \quad 12$ and 25 and 39 and 58 (18)

85 from 84 keep 1,3 (2)

8684 not $(78$ or 59 or 75 or 81$)$ (12)

87 from 86 keep 1,3-5,7-8,10 (7)

$88 \quad 12$ and 25 and 39 and 73 (102)

89 limit 88 to (human and english language) (91)

9089 not $84(74)$

91 from 90 keep 1-6,9,15,17-20,25-

27,30,36,38,41,43-46,49,52-53,55-63,65-74

(45)

\section{Number of hits (download file)}

SRs magnesium: 18

SRs magnesium + sotalol: 4

SRs sotalol: 20

RCTs magnesium: 41

RCTs magnesium + sotalol: 20

RCTs sotalol: 45

\section{Ovid MEDLINE In-Process and Other Non-Indexed Citations}

14 May 2007

Searched 15 May 2007

1 (atrial adj3 fibrillat\$).mp. (728)

2 (heart adj3 fibrillat\$).mp. (32)

3 atrial fibrillat\$.mp. (727) 
4 (atrium adj3 flutter\$).mp. (1)

5 (atrium adj3 fibrillat\$r).mp. (0)

6 (auricular\$ adj3 fibrillat\$).mp. (16)

7 (auricular\$ adj3 flutter\$).mp. (0)

8 or/1-7 (747)

9 (CABG or coronary artery bypass graft\$).ti,ab. (482)

10 (coronary artery bypass adj3 surgery).ti,ab. (220)

11 (coronary adj3 revasculari\$).ti,ab. (134)

12 (myocardial adj3 revascular\$).ti,ab. (83)

13 (coronary adj6 graft).ti,ab. (173)

14 (coronary adj6 bypass).ti,ab. (638)

15 (coronary adj6 surgery).ti,ab. (353)

16 (aortocoronary adj6 bypass).ti,ab. (22)

17 (valve $\$$ adj6 surgery).ti,ab. (117)

18 or/9-17 (968)

19 MgSO4.mp. (38)

20 (magnesium and (sulphate $\$$ or sulfate $\$$ )).ti,ab. (98)

21 magnesium sulphate\$.ti,ab. (23)

22 magnesium sulfate $\$ . t i, a b .(55)$

2319 or 20 or 21 or 22 (129)

24 sotalol.ti,ab. (30)

258 or 18 (1659)

2623 and 25 (3)

27 from 26 keep 1-3 (3)

2824 and 25 (14)

29 from 28 keep 5,8,10-13 (6)

\section{Number of hits (download file)}

RCTs magnesium: 3

RCTs sotalol: 6

\section{DARE (on CRD databases)}

magnesium and (atrial fibrillat* or coronary) Sotalol and (atrial fibrillat* or coronary)

\section{Number of hits (download file)}

Magnesium: 7

Sotalol: 10

\section{HTA Database (on CRD databases)}

Magnesium and (atrial fibrillat* or coronary) Sotalol and (atrial fibrillat* or coronary)

\section{Number of hits}

0 


\section{Appendix 2}

\section{Decision tree for screening abstracts and full papers}

\begin{abstract}
Trial name or number:
Adult patients with $A F$ after elective $C A B G$

Either on-pump or off-pump CABG techniques; any number of grafts; any conduit type

(CABG must be specified; with or without valvular surgery)
\end{abstract}

Design: RCT or systematic review

\section{Intervention ${ }^{a}$}

IV magnesium sulphate as bolus or continuous infusion, or sotalol (oral or IV) or IV magnesium sulphate combined with sotalol, each of a specified dose and duration, as a prophylactic measure before onset of AF. (NB. Oral Mg, Mg chloride and $\mathrm{Mg}$ hydroxide are outside the scope of the review)

Report one or more of primary outcomes: incidence of $A F$ after CABG (include broader arrhythmia definitions only if proportion with $A F$ reported), measured using a continuous electrocardiogram (ECG) and confirmed by standard I2-lead ECG)

Final decision
Yes
$\downarrow$
next question

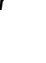<smiles>[AsH2]</smiles>
next question

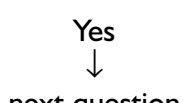

next question

$$
\begin{gathered}
\text { Unclear } \\
\downarrow \\
\text { next question }
\end{gathered}
$$
No
$\rightarrow$
Exclude

No Type:

$\rightarrow$

Exclude

Exclude I

(not the correct patient group)

$$
\begin{gathered}
\text { Unclear } \\
\downarrow \\
\text { ext question }
\end{gathered}
$$

No
$\rightarrow$
Exclude

Exclude 2

(not the right study design)

\section{Exclude 3 \\ (not the right intervention)}

IV, intravenous.

${ }^{a}$ Compared with placebo and/or sotalol. 



\section{Appendix 3}

\section{Data extraction templates for the 15 RCTs included in this review}

\begin{tabular}{|c|c|c|c|}
\hline $\begin{array}{l}\text { Reference and } \\
\text { design }\end{array}$ & Intervention & Participants & Outcome measures \\
\hline $\begin{array}{l}\text { Authors: } \\
\text { Bert et al. }{ }^{15} \\
\text { Year: } 200 \text { I } \\
\text { Country: USA } \\
\text { Study design: RCT } \\
\text { Number of centres: } \\
\text { One } \\
\text { Funding: NR }\end{array}$ & $\begin{array}{l}\text { Interventions for which } \\
\text { data extracted: } \\
\text { I. IV magnesium } \\
\text { sulphate } \\
\text { 2. Control } \\
\text { Other groups (data not } \\
\text { extracted): } \\
\text { 3. Digoxin } \\
\text { 4. MgSO }{ }_{4}+\text { digoxin } \\
\text { 5. Propranolol } \\
\text { 6. MgSO }{ }_{4}+ \\
\text { propranolol } \\
\text { Intervention details: } \\
\text { I. } 2 \mathrm{~g} \text { magnesium } \\
\text { sulphate diluted in } \\
50 \text { ml of normal } \\
\text { saline infused i.v. } \\
\text { during } 30 \text { minutes } \\
\text { after termination of } \\
\mathrm{CPB} \text { (after } \\
\text { protamine } \\
\text { neutralisation) and } \\
\text { again on arrival in } \\
\text { the ICU. A daily } \\
\text { dose of } 2 \mathrm{~g} \\
\text { magnesium sulphate } \\
\text { then infused each } \\
\text { morning for the first } \\
4 \text { days postoperation } \\
\text { for a total of I } 2 \mathrm{~g} \text { in } \\
96 \text { h. No patients } \\
\text { received magnesium } \\
\text { pre-CPB } \\
\text { 2. Received no } \\
\text { antiarrhythmic agent } \\
\text { (not stated whether } \\
\text { normal saline was } \\
\text { administered as in } \\
\text { group I) }\end{array}$ & $\begin{array}{l}\text { Sample attrition/dropout: } \\
\text { Three patients were excluded after } \\
\text { randomisation, but it was not reported whether } \\
\text { these were from the magnesium and/or control } \\
\text { groups, nor whether any data from these } \\
\text { patients were analysed } \\
\text { Inclusion criteria for study entry: } \\
\text { Patients scheduled for primary CABG surgery } \\
\text { were eligible for enrolment, including patients } \\
\text { with additional aortic valve replacement surgery } \\
\text { Exclusion criteria for study entry: } \\
\text { Patients with: a history of atrial or ventricular } \\
\text { arrhythmias, or any rhythm other than sinus } \\
\text { rhythm on the ECG obtained the evening before } \\
\text { surgery; LVEF } \leqslant 20 \% \text { on angiography; airway } \\
\text { disease requiring bronchodilator therapy; renal } \\
\text { failure requiring haemodialysis; other surgical } \\
\text { procedures (mitral valve surgery aortic arch } \\
\text { replacement, or ventricular aneurysmectomy) } \\
\text { Baseline characteristics of subjects: } \\
\text { Mean } \pm \text { SD age (years): } \\
\text { Intervention: } 62.7 \pm 9.7 \text { b } \\
\text { Control: } 63.6 \pm 9.6^{b} \\
\text { (difference was tested only across six study } \\
\text { groups) } \\
\text { Gender (M/F): } \\
\text { Intervention: } 56 / 7 \\
\text { Control: } 50 / I 0 \\
\text { (difference was tested only across six study } \\
\text { groups) } \\
\text { Magnesium/control group values appeared } \\
\text { similar for: LVEF, \% } \beta \text {-blockers, Ca channel } \\
\text { blockers, digoxin, diuretics, number of bypass } \\
\text { grafts, \% incomplete revascularisation, } \% \\
\text { inotropic use, number of patients with CABG + } \\
\text { valve surgery ( } 3 / 1 \text { ) and mean cross-clamp time } \\
\text { ( } 59.6 / 55.1 \text { minutes) (differences were tested } \\
\text { only across six study groups) }\end{array}$ & $\begin{array}{l}\text { Other outcomes } \\
\text { extracted: } \\
\text { Duration of hospital stay } \\
\text { Other outcomes (data not } \\
\text { extracted): } \\
\text { Time to extubation, MI, } \\
\text { ventricular ectopic } \\
\text { activity, initial ventricular } \\
\text { rate } \\
\text { Adverse symptoms: } \\
\text { No deaths occurred in } \\
\text { either the magnesium or } \\
\text { control group during the } \\
\text { study. The proportions } \\
\text { of patients with MI or } \\
\text { ventricular ectopic } \\
\text { activity appeared similar } \\
\text { in these groups } \\
\text { Length of follow-up: } \\
4 \text { days after CABG } \\
\text { Recruitment dates: } \\
3 \text {-year period (dates not } \\
\text { specified) }\end{array}$ \\
\hline \multicolumn{4}{|c|}{$\begin{array}{l}\text { a POAT (post-operative atrial tachyarrhythmia) includes AF, atrial flutter or an SVT that was sustained for }>5 \text { minutes and } \\
\text { warranted pharmacological therapy. } \\
\text { b Variance measure not stated. }\end{array}$} \\
\hline
\end{tabular}




\begin{tabular}{|c|c|c|c|}
\hline \multicolumn{4}{|l|}{ Results } \\
\hline AF outcome & Intervention $(n=63)$ & Control $(n=60)$ & Difference \\
\hline Incidence of POAT, $n(\%)^{c}$ & $24^{d}(38 \%)$ & $23^{d}(38 \%)$ & $p=0.98$ \\
\hline \multicolumn{4}{|c|}{ 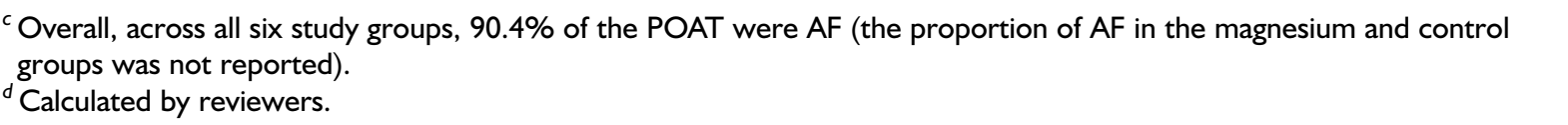 } \\
\hline Other outcomes & Intervention $(n=63)$ & Control $(n=60)$ & Difference \\
\hline Duration of hospital stay (days) & $8.2 \pm 3.1^{\mathrm{e}}$ & $8.0 \pm 2.9^{e}$ & $\begin{array}{l}\text { Not reported for } \\
\text { this comparison; for } \\
\text { comparison across } \\
\text { six groups } p=0.69 \\
\text { (ns) }\end{array}$ \\
\hline
\end{tabular}

${ }^{e}$ Assumed by reviewers (not stated) to be the mean value; variance measure not stated.

\section{Methodological comments}

Allocation to treatment groups: Stated that patients were randomised to the study groups based on a table of random numbers (no other details provided).

Blinding: Stated that all arrhythmia tracings were reviewed by a cardiologist unaware of the patient's treatment group. No other details of blinding were given.

Comparability of treatment groups: Baseline characteristics of the groups appear similar; differences were not significant if all six study groups were tested together (no pairwise tests of baseline characteristics were reported).

Method of data analysis:

- One-way analysis of variance and $2 \times 6$ contingency tables with $\chi^{2}$ test were used to compare baseline characteristics, intraoperative measures and POAT among the six treatment groups.

- $2 \times 2$ contingency tables with $\chi^{2}$ test were used to compare the incidence of POAT between each pair of treatment groups.

- An independent samples $t$-test was used to compare age between POAT and non-POAT groups (data not extracted).

- Statistical tests were not supported by hypotheses; normality of data was not reported.

Sample size/power calculation: NR.

Attrition/dropout: Three patients were excluded after randomisation, but it was not reported whether these were from the magnesium and/or control groups, nor whether any data from these patients were analysed. Patients experiencing AF were regarded as having completed the study protocol (the end-point and duration of study therefore varied among patients).

\section{General comments}

Generalisability: No details of ethnicity or social background; single-location study in USA.

Outcome measures: POAT mainly comprised AF ( $90.4 \%$ overall), but AF was not reported separately for individual treatment comparisons.

Intercentre variability: NA.

Conflict of interests: None reported.

LVEF, left ventricular ejection fraction; MI, myocardial infarction; ns, not significant; POAT, postoperative atrial tachycardia; SVT, supraventricular tachycardia. 


\begin{tabular}{|c|c|c|c|}
\hline $\begin{array}{l}\text { Reference and } \\
\text { design }\end{array}$ & Intervention & Participants & Outcome measures \\
\hline $\begin{array}{l}\text { Authors: Bhudia } \\
\text { et al. }{ }^{16} \\
\text { Year: } 2006 \\
\text { Country: USA } \\
\text { Study design: RCT } \\
\text { Number of centres: } \\
\text { One } \\
\text { Funding: NR }\end{array}$ & $\begin{array}{l}\text { Interventions: } \\
\text { I. IV magnesium } \\
\text { sulphate } \\
\text { 2. Placebo control } \\
\text { Intervention details: } \\
\text { I. } 780 \mathrm{mg} \text { ( } 32 \mathrm{mmol}) \\
\text { magnesium sulphate } \\
\text { in } 100 \mathrm{ml} \text { of normal } \\
\text { saline given i.v. over } \\
\text { I5 minutes during } \\
\text { anaesthesia } \\
\text { induction, followed } \\
\text { by } 3160 \text { mg } \\
\text { (I30 mmol) in } \\
\text { I00 ml of normal } \\
\text { saline over } 24 \text { h; the } \\
\text { CPB circuit was } \\
\text { primed with } \\
\text { magnesium sulphate } \\
\text { to a concentration of } \\
3.6 \text { to } 4.8 \text { mg dl } \\
\text { 2. Patients received } \\
\text { normal saline given } \\
\text { i.v. in the CPB circuit } \\
\text { and over } 24 \mathrm{~h} \text { in } \\
\text { bags and syringes } \\
\text { indistinguishable } \\
\text { from those used for } \\
\text { group I }\end{array}$ & 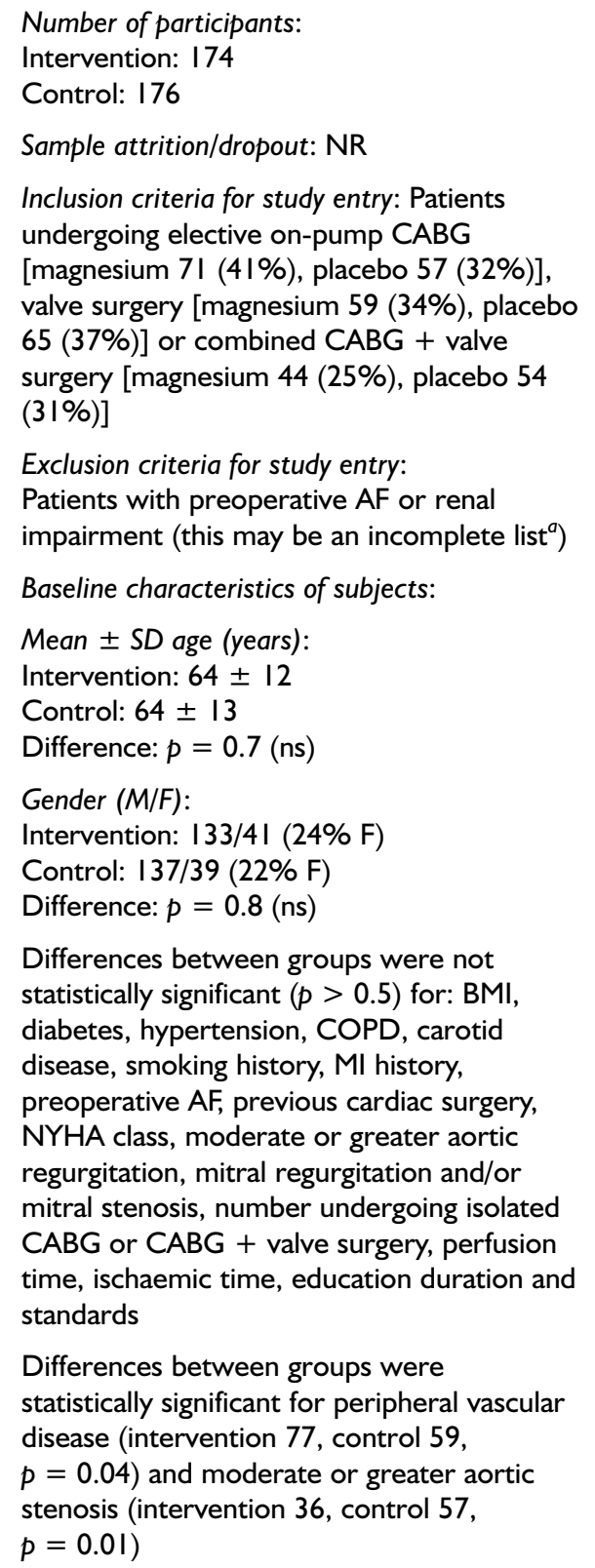 & $\begin{array}{l}\text { Other extracted outcomes: } \\
\text { Length of stay in ICU and } \\
\text { hospital } \\
\text { Other outcomes (data not } \\
\text { extracted): MI, stroke, } \\
\text { return to operating room } \\
\text { for treatment, blood } \\
\text { transfusion units, } \\
\text { neurological and } \\
\text { psychological assessments } \\
\text { (primary outcome), plasma } \\
\text { magnesium concentration, } \\
\text { renal insufficiency, } \\
\text { respiratory insufficiency, } \\
\text { septicaemia } \\
\text { Adverse symptoms: } \\
\text { One death occurred in each } \\
\text { group in hospital. Within } \\
3 \text { months of enrolment } \\
\text { there was one death in the } \\
\text { magnesium group and there } \\
\text { were four deaths in the } \\
\text { placebo group ( } p=0.2, \text { ns); } \\
\text { these were not related to } \\
\text { stroke or neurological injury } \\
\text { Length of follow-up: } \\
\text { Not stated for the } \\
\text { outcomes extracted here } \\
\text { (median length of } \\
\text { postoperative stay was } \\
6 \text { days) } \\
\text { Recruitment dates: } \\
\text { February } 2003 \text { to } \\
\text { September } 2003 \\
\end{array}$ \\
\hline \multicolumn{4}{|c|}{$\begin{array}{l}{ }^{a} \text { The authors refer to Figure EI and Appendix EI for exclusion criteria, but these sources were not included in the primary } \\
\text { article and no links for locating them elsewhere were provided }\end{array}$} \\
\hline \multicolumn{4}{|l|}{ Results } \\
\hline AF outcome & & Intervention $(n=174)$ & Difference \\
\hline No. (\%) of patients & with $\mathrm{AF}$ & 57 (33\%) & $p=0.5$ (ns) \\
\hline
\end{tabular}




\begin{tabular}{lccc} 
Other outcomes & $\begin{array}{c}\text { Intervention } \\
(\boldsymbol{n}=\mathbf{I 7 4})\end{array}$ & $\begin{array}{c}\text { Control } \\
(\boldsymbol{n}=\mathbf{I 7 6})\end{array}$ & Difference \\
\hline Median length of stay (days) in ICU (I5th, 85th percentiles) & $2(1,3)$ & $2(1,3)$ & $p>0.9$ (ns) \\
Median length of postoperative stay (days) (I5th, 85th percentiles) & $6(5,9)$ & $6(5,9)$ & $p>0.9$ (ns) \\
Median length of hospital stay (days) (I5th, 85th percentiles) & $7(5,11)$ & $7(5,10)$ & $p=0.3$ (ns)
\end{tabular}

\section{Methodological comments}

Allocation to treatment groups: Patients were randomised I:I at operation, with a block size of 2 and 4 , independently for each of II operating rooms (no other details).

Blinding: The pharmacy department who prepared study medications and the anaesthetic team who administered the 24-h infusions were blinded to the study. The perfusion teams who dosed the CPB circuits were not blinded; they were required to monitor and maintain magnesium levels during CPB.

Comparability of treatment groups: Significantly more of the magnesium group had PVD, while significantly more of the control group had aortic stenosis; other variables did not differ between the groups ( $p$-values were provided for all variables).

Method of data analysis:

- Continuous data with a skewed (unspecified) distribution were analysed with a Wilcoxon rank-sum test.

- Categorical data were analysed using a $\chi^{2}$ test, or Fisher's exact test when the frequency was $<5$.

- Presentation of results did not indicate which tests were actually used for each outcome; normality of outcomes was not reported.

- Statistical tests were not supported by hypotheses.

Sample size/power calculation: Stated that the study was powered for 300 patients, based on neurological assessments as the primary outcome, but no details given.

Attrition/dropout: NR.

\section{General comments}

Generalisability: No details of ethnicity or social background; single-location study in USA.

Outcome measures: Appropriate.

Intercentre variability: NA.

Conflict of interests: None reported.

BMI, body mass index; COPD, chronic obstructive pulmonary diseases; NYHA, New York Heart Association; PVD, peripheral vascular disease. 


\begin{tabular}{|c|c|c|c|}
\hline $\begin{array}{l}\text { Reference and } \\
\text { design }\end{array}$ & Intervention & Participants & Outcome measures \\
\hline $\begin{array}{l}\text { Authors: } \\
\text { Caspi et al. }{ }^{13} \\
\text { Year: } 1995 \\
\text { Country: Israel } \\
\text { Study design: RCT } \\
\text { Number of centres: } \\
\text { One } \\
\text { Funding: NR }\end{array}$ & $\begin{array}{l}\text { Interventions: } \\
\text { I. Intravenous } \\
\text { magnesium sulphate } \\
\text { 2. Placebo control } \\
\text { Intervention details: } \\
\text { I. Two doses of } \\
\text { magnesium sulphate } \\
\text { continuously with a } \\
\text { syringe pump } \\
\text { (Graseby } 3100 \text {; } \\
\text { Watford, Herts, UK): } \\
\text { - I6 mmol from the } \\
\text { time of anaesthetic } \\
\text { induction to aortic } \\
\text { cross-clamping } \\
\text { - } 32 \text { mmol after the } \\
\text { release of aortic } \\
\text { cross-clamping until } \\
24 \text { h later }\end{array}$ & $\begin{array}{l}\text { Inclusion criteria for study entry: Patients with } \\
\text { unstable angina (grade IV) undergoing } \\
\text { CABG, the criteria for unstable angina: the } \\
\text { presence of chest pain at rest lasting for } \\
\text { more than I5 minutes, associated with } \\
\text { transient ST segment changes and with or } \\
\text { without haemodynamic instability } \\
\text { Exclusion criteria for study entry: } \\
\text { NR } \\
\text { Baseline characteristics of subjects: } \\
\text { Mean age (range) (years): } \\
\text { Intervention: } 60 \text { (4I-78) } \\
\text { Control: } 62(43-76) \\
\text { Gender (M/F) (n): } \\
\text { Intervention: } 34 / 16 \\
\text { Control: } 38 / 10\end{array}$ & 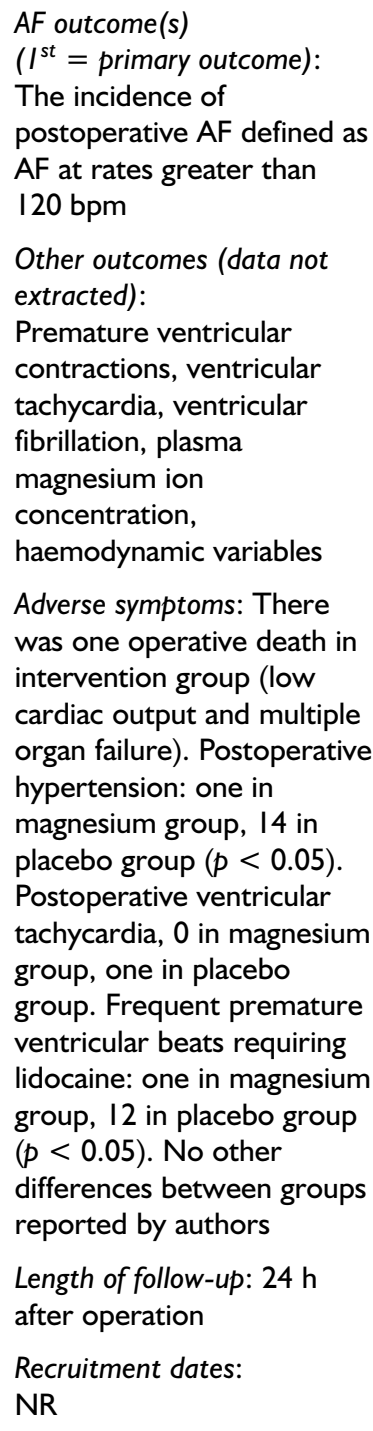 \\
\hline \multicolumn{4}{|l|}{ Results } \\
\hline \multicolumn{2}{|l|}{ AF outcome } & Intervention $(n=50)$ & Control $(n=48)$ \\
\hline \multicolumn{2}{|c|}{ Incidence of postoperative AF } & $22(44.0 \%)$ & $18(37.5 \%)$ \\
\hline \multicolumn{4}{|c|}{$\begin{array}{l}\text { Authors reported only the numbers of patients with AF in intervention and placebo groups. Other outcomes are given with } \\
\text { p-value or standard deviation. } \\
\text { Methodological comments } \\
\text { Allocation to treatment groups: It is stated that patients were randomly assigned to receive treatment or placebo in coded } \\
\text { ampules. The means by which an allocation sequence was generated is not reported and the allocation concealment is } \\
\text { unclear. }\end{array}$} \\
\hline \multicolumn{4}{|c|}{$\begin{array}{l}\text { Comparability of treatment groups: No notable differences; authors report that the groups were similar in baseline } \\
\text { characteristics and other preoperative and operative characteristics. No statistical tests reported. }\end{array}$} \\
\hline
\end{tabular}


Method of data analysis: Patients' parameters were compared between two groups using an unpaired $t$-test and $\chi^{2}$ test, as required. However, no statistical method used in the analysis of the outcome concerning AF.

Sample size/power calculation: The power calculations and variance estimates are not provided.

Attrition/dropout: NR.

\section{General comments}

Generalisability: No details of ethnicity or social background; single location in Israel.

Outcome measures: Appropriate.

Intercentre variability: NA

Conflict of interests: NR.

\begin{tabular}{|c|c|c|c|}
\hline $\begin{array}{l}\text { Reference and } \\
\text { design }\end{array}$ & Intervention & Participants & Outcome measures \\
\hline $\begin{array}{l}\text { Authors: } \\
\text { Dagdelen et al. }{ }^{17,18 a} \\
\text { Year: } 2002\left(2003^{a}\right) \\
\text { Country: Turkey } \\
\text { Study design: RCT } \\
\text { Number of centres: } \\
\text { NR (assumed one) } \\
\text { Funding: Not stated }\end{array}$ & $\begin{array}{l}\text { Interventions: } \\
\text { I: Intravenous } \\
\text { magnesium sulphate } \\
\text { 2: Control (not } \\
\text { reported as placebo) } \\
\text { Intervention details: } \\
\text { I: I. } 5 \mathrm{~g} \text { day } \\
\text { magnesium sulphate } \\
\text { in } 100 \mathrm{ml} \text { of } 0.9 \% \\
\text { sodium chloride } \\
\left(25 \mathrm{ml} \mathrm{h}^{-1}\right) \text { I day } \\
\text { before CPB, just } \\
\text { after } \mathrm{CPB} \text { surgery } \\
\text { and then once daily } \\
\text { for } 4 \text { days after CPB } \\
\text { 2: } 100 \mathrm{ml}^{-} \text {of } 0.9 \% \\
\text { sodium chloride } \\
\left(25 \mathrm{ml} \mathrm{h}^{-1} \text { ) at the }\right. \\
\text { same time-points as } \\
\text { in the magnesium } \\
\text { sulphate group }\end{array}$ & $\begin{array}{l}\text { Number of participants: } \\
\text { Intervention: } 93 \\
\text { Control: } 55 \\
\text { Sample attrition/dropout: } \\
\text { NR } \\
\text { Inclusion criteria for study entry: Patients } \\
\text { scheduled for elective, first time, isolated CABG } \\
\text { (no other details) } \\
\text { Exclusion criteria for study entry: } \\
\text { Patients with AF, a past history of AF, heart valve } \\
\text { disease, diabetes, chronic renal disease, thyroid } \\
\text { disorders and/or COPD; cardiomyopathy, } \\
\text { congenital heart disease, congestive heart failure, } \\
\text { pericarditis, pulmonary embolism, pre-excitation } \\
\text { syndromes, sick sinus syndrome, complete } \\
\text { bundle branch block, atrioventricular block, and } \\
\text { patients receiving antiarrhythmic drugs, digoxin } \\
\text { and/or } \beta \text {-blocking agents } \\
\text { Baseline characteristics of subjects: } \\
\text { Mean } \pm \text { SD age (years): } \\
\text { Intervention: } 62.5 \pm 7.0 \\
\text { Control: } 6 I .3 \pm 7.0 \text {; difference ns } \\
\text { Gender (M/F) (n): Intervention: } 93 / 21 \\
\text { Control: } 43 / I 2 \text {; difference: ns } \\
\text { Preoperative heart rate, magnesium } \\
\text { concentration, QRS interval duration, PQ } \\
\text { interval duration, P wave maximum, } P \text { wave } \\
\text { minimum, and P wave dispersion did not differ } \\
\text { significantly between groups (data not extracted) }\end{array}$ & $\begin{array}{l}\text { AF outcome(s): Incidence } \\
\text { of AF after CABG } \\
\text { Other outcomes (data not } \\
\text { extracted): Heart rate; } \\
\text { magnesium } \\
\text { concentration. Also ECG } \\
\text { characteristics of QRS, } \\
\text { PQ intervals and P wave } \\
\text { Adverse symptoms: NR } \\
\text { Length of follow-up: } \\
4 \text { days after CABG } \\
\text { surgery } \\
\text { Recruitment dates: NR }\end{array}$ \\
\hline \multicolumn{4}{|c|}{${ }^{a}$ Dagdelen et al. $(2003)^{18}$ is a brief summary of the same data. } \\
\hline
\end{tabular}




\section{Results}

AF outcome Intervention $(n=93) \quad$ Control $(n=55) \quad$ Difference

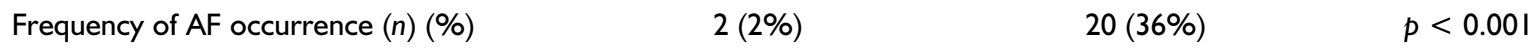

\section{Other outcomes \\ Outside scope of assessment: data not extracted}

\section{Methodological comments}

Allocation to treatment groups: Stated that this was randomised, but no details provided.

Blinding: Control group patients received the same doses and times of saline solution administration as the intervention group, but without magnesium; cardiologist reading ECGs was blinded.

Comparability of treatment groups: No notable differences.

Method of data analysis:

- Stated that demographic and clinical variables as well as the incidence of AF were analysed using the $\chi^{2}$-test or Fisher's exact test for categorical variables and paired or unpaired $t$-tests for continuous variables. However, the results presented do not indicate in which cases each of these tests was applied, nor whether the data satisfied assumptions of normality.

- Overall, statistical tests were not supported by any hypotheses.

Sample size/power calculation: NR.

Attrition/dropout: NR.

\section{General comments}

Generalisability: No details of ethnicity; limited information on social background; single-location study in Turkey.

Outcome measures: Appropriate, but note that 12-lead Holter ECG was only used for reactive, not continuous, monitoring (authors discuss whether this might have missed some cases of AF).

Intercentre variability: NA.

Conflict of interests: None reported. 


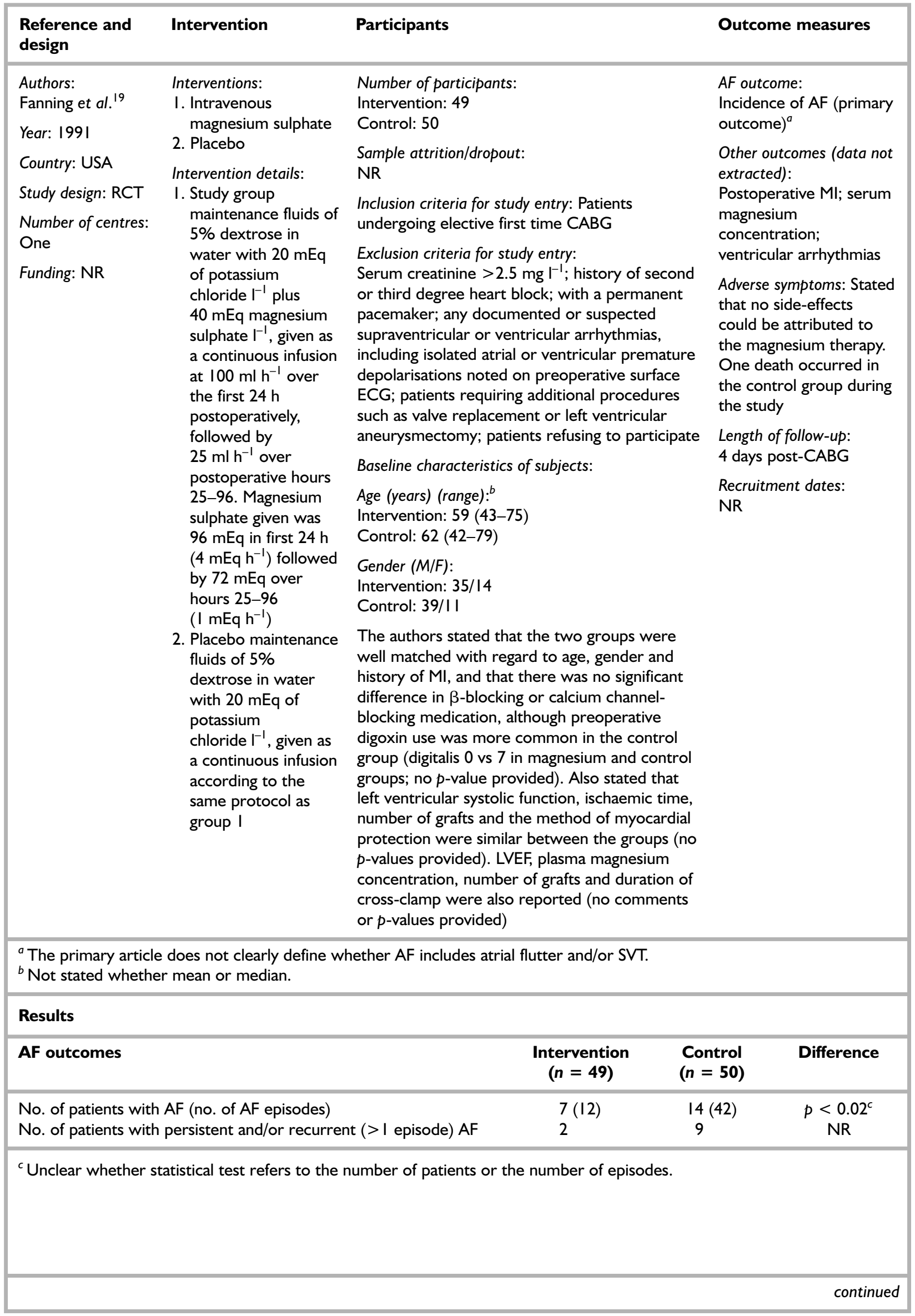




\section{Other outcomes Outside scope of assessment: data not extracted}

\section{Methodological comments}

Allocation to treatment groups: Stated that patients were randomised, but no details were provided.

Blinding: Stated that: (I) all patients received the intervention or placebo in a double-blind fashion (no details); (2) the patient's physicians were not blinded to the results of serum magnesium testing but no patient received additional magnesium therapy.

Comparability of treatment groups: Preoperative digoxin and diuretic use was more frequent in the control group; other baseline variables were similar between the groups (reported narratively; no $p$-values provided).

Method of data analysis:

- The incidence of postoperative arrhythmias was analysed for group differences using a two-sided $\chi^{2}$ analysis.

- Mean serum magnesium levels and the mean number of episodes of arrhythmias between groups were analysed using a paired or two-sample $t$-test where appropriate.

- Presentation of results did not indicate which tests were actually used for each outcome; normality of outcomes was not reported.

Sample size/power calculation: NR.

Attrition/dropout: NR.

\section{General comments}

Generalisability: No details of ethnicity or social background; single-location study in USA.

Outcome measures: Appropriate, but note ambiguous definition of AF (see above).

Intercentre variability: NA.

Conflict of interests: None reported.

\begin{tabular}{|c|c|c|c|}
\hline $\begin{array}{l}\text { Reference and } \\
\text { design }\end{array}$ & Intervention & Participants & Outcome measures \\
\hline $\begin{array}{l}\text { Authors: } \\
\text { Forlani et al. }{ }^{20,21 a} \\
\text { Year: } 2002\left(2003^{a}\right) \\
\text { Country: Italy } \\
\text { Study design: RCT } \\
\text { Number of centres: } \\
\text { NR (assumed one) } \\
\text { Funding: NR }\end{array}$ & $\begin{array}{l}\text { Interventions: } \\
\text { I. Intravenous } \\
\text { magnesium sulphate } \\
\text { 2. Control } \\
\text { 3. Oral sotalol } \\
\text { 4. Intravenous } \\
\text { magnesium sulphate } \\
\text { + oral sotalol } \\
\text { Intervention details: } \\
\text { I. I.5 g ( } 12 \text { mEq) i.v. } \\
\text { magnesium sulphate } \\
\text { daily, starting just } \\
\text { before CPB until } \\
5 \text { days postoperation } \\
\text { 2. No drug } \\
\text { 3. } 80 \text { mg sotalol given } \\
\text { orally twice daily } \\
\text { from I day to } 5 \text { days } \\
\text { postoperation, then } \\
40 \text { mg orally twice } \\
\text { daily for } 4 \text { weeks } \\
\text { 4. A combination of } \\
\text { magnesium sulphate } \\
\text { and sotalol in the } \\
\text { same dosages as } \\
\text { groups I and } 3\end{array}$ & 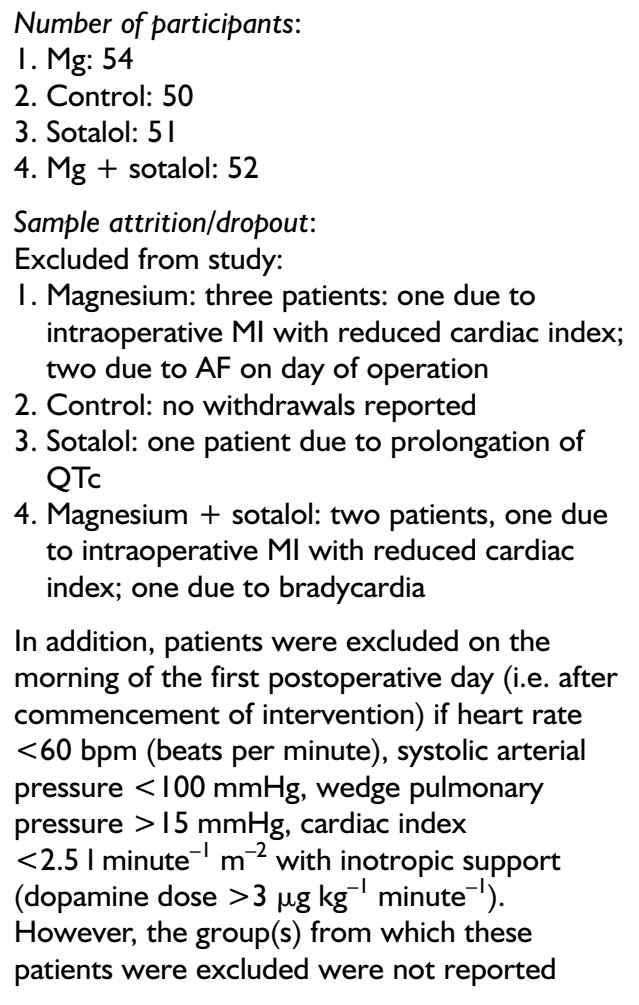 & $\begin{array}{l}\text { AF outcomes: } \\
\text { Incidence, and time to } \\
\text { onset, of AF } \\
\text { Other outcomes } \\
\text { extracted: } \\
\text { Postoperative length of } \\
\text { stay } \\
\text { Other outcomes (data not } \\
\text { extracted): } \\
\text { Heart rate during AF; } \\
\text { serum magnesium } \\
\text { concentration } \\
\text { Adverse symptoms: } \\
\text { One patient in the } \\
\text { magnesium group died } \\
\text { of a pulmonary } \\
\text { embolism } 5 \text { days after } \\
\text { operation. One patient } \\
\text { in the magnesium group } \\
\text { and one in the } \\
\text { magnesium + sotalol } \\
\text { group (both excluded) } \\
\text { had intraoperative MI } \\
\text { with reduced cardiac } \\
\text { index. Sotalol was } \\
\text { cautiously discontinued }\end{array}$ \\
\hline
\end{tabular}




\begin{tabular}{|c|c|c|}
\hline $\begin{array}{l}\text { Reference and } \\
\text { design }\end{array}$ & Intervention & Participants \\
\hline & & $\begin{array}{l}\text { Inclusion criteria for study entry: Patients } \\
\text { undergoing first time isolated CABG with CPB }\end{array}$ \\
\hline & & $\begin{array}{l}\text { Exclusion criteria for study entry: } \\
\text { Patients with preoperative ejection fraction } \\
<0.40 \text {, sick sinus syndrome and atrioventral } \\
\text { node disease, a corrected QT interval }>440 \mathrm{~ms} \text {; } \\
\text { preoperative use of antiarrhythmic drugs, with } \\
\text { the exception of } \beta \text {-blockers; history of SVA, } \\
\text { severe COPD, serum creatinine levels } \\
>2.0 \mathrm{mg} \mathrm{dl}^{-1}\end{array}$ \\
\hline & & Baseline characteristics of subjects: \\
\hline & & $\begin{array}{l}\text { Mean } \pm \text { SD age (years): } \\
\text { I. Mg: } 64 \pm 7 \\
\text { 2. Control: } 64 \pm 9 \\
\text { 3. Sotalol: } 64 \pm 10 \\
\text { 4. Mg+ sotalol: } 62 \pm 11\end{array}$ \\
\hline & & $\begin{array}{l}\text { Gender }(\% M) \text { : } \\
\text { I. Mg: } 85 \% \\
\text { 2. Control: } 88 \% \\
\text { 3. Sotalol: } 82 \% \\
\text { 4. Mg+ sotalol: } 91 \%\end{array}$ \\
\hline & & $\begin{array}{l}\text { With reference to } 18 \text { listed variables, the } \\
\text { authors stated that preoperative and } \\
\text { intraoperative variables did not differ significantly } \\
\text { among the four groups (SD provided for six of } \\
\text { these variables) }\end{array}$ \\
\hline
\end{tabular}

Outcome measures

3 days postoperation in two patients (both excluded) due to bradycardia (one patient in magnesium + sotalol group) and prolongation of QTc (one patient in sotalol group). The authors reported that there were no noted proarrhythmic effects of magnesium, sotalol or magnesium + sotalol

Length of follow-up: End-point of study was considered any $\mathrm{AF}$ episode that required treatment for symptoms or haemodynamic deterioration from I day to I month postoperation. Interventions were administered for 5 days postoperation

Recruitment dates: January to July 200I

${ }^{a}$ Forlani et al. $(2003)^{21}$ is a brief summary of the same data.

\section{Results}

\begin{tabular}{|c|c|c|c|c|c|}
\hline AF Outcomes & $\begin{array}{c}\mathrm{I} . \mathrm{Mg} \\
(n=54)\end{array}$ & $\begin{array}{l}\text { 2. Control } \\
(n=50)\end{array}$ & $\begin{array}{l}\text { 3. Sotalol } \\
(n=5 I)\end{array}$ & 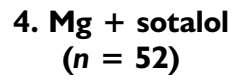 & Difference \\
\hline \multirow[t]{3}{*}{ Incidence of AF, $n(\%)$} & $8(14.8 \%)$ & $19(38 \%)$ & $6(11.8 \%)$ & I (I.9\%) & $\begin{array}{l}\text { Versus control: } \\
\text { I. } p=0.007 \\
\text { 3. } p=0.002 \\
\text { 4. } p<0.000 \text { I }\end{array}$ \\
\hline & & & & & $\begin{array}{l}\text { Versus } M g+\text { sotalol: } \\
\text { I. } p=0.0 \mathrm{I} \\
\text { 3. } p=0.04\end{array}$ \\
\hline & & & & & $\begin{array}{l}\text { Mg versus sotalol: } \\
p>0.05(\mathrm{~ns})^{a}\end{array}$ \\
\hline $\begin{array}{l}\text { Mean } \pm S D \text { time (days } \\
\text { postoperation) to onset of } A F\end{array}$ & $2.4 \pm 1.4$ & $2.3 \pm 0.8$ & $2.0 \pm 1.6$ & $2.0 \pm 0.0$ & $p>0.05(\mathrm{~ns})^{a}$ \\
\hline
\end{tabular}

${ }^{a}$ Inferred by reviewers (not directly reported). 


\begin{tabular}{|c|c|c|c|c|c|}
\hline Other outcomes & $\begin{array}{c}\mathrm{I} . \mathrm{Mg} \\
(n=54)\end{array}$ & $\begin{array}{l}\text { 2. Control } \\
(n=50)\end{array}$ & $\begin{array}{l}\text { 3. Sotalol } \\
(n=5 I)\end{array}$ & 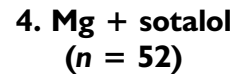 & Difference \\
\hline \multirow[t]{2}{*}{$\begin{array}{l}\text { Mean } \pm \text { SD length of stay } \\
\text { (days postoperation) }\end{array}$} & $5.7 \pm 0.9$ & $5.9 \pm 1.7$ & $5.6 \pm 1.4$ & $5.2 \pm 1.3$ & $\begin{array}{l}\text { Versus control: } \\
\text { 4. } p=0.02\end{array}$ \\
\hline & & & & & $\begin{array}{l}\text { All other pairwise } \\
\text { comparisons: } \\
p>0.05(n s)^{b}\end{array}$ \\
\hline \multicolumn{6}{|c|}{${ }^{b}$ Inferred by reviewers (not directly reported). } \\
\hline \multicolumn{6}{|c|}{$\begin{array}{l}\text { Methodological comments } \\
\text { Allocation to treatment groups: Stated that patients were randomised to the study groups according to a computer-generated } \\
\text { random code. }\end{array}$} \\
\hline \multicolumn{6}{|l|}{ Blinding: NR. } \\
\hline \multicolumn{6}{|c|}{$\begin{array}{l}\text { Comparability of treatment groups: Authors stated that preoperative and intraoperative measurements did not differ } \\
\text { significantly among the four groups of patients. }\end{array}$} \\
\hline \multicolumn{6}{|c|}{$\begin{array}{l}\text { Method of data analysis: } \\
\text { - Comparisons of continuous or discrete variables between the four groups were performed using an unpaired St } \\
\text { - } \text {-test or a } \chi^{2} \text { test, respectively. } \\
\text { Other analyses were also carried out for comparisons outside the scope of this assessment, including stepwise lo } \\
\text { regression to investigate predictors of AF (data not extracted). }\end{array}$} \\
\hline \multicolumn{6}{|c|}{ Sample size/power calculation: NR. } \\
\hline \multicolumn{6}{|c|}{$\begin{array}{l}\text { Attrition/dropout: Stated that all analyses were performed according to the ITT principle (ITT not defined). Patients excluded } \\
\text { owing to AF, MI or related arrhythmia were described, but it is unclear whether these patients were also excluded from the } \\
\text { analyses (if so, also unclear how the missing data were treated). Other patients were excluded after CABG if haemodynamic } \\
\text { criteria were not met, but the numbers and identities of these patients were not reported. Accordingly, there is } \\
\text { considerable doubt as to the final composition of the analysed populations. }\end{array}$} \\
\hline \multicolumn{6}{|c|}{$\begin{array}{l}\text { Generalisability: No details of ethnicity or social background; assumed single-location study in Italy. Following the oral } \\
\text { presentation of this paper at the 38th Annual Meeting of the Society of Thoracic Surgeons, limited generalisability of the } \\
\text { findings due to the highly-selected patient population was noted. }\end{array}$} \\
\hline \multicolumn{6}{|c|}{ Outcome measures: Appropriate. } \\
\hline \multicolumn{6}{|l|}{ Intercentre variability: NA } \\
\hline \multicolumn{6}{|c|}{ Conflict of interests: None reported. } \\
\hline
\end{tabular}




\begin{tabular}{|c|c|c|c|}
\hline $\begin{array}{l}\text { Reference and } \\
\text { design }\end{array}$ & Intervention & Participants & Outcome measures \\
\hline $\begin{array}{l}\text { Authors: } \\
\text { Hazelrigg et al. }{ }^{22} \\
\text { Year: } 2004 \\
\text { Country: USA } \\
\text { Study design: RCT } \\
\text { Number of centres: } \\
\text { one (comprising } \\
\text { two hospitals) } \\
\text { Funding: } \\
\text { Part-funded by } \\
\text { Southern Illinois } \\
\text { University School of } \\
\text { Medicine, Central } \\
\text { Research } \\
\text { Committee grant }\end{array}$ & $\begin{array}{l}\text { Interventions: } \\
\text { I. Intravenous } \\
\text { magnesium sulphate } \\
\text { 2. Control } \\
\text { Intervention details: } \\
\text { I. } 80 \mathrm{mg} \mathrm{kg}^{-1} \text { (ideal } \\
\text { body weight) of } \\
\text { magnesium sulphate } \\
\text { administered in } \\
100 \mathrm{ml} \mathrm{D}_{5} \mathrm{~W} \text { over a } \\
30-\text { minute period } \\
\text { before CPB. } \\
\text { Thereafter, } \\
8 \text { mg kg- (ideal } \\
\text { body weight) per } \\
\text { hour magnesium } \\
\text { sulphate i.v. infusion } \\
\text { in } 100 \mathrm{ml} \mathrm{D}_{5} \mathrm{~W} \\
\text { continued for } 48 \mathrm{~h} \\
\text { 2. } 100 \mathrm{ml} \text { of } \mathrm{D}_{5} \mathrm{~W} \\
\text { pre- } \mathrm{CPB} \text { and I } 00 \mathrm{ml} \\
\text { of } \mathrm{D} 5 \mathrm{~W} \text { for } 48 \mathrm{~h} \\
\text { post-CPB according } \\
\text { to same schedule as } \\
\text { intervention group }\end{array}$ & 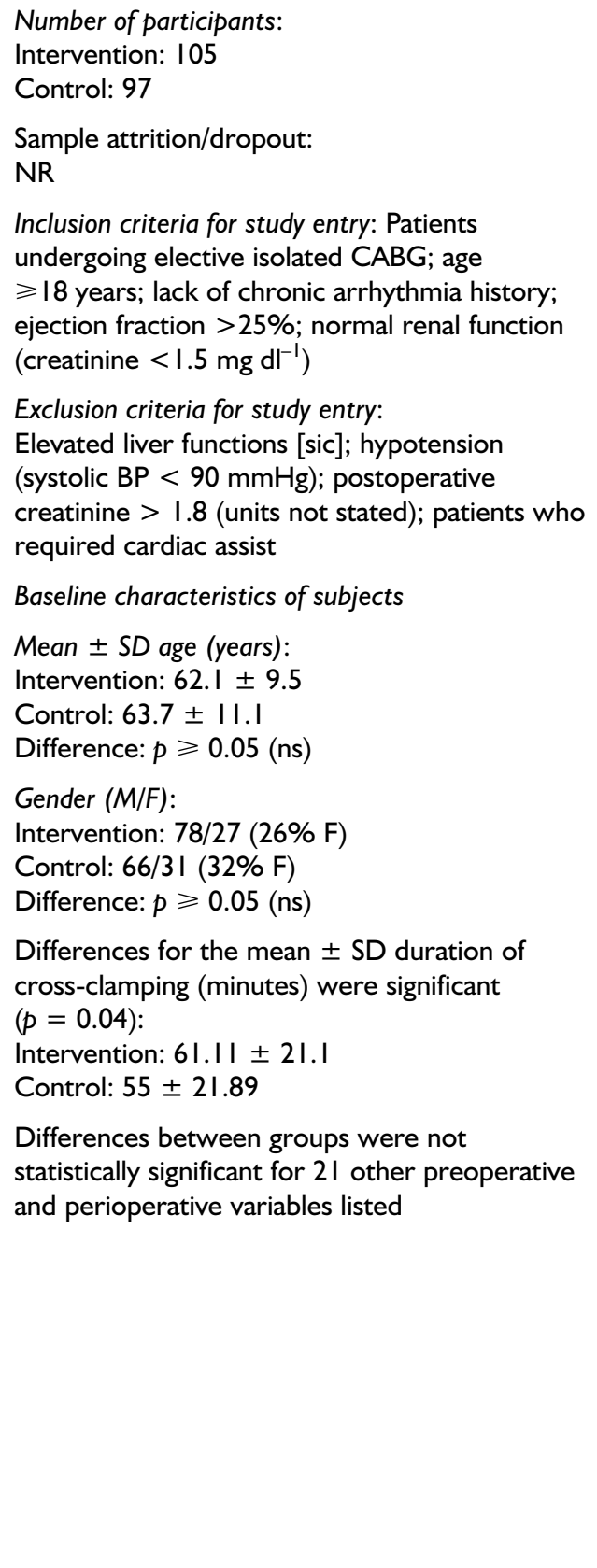 & $\begin{array}{l}\text { AF outcome: } \\
\text { Incidence of AF (primary } \\
\text { outcome) } \\
\text { Method of assessing AF } \\
\text { outcome: } \\
\text { NR } \\
\text { Other extracted } \\
\text { outcomes: } \\
\text { Length of stay in ICU; } \\
\text { length of stay in hospital } \\
\text { Other outcomes (data not } \\
\text { extracted): Incidence of } \\
\text { atrial flutter; incidence of } \\
\text { frequent/multifocal } \\
\text { premature ventricular } \\
\text { contraction; ventricular } \\
\text { tachycardia; ventricular } \\
\text { fibrillation; mean arterial } \\
\text { pressure, BP and other } \\
\text { haemodynamic variables; } \\
\text { serum, urine and tissue } \\
\text { electrolyte } \\
\text { concentrations } \\
\text { Adverse symptoms: } \\
\text { Ventricular tachycardia } \\
\text { occurred in significantly } \\
\text { more control patients } \\
\text { (details below); urine } \\
\text { magnesium and calcium } \\
\text { excretion were } \\
\text { significantly higher in the } \\
\text { intervention group } \\
\text { (details below); death } \\
\text { occurred in one and } \\
\text { two patients in } \\
\text { intervention and control } \\
\text { groups, respectively } \\
\text { ( } \geqslant \geqslant 0.05, \text { ns) } \\
\text { Length of follow-up: } \\
5 \text { days after operation } \\
\text { Recruitment dates: } \\
\text { Over a 5-year period } \\
\text { (dates not reported) }\end{array}$ \\
\hline
\end{tabular}




\begin{tabular}{|l|}
\hline Results \\
\hline AF outcomes \\
Interv \\
No. of patients with AF \\
Operative \\
0 days postoperative \\
I day postoperative \\
2 days postoperative \\
3 days postoperative \\
4 days postoperative \\
5 days postoperative \\
Total
\end{tabular}

Specific $p$-values were not provided.

\begin{tabular}{|lccl}
\hline Other outcomes & $\begin{array}{c}\text { Intervention } \\
(\boldsymbol{n}=\mathbf{1 0 5})\end{array}$ & $\begin{array}{c}\text { Control } \\
(\boldsymbol{n}=\mathbf{9 7})\end{array}$ & Difference \\
\hline Mean \pm SD length of ICU stay (days) & $1.33 \pm 0.72$ & $1.36 \pm 1.4$ & $p \geqslant 0.05$ (ns) \\
Mean \pm SD length of hospital stay (days) & $6.65 \pm 3.27$ & $6.96 \pm 4.98$ & $p \geqslant 0.05$ (ns)
\end{tabular}

Specific $p$-values were not provided.

\section{Methodological comments}

Allocation to treatment groups: Pharmacy staff randomised patients to the interventions using a randomisation table created by a statistician (no other details).

Blinding: The patients and those caring for them were blinded to the randomisation arm [sic].

Comparability of treatment groups: No notable differences, except that mean cross-clamp time was significantly $(\sim 5$ minutes) longer in the magnesium sulphate group $(p=0.04)$.

Method of data analysis:

- A $2 \times 2 \chi^{2}$ test was used to compare incidence of AF between the groups.

- For other comparisons between the groups, $\chi^{2}$ tests, a Fisher's exact test for categorised variables, and an independentgroups $t$-test for continuous variables were used. However, the results presented do not indicate in which cases each of these tests was applied, nor whether the data satisfied assumptions of normality.

- Overall, statistical tests were not supported by any hypotheses.

Sample size/power calculation: Stated that, based on the incidence of arrhythmias after CABG (data source not reported), 100 patients per group would assure detecting an effect of supplemental magnesium that reduced arrhythmias by half, with power 0.80 and $\alpha=0.05$ (two-sided).

Attrition/dropout: NR.

\section{General comments}

Generalisability: No details of ethnicity or social background; single-location study in USA.

Outcome measures: Appropriate.

Intercentre variability: NA.

Conflict of interests: None reported.

BP, blood pressure. 


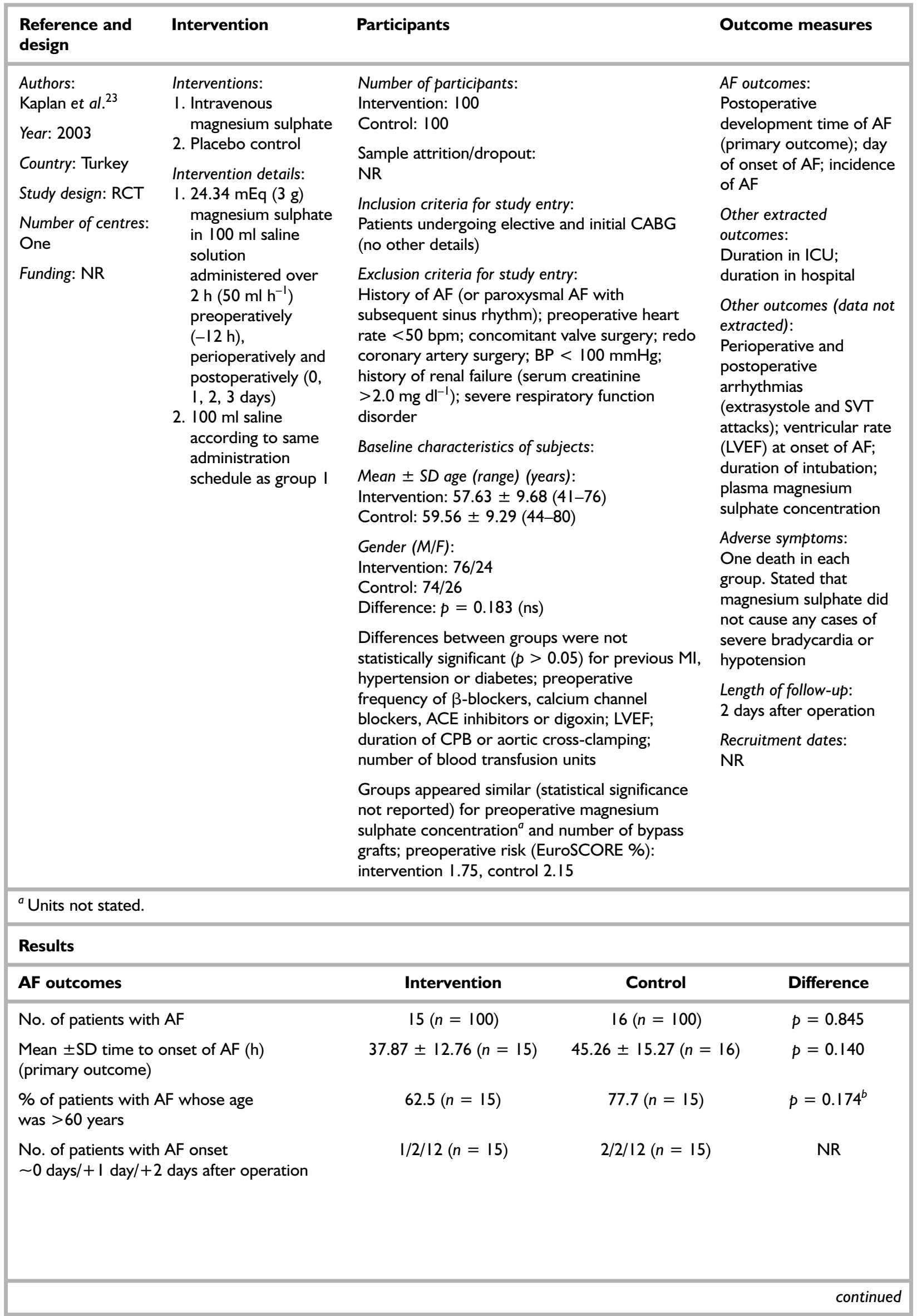




\begin{tabular}{|c|c|c|c|}
\hline Other outcomes & Intervention $(n=100)$ & Control $(n=100)$ & Difference \\
\hline Mean \pm SD length of ICU stay $(h)$ & $22.40 \pm 4.79$ & $23 \pm 4.46$ & $p=0.650$ \\
\hline Mean \pm SD length of hospital stay (days) ${ }^{c}$ & $5.16 \pm 1.18^{c}$ & $5.67 \pm 1.3 I^{c}$ & $p=0.004^{c}$ \\
\hline $\begin{array}{l}\text { Mean } \pm \text { SD length of hospital stay (days) } \\
\text { in patients with AF }\end{array}$ & $6.0 \pm 1.2\left(n=15^{d}\right)$ & $6.31 \pm 0.87\left(n=16^{d}\right)$ & $p=0.410$ \\
\hline \multicolumn{4}{|c|}{$\begin{array}{l}{ }^{b} \text { This } p \text {-value is assumed by the reviewers to refer to the difference between interventions (meaning not stated in the } \\
\text { primary article). } \\
\text { c It is unclear whether these data refer to the total population (with AF + without AF) or the cohort without AF } \\
\text { (accordingly, the appropriate } n \text {-value is also unclear). } \\
{ }_{n} \text {-Values were not reported here, but are assumed by the reviewers to include all patients with AF. }\end{array}$} \\
\hline \multicolumn{4}{|c|}{$\begin{array}{l}\text { Methodological comments } \\
\text { Allocation to treatment groups: stated random; no further details. }\end{array}$} \\
\hline \multicolumn{4}{|c|}{$\begin{array}{l}\text { Blinding: Stated that only } 100 \mathrm{ml} \text { of saline was administered to the control group for the placebo effect (no other details } \\
\text { reported). }\end{array}$} \\
\hline \multicolumn{4}{|c|}{ Comparability of treatment groups: No notable significant differences. } \\
\hline \multicolumn{4}{|c|}{$\begin{array}{l}\text { Method of data analysis: } \\
\text { - Independent samples } t \text {-test for comparing mean durations of hospitalisation. } \\
\text { - Fisher's exact test for comparing ratios of atrial extrasystole and SVT in treatment and control groups (interpretation } \\
\text { ambiguous). } \\
\text { - Mann-Whitney U-test for comparing numbers of patients with/without AF (unequal } n \text { precluded } t \text {-test). } \\
\text { - Pearson } \chi^{2} \text { test for effects of interventions on time to onset of AF and for age differences in incidence of AF. } \\
\text { - Binary logistic regression used to evaluate the importance of baseline risk factors on incidence of AF (data not extracted; } \\
\text { all } p \text {-values ns). } \\
\text { - Multivariate linear regression to investigate correlation between heart rate and serum magnesium sulphate concentration } \\
\text { (data not extracted; } p=0.158) \text {. }\end{array}$} \\
\hline \multicolumn{4}{|l|}{ Sample size/power calculation: NR. } \\
\hline \multicolumn{4}{|l|}{ Attrition/dropout: NR. } \\
\hline $\begin{array}{l}\text { General comments } \\
\text { Generalisability: No details of ethnicity or s } \\
\text { Outcome measures: Appropriate. } \\
\text { Intercentre variability: NA. } \\
\text { Conflict of interests: None reported. }\end{array}$ & background; single-location & dy in USA. & \\
\hline
\end{tabular}




\begin{tabular}{|c|c|}
\hline $\begin{array}{l}\text { Reference and } \\
\text { design }\end{array}$ & Intervention \\
\hline $\begin{array}{l}\text { Authors: } \\
\text { Karmy-Jones et al. }{ }^{24} \\
\text { Year: I995 } \\
\text { Country: Canada } \\
\text { Study design: RCT } \\
\text { Number of centres: } \\
\text { One (assumed by } \\
\text { the reviewers) } \\
\text { Funding: NR }\end{array}$ & $\begin{array}{l}\text { Interventions: } \\
\text { I. Intravenous } \\
\text { magnesium sulphate } \\
\text { 2. Placebo control } \\
\text { Intervention details: } \\
\text { I. Six doses of } 2.4 \mathrm{~g} \\
\text { ( } 19.2 \mathrm{mEq}) \\
\text { magnesium sulphate } \\
\text { i.v. in the first } \\
24 \mathrm{~h} \text { after the } \\
\text { cardiac operation. } \\
\text { Total dosage: } 14.4 \mathrm{~g} \\
\text { ( } 115 \text { mEq). First } \\
\text { dose: magnesium } \\
\text { sulphate in } 50 \mathrm{ml} \text { of } \\
\mathrm{D}_{5} \mathrm{~W} \text { over } \\
20 \mathrm{minutes} \text { at the } \\
\text { termination of } \mathrm{CPB} \text {; } \\
\text { further } 5 \text { doses: the } \\
\text { same dosage every } \\
4 \mathrm{~h} \\
\text { 2. } 50 \text { ml } \mathrm{D}_{5} \mathrm{~W} \text { at the } \\
\text { same time-points as } \\
\text { group I }\end{array}$ \\
\hline
\end{tabular}

Participants

Outcome measures

Number of participants:

Intervention: 46

Control: 54

Sample attrition/dropout:

NR

Inclusion criteria for study entry:

Patients who were undergoing elective coronary artery bypass, valve replacement/repair, or a combination of these; enrolled after informed consent was obtained. 39 patients (84.8\%) in intervention group and 47 patients in control group $(87.0 \%)$ were undergoing CABG. One patient in intervention group and two patients in control were undergoing combined procedure

Exclusion criteria for study entry:

Abnormal renal function, reoperation, emergency operation, evidence of ongoing ischaemia (angina, ST changes), use of medications to control dysrhythmias, and inability to obtain informed consent

Baseline characteristics of subjects:

Mean $\pm S D$ age (years):

Intervention: $64.5 \pm 7.9$

Control: $60.2 \pm 11.9$

Gender (M/F) (n):

Intervention: $28 / 18$

Control: $38 / 16$

Authors noted that the magnesium group was significantly older ( $p=0.036$ reported) and that there were no significant differences in other baseline characteristics between groups (mean \pm SD but not $p$-values reported): preoperative calcium channel blocker, $\beta$-blocker, diuretics, digoxin; COPD; diabetes; prior Ml; history of dysrhythmia: supraventricular or ventricular, palpitations; NYHA class; Canadian Cardiovascular Society class; ejection fraction; number of vein grafts; cross-clamp time; $C P B$ time
AF outcome:

Not reported directly; however, incidence of $\mathrm{AF}$ inferred from the incidence of SVAs (of which $92 \%$ overall were $\mathrm{AF})$

Other extracted outcomes:

Length of hospital stay (days); length of stay at ICU (h)

Other outcomes (data not extracted):

Ventilator hours (mean $\pm \mathrm{SD}$ ); number of patients with ventilator hours $>24 \mathrm{~h}$; cardiac performance after CABG (cardiac index, left ventricular stroke work index, stroke volume index); patients with inotropes, intraaortic balloon pump, pacing and/or ischaemia; ventricular and supraventricular arrhythmias (and Lown grades); MB isoenzyme of creatine kinase and serum magnesium concentrations

Adverse symptoms: There were two deaths in the placebo group, one caused by multiple organ failure and the other caused by ventricular fibrillation. Over the whole hospital stay, six types of ventricular tachycardia and two classes of ischaemia were each significantly more frequent in placebo than magnesium group (various $p$-values) Postoperative ST segment elevation was significantly less frequent in the magnesium group. Postoperative creatinine kinase concentration was significantly lower in the magnesium group 


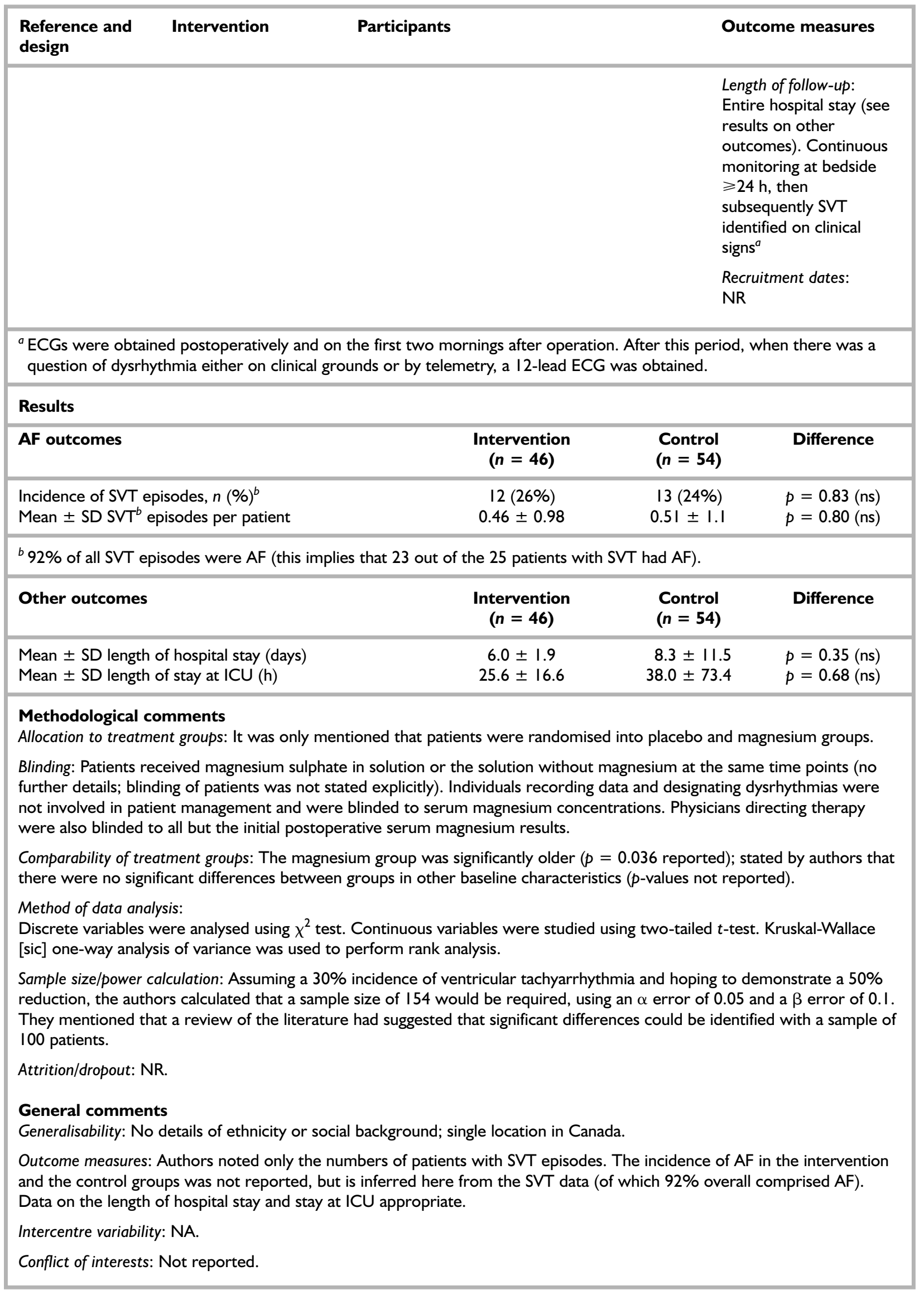




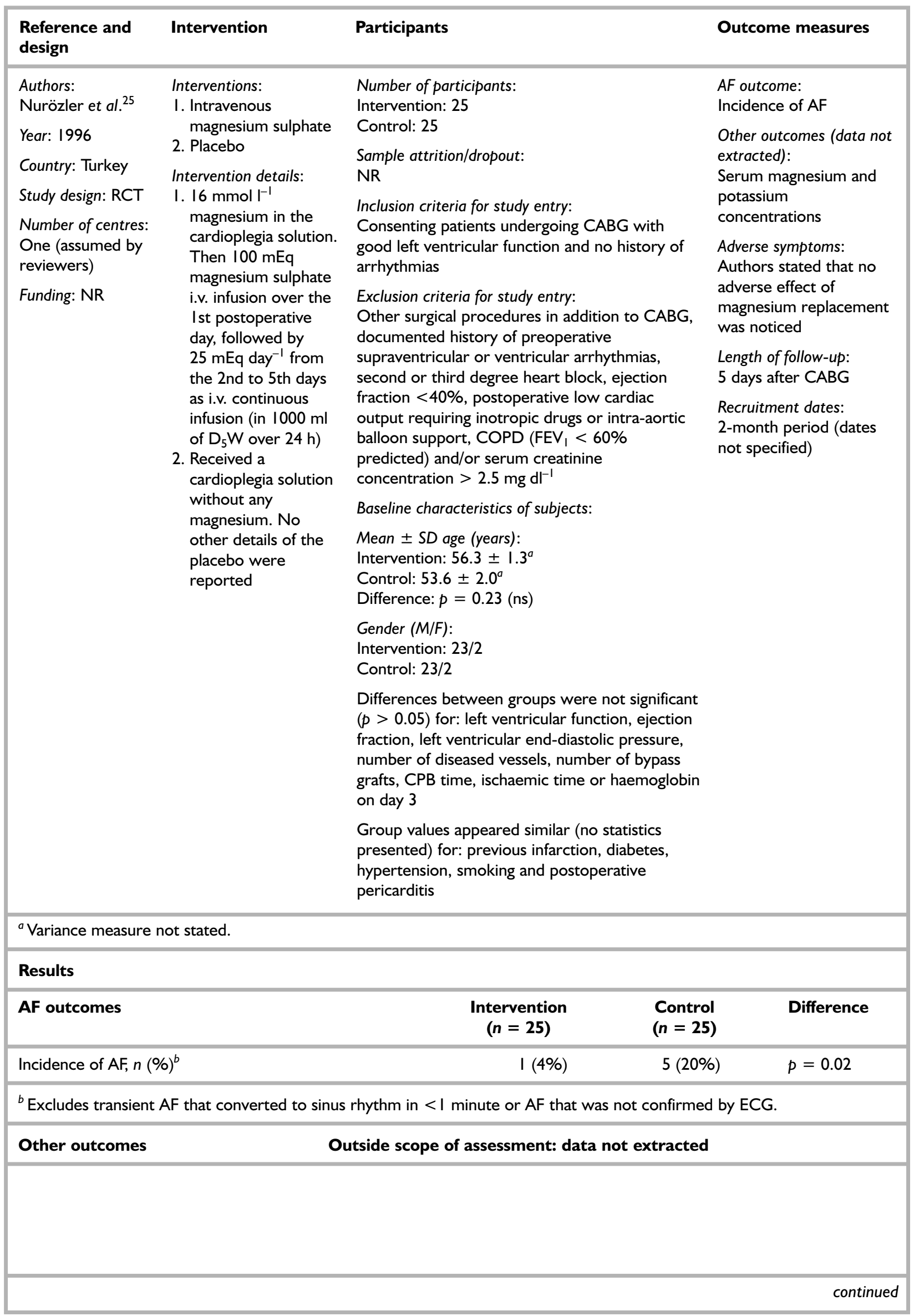




\section{Methodological comments}

Allocation to treatment groups: Stated that patients were randomised, but no details of the procedure were given.

Blinding: Stated that the design was double-blind, but no details were given.

Comparability of treatment groups: Stated that there were no differences in clinical, angiographic and surgical characteristics between the two groups; where $p$-values were provided (for six continuous variables) they were not significant $(p>0.05)$.

Method of data analysis:

- $\chi^{2}$ test was used to analyse differences in proportions.

- Multiple logistic regression and analysis of variance were also used, but address questions outside the scope of this assessment (data not extracted).

- Statistical tests were not supported by hypotheses; normality of data was not reported.

Sample size/power calculation: NR.

Attrition/dropout: NR.

\section{General comments}

Generalisability: No details of ethnicity or social background; single-location study in Turkey.

Outcome measures: Appropriate.

Intercentre variability: NA.

Conflict of interests: None reported.

FEV , forced expiratory volume in I second.

\begin{tabular}{|c|c|c|c|}
\hline $\begin{array}{l}\text { Reference and } \\
\text { design }\end{array}$ & Intervention & Participants & Outcome measures \\
\hline $\begin{array}{l}\text { Authors: } \\
\text { Parikka et al. }{ }^{26} \\
\text { Year: } 1993 \\
\text { Country: Finland } \\
\text { Study design: RCT } \\
\text { Number of centres: } \\
\text { One (assumed by } \\
\text { reviewers) } \\
\text { Funding: Finnish } \\
\text { Heart Foundation, } \\
\text { Helsinki }\end{array}$ & $\begin{array}{l}\text { Interventions: } \\
\text { I. Intravenous } \\
\text { magnesium sulphate } \\
\text { 2. Placebo control } \\
\text { Intervention details: } \\
\text { I. Two doses of } \\
\text { magnesium sulphate: } \\
\text { - } 40 \mathrm{mmol}^{-1} \text { of } 5 \% \\
\text { glucose-in-water } \\
\text { solution during the } \\
\text { first } 24 \mathrm{~h} \text { after the } \\
\text { infusion (the } \\
\text { infusion was } \\
\text { started within } 2 \mathrm{~h} \\
\text { of the operation) } \\
\text { - } 30 \text { mmol } 500 \mathrm{ml} \mathrm{I}^{-1} \\
\text { of the solution } \\
\text { during the next } \\
24 \mathrm{~h} \\
\text { 2. The same as in the } \\
\text { intervention: } 5 \% \\
\text { glucose-water } \\
\text { solution without } \\
\text { magnesium }\end{array}$ & $\begin{array}{l}\text { Number of participants: } \\
\text { Intervention: } 69 \\
\text { Control: } 7 \text { I } \\
\text { Sample attrition/dropout: } \\
\text { In the final postoperative analysis the number of } \\
\text { patients in the control group was } 70 \text {. One } \\
\text { patient died on the first postoperative day } \\
\text { because of graft occlusion and consequent } \\
\text { perioperative infarction } \\
\text { Inclusion criteria for study entry: Consecutive } \\
\text { patients, who had had their first CABG } \\
\text { Exclusion criteria for study entry: Patients with } \\
\text { chronic AF, concomitant valve replacement and } \\
\text { antiarrhythmic medication } \\
\text { Baseline characteristics of subjects: } \\
\text { Mean age (mean }+ \text { SD) (years): } \\
\text { Intervention: } 57 \pm 8 \\
\text { Control: } 54 \pm 8 \\
\text { Authors noted that the magnesium group was } \\
\text { older, } p=0.032 \text { (ns) } \\
\text { Gender (proportion of males, \%) } \\
\text { Intervention: } 84 \% \\
\text { Control: } 82 \% \\
\text { Difference: ns } \\
\text { Authors stated that prior AF episodes were } \\
\text { more common in the magnesium group ( } 9 \% \text { vs } \\
\text { I\%; } p=0.06 I ; \text { ns), and (probably) owing to }\end{array}$ & $\begin{array}{l}\text { AF outcomes: } \\
\text { Clinically determined: } \\
\text { - incidence of AF; } \\
\text { - time of first AF (days) } \\
\text { - incidence of AF } \\
\text { relapsed } \\
\text { Holter ECG determined } \\
2 \text { days postsurgery: } \\
\text { - incidence of AF } \\
\text { - AF episodes per } \\
\text { patient } \\
\text { - duration of AF (h) } \\
\text { - rate of AF (bpm) } \\
\text { Other outcomes (data not } \\
\text { extracted): } \\
\text { Ventricular ectopic beat; } \\
\text { ventricular tachycardia; } \\
\text { supraventricular ectopic } \\
\text { beat; SVT other than AF } \\
\text { or atrial flutter; serum } \\
\text { total calcium, } \\
\text { magnesium, sodium and } \\
\text { potassium } \\
\text { concentrations; } \\
\text { haematology (creatinine, } \\
\text { creatine kinase } \\
\text { isoenzyme and } \\
\text { C-reactive protein } \\
\text { measurements); } \\
\text { perioperative MI; sinus } \\
\text { rate (bpm) }\end{array}$ \\
\hline
\end{tabular}




\begin{tabular}{|c|c|c|}
\hline $\begin{array}{l}\text { Reference and } \\
\text { design }\end{array}$ & Intervention & Participants \\
\hline & & $\begin{array}{l}\text { this, digoxin therapy was more frequent in this } \\
\text { group ( } 12 \% \text { vs } 3 \% ; p=0.054 ; \text { ns). Groups } \\
\text { were not statistically different considering other } \\
\text { baseline characteristics, e.g. NYHA class, left } \\
\text { ventricular and diastolic BP, ejection fraction, } \\
\text { incidence of three-vessel disease, prior } \\
\beta \text {-blockers, diuretics ( } p \text {-values not provided) or } \\
\text { left atrial transverse diameter in } \\
\text { echocardiography ( } p=0.07 \mathrm{I} \text {; ns) }\end{array}$ \\
\hline
\end{tabular}

Outcome measures

Adverse symptoms:

One patient had

postoperative cerebral thrombosis and died of massive pulmonary embolism 4 weeks after CABG. It is not stated in which group the death occurred

Length of follow-up:

I. Cardiac rhythm was monitored continuously the first 2 postoperative days. Thereafter, for up to 10 days every symptomatic palpitation was recorded by 12-lead ECG (monitoring in total 12 days after operation)

2. A 48-h two-channel Holter recording was started on the second postoperative day

Recruitment dates:

NR

${ }^{a}$ Technically acceptable recording was achieved in 108 patients.

Results

\begin{tabular}{lccc}
\hline Clinical AF outcomes & Intervention $(\boldsymbol{n}=\mathbf{6 9})$ & Control $(\boldsymbol{n}=\mathbf{7 0})$ & Difference \\
\hline Incidence of AF, $n(\%)$ & $20(29 \%)$ & $18(26 \%)$ & $\mathrm{ns}$ \\
Mean \pm SD time of first AF (days) & $3.5 \pm 1.9$ & $3.8 \pm 2.7$ & $\mathrm{~ns}$ \\
Incidence of AF relapsed, $n$ (\% of AF patients) & $9(45 \%$ of AF patients) & II (61\% of AF patients) & ns
\end{tabular}

\begin{tabular}{lccc} 
Holter AF outcomes & Intervention $(\boldsymbol{n}=\mathbf{5 2})$ & Control $(\boldsymbol{n}=\mathbf{5 6})$ & Difference \\
\hline Incidence of AF, $n(\%)$ & $7(14 \%)$ & $7(13 \%)$ & $\mathrm{ns}$ \\
Mean \pm SD episodes of AF & $1.4 \pm 0.8$ & $1.2 \pm 0.4$ & $\mathrm{~ns}$ \\
Mean \pm SD duration of AF $(\mathrm{h})$ & $5.1 \pm 4.3$ & $5.0 \pm 6.3$ & $\mathrm{~ns}$ \\
Mean \pm SD rate of AF $(\mathrm{bpm})$ & $115 \pm 26$ & $123 \pm 15$ & $\mathrm{NS}(p=0.538)$
\end{tabular}

\section{Methodological comments}

Allocation to treatment groups: It was only mentioned that patients were randomised.

Blinding: Patients were blinded (received magnesium sulphate in solution or the same volume of solution without magnesium). Authors did not provide any information concerning the blinding of doctors or assessors.

Comparability of treatment groups: In the magnesium group patients were older $(p=0.032)$, prior AF episodes were more common ( $9 \%$ vs $1 \% ; p=0.061, n s)$ and digoxin therapy was more frequent $(12 \%$ vs $3 \% ; p=0.054$, ns). The groups were not statistically different in terms of other prognostic factors (either $p$-values were reported or ns stated if the difference was not significant). 
Method of data analysis:

- Continuous variables were analysed by two-tailed Student's $t$-test and for non-normal distributions by the Mann-Whitney rank sum test.

- Predictors of AF were investigated (data not extracted).

- However, it was not stated whether data sets conformed to normality.

Sample size/power calculation: NR.

Attrition/dropout: One patient in the control group died on the first postoperative day because of graft occlusion and consequent perioperative infarction.

\section{General comments}

Generalisability: No details of ethnicity or social background; single location in Finland.

Outcome measures: Appropriate.

Intercentre variability: NA.

Conflict of interests: Not reported.

\begin{tabular}{|c|c|c|c|}
\hline $\begin{array}{l}\text { Reference and } \\
\text { design }\end{array}$ & Intervention & Participants & Outcome measures \\
\hline $\begin{array}{l}\text { Authors: } \\
\text { Toraman et al. }{ }^{27} \\
\text { Year: } 200 \text { I } \\
\text { Country: Turkey } \\
\text { Study design: RCT } \\
\text { Number of centres: } \\
\text { One } \\
\text { Funding: NR }\end{array}$ & $\begin{array}{l}\text { Interventions: } \\
\text { I. Intravenous } \\
\text { magnesium sulphate } \\
\text { 2. Control (not } \\
\text { reported as placebo) } \\
\text { Intervention details: } \\
\text { I. } 6 \text { mmol magnesium } \\
\text { sulphate in } 100 \mathrm{ml} \text { of } \\
0.9 \% \text { sodium } \\
\text { chloride }\left(25 \mathrm{ml} \mathrm{h}^{-1}\right) \\
\text { I day before CBP, } \\
\text { just after CBP } \\
\text { surgery and then } \\
\text { once daily for } 4 \text { days } \\
\text { after CBP } \\
\text { 2. } 100 \mathrm{ml} \text { of } 0.9 \% \\
\text { sodium chloride } \\
\left(25 \mathrm{ml} \mathrm{h}^{-1} \text { ) at the }\right. \\
\text { same time-points as } \\
\text { in the magnesium } \\
\text { sulphate group }\end{array}$ & $\begin{array}{l}\text { Number of participants: } \\
\text { Intervention: I00 } \\
\text { Control: I00 } \\
\text { Sample attrition/dropout: } \\
\text { NR } \\
\text { Inclusion criteria for study entry: Patients } \\
\text { scheduled for elective, first time, isolated CABG } \\
\text { (no other details) } \\
\text { Exclusion criteria for study entry: } \\
\text { Patients with AF, a past history of AF, heart valve } \\
\text { disease, diabetes, chronic renal disease, thyroid } \\
\text { disorders and/or COPD; patients receiving } \\
\text { antiarrhythmic drugs, digoxin and/or } \beta \text {-blocking } \\
\text { agents } \\
\text { Baseline characteristics of subjects: } \\
\text { Mean } \pm S D \text { age (years): } \\
\text { Intervention: } 62 \pm 6.7 \\
\text { Control: } 61.4 \pm 8.7 \\
\text { Difference: } p=0.56 \text { (ns) } \\
\text { Gender (M/F) (n): } \\
\text { Intervention: } 78 / 22 \\
\text { Control: } 83 / 17 \\
\text { Difference: } p=0.48 \text { (ns) } \\
\text { There were no significant differences between } \\
\text { the groups in } 14 \text { other preoperative and } \\
\text { I } 2 \text { perioperative variables reported ( } p \text {-values } \\
\text { were provided; all } p>0.05 \text { ) }\end{array}$ & $\begin{array}{l}\text { Other outcomes (data not } \\
\text { extracted) } \\
\text { Stroke incidence, } \\
\text { duration of extubation, } \\
\text { postoperative cardiac } \\
\text { output, total chest } \\
\text { drainage, serum } \\
\text { magnesium } \\
\text { concentration } \\
\text { Adverse symptoms: Stated } \\
\text { that all patients in the } \\
\text { magnesium group } \\
\text { received their scheduled } \\
\text { doses of magnesium } \\
\text { without any adverse } \\
\text { effects such as } \\
\text { bradycardia or } \\
\text { hypotension (no other } \\
\text { details) } \\
\text { Length of follow-up: } \\
4 \text { days after CABG } \\
\text { surgery } \\
\text { Recruitment dates: } \\
\text { February I } 999 \text { to March } \\
2000\end{array}$ \\
\hline
\end{tabular}




\begin{tabular}{|c|c|c|c|}
\hline \multicolumn{4}{|l|}{ Results } \\
\hline AF outcome & Intervention $(n=100)$ & Control $(n=100)$ & Difference \\
\hline Frequency of AF occurrence, $n(\%)$ & $2(2 \%)$ & $2 \mid(2 \mid \%)$ & $p<0.001$ \\
\hline Other outcomes & Intervention $(n=100)$ & Control $(n=100)$ & Difference \\
\hline $\begin{array}{l}\text { Mean } \pm \text { SD length of stay in ICU }(h) \\
\text { ICU readmission, } n \\
\text { Mean } \pm \text { SD length of postoperative hospital stay (days) }\end{array}$ & $\begin{array}{l}21.6 \pm 5.6 \\
1 \\
5.4 \pm 0.9\end{array}$ & $\begin{array}{c}22.6 \pm 6.9 \\
3 \\
5.8 \pm 4.1\end{array}$ & $\begin{array}{l}p=0.58 \\
p=0.62 \\
p=0.36\end{array}$ \\
\hline \multicolumn{4}{|c|}{$\begin{array}{l}\text { Methodological comments } \\
\text { Allocation to treatment groups: Stated that this was randomised, but no details provided. }\end{array}$} \\
\hline \multirow{2}{*}{\multicolumn{4}{|c|}{ Blinding: Stated that all ECGs were analysed by a cardiologist who was blinded to the study (no further details provided). }} \\
\hline & & & \\
\hline \multicolumn{4}{|c|}{$\begin{array}{l}\text { Method of data analysis: } \\
\text { - Stated that demographic and clinical variables as well as the incidence of AF were analysed using the } \chi^{2} \text { test or Fisher's } \\
\text { exact test for categorical variables and } t \text {-tests for continuous variables. Kruskal-Wallis one-way analysis of variance was } \\
\text { used to perform rank analysis. However, the results presented do not indicate in which cases each of these tests was } \\
\text { applied, nor whether the data satisfied assumptions of normality. } \\
\text { - Overall, statistical tests were not supported by any hypotheses. }\end{array}$} \\
\hline \multicolumn{4}{|l|}{ Sample size/power calculation: NR. } \\
\hline \multicolumn{4}{|l|}{ Attrition/dropout: NR. } \\
\hline \multicolumn{4}{|c|}{$\begin{array}{l}\text { General comments } \\
\text { Generalisability: No details of ethnicity; limited information on social background; single-location study in Turkey. }\end{array}$} \\
\hline \multicolumn{4}{|c|}{$\begin{array}{l}\text { Outcome measures: Appropriate, but note that I2-lead Holter ECG was only used for reactive, not continuous, monitoring } \\
\text { (authors discuss whether this might have missed some cases of AF). }\end{array}$} \\
\hline \multicolumn{4}{|l|}{ Intercentre variability: NA. } \\
\hline Conflict of interests: None reported. & & & \\
\hline
\end{tabular}




\begin{tabular}{|c|c|c|c|c|c|}
\hline $\begin{array}{l}\text { Reference and } \\
\text { design }\end{array}$ & Intervention & \multicolumn{2}{|l|}{ Participants } & \multicolumn{2}{|c|}{ Outcome measures } \\
\hline $\begin{array}{l}\text { Authors: Treggiari- } \\
\text { Venzi et al. } \\
\text { Year: } 2000 \\
\text { Country: } \\
\text { Switzerland } \\
\text { Study design: RCT } \\
\text { Number of centres: } \\
\text { One } \\
\text { Funding: } \\
\text { Swiss Society of } \\
\text { Cardiology }\end{array}$ & $\begin{array}{l}\text { Interventions: } \\
\text { I. Intravenous } \\
\text { magnesium sulphate } \\
\text { 2. Placebo control } \\
\text { 3. Amiodarone (data } \\
\text { not extracted) } \\
\text { Intervention details: } \\
\text { I. I } 6 \mathrm{mmol}(32 \mathrm{mEq}) \\
(4 \mathrm{~g}) \text { magnesium } \\
\text { sulphate per } 24 \mathrm{~h} \\
\text { (Bichsel, Interlaken, } \\
\text { Switzerland), over } \\
72 \mathrm{~h} \text {, starting within } \\
\text { I h of arrival in ICU } \\
\text { 2. } 0.9 \% \text { sodium } \\
\text { chloride, over } 72 \mathrm{~h} \text {, } \\
\text { starting within I } \mathrm{h} \text { of } \\
\text { arrival in ICU }\end{array}$ & $\begin{array}{l}\text { Sample attrition/dropout: } \\
\text { Magnesium sulphate and placeb } \\
\text { dropouts (magnesium sulphate: } \\
\text { cardiac arrest and one incomple } \\
\text { placebo: one due to pacemaker } \\
\text { one incomplete data) } \\
\text { Inclusion criteria for study entry: } \\
\text { Patients scheduled for elective } \\
\text { details) } \\
\text { Exclusion criteria for study entry: } \\
\text { Refusal of consent; chronic AF, } \\
\text { degree atrioventricular block, } \mathrm{p} \\
\text { dependence, amiodarone treatr } \\
\text { before operation; thyroid disea } \\
\text { associated heart surgery, valvula } \\
\text { chronic renal failure (creatinine } \\
<30 \text { ml minute }{ }^{-1} \text { ) and liver dys } \\
\text { (prothrombin time < }<0 \% \text { and// } \\
>35 \mu \text { mol } I^{-1} \text { and/or presence } \\
\text { Baseline characteristics of subjec }\end{array}$ & $\begin{array}{l}\text { each had two } \\
\text { one due to } \\
\text { te ECG data; } \\
\text { dependence and } \\
\text { ABG (no other } \\
\text { econd or third } \\
\text { cemaker } \\
\text { ent < year } \\
\text { e, other } \\
\text { disease, } \\
\text { clearance rate } \\
\text { unction } \\
\text { f bilirubin } \\
\text { f ascites) } \\
\text { s: }\end{array}$ & $\begin{array}{l}\text { Other } \\
\text { extrac } \\
\text { Durati } \\
\text { perioc } \\
\text { catech } \\
\text { plasm } \\
\text { sulpha } \\
\text { Advers } \\
\text { Stated } \\
\text { Ml, ca } \\
\text { for sur } \\
\text { and pr } \\
\text { intuba } \\
\text { similar } \\
\text { Length } \\
3 \text { days } \\
\text { of inte }\end{array}$ & $\begin{array}{l}\text { utcomes (data not } \\
\text { d): } \\
\text { n of intubation; } \\
\text { of required } \\
\text { lamine infusion; } \\
\text { magnesium } \\
\text { e concentration } \\
\text { symptoms: } \\
\text { hat incidences of } \\
\text { diac arrest, need } \\
\text { sical haemostasis } \\
\text { longed tracheal } \\
\text { on (> } 72 \text { h) were } \\
\text { n the two groups } \\
\text { f follow-up: } \\
72 \text { h) after start } \\
\text { vention } \\
\text { nent dates: }\end{array}$ \\
\hline \multicolumn{6}{|c|}{${ }^{a}$ Primary end-point (outcome) definition does not precisely correspond with the reported data. } \\
\hline \multicolumn{6}{|l|}{ Results } \\
\hline \multicolumn{2}{|l|}{ AF outcomes } & Intervention $(n=47)$ & \multicolumn{2}{|c|}{ Control $(n=5 \mathrm{I})$} & Difference \\
\hline \multicolumn{2}{|c|}{ Frequency of $\mathrm{AF}$ occurrence $>30$ s $n(\%)$} & II (23\%) & \multicolumn{2}{|l|}{$14(27 \%)$} & $p=0.82$ \\
\hline \multicolumn{2}{|c|}{$\begin{array}{l}\text { Time to onset of } A F(h) \text { after start of } \\
\text { intervention from log-rank test }\end{array}$} & $\begin{array}{l}\text { Given in chart, but } \\
\text { not clearly extractable }\end{array}$ & \multicolumn{2}{|c|}{$\begin{array}{l}\text { Given in chart, but } \\
\text { not clearly extractable }\end{array}$} & $p=0.5$ \\
\hline \multicolumn{2}{|c|}{$\begin{array}{l}\text { Mean } \pm \mathrm{SD} \text { delay in } \mathrm{AF} \text { onset }(\mathrm{h}) \\
\text { after start of intervention }\end{array}$} & $45 \pm 14$ & \multicolumn{2}{|l|}{$42 \pm 12$} & $p=0.37$ \\
\hline \multicolumn{2}{|c|}{ No. of $A F$ episodes (maximum) per patient ${ }^{c}$} & $17(3)$ & \multicolumn{2}{|l|}{$14(1)$} & $p=0.88$ \\
\hline \multicolumn{2}{|c|}{ Mean $\pm \mathrm{SD}$ heart rate $(\mathrm{bpm})$ during $\mathrm{AF}$} & $146 \pm 9$ & \multicolumn{2}{|l|}{$153 \pm 18$} & $p=0.26$ \\
\hline \multicolumn{6}{|c|}{$\begin{array}{l}{ }^{b} \text { It is not clear which statistical analysis was used here; this could have been an unpaired t-test or a Mann-Whitney test } \\
\text { depending upon normality of the variable (not stated). } \\
\text { c Assumed by reviewers (not stated) to be the number per patient. }\end{array}$} \\
\hline \multicolumn{2}{|l|}{ Other outcomes } & Intervention $(n=47)$ & \multicolumn{2}{|c|}{ Control $(n=51)$} & Difference \\
\hline \multicolumn{2}{|c|}{ Median (range) length of stay in ICU (days) } & $3(2-2 I)$ & $3(2-7)$ & & NR \\
\hline
\end{tabular}


Adverse events: One patient in the placebo group died 5 days after surgery

\section{Methodological comments}

Allocation to treatment groups: Random assignment of patients to interventions was based on colour-coded spheres drawn from an opaque container (no other details). Additional patients were added to compensate for 'technical' dropouts, but no indication is given of whether this procedure was also randomised. Precise timing of the start of interventions not reported; assumed to be immediately post-CABG operation in ICU.

Blinding: Study drugs were prepared in an opaque syringe with opaque tubing by an independent observer; study described as 'double blind' (no other details given).

Comparability of treatment groups: No notable differences; authors report that the groups were similar in baseline characteristics and surgical procedure.

Method of data analysis:

- For continuous data, either an unpaired $t$-test (normally distributed data) or a Mann-Whitney test (non-normal data) was used. However, it is not stated which data sets conformed to normality, hence it is unclear which tests were used for each comparison.

- For categorical variables a $\chi^{2}$ test was used. However, no $\chi^{2}$ results were presented, only $p$-values were given, so it is unclear where this test was applied.

- Kaplan-Meier analysis was used to analyse the delay in onset and the duration of AF (no other details provided).

- Overall, statistical tests were not supported by any hypotheses.

Sample size/power calculation: Reported for detecting a $50 \%$ reduction of frequency of AF using Holter ECG (80\% power with $\alpha=0.5$ ), but the power calculation is unclear (no variance estimate provided).

Attrition/dropout: Reported, but not stated whether accounted for in analysis. Probably not analysed according to ITT (the authors remarked for the magnesium group that "the final number of patients in the interim analysis was 47 ").

\section{General comments}

Generalisability: No details of ethnicity or social background; single-location study in Switzerland.

Outcome measures: Appropriate.

Inter-centre variability: NA.

Conflict of interests: None reported.

\begin{tabular}{|c|c|c|c|}
\hline $\begin{array}{l}\text { Reference and } \\
\text { design }\end{array}$ & Intervention & Participants & Outcome measures \\
\hline $\begin{array}{l}\text { Authors: } \\
\text { Yilmaz et al. }{ }^{14} \\
\text { Year: } 2000 \\
\text { Country: Turkey } \\
\text { Study design: RCT } \\
\text { Number of centres: } \\
\text { One (assumed by } \\
\text { reviewers) } \\
\text { Funding: NR }\end{array}$ & $\begin{array}{l}\text { Interventions: } \\
\text { I. Magnesium sulphate } \\
\text { bolus } \\
\text { 2. Control } \\
\text { Intervention details: } \\
\text { I. I } 7 \text { mmol I-1 } \\
\text { magnesium sulphate } \\
\text { in cardioplegia } \\
\text { infusion and } \\
0.4 \mathrm{mmol}^{-1} \mathrm{~kg}^{-1} \text { bolus } \\
\text { of magnesium } \\
\text { sulphate } \\
\text { administered at the } \\
\text { start of CPB } \\
\text { 2. I } \mathrm{mmol} \mathrm{I}^{-1} \\
\text { magnesium sulphate } \\
\text { in cardioplegia } \\
\text { infusion only }\end{array}$ & $\begin{array}{l}\text { Number of participants: } \\
\text { Intervention: I5 } \\
\text { Control: I5 } \\
\text { Sample attrition/dropout: } \\
\text { NR } \\
\text { Inclusion criteria for study entry: Patients } \\
\text { undergoing elective CABG, with ejection } \\
\text { fraction of }>50 \% \text { and no arrhythmias before } \\
\text { surgery } \\
\text { Exclusion criteria for study entry: } \\
\text { NR }\end{array}$ & $\begin{array}{l}\text { AF outcome: } \\
\text { Incidence of AF } \\
\text { Other outcomes (data not } \\
\text { extracted): } \\
\text { Defibrillation, total } \\
\text { postoperative } \\
\text { arrhythmias, undefined } \\
\text { arrhythmia subgroup } \\
\text { ('VES'), total lidocaine } \\
\text { Adverse symptoms: } \\
\text { NR } \\
\text { Length of follow-up: } \\
\text { Stated that an ECG was } \\
\text { analysed for each patient } \\
24 \text { h postoperation (no } \\
\text { other details reported) } \\
\text { Recruitment dates: } \\
\text { NR }\end{array}$ \\
\hline $\begin{array}{l}{ }^{a} \text { It was not stated } \\
\text { reported. }\end{array}$ & 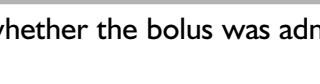 & ( & of the infusion were not \\
\hline
\end{tabular}




\section{Results}

\begin{tabular}{|c|c|c|c|}
\hline AF outcome & Intervention $(n=15)$ & Control $(n=15)$ & Difference \\
\hline Incidence of AF, $n$ & I & 3 & $\mathrm{~ns}^{b}$ \\
\hline
\end{tabular}

\section{Other outcomes Outside scope of assessment: data not extracted}

\section{Methodological comments}

Allocation to treatment groups: Stated that patients were randomised, but no details were provided.

Blinding: NR.

Comparability of treatment groups: Unclear, as few baseline characteristics were reported.

Method of data analysis:

- An unpaired $t$-test was used for data analysis.

- Statistical testing was not supported by hypotheses; normality of data was not reported.

Sample size/power calculation: NR.

Attrition/dropout: NR.

\section{General comments}

Generalisability: No details of ethnicity or social background; single-location study in Turkey.

Outcome measures: Appropriate but described only briefly.

Intercentre variability: NA.

Conflict of interests: None reported.

\begin{tabular}{|c|c|c|c|}
\hline $\begin{array}{l}\text { Reference and } \\
\text { design }\end{array}$ & Intervention & Participants & Outcome measures \\
\hline $\begin{array}{l}\text { Authors: } \\
\text { Zangrillo et al. }{ }^{29} \\
\text { Year: } 2005 \\
\text { Country: Italy } \\
\text { Study design: RCT } \\
\text { Number of centres: } \\
\text { One } \\
\text { Funding: NR }\end{array}$ & $\begin{array}{l}\text { Interventions: } \\
\text { I. Intravenous } \\
\text { magnesium sulphate } \\
\text { 2. Placebo } \\
\text { Intervention details: } \\
\text { I. } 2.5 \mathrm{~g}(20 \mathrm{mEq}) \\
\text { magnesium sulphate } \\
\text { diluted in } 100 \mathrm{ml} \\
\text { normal saline } \\
\text { solution over a } \\
30 \text {-minute period, } \\
\text { immediately after } \\
\text { central venous } \\
\text { cannulation } \\
\text { 2. Placebo of } 100 \mathrm{ml} \\
\text { normal saline } \\
\text { solution }\end{array}$ & $\begin{array}{l}\text { Number of participants: } \\
\text { Intervention: } 80 \\
\text { Control: } 80 \\
\text { Sample attrition/dropout: } \\
\text { The analysis focused on patients receiving off- } \\
\text { pump CABG; patients who required conversion } \\
\text { to on-pump CABG were discontinued from the } \\
\text { intervention (eight in magnesium group, nine in } \\
\text { placebo group) but were included in the analysis } \\
\text { on an ITT basis (all randomised patients were } \\
\text { analysed in their allocated groups) } \\
\text { Inclusion criteria for study entry: } \\
\text { Patients referred for isolated elective coronary } \\
\text { artery surgery; age } \geqslant 18 \text { years; in sinus rhythm } \\
\text { and for whom off-pump CBP was deemed } \\
\text { technically feasible } \\
\text { Exclusion criteria for study entry: } \\
\text { History of AF; any other surgical procedure } \\
\text { during the current admission; Q-wave MI in the } \\
\text { preceding } 6 \text { weeks; ongoing treatment with } \\
\text { amiodarone, digoxin or warfarin; permanent } \\
\text { pacemaker implanted; or valvular regurgitation }\end{array}$ & $\begin{array}{l}\text { AF outcomes: } \\
\text { Incidence of AF (primary } \\
\text { outcome); AF at hospital } \\
\text { discharge } \\
\text { Other outcomes } \\
\text { extracted: } \\
\text { Length of stay in ICU; } \\
\text { length of stay in hospital } \\
\text { Other outcomes (data not } \\
\text { extracted): } \\
\text { Ventricular tachycardia; } \\
\text { low cardiac output; } \\
\text { mechanical ventilation; } \\
\text { biochemical data; oral } \\
\text { amiodarone at hospital } \\
\text { discharge; pacemaker, } \\
\text { inotropes and } \\
\text { transfusion frequency } \\
\text { Adverse symptoms: Stated } \\
\text { that there were no } \\
\text { serious adverse drug } \\
\text { events and no patients } \\
\text { died in the hospital }\end{array}$ \\
\hline
\end{tabular}




\begin{tabular}{|c|c|c|}
\hline $\begin{array}{l}\text { Reference and } \\
\text { design }\end{array}$ & Intervention & Participants \\
\hline & & Baseline characteristics of subjects \\
\hline & & $\begin{array}{l}\text { Mean } \pm S D \text { age (years): } \\
\text { Intervention: } 65 \pm 9.8 \\
\text { Control: } 66 \pm 9.7\end{array}$ \\
\hline & & $\begin{array}{l}\text { Gender }(M / F) \text { : } \\
\text { Intervention: } 74 / 6(7.5 \% \mathrm{~F}) \\
\text { Control: } 69 / \mathrm{I} \text { ( }(13.8 \% \mathrm{~F})\end{array}$ \\
\hline & & $\begin{array}{l}\text { Preoperative data were presented for } 2 \mathrm{I} \text { other } \\
\text { variables; mean } \pm \text { SD were reported for nine of } \\
\text { these, but only } n \text { and } \% \text { were reported for the } \\
\text { remaining } 12 \text {. The authors stated that baseline } \\
\text { clinical characteristics and demographic details } \\
\text { of the two groups were similar, but statistical } \\
\text { significance was not mentioned and no } p \text {-values } \\
\text { were provided }\end{array}$ \\
\hline & & $\begin{array}{l}\text { There were no significant intraoperative } \\
\text { differences }(p>0.05) \text { between the groups in: } \\
\text { number of grafts, pacemakers, ischaemia } \\
\text { ( }>2 \text { minutes), perioperative } A F^{a} \text { or patients with } \\
\text { conversion from off-pump to on-pump CABG }\end{array}$ \\
\hline
\end{tabular}

${ }^{a}$ Perioperative AF was restored to sinus rhythm in all cases by direct synchronised electric shock (20 J). Patients ( $n$, \%) with perioperative AF were: magnesium 7 (8.8\%), placebo 4 (5.0\%), $p=0.5$.

Results $^{b}$

\begin{tabular}{|lccr}
\hline AF outcomes & Intervention $(\boldsymbol{n}=\mathbf{8 0})$ & Control $(\boldsymbol{n}=\mathbf{8 0})$ & Difference \\
\hline Postoperative AF, $n(\%)^{c}$ & $16(20 \%)^{c}$ & $18(22.5 \%)$ & $p=0.8(\mathrm{~ns})$ \\
AF at hospital discharge, $n(\%)$ & $2(2.5 \%)$ & $2(2.5 \%)$ & $p=0.7(\mathrm{~ns})$
\end{tabular}

Other outcomes Intervention $(n=80) \quad$ Control $(n=80) \quad$ Difference

$\begin{array}{lrrr}\text { Mean } \pm \text { SD length of ICU stay (h) } & 26 \pm 20.9 & 31 \pm 24.4 & p=0.2(\mathrm{~ns}) \\ \text { Mean } \pm \text { SD length of hospital stay (days) }^{d} & 7 \pm 3.8^{d} & 6 \pm 2.8^{d} & p=0.004^{d}\end{array}$

${ }^{b}$ No indication was given about the timing of the results relative to patient admission, surgery or intervention.

${ }^{c}$ Four patients who had perioperative AF went on to also develop postoperative AF; these four were all in the magnesium group and their data are included here.

${ }^{d}$ The data given here are credited to two different comparisons in the primary article: $(I)$ a comparison between magnesium and placebo groups (reported in Table 4), and (2) a comparison between AF and non-AF groups (reported in the text). The reviewers have assumed that the tabulated data (as extracted here) are correct (those data reported in the text appear inconsistent, suggesting a misprint).

\section{Methodological comments}

Allocation to treatment groups: Randomisation was stratified in blocks of 40 patients; independent nurses dispensed either magnesium or placebo in the operating room according to a computer-generated list (no other details).

Blinding: Stated that all study personnel and participants were blinded to treatment assignment for the duration of the study (no details provided).

Comparability of treatment groups: Some slight preoperative differences in numbers in magnesium/placebo groups for diabetes (30/24), COPD (3/6), MI (44/49), $\beta$-blocker use (54/42), calcium channel blockers (24/37) and ACE inhibitors (3I/36), but no variance measures or $p$-values were provided for these variables. The authors considered that the baseline characteristics were similar between the groups, but did not robustly test for differences. 
Method of data analysis:

- The study tested the hypothesis that prophylactic magnesium supplementation as compared with placebo would reduce the occurrence of postoperative AF. Perioperative AF was noted, but not included in the analysis. All significance tests were two-sided.

- Analysis focused on patients receiving off-pump CABG; patients who required conversion to on-pump CABG were discontinued from the intervention (eight in magnesium group, nine in placebo group), but were included in the analysis on an ITT basis (no definition of ITT given).

- Dichotomous data were compared using a two-tailed $\chi^{2}$ test with Yates' correction, or a Fisher's exact test when appropriate.

- Continuous measures were compared with analysis of variance or the Mann-Whitney U-test when appropriate.

- Presentation of results did not indicate which tests were actually used for each outcome; normality of outcomes was not reported.

- Stepwise multivariate logistic regression was used to investigate predictors of AF (analysis outside the scope of this assessment; data not extracted).

Sample size/power calculation: With two-sided $\alpha=0.05$ and $80 \%$ power, based on previous publications, frequency of arrhythmia in intervention and placebo groups was assumed to be $30 \%$ and $50 \%$, respectively, which would require 120 patients per group to detect. The actual number of patients recruited was 80 per group, suggesting that statistical power would have been $<80 \%$. However, the actual statistical power is unclear (interim analyses were included in the protocol for analyses with 40 patients per group or 80 patients per group, but the statistical power of the interim analyses was not stated; the study was terminated after interim analysis with 80 patients per group, as recruitment of a further 80 per group was considered unlikely to detect a benefit in either treatment group, but no explanation was given).

Attrition/dropout: All randomised patients were analysed; there were no losses to follow-up. Patients who withdrew from intervention (due to conversion to on-pump CABG) were included according to the ITT principle (ITT not defined).

\section{General comments}

Generalisability: No details of ethnicity or social background; single-location study in Italy.

Outcome measures: Appropriate.

Intercentre variability: NA.

Conflict of interests: None reported. 



\section{Appendix 4}

\section{Studies screened and included in the current review}

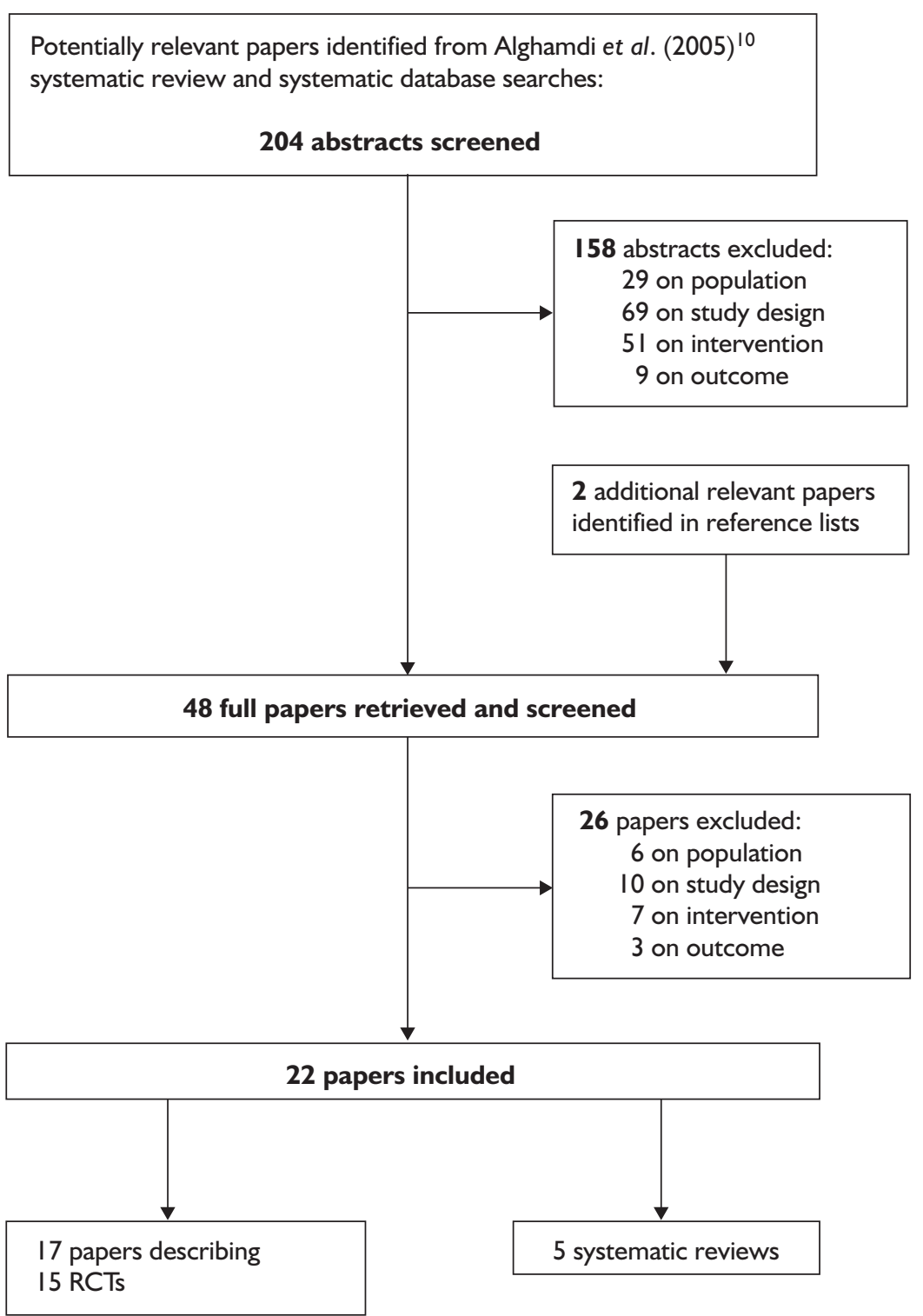





\section{Appendix 5}

\section{Detection and definitions of atrial fibrillation given in the included RCTs}

\begin{tabular}{|c|c|c|}
\hline Study & Method of detecting AF & Definition of AF \\
\hline Bert, $200 \mathrm{I}^{15}$ & $\begin{array}{l}\text { Continuous bedside ECG monitoring with automated alarmed } \\
\text { arrhythmia detection and recall (Hewlett-Packard) in the ICU. On } \\
\text { hospital wards, monitoring was performed by telemetry to a central } \\
\text { nursing station to } \geqslant 4 \text { days postoperation. Thereafter, clinical } \\
\text { observation and a daily ECG study were performed. If a suspected } \\
\text { arrhythmia occurred after discontinuation of continuous ECG } \\
\text { monitoring, a I } 2 \text {-lead ECG study was obtained to confirm arrhythmia } \\
\text { classification }\end{array}$ & $\begin{array}{l}\text { AF was not defined separately } \\
\text { from atrial flutter and SVT. } \\
\text { These arrhythmias together } \\
\text { were referred to as } \\
\text { postoperative atrial } \\
\text { tachycardias (POAT). All } \\
\text { episodes of POAT had an } \\
\text { initial ventricular rate } \\
>110 \text { bpm, were sustained for } \\
>5 \text { minutes and warranted } \\
\text { pharmacological therapy. } \\
\text { POAT classification excluded } \\
\text { premature atrial contractions }\end{array}$ \\
\hline Bhudia, $2006^{16}$ & NR & $\begin{array}{l}\text { NR (AF was not a primary } \\
\text { outcome) }\end{array}$ \\
\hline Caspi, $1995^{13}$ & $\begin{array}{l}\text { I2-Lead ECG was performed before operation and at } 6,12 \text { and } 24 \mathrm{~h} \\
\text { after operation. All patients underwent ECG monitoring to } 3 \text { days } \\
\text { postoperation using a bedside arrhythmia detection system (Mennen } \\
\text { Horizon 2000) }\end{array}$ & $\begin{array}{l}\text { Reported only that } \mathrm{AF} \text { was at } \\
\text { rates greater than } 120 \mathrm{bpm}\end{array}$ \\
\hline Dagdelen, $2002^{17}$ & $\begin{array}{l}\text { Standard I2-lead surface ECG was obtained on the day before } \\
\text { operation, just after operation, and once daily for } 4 \text { days } \\
\text { postoperation. After ICU discharge, trained nurses performed clinical } \\
\text { observation every hour. Patients were monitored routinely with an } \\
\text { alarm-triggered seven-lead telemetry system (Siemens Infinity) until } \\
4 \text { days postoperation under the close attention of a monitor technician. } \\
\text { When there was a question of AF on clinical grounds or by telemetry, a } \\
\text { I2-lead ECG was obtained }\end{array}$ & $\begin{array}{l}\text { AF was defined as the absence } \\
\text { of consistent } P \text { waves before } \\
\text { each QRS complex, irregular } \\
\text { QRS complexes and } \\
\text { appearance of } F \text { waves }\end{array}$ \\
\hline Fanning, $1991^{19}$ & $\begin{array}{l}\text { Continuous ECG monitoring to } 4 \text { days postoperation using a bedside } \\
\text { arrhythmia detection system (Mennen Horizon 2000) }\end{array}$ & $\begin{array}{l}\text { AF was not defined separately } \\
\text { from atrial flutter and SVT } \\
\text { with rates }>110 \mathrm{bpm} \text { and } \\
\text { duration }>30 \mathrm{~s}\end{array}$ \\
\hline Forlani, $2003^{21}$ & $\begin{array}{l}\text { Cardiac rhythm was continuously monitored in the ICU until the } \\
\text { morning of the second postoperative day. For the remaining days until } \\
\text { discharge, I } 2 \text {-lead ECG was recorded every } 8 \mathrm{~h}\end{array}$ & NR \\
\hline Hazelrigg, $2004^{22}$ & NR & NR \\
\hline Kaplan, $2003^{23}$ & $\begin{array}{l}\text { Rhythm was monitored continuously during the operation and first } \\
2 \text { days postoperation (Datascope, Datascope } 200 \text { IA). In the wards } \\
\text { patients were monitored with a I 2-lead ECG and telemetry system } \\
\text { (Fukuda Denshi DynaScope) if physical examination revealed a } \\
\text { tachycardia attack or the development of an arrhythmia or if a patient } \\
\text { had a palpitation or any rhythm-related complaint }\end{array}$ & NR \\
\hline
\end{tabular}




\begin{tabular}{|c|c|c|}
\hline Study & Method of detecting AF & Definition of AF \\
\hline $\begin{array}{l}\text { Karmy-Jones, } \\
1995^{24}\end{array}$ & $\begin{array}{l}\text { Continuous monitoring for minimum } 24 \mathrm{~h} \text { using alarm-triggered } \\
\text { bedside monitors (Hewlett-Packard) capable of automated recall, } \\
\text { observed constantly by monitor nurses. ECG were obtained } \\
\text { postoperatively and on the first } 2 \text { mornings postoperation. } \\
\text { Thereafter, a I 2-lead ECG was obtained if there was a question } \\
\text { of dysrhythmia either on clinical grounds or by telemetry }\end{array}$ & NR \\
\hline $\begin{array}{l}\text { Nurözler, } \\
1996^{25}\end{array}$ & $\begin{array}{l}\text { Continuous ECG over } 5 \text { days postoperation with I2-h memorised } \\
\text { arrhythmia detection monitor (Drager U-M 3). AF identified on } \\
\text { the monitor confirmed by a reading of a rhythm strip. AF } \\
\text { excluded if not confirmed by ECG or if }<I \text { minute duration }\end{array}$ & $\begin{array}{l}\text { NR (except for duration } \\
\geqslant I \text { minute) }\end{array}$ \\
\hline Parikka, $1993^{26}$ & $\begin{array}{l}\text { Continuous monitoring of cardiac rhythm with bedside monitors } \\
\text { on the first } 2 \text { days postoperation in the ICU. Thereafter, for up to } \\
\text { IO days, every symptomatic palpitation was recorded by I } 2 \text {-lead } \\
\text { ECG. A 48-h two-channel Holter recording was started } 2 \text { days } \\
\text { postoperation. The recording was analysed by one of the } \\
\text { investigators using a Marquette electrocardioscanner }\end{array}$ & $\begin{array}{l}\text { Clinical AF was defined as irregular } \\
\text { QRS complexes without detectable } \\
\text { regular atrial activity continuing for } \\
\text { I h, or less if treatment was } \\
\text { necessary because of intolerable } \\
\text { symptoms or haemodynamic } \\
\text { deterioration. Episodes of this type } \\
\text { of arrhythmia seen at Holter were } \\
\text { defined as AF episodes if they } \\
\text { lasted for I5 s and were at least } \\
\text { I minute apart. Holter recording } \\
\text { did not reveal any AF patient who } \\
\text { had not been identified by clinical } \\
\text { symptoms }\end{array}$ \\
\hline $\begin{array}{l}\text { Toraman, } \\
2001^{27}\end{array}$ & $\begin{array}{l}\text { ECGs were obtained preoperatively and } 0-5 \text { days } \\
\text { postoperatively. Patients were continuously monitored while in } \\
\text { the ICU using alarm-triggered bedside monitors (Siemens). After } \\
\text { discharge from the ICU, trained nurses performed clinical } \\
\text { observations every } 4 \mathrm{~h} \text { and all patients were monitored with an } \\
\text { alarm-triggered seven-lead telemetry system (Siemens Infinity), } \\
\text { under close attention of a monitor technician, until the morning } \\
\text { of day } 5 \text { postoperation. When AF was suspected clinically or by } \\
\text { telemetry a I } 2 \text {-lead ECG was obtained }\end{array}$ & $\begin{array}{l}\text { AF was defined as the absence of } \\
\text { consistent } P \text { waves before each } \\
Q R S \text { complex and an irregular rate } \\
\text { lasting for }>10 \text { minutes or } \\
\text { requiring therapy as a result of } \\
\text { haemodynamic compromise }\end{array}$ \\
\hline $\begin{array}{l}\text { Treggiari-Venzi, } \\
2000^{28}\end{array}$ & $\begin{array}{l}\text { A Holter ECG (Delmar Avionics three-channel Cardiocorder) } \\
\text { recording was obtained throughout the } 72-\mathrm{h} \text { infusion period. } \\
\text { Additional I } 2 \text {-lead ECGs were recorded every } 12 \mathrm{~h} \text {. The Holter } \\
\text { recording was analysed on completion of the } 72-\mathrm{h} \text { study period } \\
\text { or earlier if the study was terminated because of arrhythmia. SVA } \\
\text { episodes were detected visually and printed for accurate } \\
\text { diagnosis by two investigators }\end{array}$ & $\begin{array}{l}\text { SVT was defined as an arrhythmia } \\
\text { of more than three narrow QRS } \\
\text { complexes at a rate greater than } \\
\text { I00 bpm and lasting for more than } \\
30 \text { s. AF was defined as a totally } \\
\text { irregular atrial rhythm leading to } \\
\text { irregular ventricular rhythm. } \\
\text { Unclear whether AF definition was } \\
\text { independent of the definition of } \\
\text { SVT; note that the authors mention } \\
\text { both SVA and SVT as extracted } \\
\text { here }\end{array}$ \\
\hline Yilmaz, $2000^{14}$ & $\begin{array}{l}\text { A I 2-lead standard ECG was analysed for each patient during } \\
30 \text { minutes and } 24 \text { h postoperation }\end{array}$ & NR \\
\hline $\begin{array}{l}\text { Zangrillo, } \\
2005^{29}\end{array}$ & $\begin{array}{l}\text { Continuous monitoring until hospital discharge through telemetry } \\
\text { with continuous display of the ECGs on multiple oscilloscopes } \\
\text { simultaneously in the ICU, high-dependency unit (HDU) or main } \\
\text { ward. I2-Lead ECGs were obtained routinely every } 6 \text { h in ICU } \\
\text { and daily in HDU, at hospital discharge, and when AF was } \\
\text { detected on telemetry. In addition, ECG was performed } \\
\text { whenever AF was suspected clinically }\end{array}$ & $\begin{array}{l}\text { Any documented episode of AF } \\
\text { ( } 12 \text {-lead ECG) defined as an } \\
\text { irregular rhythm with an irregular } \\
\text { fluctuating baseline, without well- } \\
\text { defined } P \text { waves and irregular RR } \\
\text { intervals. AF excluded if } \\
\leqslant 10 \text { minutes or requiring medical } \\
\text { attention owing to patient } \\
\text { instability }\end{array}$ \\
\hline
\end{tabular}




\section{Appendix 6}

\section{Exclusion criteria reported for the selection of patients in RCTs}

\begin{tabular}{|c|c|c|c|c|c|c|c|c|c|c|c|c|c|c|}
\hline \multirow[b]{2}{*}{ Exclusion criterion } & \multicolumn{14}{|c|}{ Study } \\
\hline & D̃ & 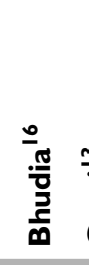 & $\frac{m}{\bar{a}}$ & 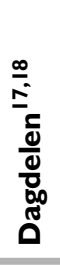 & 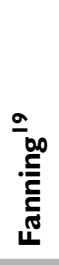 & 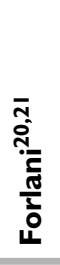 & 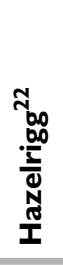 & 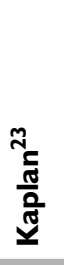 & 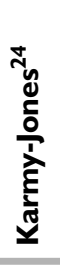 & 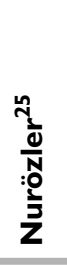 & & 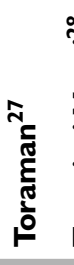 & 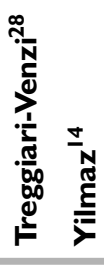 & 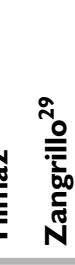 \\
\hline $\begin{array}{l}\text { Previous AF } \\
\text { Atrial arrhythmias }\end{array}$ & & $x$ & & $x$ & & & & $x$ & & & & $x$ & $x$ & $x$ \\
\hline Atrial arrhythmias & $x$ & & & & & & & & & & & & & \\
\hline $\begin{array}{l}\text { Atrioventricular block } \\
\text { Angina }\end{array}$ & & & & $x$ & & & & & $x$ & & & & $\times$ & \\
\hline Atrioventricular node disorder & & & & & & $x$ & & & & & & & & \\
\hline Bradycardia & & & & & & & & $x$ & & & & & & \\
\hline Bronchospastic & $x$ & & & & & & & & & & & & & \\
\hline Bundle branch block & & & & $x$ & & & & & & & & & & \\
\hline COPD (defined or undefined) & & & & $x$ & & $x$ & & & & $x$ & & $x$ & & \\
\hline Diabetes & & & & & & & & & & & & $x$ & & \\
\hline Heart block, heart disease & & & & $x$ & $x$ & & & & & $x$ & & & & \\
\hline Liver dysfunction & & & & & & & $x$ & & & & & & $x$ & \\
\hline Hypotension & & & & & & & $x$ & $x$ & & & & & & \\
\hline Inotropic drugs required & & & & & & & & & & $x$ & & & & \\
\hline Intra-aortic balloon required & & & & & & & & & & $x$ & & & & \\
\hline Ischaemia ongoing & & & & & & & & & $x$ & & & & & \\
\hline LV function or LVEF abnormal & $x$ & & & & & $x$ & & & & $x$ & & & & \\
\hline Non-sinus rhythm & $x$ & & & & & & & & & & & & & \\
\hline Pacemaker/cardiac assistance & & & & & $x$ & & $x$ & & & & & & $x$ & $x$ \\
\hline Pericarditis & & & & $x$ & & & & & & & & & & \\
\hline Pre-excitation syndrome & & & & $x$ & & & & & & & & & & \\
\hline Pulmonary embolism & & & & $x$ & & & & & & & & & & \\
\hline QT interval increased & & & & & & $x$ & & & & & & & & \\
\hline $\mathrm{Q}$ wave $\mathrm{MI} \leqslant 6$ weeks presurgery & & & & & & & & & & & & & & $x$ \\
\hline Creatinine elevated & & & & & $x$ & $x$ & $x$ & $x$ & & $x$ & & & & \\
\hline Creatinine clearance decreased & & & & & & & & & & & & & $x$ & \\
\hline Reoperation & & & & & & & & $x$ & $x$ & & & & & \\
\hline Severe respiratory disorder & & & & & & & & $x$ & & & & & & \\
\hline Sick sinus syndrome & & & & $x$ & & $x$ & & & & & & & & \\
\hline Surgery, cardiac & $x$ & & & & $x$ & & & & & & & & $x$ & \\
\hline Surgery, concomitant & & & & & & & & & & $x$ & & & & $x$ \\
\hline Surgery, emergency & & & & & & & & & $x$ & & & & & \\
\hline SVA or SVT & & & & & $x$ & $x$ & & & & $x$ & & & & \\
\hline Valve disease or valve surgery & & & & $x$ & & & & $x$ & & & $x$ & $\times$ & $x$ & $x$ \\
\hline Ventricular arrhythmias & $x$ & & & & $x$ & & & & & $x$ & & & & \\
\hline Non-consent or unavailable consent & & & & & $x$ & & & & $x$ & & & & $x$ & \\
\hline Renal disease, impairment or failure & $x$ & $x$ & & $x$ & & & & $x$ & $x$ & & & $\times$ & $x$ & \\
\hline Thyroid disorders & & & & $\times$ & & & & & & & & $x$ & $x$ & \\
\hline Antiarrhythmics & & & & $x$ & & $x$ & & & $x$ & & $x$ & $x$ & & \\
\hline Digoxin & & & & $\times$ & & & & & & & & $x$ & & \\
\hline$\beta$-blockers & & & & $x$ & & & & & & & & $x$ & & \\
\hline Amiodarone $\leqslant$ I year presurgery & & & & & & & & & & & & & $x$ & \\
\hline Amiodarone ongoing & & & & & & & & & & & & & & $x$ \\
\hline Digoxin ongoing & & & & & & & & & & & & & & $x$ \\
\hline Warfarin ongoing & & & & & & & & & & & & & & $x$ \\
\hline No exclusion criteria reported & & & $x$ & & & & & & & & & & $x$ & K \\
\hline
\end{tabular}





\section{Appendix 7}

\section{Search strategy for economic evaluations}

\section{Ovid MEDLINE}

1950 to May week 12007

Searched 15 May 2007

1 "Atrial Fibrillation"/ (19465)

2 Atrial Flutter/ (3991)

3 (atrial adj3 fibrillat\$).mp. (25464)

4 (heart adj3 fibrillat\$).mp. (950)

5 atrial fibrillat\$.mp. (25294)

6 (atrium adj3 flutter\$).mp. (23)

7 (atrium adj3 fibrillat\$r).mp. (0)

8 (auricular\$ adj3 fibrillat\$).mp. (736)

9 (auricular\$ adj3 flutter\$).mp. (274)

10 Tachycardia Supraventricular/ (3781)

11 or/1-10 (30644)

12 "Coronary Artery Bypass"/ (31512)

13 (CABG or coronary artery bypass graft\$).ti,ab. (16229)

14 (coronary artery bypass adj3 surgery).ti,ab. (7332)

15 (coronary adj3 revasculari\$).ti,ab. (4439)

16 (myocardial adj3 revascular\$).ti,ab. (4063)

17 (coronary adj6 graft).ti,ab. (6832)

18 (coronary adj6 bypass).ti,ab. (26085)

19 (coronary adj6 surgery).ti,ab. (15257)

20 (aortocoronary adj6 bypass).ti,ab. (2453)

21 (valve $\$$ adj6 surgery).ti,ab. (4554)

22 Cardiac Surgical Procedures/ (23335)

23 or/12-22 (71271)

24 MgSO4.mp. (1029)

25 magnesium sulfate/ (3419)

26 magnesium sulfate $\$ . t i, a b .(1735)$

27 exp magnesium compounds/ (10471)

28 magnesium/ (56302)

29 (magnesium and (sulphate $\$$ or sulfate $\$$ )).ti,ab. (3192)

30 magnesium sulphate\$.ti,ab. (729)

31 magnesium sulfate $\$ . t i, a b .(1735)$

32 7487-88-9.rn. (3419)

33 Magnesium Deficiency/ (3387)

34 or/24-33 (67330)

35 3930-20-9.rn. (1695)

36 Sotalol/ (1695)

37 sotalol.ti,ab. (1997)

38 or/35-37 (2418)

3911 and 23 and 34 (48)

4023 and 34 (242)

4111 and 34 (151)
4239 or 40 or $41(345)$

43 limit 42 to (humans and english language and $\mathrm{yr}=" 2004-2007 ")(45)$

113 exp ECONOMICS/ (374970)

$114 \exp$ ECONOMICS, HOSPITAL/ (14701)

115 exp ECONOMICS, PHARMACEUTICAL/ (1761)

$116 \exp$ ECONOMICS, NURSING/ (3739)

117 exp ECONOMICS, DENTAL/ (3555)

118 exp ECONOMICS, MEDICAL/ (11345)

119 exp "Costs and Cost Analysis"/ (129053)

120 Cost-Benefit Analysis/ (39951)

121 VALUE OF LIFE/ (4844)

122 exp MODELS, ECONOMIC/ (5178)

123 exp FEES/ and CHARGES/ (7124)

124 exp BUDGETS/ (9947)

125 (economic $\$$ or price $\$$ or pricing or financ $\$$ or fee $\$$ or pharmacoeconomic $\$$ or pharma economic\$).tw. (325412)

126 (cost\$ or costly or costing $\$$ or costed).tw. (189830)

127 (cost\$ adj2 (benefit $\$$ or utilit\$ or minim $\$$ or effective $\$)$ ).tw. (48757)

128 (expenditure $\$$ not energy).tw. (10369)

129 (value adj2 (money or monetary)).tw. (595)

130 budget\$.tw. (10852)

131 (economic adj2 burden).tw. (1410)

132 "resource use".ti,ab. (2055)

133 or/113-131 (754771)

134 news.pt. (118759)

135 letter.pt. (589482)

136 editorial.pt. (202717)

137 comment.pt. (329262)

138 or/134-137 (951676)

139133 not $138(695184)$

14042 and $139(8)$

141 from 140 keep 4-6,8 (4)

14223 and 38 and 139 (13)

143 from 142 keep 4-5,8-9,12-13 (6)

14411 and 38 and 139 (27)

145 limit 144 to english language (25)

146 from 145 keep 1,9,11-15,17,19-20,24 (11)

14734 and 38 and 139 (2)

\section{Number of hits (download file)}

Costs magnesium: 4

Costs sotalol: 17

Costs magnesium + sotalol: 2 


\section{EMBASE}

1980 to 2007 week 19

Searched 16 May 2007

1 heart atrium fibrillation/ (21875)

2 heart atrium flutter/ (3362)

3 exp Heart Atrium Arrhythmia/ (35266)

4 (atrial adj3 fibrillat\$).mp. (17803)

5 (heart adj3 fibrillat\$).mp. (31983)

6 atrial fibrillat\$.mp. (17577)

7 (atrium adj3 flutter\$).mp. (3380)

8 (atrium adj3 fibrillat $\$ r$ ).mp. (0)

9 (auricular\$ adj3 fibrillat\$).mp. (108)

10 (auricular\$ adj3 flutter\$).mp. (29)

11 Supraventricular Tachycardia/ (5812)

12 or/1-11 (47152)

13 coronary artery bypass graft/ (22523)

14 Coronary Artery Bypass Surgery/ (6944)

15 exp coronary artery surgery/ (39530)

16 (CABG or coronary artery bypass graft\$).ti,ab. (14959)

17 (coronary artery bypass adj3 surgery).ti,ab. (6804)

18 (coronary adj3 revasculari\$).ti,ab. (4087)

19 (myocardial adj3 revascular\$).ti,ab. (3015)

20 (coronary adj6 graft).ti,ab. (6026)

21 (coronary adj6 bypass).ti,ab. (23026)

22 (coronary adj6 surgery).ti,ab. (13234)

23 (aortocoronary adj6 bypass).ti,ab. (1469)

24 (valve $\$$ adj6 surgery).ti,ab. (3618)

25 or/13-24 (50320)

26 MgSO4.mp. (1011)

27 magnesium sulfate/ (6009)

28 Magnesium Derivative/ (989)

29 magnesium/ (23019)

30 (magnesium and (sulphate $\$$ or sulfate $\$$ )).ti,ab. (2910)

31 magnesium sulphate\$.ti,ab. (642)

32 magnesium sulfate $\$ . t i, a b .(1548)$

33 7487-88-9.rn. (6022)

34 Magnesium Deficiency/ (1203)

35 or/26-34 (30923)

36 3930-20-9.rn. (7170)

37 Sotalol/ (7144)

38 sotalol.ti,ab. (2048)

39 or/36-38 (7279)

$40 \quad 12$ and 25 and 35 (88)

4125 and 35 (209)

4212 and 35 (667)

4341 or $42(788)$

44 limit 43 to (humans and english language and $\mathrm{yr}=" 2004-2007 ")(229)$

4512 or 25 (95066)

4635 and 39 and 45 (149)

92 (cost\$ adj2 effective\$).ti,ab. (37066)

93 (cost\$ adj2 benefit\$).ti,ab. (7616)

94 cost effectiveness analysis/ (48505)
95 cost benefit analysis/ (26055)

96 budget\$.ti,ab. (7837)

97 cost\$.ti. (34748)

98 (cost\$ adj2 (effective\$ or utilit\$ or benefit $\$$ or minimi\$)).ab. (40355)

99 (economic $\$$ or pharmacoeconomic $\$$ or pharmaco economic\$).ti. (13532)

100 (price $\$$ or pricing\$).ti,ab. (10064)

101 (financial or finance or finances or financed).ti,ab. (20781)

102 (fee or fees).ti,ab. (4745)

103 cost/ (19051)

104 cost minimization analysis/ (1127)

105 cost of illness/ (3798)

106 cost utility analysis/ (1908)

107 drug cost/ (29425)

108 health care cost/ (52431)

109 health economics/ (9184)

110 economic evaluation/ (3590)

111 economics/ (5146)

112 pharmacoeconomics/ (884)

113 budget/ (6946)

114 economic burden.ti,ab. (1415)

115 "resource use".ti,ab. (1899)

116 or/92-115 (214586)

117 (editorial or letter).pt. (525894)

118116 not 117 (191116)

119118 and 35 and (12 or 25) (43)

120 from 119 keep 7,15,22,32,34,39 (6)

121118 and 39 and (12 or 25) (137)

122121 not 119 (123)

123 limit 122 to english language (118)

124 from 123 keep 3,10,18,25-27,31-32,42,47, 49-50,52-56,61,63-64,66,68-69,71,73,77, 79-80,86,88-89,92,94-97,99-100,102-104, 106,111-113,115-118 (49)

\section{Number of hits (download file)}

Costs magnesium: 6

Costs sotalol: 49

\section{Ovid MEDLINE In-Process and Other Non-Indexed Citations}

14 May 2007

Searched 15 May 2007

1 (atrial adj3 fibrillat\$).mp. (728)

2 (heart adj3 fibrillat\$).mp. (32)

3 atrial fibrillat\$.mp. (727)

4 (atrium adj3 flutter\$).mp. (1)

5 (atrium adj3 fibrillat\$r).mp. (0)

6 (auricular\$ adj3 fibrillat\$).mp. (16)

7 (auricular\$ adj3 flutter\$).mp. (0)

8 or/1-7 (747)

9 (CABG or coronary artery bypass graft\$).ti,ab. (482) 
10 (coronary artery bypass adj3 surgery).ti,ab. (220)

11 (coronary adj3 revasculari\$).ti,ab. (134)

12 (myocardial adj3 revascular\$).ti,ab. (83)

13 (coronary adj6 graft).ti,ab. (173)

14 (coronary adj6 bypass).ti,ab. (638)

15 (coronary adj6 surgery).ti,ab. (353)

16 (aortocoronary adj6 bypass).ti,ab. (22)

17 (valve $\$$ adj6 surgery).ti,ab. (117)

18 or/9-17 (968)

19 MgSO4.mp. (38)

20 (magnesium and (sulphate $\$$ or sulfate $\$$ )).ti,ab. (98)

21 magnesium sulphate $\$ . t i, a b .(23)$

22 magnesium sulfate $\$ . t i, a b$. (55)

2319 or 20 or 21 or 22 (129)

24 sotalol.ti,ab. (30)

258 or 18 (1659)

2623 and 25 (3)

27 from 26 keep 1-3 (3)

2824 and 25 (14)

29 from 28 keep 5,8,10-13 (6)

30 (economic\$ or price $\$$ or pricing or pharmacoeconomic $\$$ or pharma economic\$).tw. (3394)

31 (cost\$ or budget\$).tw. (7334)

32 (cost\$ adj2 (benefit\$ or utilit\$ or minim\$)).tw. (373)

33 (value adj2 (money or monetary)).tw. (31)

3430 or 31 or 32 or $33(9858)$

3523 and $34(2)$

\section{Number of hits (download file)}

Costs magnesium: 3

Costs sotalol: 2

\section{NHS EED (CRD database)}

Magnesium and (atrial fibrillate* or coronary)

Sotalol and atrial fibrillat*

\section{Number of hits (download file)}

Costs magnesium: 1

Costs sotalol: 6

\section{Econlit}

Magnesium 0

Sotalol 0

\section{Number of hits (download file)}

0

Total keyworded

Costs magnesium: 8

Costs sotalol: 25

Number of hits (download file)

8

55 



\section{Appendix 8}

\section{Inclusion criteria for economic review}

\begin{tabular}{|c|c|c|c|}
\hline $\begin{array}{l}\text { QI. Economic evaluation } \\
\text { or costing study }\end{array}$ & $\begin{array}{l}\text { Q2. Prophylaxis for } \\
\text { AF following CABG }\end{array}$ & Q3. Comparators & Q4. Include \\
\hline $\begin{aligned} I= & \text { Full economic evaluation } \\
& (\text { CBA, CUA, CEA or } \\
& \text { CMA) } \\
2= & \text { Costing study (no } \\
& \text { assessment of } \\
& \text { effectiveness). Reports } \\
& \text { costings or resource use } \\
3= & \text { No } \\
4= & \text { Unclear }\end{aligned}$ & $\begin{array}{l}I=Y \\
2=N \\
4=\text { Unclear }\end{array}$ & $\begin{array}{l}1=M g \\
2=\text { Sotalol } \\
3=\text { Other }\end{array}$ & $\begin{array}{l}\mathrm{I}=\mathrm{Y}(\text { primary }) \\
2=\mathrm{Y}(\text { secondary }) \\
3=\mathrm{N} \\
4=\text { Unclear }\end{array}$ \\
\hline \multicolumn{4}{|c|}{$\begin{array}{l}\text { If } \mathrm{QI}=(\mathrm{I} \text { or } 2) \mathrm{AND} Q 2=I \text { AND } \mathrm{Q} 3=(\mathrm{I} \text { and } 2)-\text { then include }=I \\
\text { If } \mathrm{Q} \mid=(\mathrm{I} \text { or } 2) \mathrm{AND} \mathrm{Q} 2=\mathrm{I} \text { AND } \mathrm{Q} 3=(\mathrm{I} \text { or } 2 \text { or } 3)-\text { then include }=2 \\
\text { If } 4-\text { then include }=4 \\
\text { Otherwise include }=3 \\
\text { CBA, cost-benefit analysis; CEA, cost-effectiveness analysis; CMA, cost-minimisation analysis; CUA, cost-utility analysis. }\end{array}$} \\
\hline
\end{tabular}





\section{Health Technology Assessment reports published to date}

\section{Volume I, 1997}

No. 1

Home parenteral nutrition: a systematic review.

By Richards DM, Deeks JJ, Sheldon TA, Shaffer JL.

No. 2

Diagnosis, management and screening of early localised prostate cancer.

A review by Selley S, Donovan J, Faulkner A, Coast J, Gillatt D.

No. 3

The diagnosis, management, treatment and costs of prostate cancer in England and Wales.

A review by Chamberlain J, Melia J, Moss S, Brown J.

No. 4

Screening for fragile $\mathrm{X}$ syndrome.

A review by Murray J, Cuckle $\mathrm{H}$, Taylor G, Hewison J.

No. 5

A review of near patient testing in primary care.

By Hobbs FDR, Delaney BC, Fitzmaurice DA, Wilson S, Hyde CJ, Thorpe GH, et al.

No. 6

Systematic review of outpatient services for chronic pain control.

By McQuay HJ, Moore RA, Eccleston

C, Morley S, de C Williams AC.

No. 7

Neonatal screening for inborn errors of metabolism: cost, yield and outcome.

A review by Pollitt RJ, Green A,

McCabe CJ, Booth A, Cooper NJ,

Leonard JV, et al.

No. 8

Preschool vision screening.

A review by Snowdon SK,

Stewart-Brown SL.

No. 9

Implications of socio-cultural contexts for the ethics of clinical trials.

A review by Ashcroft RE, Chadwick

DW, Clark SRL, Edwards RHT, Frith L, Hutton JL.

No. 10

A critical review of the role of neonatal hearing screening in the detection of congenital hearing impairment.

By Davis A, Bamford J, Wilson I, Ramkalawan T, Forshaw M, Wright S.
No. 11

Newborn screening for inborn errors of metabolism: a systematic review.

By Seymour CA, Thomason MJ,

Chalmers RA, Addison GM, Bain MD, Cockburn F, et al.

No. 12

Routine preoperative testing:

a systematic review of the evidence.

By Munro J, Booth A, Nicholl J.

No. 13

Systematic review of the effectiveness of laxatives in the elderly.

By Petticrew M, Watt I, Sheldon T.

No. 14

When and how to assess fast-changing technologies: a comparative study of medical applications of four generic technologies.

A review by Mowatt G, Bower DJ, Brebner JA, Cairns JA, Grant AM, McKee L.

\section{Volume 2, 1998}

No. 1

Antenatal screening for Down's syndrome.

A review by Wald NJ, Kennard A, Hackshaw A, McGuire A.

No. 2

Screening for ovarian cancer: a systematic review.

By Bell R, Petticrew M, Luengo S, Sheldon TA.

No. 3

Consensus development methods, and their use in clinical guideline development.

A review by Murphy MK, Black NA, Lamping DL, McKee CM, Sanderson CFB, Askham J, et al.

No. 4

A cost-utility analysis of interferon beta for multiple sclerosis.

By Parkin D, McNamee P, Jacoby A, Miller P, Thomas S, Bates D.

No. 5

Effectiveness and efficiency of methods of dialysis therapy for end-stage renal disease: systematic reviews.

By MacLeod A, Grant A

Donaldson C, Khan I, Campbell M, Daly C, et al.
No. 6

Effectiveness of hip prostheses in primary total hip replacement: a critical review of evidence and an economic model.

By Faulkner A, Kennedy LG, Baxter K, Donovan J, Wilkinson M, Bevan G.

No. 7

Antimicrobial prophylaxis in colorectal surgery: a systematic review of randomised controlled trials.

By Song F, Glenny AM.

No. 8

Bone marrow and peripheral blood stem cell transplantation for malignancy.

A review by Johnson PWM, Simnett SJ, Sweetenham JW, Morgan GJ, Stewart LA.

No. 9

Screening for speech and language delay: a systematic review of the literature.

By Law J, Boyle J, Harris F, Harkness A, Nye C.

No. 10

Resource allocation for chronic stable angina: a systematic review of effectiveness, costs and

cost-effectiveness of alternative interventions.

By Sculpher MJ, Petticrew M, Kelland JL, Elliott RA, Holdright DR, Buxton MJ.

No. 11

Detection, adherence and control of hypertension for the prevention of stroke: a systematic review.

By Ebrahim S.

No. 12

Postoperative analgesia and vomiting, with special reference to day-case surgery: a systematic review.

By McQuay HJ, Moore RA.

No. 13

Choosing between randomised and nonrandomised studies: a systematic review.

By Britton A, McKee M, Black N, McPherson K, Sanderson C, Bain C.

No. 14

Evaluating patient-based outcome measures for use in clinical trials.

A review by Fitzpatrick R, Davey C, Buxton MJ, Jones DR. 
No. 15

Ethical issues in the design and conduct of randomised controlled trials.

A review by Edwards SJL, Lilford RJ, Braunholtz DA, Jackson JC, Hewison J, Thornton J.

\section{No. 16}

Qualitative research methods in health technology assessment: a review of the literature.

By Murphy E, Dingwall R, Greatbatch D, Parker S, Watson P.

No. 17

The costs and benefits of paramedic skills in pre-hospital trauma care.

By Nicholl J, Hughes S, Dixon S, Turner J, Yates D.

\section{No. 18}

Systematic review of endoscopic ultrasound in gastro-oesophageal cancer.

By Harris KM, Kelly S, Berry E, Hutton J, Roderick P, Cullingworth J, et al.

No. 19

Systematic reviews of trials and other studies.

By Sutton AJ, Abrams KR, Jones DR, Sheldon TA, Song F.

\section{No. 20}

Primary total hip replacement surgery: a systematic review of outcomes and modelling of cost-effectiveness associated with different prostheses.

A review by Fitzpatrick R, Shortall E, Sculpher M, Murray D, Morris R, Lodge M, et al.

\section{Volume 3, 1999}

No. 1

Informed decision making: an annotated bibliography and systematic review.

By Bekker H, Thornton JG,

Airey CM, Connelly JB, Hewison J, Robinson MB, et al.

No. 2

Handling uncertainty when performing economic evaluation of healthcare interventions.

A review by Briggs AH, Gray AM.

No. 3

The role of expectancies in the placebo effect and their use in the delivery of health care: a systematic review.

By Crow R, Gage H, Hampson S, Hart J, Kimber A, Thomas H.

No. 4

A randomised controlled trial of different approaches to universal antenatal HIV testing: uptake and acceptability. Annex: Antenatal HIV testing - assessment of a routine voluntary approach.

By Simpson WM, Johnstone FD, Boyd
No. 5

Methods for evaluating area-wide and organisation-based interventions in health and health care: a systematic review.

By Ukoumunne OC, Gulliford MC, Chinn S, Sterne JAC, Burney PGJ.

No. 6

Assessing the costs of healthcare technologies in clinical trials.

A review by Johnston $\mathrm{K}$, Buxton MJ, Jones DR, Fitzpatrick R.

No. 7

Cooperatives and their primary care emergency centres: organisation and impact.

By Hallam L, Henthorne K.

No. 8

Screening for cystic fibrosis.

A review by Murray J, Cuckle $\mathrm{H}$, Taylor G, Littlewood J, Hewison J.

No. 9

A review of the use of health status measures in economic evaluation.

By Brazier J, Deverill M, Green C, Harper R, Booth A.

No. 10

Methods for the analysis of quality-oflife and survival data in health technology assessment.

A review by Billingham LJ, Abrams KR, Jones DR.

No. 11

Antenatal and neonatal

haemoglobinopathy screening in the

UK: review and economic analysis.

By Zeuner D, Ades AE, Karnon J,

Brown J, Dezateux C, Anionwu EN.

\section{No. 12}

Assessing the quality of reports of randomised trials: implications for the conduct of meta-analyses.

A review by Moher D, Cook DJ, Jadad AR, Tugwell P, Moher M, Jones A, et al.

No. 13

'Early warning systems' for identifying new healthcare technologies.

By Robert G, Stevens A, Gabbay J.

No. 14

A systematic review of the role of human papillomavirus testing within a cervical screening programme.

By Cuzick J, Sasieni P, Davies P, Adams J, Normand C, Frater A, et al.

\section{No. 15}

Near patient testing in diabetes clinics: appraising the costs and outcomes.

By Grieve R, Beech R, Vincent J, Mazurkiewicz J.

\section{No. 16}

Positron emission tomography: establishing priorities for health technology assessment.

A review by Robert $\mathrm{G}$, Milne $\mathrm{R}$.
No. 17 (Pt 1)

The debridement of chronic wounds: a systematic review.

By Bradley M, Cullum N, Sheldon T.

\section{No. 17 (Pt 2)}

Systematic reviews of wound care management: (2) Dressings and topical agents used in the healing of chronic wounds.

By Bradley M, Cullum N, Nelson EA, Petticrew M, Sheldon T, Torgerson D.

\section{No. 18}

A systematic literature review of spiral and electron beam computed

tomography: with particular reference to clinical applications in hepatic lesions, pulmonary embolus and coronary artery disease.

By Berry E, Kelly S, Hutton J, Harris KM, Roderick P, Boyce JC, et al.

\section{No. 19}

What role for statins? A review and economic model.

By Ebrahim S, Davey Smith G, McCabe C, Payne N, Pickin M, Sheldon TA, et al

\section{No. 20}

Factors that limit the quality, number and progress of randomised controlled trials.

A review by Prescott RJ, Counsell CE, Gillespie WJ, Grant AM, Russell IT, Kiauka S, et al.

No. 21

Antimicrobial prophylaxis in total hip replacement: a systematic review.

By Glenny AM, Song F.

No. 22

Health promoting schools and health promotion in schools: two systematic reviews.

By Lister-Sharp D, Chapman S, Stewart-Brown S, Sowden A.

No. 23

Economic evaluation of a primary carebased education programme for patients with osteoarthritis of the knee.

A review by Lord J, Victor C, Littlejohns P, Ross FM, Axford JS.

\section{Volume 4, 2000}

No. 1

The estimation of marginal time preference in a UK-wide sample (TEMPUS) project.

A review by Cairns JA, van der Pol MM.

No. 2

Geriatric rehabilitation following fractures in older people: a systematic review.

By Cameron I, Crotty M, Currie C, Finnegan T, Gillespie L, Gillespie W, et al. 
No. 3

Screening for sickle cell disease and thalassaemia: a systematic review with supplementary research.

By Davies SC, Cronin E, Gill M, Greengross P, Hickman M, Normand C.

No. 4

Community provision of hearing aids and related audiology services.

A review by Reeves DJ, Alborz A, Hickson FS, Bamford JM.

No. 5

False-negative results in screening programmes: systematic review of impact and implications.

By Petticrew MP, Sowden AJ, Lister-Sharp D, Wright K.

No. 6

Costs and benefits of community postnatal support workers: a randomised controlled trial.

By Morrell CJ, Spiby H, Stewart P, Walters S, Morgan A.

No. 7

Implantable contraceptives (subdermal implants and hormonally impregnated intrauterine systems) versus other forms of reversible contraceptives: two systematic reviews to assess relative effectiveness, acceptability, tolerability and cost-effectiveness.

By French RS, Cowan FM, Mansour DJA, Morris S, Procter T, Hughes D, et al.

No. 8

An introduction to statistical methods for health technology assessment.

A review by White SJ, Ashby D, Brown PJ.

No. 9

Disease-modifying drugs for multiple sclerosis: a rapid and systematic review.

By Clegg A, Bryant J, Milne R.

\section{No. 10}

Publication and related biases.

A review by Song F, Eastwood AJ,

Gilbody S, Duley L, Sutton AJ.

No. 11

Cost and outcome implications of the organisation of vascular services.

By Michaels J, Brazier J, Palfreyman S, Shackley P, Slack R.

\section{No. 12}

Monitoring blood glucose control in diabetes mellitus: a systematic review.

By Coster S, Gulliford MC, Seed PT, Powrie JK, Swaminathan R.

No. 13

The effectiveness of domiciliary health visiting: a systematic review of international studies

and a selective review of the British literature.

By Elkan R, Kendrick D, Hewitt M, Robinson JJA, Tolley K, Blair M, et al.

\section{No. 14}

The determinants of screening uptake and interventions for increasing uptake: a systematic review.

By Jepson R, Clegg A, Forbes C, Lewis R, Sowden A, Kleijnen J.

\section{No. 15}

The effectiveness and cost-effectiveness of prophylactic removal of wisdom teeth.

A rapid review by Song F, O'Meara S, Wilson P, Golder S, Kleijnen J.

\section{No. 16}

Ultrasound screening in pregnancy: a systematic review of the clinical effectiveness, cost-effectiveness and women's views.

By Bricker L, Garcia J, Henderson J, Mugford M, Neilson J, Roberts T, et al.

\section{No. 17}

A rapid and systematic review of the effectiveness and cost-effectiveness of the taxanes used in the treatment of advanced breast and ovarian cancer.

By Lister-Sharp D, McDonagh MS, Khan KS, Kleijnen J.

\section{No. 18}

Liquid-based cytology in cervical screening: a rapid and systematic review.

By Payne N, Chilcott J, McGoogan E.

No. 19

Randomised controlled trial of non-

directive counselling,

cognitive-behaviour therapy and usual general practitioner care in the management of depression as well as mixed anxiety and depression in primary care.

By King M, Sibbald B, Ward E, Bower P, Lloyd M, Gabbay M, et al.

\section{No. 20}

Routine referral for radiography of patients presenting with low back pain: is patients' outcome influenced by GPs' referral for plain radiography?

By Kerry S, Hilton S, Patel S, Dundas D, Rink E, Lord J.

\section{No. 21}

Systematic reviews of wound care management: (3) antimicrobial agents for chronic wounds; (4) diabetic foot ulceration.

By O'Meara S, Cullum N, Majid M, Sheldon T.

\section{No. 22}

Using routine data to complement and enhance the results of randomised controlled trials.

By Lewsey JD, Leyland AH,

Murray GD, Boddy FA.

\section{No. 23}

Coronary artery stents in the treatment of ischaemic heart disease: a rapid and systematic review.

By Meads C, Cummins C, Jolly K, Stevens A, Burls A, Hyde C.
No. 24

Outcome measures for adult critical

care: a systematic review.

By Hayes JA, Black NA,

Jenkinson C, Young JD, Rowan KM, Daly K, et al.

\section{No. 25}

A systematic review to evaluate the effectiveness of interventions to promote the initiation of breastfeeding.

By Fairbank L, O'Meara S, Renfrew MJ, Woolridge M, Sowden AJ, Lister-Sharp D.

No. 26

Implantable cardioverter defibrillators: arrhythmias. A rapid and systematic review.

By Parkes J, Bryant J, Milne R.

No. 27

Treatments for fatigue in multiple sclerosis: a rapid and systematic review.

By Brañas P, Jordan R, Fry-Smith A, Burls A, Hyde C.

No. 28

Early asthma prophylaxis, natural history, skeletal development and economy (EASE): a pilot randomised controlled trial.

By Baxter-Jones ADG, Helms PJ, Russell G, Grant A, Ross S, Cairns JA, et al.

No. 29

Screening for hypercholesterolaemia versus case finding for familial hypercholesterolaemia: a systematic review and cost-effectiveness analysis.

By Marks D, Wonderling D,

Thorogood M, Lambert H, Humphries SE, Neil HAW.

No. 30

A rapid and systematic review of the clinical effectiveness and cost-

effectiveness of glycoprotein IIb/IIIa antagonists in the medical management of unstable angina.

By McDonagh MS, Bachmann LM, Golder S, Kleijnen J, ter Riet G.

\section{No. 31}

A randomised controlled trial of prehospital intravenous fluid replacement therapy in serious trauma. By Turner J, Nicholl J, Webber L, Cox H, Dixon S, Yates D.

No. 32

Intrathecal pumps for giving opioids in chronic pain: a systematic review.

By Williams JE, Louw G, Towlerton G.

No. 33

Combination therapy (interferon alfa and ribavirin) in the treatment of chronic hepatitis C: a rapid and systematic review.

By Shepherd J, Waugh N, Hewitson P. 
No. 34

A systematic review of comparisons of effect sizes derived from randomised and non-randomised studies.

By MacLehose RR, Reeves BC, Harvey IM, Sheldon TA, Russell IT, Black AMS.

No. 35

Intravascular ultrasound-guided interventions in coronary artery disease: a systematic literature review, with decision-analytic modelling, of outcomes and cost-effectiveness.

By Berry E, Kelly S, Hutton J, Lindsay HSJ, Blaxill JM, Evans JA, et al.

No. 36

A randomised controlled trial to evaluate the effectiveness and costeffectiveness of counselling patients with chronic depression.

By Simpson S, Corney R, Fitzgerald P, Beecham J.

No. 37

Systematic review of treatments for atopic eczema.

By Hoare C, Li Wan Po A, Williams H.

No. 38

Bayesian methods in health technology assessment: a review.

By Spiegelhalter DJ, Myles JP, Jones DR, Abrams KR.

No. 39

The management of dyspepsia: a systematic review.

By Delaney B, Moayyedi P, Deeks J, Innes M, Soo S, Barton P, et al.

No. 40

A systematic review of treatments for severe psoriasis.

By Griffiths CEM, Clark CM, Chalmers RJG, Li Wan Po A, Williams HC.

\section{Volume 5, 200I}

No. 1

Clinical and cost-effectiveness of donepezil, rivastigmine and galantamine for Alzheimer's disease: a rapid and systematic review.

By Clegg A, Bryant J, Nicholson T, McIntyre L, De Broe S, Gerard K, et al.

No. 2

The clinical effectiveness and costeffectiveness of riluzole for motor neurone disease: a rapid and systematic review.

By Stewart A, Sandercock J, Bryan S, Hyde C, Barton PM, Fry-Smith A, et al.

No. 3

Equity and the economic evaluation of healthcare.

By Sassi F, Archard L, Le Grand J.

No. 4

Quality-of-life measures in chronic

diseases of childhood.

By Eiser C, Morse R.
No. 5

Eliciting public preferences for

healthcare: a systematic review of techniques.

By Ryan M, Scott DA, Reeves C, Bate A, van Teijlingen ER, Russell EM, et al.

No. 6

General health status measures for people with cognitive impairment: learning disability and acquired brain injury.

By Riemsma RP, Forbes CA, Glanville JM, Eastwood AJ, Kleijnen J.

No. 7

An assessment of screening strategies for fragile $\mathrm{X}$ syndrome in the UK.

By Pembrey ME, Barnicoat AJ, Carmichael B, Bobrow M, Turner G.

No. 8

Issues in methodological research: perspectives from researchers and commissioners.

By Lilford RJ, Richardson A, Stevens A, Fitzpatrick R, Edwards S, Rock F, et al.

No. 9

Systematic reviews of wound care management: (5) beds; (6) compression;

(7) laser therapy, therapeutic

ultrasound, electrotherapy and

electromagnetic therapy.

By Cullum N, Nelson EA, Flemming

$\mathrm{K}$, Sheldon T.

No. 10

Effects of educational and psychosocial interventions for adolescents with diabetes mellitus: a systematic review.

By Hampson SE, Skinner TC, Hart J, Storey L, Gage H, Foxcroft D, et al.

\section{No. 11}

Effectiveness of autologous chondrocyte transplantation for hyaline cartilage defects in knees: a rapid and systematic review.

By Jobanputra P, Parry D, Fry-Smith A, Burls A.

\section{No. 12}

Statistical assessment of the learning curves of health technologies.

By Ramsay CR, Grant AM,

Wallace SA, Garthwaite PH, Monk AF, Russell IT.

\section{No. 13}

The effectiveness and cost-effectiveness of temozolomide for the treatment of recurrent malignant glioma: a rapid and systematic review.

By Dinnes J, Cave C, Huang S, Major K, Milne R.

\section{No. 14}

A rapid and systematic review of the clinical effectiveness and costeffectiveness of debriding agents in treating surgical wounds healing by secondary intention.

By Lewis R, Whiting P, ter Riet G, O’Meara S, Glanville J.
No. 15

Home treatment for mental health

problems: a systematic review.

By Burns T, Knapp M,

Catty J, Healey A, Henderson J, Watt $\mathrm{H}$, et al.

\section{No. 16}

How to develop cost-conscious guidelines.

By Eccles M, Mason J.

No. 17

The role of specialist nurses in multiple sclerosis: a rapid and systematic review.

By De Broe S, Christopher F, Waugh N.

\section{No. 18}

A rapid and systematic review of the clinical effectiveness and costeffectiveness of orlistat in the management of obesity.

By O'Meara S, Riemsma R, Shirran L, Mather L, ter Riet G.

\section{No. 19}

The clinical effectiveness and costeffectiveness of pioglitazone for type 2 diabetes mellitus: a rapid and systematic review.

By Chilcott J, Wight J, Lloyd Jones M, Tappenden P.

\section{No. 20}

Extended scope of nursing practice: a multicentre randomised controlled trial of appropriately trained nurses and preregistration house officers in preoperative assessment in elective general surgery.

By Kinley H, Czoski-Murray C, George S, McCabe C, Primrose J, Reilly C, et al.

No. 21

Systematic reviews of the effectiveness of day care for people with severe mental disorders: (1) Acute day hospital versus admission; (2) Vocational rehabilitation; (3) Day hospital versus outpatient care.

By Marshall M, Crowther R, Almaraz Serrano A, Creed F, Sledge W, Kluiter $\mathrm{H}$, et al.

\section{No. 22}

The measurement and monitoring of surgical adverse events.

By Bruce J, Russell EM, Mollison J, Krukowski ZH.

\section{No. 23}

Action research: a systematic review and guidance for assessment.

By Waterman H, Tillen D, Dickson R, de Koning $\mathrm{K}$.

\section{No. 24}

A rapid and systematic review of the clinical effectiveness and cost-

effectiveness of gemcitabine for the treatment of pancreatic cancer.

By Ward S, Morris E, Bansback N, Calvert N, Crellin A, Forman D, et al. 
No. 25

A rapid and systematic review of the evidence for the clinical effectiveness and cost-effectiveness of irinotecan, oxaliplatin and raltitrexed for the treatment of advanced colorectal cancer.

By Lloyd Jones M, Hummel S, Bansback N, Orr B, Seymour M.

\section{No. 26}

Comparison of the effectiveness of inhaler devices in asthma and chronic obstructive airways disease: a systematic review of the literature.

By Brocklebank D, Ram F, Wright J, Barry P, Cates C, Davies L, et al.

\section{No. 27}

The cost-effectiveness of magnetic resonance imaging for investigation of the knee joint.

By Bryan S, Weatherburn G, Bungay H, Hatrick C, Salas C, Parry D, et al.

\section{No. 28}

A rapid and systematic review of the clinical effectiveness and costeffectiveness of topotecan for ovarian cancer.

By Forbes C, Shirran L, Bagnall A-M, Duffy S, ter Riet G.

\section{No. 29}

Superseded by a report published in a later volume.

No. 30

The role of radiography in primary care patients with low back pain of at least 6 weeks duration: a randomised (unblinded) controlled trial.

By Kendrick D, Fielding K, Bentley E, Miller P, Kerslake R, Pringle M.

\section{No. 31}

Design and use of questionnaires: a review of best practice applicable to surveys of health service staff and patients.

By McColl E, Jacoby A, Thomas L, Soutter J, Bamford C, Steen N, et al.

\section{No. 32}

A rapid and systematic review of the clinical effectiveness and cost-

effectiveness of paclitaxel, docetaxel, gemcitabine and vinorelbine in nonsmall-cell lung cancer.

By Clegg A, Scott DA, Sidhu M, Hewitson P, Waugh N.

\section{No. 33}

Subgroup analyses in randomised controlled trials: quantifying the risks of false-positives and false-negatives.

By Brookes ST, Whitley E, Peters TJ, Mulheran PA, Egger M, Davey Smith G.

\section{No. 34}

Depot antipsychotic medication in the treatment of patients with schizophrenia: (1) Meta-review; (2) Patient and nurse attitudes.

By David AS, Adams C.

\section{No. 35}

A systematic review of controlled trials of the effectiveness and costeffectiveness of brief psychological treatments for depression.

By Churchill R, Hunot V, Corney R, Knapp M, McGuire H, Tylee A, et al.

No. 36

Cost analysis of child health surveillance.

By Sanderson D, Wright D, Acton C, Duree D.

\section{Volume 6, 2002}

\section{No. 1}

A study of the methods used to select review criteria for clinical audit.

By Hearnshaw H, Harker R, Cheater F, Baker R, Grimshaw G.

No. 2

Fludarabine as second-line therapy for B cell chronic lymphocytic leukaemia: a technology assessment.

By Hyde C, Wake B, Bryan S, Barton P, Fry-Smith A, Davenport C, et al.

No. 3

Rituximab as third-line treatment for refractory or recurrent Stage III or IV follicular non-Hodgkin's lymphoma: a systematic review and economic evaluation.

By Wake B, Hyde C, Bryan S, Barton P, Song F, Fry-Smith A, et al.

No. 4

A systematic review of discharge arrangements for older people.

By Parker SG, Peet SM, McPherson A, Cannaby AM, Baker R, Wilson A, et al.

No. 5

The clinical effectiveness and costeffectiveness of inhaler devices used in the routine management of chronic asthma in older children: a systematic review and economic evaluation.

By Peters J, Stevenson M, Beverley C, Lim J, Smith S.

No. 6

The clinical effectiveness and costeffectiveness of sibutramine in the management of obesity: a technology assessment.

By O’Meara S, Riemsma R, Shirran L, Mather L, ter Riet G.

No. 7

The cost-effectiveness of magnetic resonance angiography for carotid artery stenosis and peripheral vascular disease: a systematic review.

By Berry E, Kelly S, Westwood ME, Davies LM, Gough MJ, Bamford JM, et al.

No. 8

Promoting physical activity in South Asian Muslim women through 'exercise on prescription'.

By Carroll B, Ali N, Azam N.
No. 9

Zanamivir for the treatment of influenza in adults: a systematic review and economic evaluation.

By Burls A, Clark W, Stewart T, Preston C, Bryan S, Jefferson T, et al.

\section{No. 10}

A review of the natural history and epidemiology of multiple sclerosis: implications for resource allocation and health economic models.

By Richards RG, Sampson FC, Beard SM, Tappenden P.

No. 11

Screening for gestational diabetes: a systematic review and economic evaluation.

By Scott DA, Loveman E, McIntyre L, Waugh N.

No. 12

The clinical effectiveness and costeffectiveness of surgery for people with morbid obesity: a systematic review and economic evaluation.

By Clegg AJ, Colquitt J, Sidhu MK, Royle P, Loveman E, Walker A.

\section{No. 13}

The clinical effectiveness of trastuzumab for breast cancer: a systematic review.

By Lewis R, Bagnall A-M, Forbes C, Shirran E, Duffy S, Kleijnen J, et al.

No. 14

The clinical effectiveness and costeffectiveness of vinorelbine for breast cancer: a systematic review and economic evaluation.

By Lewis R, Bagnall A-M, King S, Woolacott N, Forbes C, Shirran L, et al.

\section{No. 15}

A systematic review of the effectiveness and cost-effectiveness of metal-on-metal hip resurfacing arthroplasty for treatment of hip disease.

By Vale L, Wyness L, McCormack K, McKenzie L, Brazzelli M, Stearns SC.

\section{No. 16}

The clinical effectiveness and costeffectiveness of bupropion and nicotine replacement therapy for smoking cessation: a systematic review and economic evaluation.

By Woolacott NF, Jones L, Forbes CA, Mather LC, Sowden AJ, Song FJ, et al.

No. 17

A systematic review of effectiveness and economic evaluation of new drug treatments for juvenile idiopathic arthritis: etanercept.

By Cummins C, Connock M, Fry-Smith A, Burls A.

No. 18

Clinical effectiveness and costeffectiveness of growth hormone in children: a systematic review and economic evaluation.

By Bryant J, Cave C, Mihaylova B, Chase D, McIntyre L, Gerard K, et al. 
No. 19

Clinical effectiveness and cost-

effectiveness of growth hormone in adults in relation to impact on quality of life: a systematic review and economic evaluation.

By Bryant J, Loveman E, Chase D, Mihaylova B, Cave C, Gerard K, et al.

\section{No. 20}

Clinical medication review by a pharmacist of patients on repeat prescriptions in general practice: a randomised controlled trial.

By Zermansky AG, Petty DR, Raynor DK, Lowe CJ, Freementle N, Vail A.

No. 21

The effectiveness of infliximab and etanercept for the treatment of rheumatoid arthritis: a systematic review and economic evaluation.

By Jobanputra P, Barton P, Bryan S, Burls A.

No. 22

A systematic review and economic evaluation of computerised cognitive behaviour therapy for depression and anxiety.

By Kaltenthaler E, Shackley P, Stevens K, Beverley C, Parry G, Chilcott J.

No. 23

A systematic review and economic evaluation of pegylated liposomal doxorubicin hydrochloride for ovarian cancer.

By Forbes C, Wilby J, Richardson G, Sculpher M, Mather L, Reimsma R.

No. 24

A systematic review of the effectiveness of interventions based on a stages-ofchange approach to promote individual behaviour change.

By Riemsma RP, Pattenden J, Bridle C, Sowden AJ, Mather L, Watt IS, et al.

\section{No. 25}

A systematic review update of the clinical effectiveness and costeffectiveness of glycoprotein IIb/IIIa antagonists.

By Robinson M, Ginnelly L, Sculpher $\mathrm{M}$, Jones L, Riemsma R, Palmer S, et al.

\section{No. 26}

A systematic review of the effectiveness, cost-effectiveness and barriers to implementation of thrombolytic and neuroprotective therapy for acute ischaemic stroke in the NHS.

By Sandercock P, Berge E, Dennis M, Forbes J, Hand P, Kwan J, et al.

\section{No. 27}

A randomised controlled crossover trial of nurse practitioner versus doctor-led outpatient care in a bronchiectasis clinic.

By Caine N, Sharples LD,

Hollingworth W, French J, Keogan M, Exley A, et al.

\section{No. 28}

Clinical effectiveness and cost consequences of selective serotonin reuptake inhibitors in the treatment of sex offenders.

By Adi Y, Ashcroft D, Browne K, Beech A, Fry-Smith A, Hyde C.

\section{No. 29}

Treatment of established osteoporosis: a systematic review and cost-utility analysis.

By Kanis JA, Brazier JE, Stevenson M, Calvert NW, Lloyd Jones M.

No. 30

Which anaesthetic agents are costeffective in day surgery? Literature review, national survey of practice and randomised controlled trial.

By Elliott RA Payne K, Moore JK,

Davies LM, Harper NJN, St Leger AS, et al.

\section{No. 31}

Screening for hepatitis $\mathrm{C}$ among injecting drug users and in genitourinary medicine clinics: systematic reviews of effectiveness, modelling study and national survey of current practice.

By Stein K, Dalziel K, Walker A, McIntyre L, Jenkins B, Horne J, et al.

No. 32

The measurement of satisfaction with healthcare: implications for practice from a systematic review of the literature.

By Crow R, Gage H, Hampson S, Hart J, Kimber A, Storey L, et al.

No. 33

The effectiveness and cost-effectiveness of imatinib in chronic myeloid leukaemia: a systematic review.

By Garside R, Round A, Dalziel K, Stein K, Royle R.

\section{No. 34}

A comparative study of hypertonic saline, daily and alternate-day rhDNase in children with cystic fibrosis.

By Suri R, Wallis C, Bush A, Thompson S, Normand C, Flather M et al.

No. 35

A systematic review of the costs and effectiveness of different models of paediatric home care.

By Parker G, Bhakta P, Lovett CA, Paisley S, Olsen R, Turner D, et al.

\section{Volume 7, 2003}

No. 1

How important are comprehensive literature searches and the assessment of trial quality in systematic reviews? Empirical study.

By Egger M, Jüni P, Bartlett C, Holenstein F, Sterne J.

\section{No. 2}

Systematic review of the effectiveness and cost-effectiveness, and economic evaluation, of home versus hospital or satellite unit haemodialysis for people with end-stage renal failure.

By Mowatt G, Vale L, Perez J, Wyness L, Fraser C, MacLeod A, et al.

\section{No. 3}

Systematic review and economic evaluation of the effectiveness of infliximab for the treatment of Crohn's disease.

By Clark W, Raftery J, Barton P, Song F, Fry-Smith A, Burls A.

No. 4

A review of the clinical effectiveness and cost-effectiveness of routine anti-D prophylaxis for pregnant women who are rhesus negative.

By Chilcott J, Lloyd Jones M, Wight J, Forman K, Wray J, Beverley C, et al.

No. 5

Systematic review and evaluation of the use of tumour markers in paediatric oncology: Ewing's sarcoma and neuroblastoma.

By Riley RD, Burchill SA, Abrams KR, Heney D, Lambert PC, Jones DR, et al.

No. 6

The cost-effectiveness of screening for Helicobacter pylori to reduce mortality and morbidity from gastric cancer and peptic ulcer disease: a discrete-event simulation model.

By Roderick P, Davies R, Raftery J, Crabbe D, Pearce R, Bhandari P, et al.

No. 7

The clinical effectiveness and costeffectiveness of routine dental checks: a systematic review and economic evaluation.

By Davenport C, Elley K, Salas C, Taylor-Weetman CL, Fry-Smith A, Bryan S, et al.

\section{No. 8}

A multicentre randomised controlled trial assessing the costs and benefits of using structured information and analysis of women's preferences in the management of menorrhagia.

By Kennedy ADM, Sculpher MJ, Coulter A, Dwyer N, Rees M, Horsley S, et al.

No. 9

Clinical effectiveness and cost-utility of photodynamic therapy for wet age-related macular degeneration: a systematic review and economic evaluation.

By Meads C, Salas C, Roberts T, Moore D, Fry-Smith A, Hyde C.

No. 10

Evaluation of molecular tests for prenatal diagnosis of chromosome abnormalities.

By Grimshaw GM, Szczepura A,

Hultén M, MacDonald F, Nevin NC, Sutton F, et al. 
No. 11

First and second trimester antenatal screening for Down's syndrome: the results of the Serum, Urine and Ultrasound Screening Study (SURUSS).

By Wald NJ, Rodeck C, Hackshaw AK, Walters J, Chitty L, Mackinson AM.

No. 12

The effectiveness and cost-effectiveness of ultrasound locating devices for central venous access: a systematic review and economic evaluation.

By Calvert N, Hind D, McWilliams RG, Thomas SM, Beverley C, Davidson A.

No. 13

A systematic review of atypical antipsychotics in schizophrenia.

By Bagnall A-M, Jones L, Lewis R, Ginnelly L, Glanville J, Torgerson D, et al.

\section{No. 14}

Prostate Testing for Cancer and Treatment (ProtecT) feasibility study.

By Donovan J, Hamdy F, Neal D, Peters T, Oliver S, Brindle L, et al.

No. 15

Early thrombolysis for the treatment of acute myocardial infarction: a systematic review and economic evaluation.

By Boland A, Dundar Y, Bagust A, Haycox A, Hill R, Mujica Mota R, et al.

\section{No. 16}

Screening for fragile $\mathrm{X}$ syndrome: a literature review and modelling.

By Song FJ, Barton P, Sleightholme V, Yao GL, Fry-Smith A

\section{No. 17}

Systematic review of endoscopic sinus surgery for nasal polyps.

By Dalziel K, Stein K, Round A, Garside R, Royle P.

\section{No. 18}

Towards efficient guidelines: how to monitor guideline use in primary care.

By Hutchinson A, McIntosh A, Cox S, Gilbert C.

\section{No. 19}

Effectiveness and cost-effectiveness of acute hospital-based spinal cord injuries services: systematic review.

By Bagnall A-M, Jones L,

Richardson G, Duffy S,

Riemsma R.

No. 20

Prioritisation of health technology assessment. The PATHS model: methods and case studies.

By Townsend J, Buxton M,
No. 21

Systematic review of the clinical effectiveness and cost-effectiveness of tension-free vaginal tape for treatment of urinary stress incontinence.

By Cody J, Wyness L, Wallace S, Glazener C, Kilonzo M, Stearns S, et al.

\section{No. 22}

The clinical and cost-effectiveness of patient education models for diabetes: a systematic review and economic evaluation.

By Loveman E, Cave C, Green C, Royle P, Dunn N, Waugh N.

\section{No. 23}

The role of modelling in prioritising and planning clinical trials.

By Chilcott J, Brennan A, Booth A, Karnon J, Tappenden P.

\section{No. 24}

Cost-benefit evaluation of routine influenza immunisation in people 65-74 years of age.

By Allsup S, Gosney M, Haycox A, Regan M.

No. 25

The clinical and cost-effectiveness of pulsatile machine perfusion versus cold storage of kidneys for transplantation retrieved from heart-beating and nonheart-beating donors.

By Wight J, Chilcott J, Holmes M, Brewer N

\section{No. 26}

Can randomised trials rely on existing electronic data? A feasibility study to explore the value of routine data in health technology assessment.

By Williams JG, Cheung WY,

Cohen DR, Hutchings HA, Longo MF, Russell IT.

\section{No. 27}

Evaluating non-randomised intervention studies.

By Deeks JJ, Dinnes J, D’Amico R, Sowden AJ, Sakarovitch C, Song F, et al.

\section{No. 28}

A randomised controlled trial to assess the impact of a package comprising a patient-orientated, evidence-based selfhelp guidebook and patient-centred consultations on disease management and satisfaction in inflammatory bowel disease.

By Kennedy A, Nelson E, Reeves D, Richardson G, Roberts C, Robinson A, et al.

\section{No. 29}

The effectiveness of diagnostic tests for the assessment of shoulder pain due to soft tissue disorders: a systematic review.

By Dinnes J, Loveman E, McIntyre L, Waugh N.
No. 30

The value of digital imaging in diabetic retinopathy.

By Sharp PF, Olson J, Strachan F, Hipwell J, Ludbrook A, O'Donnell M, et al.

No. 31

Lowering blood pressure to prevent myocardial infarction and stroke: a new preventive strategy.

By Law M, Wald N, Morris J.

No. 32

Clinical and cost-effectiveness of capecitabine and tegafur with uracil for the treatment of metastatic colorectal cancer: systematic review and economic evaluation.

By Ward S, Kaltenthaler E, Cowan J, Brewer N.

No. 33

Clinical and cost-effectiveness of new and emerging technologies for early localised prostate cancer: a systematic review.

By Hummel S, Paisley S, Morgan A, Currie E, Brewer N.

No. 34

Literature searching for clinical and cost-effectiveness studies used in health technology assessment reports carried out for the National Institute for Clinical Excellence appraisal system.

By Royle P, Waugh N.

No. 35

Systematic review and economic decision modelling for the prevention and treatment of influenza

$\mathrm{A}$ and $\mathrm{B}$.

By Turner D, Wailoo A, Nicholson K, Cooper N, Sutton A, Abrams K.

No. 36

A randomised controlled trial to evaluate the clinical and costeffectiveness of Hickman line insertions in adult cancer patients by nurses.

By Boland A, Haycox A, Bagust A, Fitzsimmons L.

No. 37

Redesigning postnatal care: a randomised controlled trial of protocol-based midwifery-led care focused on individual women's physical and psychological health needs.

By MacArthur C, Winter HR, Bick DE, Lilford RJ, Lancashire RJ, Knowles $\mathrm{H}$, et al.

No. 38

Estimating implied rates of discount in healthcare decision-making.

By West RR, McNabb R,

Thompson AGH, Sheldon TA, Grimley Evans J. 
No. 39

Systematic review of isolation policies in the hospital management of methicillinresistant Staphylococcus aureus: a review of the literature with epidemiological and economic modelling.

By Cooper BS, Stone SP, Kibbler CC, Cookson BD, Roberts JA, Medley GF, et al.

No. 40

Treatments for spasticity and pain in multiple sclerosis: a systematic review.

By Beard S, Hunn A, Wight J.

No. 41

The inclusion of reports of randomised trials published in languages other than English in systematic reviews.

By Moher D, Pham B, Lawson ML, Klassen TP.

No. 42

The impact of screening on future health-promoting behaviours and health beliefs: a systematic review.

By Bankhead CR, Brett J, Bukach C, Webster P, Stewart-Brown S, Munafo M, et al.

\section{Volume 8, 2004}

No. 1

What is the best imaging strategy for acute stroke?

By Wardlaw JM, Keir SL, Seymour J, Lewis S, Sandercock PAG, Dennis MS, et al.

No. 2

Systematic review and modelling of the investigation of acute and chronic chest pain presenting in primary care.

By Mant J, McManus RJ, Oakes RAL, Delaney BC, Barton PM, Deeks JJ, et al.

No. 3

The effectiveness and cost-effectiveness of microwave and thermal balloon endometrial ablation for heavy menstrual bleeding: a systematic review and economic modelling.

By Garside R, Stein K, Wyatt K, Round A, Price A.

No. 4

A systematic review of the role of bisphosphonates in metastatic disease.

By Ross JR, Saunders Y, Edmonds PM, Patel S, Wonderling D, Normand C, et al.

No. 5

Systematic review of the clinical effectiveness and cost-effectiveness of capecitabine (Xeloda ${ }^{\circledR}$ ) for locally advanced and/or metastatic breast cancer.

By Jones L, Hawkins N, Westwood M, Wright K, Richardson G, Riemsma R.

No. 6

Effectiveness and efficiency of guideline dissemination and implementation strategies.

By Grimshaw JM, Thomas RE, MacLennan G, Fraser C, Ramsay CR,
No. 7

Clinical effectiveness and costs of the Sugarbaker procedure for the treatment of pseudomyxoma peritonei.

By Bryant J, Clegg AJ, Sidhu MK, Brodin H, Royle P, Davidson P.

No. 8

Psychological treatment for insomnia in the regulation of long-term hypnotic drug use.

By Morgan K, Dixon S, Mathers N, Thompson J, Tomeny M.

No. 9

Improving the evaluation of therapeutic interventions in multiple sclerosis: development of a patient-based measure of outcome.

By Hobart JC, Riazi A, Lamping DL, Fitzpatrick R, Thompson AJ.

\section{No. 10}

A systematic review and economic evaluation of magnetic resonance cholangiopancreatography compared with diagnostic endoscopic retrograde cholangiopancreatography.

By Kaltenthaler E, Bravo Vergel Y, Chilcott J, Thomas S, Blakeborough T, Walters SJ, et al.

\section{No. 11}

The use of modelling to evaluate new drugs for patients with a chronic condition: the case of antibodies against tumour necrosis factor in rheumatoid arthritis

By Barton P, Jobanputra P, Wilson J, Bryan S, Burls A

No. 12

Clinical effectiveness and costeffectiveness of neonatal screening for inborn errors of metabolism using tandem mass spectrometry: a systematic review.

By Pandor A, Eastham J, Beverley C, Chilcott J, Paisley S.

\section{No. 13}

Clinical effectiveness and costeffectiveness of pioglitazone and rosiglitazone in the treatment of type 2 diabetes: a systematic review and economic evaluation.

By Czoski-Murray C, Warren E, Chilcott J, Beverley C, Psyllaki MA, Cowan J.

\section{No. 14}

Routine examination of the newborn: the EMREN study. Evaluation of an extension of the midwife role including a randomised controlled trial of appropriately trained midwives and paediatric senior house officers.

By Townsend J, Wolke D, Hayes J, Davé S, Rogers C, Bloomfield L, et al.
No. 15

Involving consumers in research and development agenda setting for the NHS: developing an evidence-based approach.

By Oliver S, Clarke-Jones L, Rees R, Milne R, Buchanan P, Gabbay J, et al.

No. 16

A multi-centre randomised controlled trial of minimally invasive direct coronary bypass grafting versus percutaneous transluminal coronary angioplasty with stenting for proximal stenosis of the left anterior descending coronary artery.

By Reeves BC, Angelini GD, Bryan AJ, Taylor FC, Cripps T, Spyt TJ, et al.

No. 17

Does early magnetic resonance imaging influence management or improve outcome in patients referred to secondary care with low back pain? A pragmatic randomised controlled trial.

By Gilbert FJ, Grant AM, Gillan MGC, Vale L, Scott NW, Campbell MK, et al.

No. 18

The clinical and cost-effectiveness of anakinra for the treatment of rheumatoid arthritis in adults: a systematic review and economic analysis

By Clark W, Jobanputra P, Barton P, Burls A.

No. 19

A rapid and systematic review and economic evaluation of the clinical and cost-effectiveness of newer drugs for treatment of mania associated with bipolar affective disorder.

By Bridle C, Palmer S, Bagnall A-M, Darba J, Duffy S, Sculpher M, et al.

No. 20

Liquid-based cytology in cervical screening: an updated rapid and systematic review and economic analysis.

By Karnon J, Peters J, Platt J, Chilcott J, McGoogan E, Brewer N.

No. 21

Systematic review of the long-term effects and economic consequences of treatments for obesity and implications for health improvement.

By Avenell A, Broom J, Brown TJ, Poobalan A, Aucott L, Stearns SC, et al.

No. 22

Autoantibody testing in children with newly diagnosed type 1 diabetes

mellitus.

By Dretzke J, Cummins C, Sandercock J, Fry-Smith A, Barrett T, Burls A. 
No. 23

Clinical effectiveness and cost-

effectiveness of prehospital intravenous fluids in trauma patients.

By Dretzke J, Sandercock J, Bayliss S, Burls A.

\section{No. 24}

Newer hypnotic drugs for the shortterm management of insomnia: a systematic review and economic evaluation.

By Dündar Y, Boland A, Strobl J, Dodd S, Haycox A, Bagust A, et al.

\section{No. 25}

Development and validation of methods for assessing the quality of diagnostic accuracy studies.

By Whiting P, Rutjes AWS, Dinnes J, Reitsma JB, Bossuyt PMM, Kleijnen J.

No. 26

EVALUATE hysterectomy trial: a multicentre randomised trial comparing abdominal, vaginal and laparoscopic methods of hysterectomy.

By Garry R, Fountain J, Brown J, Manca A, Mason S, Sculpher M, et al.

\section{No. 27}

Methods for expected value of information analysis in complex health economic models: developments on the health economics of interferon- $\beta$ and glatiramer acetate for multiple sclerosis.

By Tappenden P, Chilcott JB, Eggington S, Oakley J, McCabe C.

No. 28

Effectiveness and cost-effectiveness of imatinib for first-line treatment of chronic myeloid leukaemia in chronic phase: a systematic review and economic analysis.

By Dalziel K, Round A, Stein K, Garside R, Price A.

\section{No. 29}

VenUS I: a randomised controlled trial of two types of bandage for treating venous leg ulcers.

By Iglesias C, Nelson EA, Cullum NA, Torgerson DJ on behalf of the VenUS Team.

\section{No. 30}

Systematic review of the effectiveness and cost-effectiveness, and economic evaluation, of myocardial perfusion scintigraphy for the diagnosis and management of angina and myocardial infarction.

By Mowatt G, Vale L, Brazzelli M, Hernandez R, Murray A, Scott N, et al.

\section{No. 31}

A pilot study on the use of decision theory and value of information analysis as part of the NHS Health Technology Assessment programme.

By Claxton K, Ginnelly L, Sculpher M, Philips Z, Palmer S.

\section{No. 32}

The Social Support and Family Health Study: a randomised controlled trial and economic evaluation of two alternative forms of postnatal support for mothers living in disadvantaged inner-city areas.

By Wiggins M, Oakley A, Roberts I,

Turner H, Rajan L, Austerberry H, et al.

No. 33

Psychosocial aspects of genetic screening of pregnant women and newborns: a systematic review.

By Green JM, Hewison J, Bekker HL, Bryant, Cuckle HS.

\section{No. 34}

Evaluation of abnormal uterine

bleeding: comparison of three outpatient procedures within cohorts defined by age and menopausal status.

By Critchley HOD, Warner P,

Lee AJ, Brechin S, Guise J, Graham B.

\section{No. 35}

Coronary artery stents: a rapid systematic review and economic evaluation.

By Hill R, Bagust A, Bakhai A,

Dickson R, Dündar Y, Haycox A, et al.

\section{No. 36}

Review of guidelines for good practice in decision-analytic modelling in health technology assessment.

By Philips Z, Ginnelly L, Sculpher M, Claxton K, Golder S, Riemsma R, et al.

No. 37

Rituximab (MabThera ${ }^{\circledR}$ ) for aggressive non-Hodgkin's lymphoma: systematic review and economic evaluation.

By Knight C, Hind D, Brewer N, Abbott V.

No. 38

Clinical effectiveness and cost-

effectiveness of clopidogrel and modified-release dipyridamole in the secondary prevention of occlusive vascular events: a systematic review and economic evaluation.

By Jones L, Griffin S, Palmer S, Main C, Orton V, Sculpher M, et al.

\section{No. 39}

Pegylated interferon $\alpha$-2a and -2b in combination with ribavirin in the treatment of chronic hepatitis C: a systematic review and economic evaluation.

By Shepherd J, Brodin H, Cave C, Waugh N, Price A, Gabbay J.

\section{No. 40}

Clopidogrel used in combination with aspirin compared with aspirin alone in the treatment of non-ST-segmentelevation acute coronary syndromes: a systematic review and economic evaluation.

By Main C, Palmer S, Griffin S, Jones L, Orton V, Sculpher M, et al.
No. 41

Provision, uptake and cost of cardiac rehabilitation programmes: improving services to under-represented groups.

By Beswick AD, Rees K, Griebsch I, Taylor FC, Burke M, West RR, et al.

\section{No. 42}

Involving South Asian patients in clinical trials.

By Hussain-Gambles M, Leese B, Atkin K, Brown J, Mason S, Tovey P.

No. 43

Clinical and cost-effectiveness of continuous subcutaneous insulin infusion for diabetes.

By Colquitt JL, Green C, Sidhu MK, Hartwell D, Waugh N.

No. 44

Identification and assessment of ongoing trials in health technology assessment reviews.

By Song FJ, Fry-Smith A, Davenport C, Bayliss S, Adi Y, Wilson JS, et al.

No. 45

Systematic review and economic evaluation of a long-acting insulin analogue, insulin glargine

By Warren E, Weatherley-Jones E, Chilcott J, Beverley C.

\section{No. 46}

Supplementation of a home-based exercise programme with a class-based programme for people with osteoarthritis of the knees: a randomised controlled trial and health economic analysis.

By McCarthy CJ, Mills PM,

Pullen R, Richardson G, Hawkins N, Roberts CR, et al.

\section{No. 47}

Clinical and cost-effectiveness of oncedaily versus more frequent use of same potency topical corticosteroids for atopic eczema: a systematic review and economic evaluation.

By Green C, Colquitt JL, Kirby J, Davidson P, Payne E.

No. 48

Acupuncture of chronic headache disorders in primary care: randomised controlled trial and economic analysis.

By Vickers AJ, Rees RW, Zollman CE, McCarney R, Smith CM, Ellis N, et al.

\section{No. 49}

Generalisability in economic evaluation studies in healthcare: a review and case studies.

By Sculpher MJ, Pang FS, Manca A, Drummond MF, Golder S, Urdahl H, et al.

\section{No. 50}

Virtual outreach: a randomised controlled trial and economic evaluation of joint teleconferenced medical consultations.

By Wallace P, Barber J, Clayton W, Currell R, Fleming K, Garner P, et al. 


\section{Volume 9, 2005}

No. 1

Randomised controlled multiple treatment comparison to provide a cost-effectiveness rationale for the selection of antimicrobial therapy in acne.

By Ozolins M, Eady EA, Avery A, Cunliffe WJ, O'Neill C, Simpson NB, et al.

No. 2

Do the findings of case series studies vary significantly according to methodological characteristics?

By Dalziel K, Round A, Stein K, Garside R, Castelnuovo E, Payne L.

No. 3

Improving the referral process for familial breast cancer genetic counselling: findings of three randomised controlled trials of two interventions.

By Wilson BJ, Torrance N, Mollison J, Wordsworth S, Gray JR, Haites NE, et al.

No. 4

Randomised evaluation of alternative electrosurgical modalities to treat bladder outflow obstruction in men with benign prostatic hyperplasia.

By Fowler C, McAllister W, Plail R, Karim O, Yang $Q$.

No. 5

A pragmatic randomised controlled trial of the cost-effectiveness of palliative therapies for patients with inoperable oesophageal cancer.

By Shenfine J, McNamee P, Steen N, Bond J, Griffin SM.

\section{No. 6}

Impact of computer-aided detection prompts on the sensitivity and specificity of screening mammography.

By Taylor P, Champness J, GivenWilson R, Johnston K, Potts H.

No. 7

Issues in data monitoring and interim analysis of trials.

By Grant AM, Altman DG, Babiker $\mathrm{AB}$, Campbell MK, Clemens FJ, Darbyshire JH, et al.

No. 8

Lay public's understanding of equipoise and randomisation in randomised controlled trials.

By Robinson EJ, Kerr CEP, Stevens AJ, Lilford RJ, Braunholtz DA, Edwards SJ, et al.

No. 9

Clinical and cost-effectiveness of electroconvulsive therapy for depressive illness, schizophrenia, catatonia and mania: systematic reviews and economic modelling studies.

By Greenhalgh J, Knight C, Hind D, Beverley C, Walters S.

\section{No. 10}

Measurement of health-related quality of life for people with dementia: development of a new instrument (DEMQOL) and an evaluation of current methodology.

By Smith SC, Lamping DL,

Banerjee S, Harwood R, Foley B, Smith P, et al.

\section{No. 11}

Clinical effectiveness and costeffectiveness of drotrecogin alfa (activated) $\left(\right.$ Xigris $\left.^{\circledR}\right)$ for the treatment of severe sepsis in adults: a systematic review and economic evaluation.

By Green C, Dinnes J, Takeda A, Shepherd J, Hartwell D, Cave C, et al.

\section{No. 12}

A methodological review of how heterogeneity has been examined in systematic reviews of diagnostic test accuracy.

By Dinnes J, Deeks J, Kirby J, Roderick P.

\section{No. 13}

Cervical screening programmes: can automation help? Evidence from systematic reviews, an economic analysis and a simulation modelling exercise applied to the UK.

By Willis BH, Barton P, Pearmain P, Bryan S, Hyde C.

\section{No. 14}

Laparoscopic surgery for inguinal hernia repair: systematic review of effectiveness and economic evaluation.

By McCormack K, Wake B, Perez J, Fraser C, Cook J, McIntosh E, et al.

\section{No. 15}

Clinical effectiveness, tolerability and cost-effectiveness of newer drugs for epilepsy in adults: a systematic review and economic evaluation.

By Wilby J, Kainth A, Hawkins N, Epstein D, McIntosh H, McDaid C, et al.

\section{No. 16}

A randomised controlled trial to compare the cost-effectiveness of tricyclic antidepressants, selective serotonin reuptake inhibitors and lofepramine.

By Peveler R, Kendrick T, Buxton M, Longworth L, Baldwin D, Moore M, et al.

No. 17

Clinical effectiveness and costeffectiveness of immediate angioplasty for acute myocardial infarction: systematic review and economic evaluation.

By Hartwell D, Colquitt J, Loveman E, Clegg AJ, Brodin H, Waugh N, et al.
No. 18

A randomised controlled comparison of alternative strategies in stroke care.

By Kalra L, Evans A, Perez I,

Knapp M, Swift C, Donaldson N.

No. 19

The investigation and analysis of critical incidents and adverse events in healthcare.

By Woloshynowych M, Rogers S, Taylor-Adams S, Vincent C.

\section{No. 20}

Potential use of routine databases in health technology assessment.

By Raftery J, Roderick P, Stevens A.

No. 21

Clinical and cost-effectiveness of newer immunosuppressive regimens in renal transplantation: a systematic review and modelling study.

By Woodroffe R, Yao GL, Meads C, Bayliss S, Ready A, Raftery J, et al.

No. 22

A systematic review and economic evaluation of alendronate, etidronate, risedronate, raloxifene and teriparatide for the prevention and treatment of postmenopausal osteoporosis.

By Stevenson M, Lloyd Jones M, De Nigris E, Brewer N, Davis S, Oakley J.

No. 23

A systematic review to examine the impact of psycho-educational interventions on health outcomes and costs in adults and children with difficult asthma.

By Smith JR, Mugford M, Holland R, Candy B, Noble MJ, Harrison BDW, et al.

No. 24

An evaluation of the costs, effectiveness and quality of renal replacement therapy provision in renal satellite units in England and Wales.

By Roderick P, Nicholson T, Armitage A, Mehta R, Mullee M, Gerard K, et al.

No. 25

Imatinib for the treatment of patients with unresectable and/or metastatic gastrointestinal stromal tumours: systematic review and economic evaluation.

By Wilson J, Connock M, Song F, Yao G, Fry-Smith A, Raftery J, et al.

No. 26

Indirect comparisons of competing interventions.

By Glenny AM, Altman DG, Song F, Sakarovitch C, Deeks JJ, D'Amico R, et al.

No. 27

Cost-effectiveness of alternative strategies for the initial medical management of non-ST elevation acute coronary syndrome: systematic review and decision-analytical modelling.

By Robinson M, Palmer S, Sculpher M, Philips Z, Ginnelly L, Bowens A, et al. 
No. 28

Outcomes of electrically stimulated gracilis neosphincter surgery.

By Tillin T, Chambers M, Feldman R.

No. 29

The effectiveness and cost-effectiveness of pimecrolimus and tacrolimus for atopic eczema: a systematic review and economic evaluation.

By Garside R, Stein K, Castelnuovo E, Pitt M, Ashcroft D, Dimmock P, et al.

No. 30

Systematic review on urine albumin testing for early detection of diabetic complications.

By Newman DJ, Mattock MB, Dawnay ABS, Kerry S, McGuire A, Yaqoob M, et al.

No. 31

Randomised controlled trial of the costeffectiveness of water-based therapy for lower limb osteoarthritis.

By Cochrane T, Davey RC, Matthes Edwards SM.

No. 32

Longer term clinical and economic benefits of offering acupuncture care to patients with chronic low back pain.

By Thomas KJ, MacPherson H, Ratcliffe J, Thorpe L, Brazier J, Campbell M, et al.

No. 33

Cost-effectiveness and safety of epidural steroids in the management of sciatica.

By Price C, Arden N, Coglan L, Rogers P.

No. 34

The British Rheumatoid Outcome Study Group (BROSG) randomised controlled trial to compare the effectiveness and cost-effectiveness of aggressive versus symptomatic therapy in established rheumatoid arthritis.

By Symmons D, Tricker K, Roberts C, Davies L, Dawes P, Scott DL.

No. 35

Conceptual framework and systematic review of the effects of participants' and professionals' preferences in randomised controlled trials.

By King M, Nazareth I, Lampe F, Bower P, Chandler M, Morou M, et al.

No. 36

The clinical and cost-effectiveness of implantable cardioverter defibrillators: a systematic review.

By Bryant J, Brodin H, Loveman E, Payne E, Clegg A.

No. 37

A trial of problem-solving by community mental health nurses for anxiety, depression and life difficulties among general practice patients. The CPN-GP study.

By Kendrick T, Simons L,

Mynors-Wallis L, Gray A, Lathlean J,

Pickering R, et al.
No. 38

The causes and effects of sociodemographic exclusions from clinical trials.

By Bartlett C, Doyal L, Ebrahim S, Davey P, Bachmann M, Egger M, et al.

\section{No. 39}

Is hydrotherapy cost-effective? A randomised controlled trial of combined hydrotherapy programmes compared with physiotherapy land techniques in children with juvenile idiopathic arthritis.

By Epps H, Ginnelly L, Utley M, Southwood T, Gallivan S, Sculpher M, et al.

\section{No. 40}

A randomised controlled trial and costeffectiveness study of systematic screening (targeted and total population screening) versus routine practice for the detection of atrial fibrillation in people aged 65 and over. The SAFE study.

By Hobbs FDR, Fitzmaurice DA, Mant J, Murray E, Jowett S, Bryan S, et al.

\section{No. 41}

Displaced intracapsular hip fractures in fit, older people: a randomised comparison of reduction and fixation, bipolar hemiarthroplasty and total hip arthroplasty.

By Keating JF, Grant A, Masson M, Scott NW, Forbes JF.

\section{No. 42}

Long-term outcome of cognitive behaviour therapy clinical trials in central Scotland.

By Durham RC, Chambers JA, Power KG, Sharp DM, Macdonald RR, Major KA, et al.

\section{No. 43}

The effectiveness and cost-effectiveness of dual-chamber pacemakers compared with single-chamber pacemakers for bradycardia due to atrioventricular block or sick sinus syndrome: systematic review and economic evaluation.

By Castelnuovo E, Stein K, Pitt M, Garside R, Payne E.

\section{No. 44}

Newborn screening for congenital heart defects: a systematic review and cost-effectiveness analysis.

By Knowles R, Griebsch I, Dezateux C, Brown J, Bull C, Wren C.

\section{No. 45}

The clinical and cost-effectiveness of left ventricular assist devices for end-stage heart failure: a systematic review and economic evaluation.

By Clegg AJ, Scott DA, Loveman E, Colquitt J, Hutchinson J, Royle P, et al.
No. 46

The effectiveness of the Heidelberg

Retina Tomograph and laser diagnostic glaucoma scanning system (GDx) in detecting and monitoring glaucoma

By Kwartz AJ, Henson DB,

Harper RA, Spencer AF, McLeod D.

No. 47

Clinical and cost-effectiveness of autologous chondrocyte implantation for cartilage defects in knee joints: systematic review and economic evaluation.

By Clar C, Cummins E, McIntyre L, Thomas S, Lamb J, Bain L, et al.

\section{No. 48}

Systematic review of effectiveness of different treatments for childhood retinoblastoma.

By McDaid C, Hartley S, Bagnall A-M, Ritchie G, Light K, Riemsma R.

No. 49

Towards evidence-based guidelines for the prevention of venous thromboembolism: systematic reviews of mechanical methods, oral anticoagulation, dextran and regional anaesthesia as thromboprophylaxis.

By Roderick P, Ferris G, Wilson K, Halls H, Jackson D, Collins R, et al.

No. 50

The effectiveness and cost-effectiveness of parent training/education programmes for the treatment of conduct disorder, including oppositional defiant disorder, in children.

By Dretzke J, Frew E, Davenport C, Barlow J, Stewart-Brown S, Sandercock J, et al.

\section{Volume 10, 2006}

No. 1

The clinical and cost-effectiveness of donepezil, rivastigmine, galantamine and memantine for Alzheimer's disease.

By Loveman E, Green C, Kirby J, Takeda A, Picot J, Payne E, et al.

No. 2

FOOD: a multicentre randomised trial evaluating feeding policies in patients admitted to hospital with a recent stroke.

By Dennis M, Lewis S, Cranswick G, Forbes J.

No. 3

The clinical effectiveness and costeffectiveness of computed tomography screening for lung cancer: systematic reviews.

By Black C, Bagust A, Boland A, Walker S, McLeod C, De Verteuil R, et al. 
No. 4

A systematic review of the effectiveness and cost-effectiveness of neuroimaging assessments used to visualise the seizure focus in people with refractory epilepsy being considered for surgery.

By Whiting P, Gupta R, Burch J, Mujica Mota RE, Wright K, Marson A, et al.

No. 5

Comparison of conference abstracts and presentations with full-text articles in the health technology assessments of rapidly evolving technologies.

By Dundar Y, Dodd S, Dickson R, Walley T, Haycox A, Williamson PR.

\section{No. 6}

Systematic review and evaluation of methods of assessing urinary incontinence.

By Martin JL, Williams KS, Abrams KR, Turner DA, Sutton AJ, Chapple C, et al.

\section{No. 7}

The clinical effectiveness and costeffectiveness of newer drugs for children with epilepsy. A systematic review.

By Connock M, Frew E, Evans B-W, Bryan S, Cummins C, Fry-Smith A, et al.

\section{No. 8}

Surveillance of Barrett's oesophagus: exploring the uncertainty through systematic review, expert workshop and economic modelling.

By Garside R, Pitt M, Somerville M, Stein K, Price A, Gilbert N.

No. 9

Topotecan, pegylated liposomal doxorubicin hydrochloride and paclitaxel for second-line or subsequent treatment of advanced ovarian cancer: a systematic review and economic evaluation.

By Main C, Bojke L, Griffin S, Norman G, Barbieri M, Mather L, et al.

No. 10

Evaluation of molecular techniques in prediction and diagnosis of cytomegalovirus disease in immunocompromised patients.

By Szczepura A, Westmoreland D, Vinogradova Y, Fox J, Clark M.

No. 11

Screening for thrombophilia in high-risk situations: systematic review and costeffectiveness analysis. The Thrombosis: Risk and Economic Assessment of Thrombophilia Screening (TREATS) study.

By Wu O, Robertson L, Twaddle S, Lowe GDO, Clark P, Greaves M, et al.

\section{No. 12}

A series of systematic reviews to inform a decision analysis for sampling and treating infected diabetic foot

ulcers.

By Nelson EA, O'Meara S, Craig D, Iglesias C, Golder S, Dalton J, et al.

\section{No. 13}

Randomised clinical trial, observational study and assessment of cost-

effectiveness of the treatment of varicose veins (REACTIV trial).

By Michaels JA, Campbell WB,

Brazier JE, MacIntyre JB, Palfreyman SJ, Ratcliffe J, et al.

\section{No. 14}

The cost-effectiveness of screening for oral cancer in primary care.

By Speight PM, Palmer S, Moles DR, Downer MC, Smith DH, Henriksson M et al.

\section{No. 15}

Measurement of the clinical and costeffectiveness of non-invasive diagnostic testing strategies for deep vein thrombosis.

By Goodacre S, Sampson F, Stevenson M, Wailoo A, Sutton A, Thomas S, et al.

\section{No. 16}

Systematic review of the effectiveness and cost-effectiveness of HealOzone ${ }^{\circledR}$ for the treatment of occlusal pit/fissure caries and root caries.

By Brazzelli M, McKenzie L, Fielding S, Fraser C, Clarkson J, Kilonzo M, et al.

\section{No. 17}

Randomised controlled trials of conventional antipsychotic versus new atypical drugs, and new atypical drugs versus clozapine, in people with schizophrenia responding poorly to, or intolerant of, current drug treatment.

By Lewis SW, Davies L, Jones PB, Barnes TRE, Murray RM, Kerwin R, et al.

\section{No. 18}

Diagnostic tests and algorithms used in the investigation of haematuria: systematic reviews and economic evaluation.

By Rodgers M, Nixon J, Hempel S, Aho T, Kelly J, Neal D, et al.

\section{No. 19}

Cognitive behavioural therapy in addition to antispasmodic therapy for irritable bowel syndrome in primary care: randomised controlled trial.

By Kennedy TM, Chalder T, McCrone P, Darnley S, Knapp M, Jones RH, et al.
No. 20

A systematic review of the clinical effectiveness and cost-effectiveness of enzyme replacement therapies for

Fabry's disease and mucopolysaccharidosis type 1 .

By Connock M, Juarez-Garcia A, Frew E, Mans A, Dretzke J, Fry-Smith A, et al.

No. 21

Health benefits of antiviral therapy for mild chronic hepatitis C: randomised controlled trial and economic evaluation.

By Wright M, Grieve R, Roberts J, Main J, Thomas HC on behalf of the UK Mild Hepatitis C Trial Investigators.

\section{No. 22}

Pressure relieving support surfaces: a randomised evaluation.

By Nixon J, Nelson EA, Cranny G, Iglesias CP, Hawkins K, Cullum NA, et al.

No. 23

A systematic review and economic model of the effectiveness and costeffectiveness of methylphenidate, dexamfetamine and atomoxetine for the treatment of attention deficit hyperactivity disorder in children and adolescents.

By King S, Griffin S, Hodges Z, Weatherly H, Asseburg C, Richardson G, et al.

No. 24

The clinical effectiveness and costeffectiveness of enzyme replacement therapy for Gaucher's disease:

a systematic review.

By Connock M, Burls A, Frew E, Fry-Smith A, Juarez-Garcia A, McCabe C, et al.

No. 25

Effectiveness and cost-effectiveness of salicylic acid and cryotherapy for cutaneous warts. An economic decision model

By Thomas KS, Keogh-Brown MR, Chalmers JR, Fordham RJ, Holland RC, Armstrong SJ, et al.

No. 26

A systematic literature review of the effectiveness of non-pharmacological interventions to prevent wandering in dementia and evaluation of the ethical implications and acceptability of their use.

By Robinson L, Hutchings D, Corner L, Beyer F, Dickinson H, Vanoli A, et al.

\section{No. 27}

A review of the evidence on the effects and costs of implantable cardioverter defibrillator therapy in different patient groups, and modelling of costeffectiveness and cost-utility for these groups in a UK context.

By Buxton M, Caine N, Chase D, Connelly D, Grace A, Jackson C, et al. 
No. 28

Adefovir dipivoxil and pegylated interferon alfa-2a for the treatment of chronic hepatitis B: a systematic review and economic evaluation.

By Shepherd J, Jones J, Takeda A, Davidson P, Price A.

No. 29

An evaluation of the clinical and costeffectiveness of pulmonary artery catheters in patient management in intensive care: a systematic review and a randomised controlled trial.

By Harvey S, Stevens K, Harrison D, Young D, Brampton W, McCabe C, et al.

\section{No. 30}

Accurate, practical and cost-effective assessment of carotid stenosis in the UK.

By Wardlaw JM, Chappell FM, Stevenson M, De Nigris E, Thomas S, Gillard J, et al.

\section{No. 31}

Etanercept and infliximab for the treatment of psoriatic arthritis: a systematic review and economic evaluation.

By Woolacott N, Bravo Vergel Y, Hawkins N, Kainth A, Khadjesari Z, Misso K, et al.

No. 32

The cost-effectiveness of testing for hepatitis $\mathrm{C}$ in former injecting drug users.

By Castelnuovo E, Thompson-Coon J, Pitt M, Cramp M, Siebert U, Price A, et al.

No. 33

Computerised cognitive behaviour therapy for depression and anxiety update: a systematic review and economic evaluation.

By Kaltenthaler E, Brazier J, De Nigris E, Tumur I, Ferriter M, Beverley C, et al.

No. 34

Cost-effectiveness of using prognostic information to select women with breast cancer for adjuvant systemic therapy.

By Williams C, Brunskill S, Altman D, Briggs A, Campbell H, Clarke M, et al.

No. 35

Psychological therapies including dialectical behaviour therapy for borderline personality disorder: a systematic review and preliminary economic evaluation.

By Brazier J, Tumur I, Holmes M, Ferriter M, Parry G, Dent-Brown K, et al.

No. 36

Clinical effectiveness and cost-

effectiveness of tests for the diagnosis and investigation of urinary tract infection in children: a systematic review and economic model.

By Whiting P, Westwood M, Bojke L, Palmer S, Richardson G, Cooper J, et al.
No. 37

Cognitive behavioural therapy in chronic fatigue syndrome: a randomised controlled trial of an outpatient group programme.

By O'Dowd H, Gladwell P, Rogers CA, Hollinghurst S, Gregory A.

No. 38

A comparison of the cost-effectiveness of five strategies for the prevention of nonsteroidal anti-inflammatory drug-induced gastrointestinal toxicity: a systematic review with economic modelling.

By Brown TJ, Hooper L, Elliott RA, Payne K, Webb R, Roberts C, et al.

\section{No. 39}

The effectiveness and cost-effectiveness of computed tomography screening for coronary artery disease: systematic review.

By Waugh N, Black C, Walker S, McIntyre L, Cummins E, Hillis G.

No. 40

What are the clinical outcome and costeffectiveness of endoscopy undertaken by nurses when compared with doctors? A Multi-Institution Nurse Endoscopy Trial (MINuET).

By Williams J, Russell I, Durai D, Cheung W-Y, Farrin A, Bloor K, et al.

\section{No. 41}

The clinical and cost-effectiveness of oxaliplatin and capecitabine for the adjuvant treatment of colon cancer: systematic review and economic evaluation.

By Pandor A, Eggington S, Paisley S, Tappenden P, Sutcliffe P.

\section{No. 42}

A systematic review of the effectiveness of adalimumab, etanercept and infliximab for the treatment of rheumatoid arthritis in adults and an economic evaluation of their costeffectiveness.

By Chen Y-F, Jobanputra P, Barton P, Jowett S, Bryan S, Clark W, et al.

No. 43

Telemedicine in dermatology: a randomised controlled trial.

By Bowns IR, Collins K, Walters SJ, McDonagh AJG.

\section{No. 44}

Cost-effectiveness of cell salvage and alternative methods of minimising perioperative allogeneic blood transfusion: a systematic review and economic model.

By Davies L, Brown TJ, Haynes S, Payne K, Elliott RA, McCollum C.

\section{No. 45}

Clinical effectiveness and cost-

effectiveness of laparoscopic surgery for colorectal cancer: systematic reviews and economic evaluation.

By Murray A, Lourenco T,

de Verteuil R, Hernandez R, Fraser C, McKinley A, et al.
No. 46

Etanercept and efalizumab for the treatment of psoriasis: a systematic review.

By Woolacott N, Hawkins N, Mason A, Kainth A, Khadjesari Z, Bravo Vergel Y, et al.

No. 47

Systematic reviews of clinical decision tools for acute abdominal pain.

By Liu JLY, Wyatt JC, Deeks JJ, Clamp S, Keen J, Verde P, et al.

\section{No. 48}

Evaluation of the ventricular assist device programme in the UK.

By Sharples L, Buxton M, Caine N, Cafferty F, Demiris N, Dyer M, et al.

\section{No. 49}

A systematic review and economic model of the clinical and costeffectiveness of immunosuppressive therapy for renal transplantation in children.

By Yao G, Albon E, Adi Y, Milford D, Bayliss S, Ready A, et al.

No. 50

Amniocentesis results: investigation of anxiety. The ARIA trial.

By Hewison J, Nixon J, Fountain J, Cocks K, Jones C, Mason G, et al.

\section{Volume II, 2007}

No. 1

Pemetrexed disodium for the treatment of malignant pleural mesothelioma: a systematic review and economic evaluation.

By Dundar Y, Bagust A, Dickson R, Dodd S, Green J, Haycox A, et al.

No. 2

A systematic review and economic model of the clinical effectiveness and cost-effectiveness of docetaxel in combination with prednisone or prednisolone for the treatment of hormone-refractory metastatic prostate cancer

By Collins R, Fenwick E, Trowman R, Perard R, Norman G, Light K, et al.

No. 3

A systematic review of rapid diagnostic tests for the detection of tuberculosis infection.

By Dinnes J, Deeks J, Kunst H, Gibson A, Cummins E, Waugh N, et al.

No. 4

The clinical effectiveness and costeffectiveness of strontium ranelate for the prevention of osteoporotic fragility fractures in postmenopausal women.

By Stevenson M, Davis S, Lloyd-Jones M, Beverley C. 
No. 5

A systematic review of quantitative and qualitative research on the role and effectiveness of written information available to patients about individual medicines.

By Raynor DK, Blenkinsopp A, Knapp P, Grime J, Nicolson DJ, Pollock K, et al.

No. 6

Oral naltrexone as a treatment for relapse prevention in formerly opioid-dependent drug users: a systematic review and economic evaluation.

By Adi Y, Juarez-Garcia A, Wang D, Jowett $\mathrm{S}$, Frew E, Day E, et al.

No. 7

Glucocorticoid-induced osteoporosis: a systematic review and cost-utility analysis.

By Kanis JA, Stevenson M, McCloskey EV, Davis S, Lloyd-Jones M.

\section{No. 8}

Epidemiological, social, diagnostic and economic evaluation of population screening for genital chlamydial infection.

By Low N, McCarthy A, Macleod J, Salisbury C, Campbell R, Roberts TE, et al.

\section{No. 9}

Methadone and buprenorphine for the management of opioid dependence: a systematic review and economic evaluation.

By Connock M, Juarez-Garcia A, Jowett S, Frew E, Liu Z, Taylor RJ, et al.

\section{No. 10}

Exercise Evaluation Randomised Trial (EXERT): a randomised trial comparing GP referral for leisure centre-based exercise, community-based walking and advice only.

By Isaacs AJ, Critchley JA, See Tai S, Buckingham K, Westley D, Harridge SDR, et al.

\section{No. 11}

Interferon alfa (pegylated and non-pegylated) and ribavirin for the treatment of mild chronic hepatitis C: a systematic review and economic evaluation.

By Shepherd J, Jones J, Hartwell D, Davidson P, Price A, Waugh N.

No. 12

Systematic review and economic evaluation of bevacizumab and cetuximab for the treatment of metastatic colorectal cancer.

By Tappenden P, Jones R, Paisley S, Carroll C.

\section{No. 13}

A systematic review and economic evaluation of epoetin alfa, epoetin beta and darbepoetin alfa in anaemia associated with cancer, especially that attributable to cancer treatment.

By Wilson J, Yao GL, Raftery J,

Bohlius J, Brunskill S, Sandercock J, et al.

\section{No. 14}

A systematic review and economic evaluation of statins for the prevention of coronary events.

By Ward S, Lloyd Jones M, Pandor A, Holmes M, Ara R, Ryan A, et al.

\section{No. 15}

A systematic review of the effectiveness and cost-effectiveness of different models of community-based respite care for frail older people and their carers.

By Mason A, Weatherly H, Spilsbury K, Arksey H, Golder S, Adamson J, et al.

\section{No. 16}

Additional therapy for young children with spastic cerebral palsy: a randomised controlled trial.

By Weindling AM, Cunningham CC, Glenn SM, Edwards RT, Reeves DJ.

\section{No. 17}

Screening for type 2 diabetes: literature review and economic modelling.

By Waugh N, Scotland G,

McNamee P, Gillett M, Brennan A, Goyder E, et al.

\section{No. 18}

The effectiveness and cost-effectiveness of cinacalcet for secondary hyperparathyroidism in end-stage renal disease patients on dialysis: a systematic review and economic evaluation.

By Garside R, Pitt M, Anderson R, Mealing S, Roome C, Snaith A, et al.

\section{No. 19}

The clinical effectiveness and cost-effectiveness of gemcitabine for metastatic breast cancer: a systematic review and economic evaluation.

By Takeda AL, Jones J, Loveman E, Tan SC, Clegg AJ.

\section{No. 20}

A systematic review of duplex ultrasound, magnetic resonance angiography and computed tomography angiography for the diagnosis and assessment of symptomatic, lower limb peripheral arterial disease.

By Collins R, Cranny G, Burch J, Aguiar-Ibáñez R, Craig D, Wright K, et al.
No. 21

The clinical effectiveness and costeffectiveness of treatments for children with idiopathic steroid-resistant nephrotic syndrome: a systematic review.

By Colquitt JL, Kirby J, Green C, Cooper K, Trompeter RS.

No. 22

A systematic review of the routine monitoring of growth in children of primary school age to identify growth-related conditions.

By Fayter D, Nixon J, Hartley S, Rithalia A, Butler G, Rudolf M, et al.

No. 23

Systematic review of the effectiveness of preventing and treating Staphylococcus aureus carriage in reducing peritoneal catheter-related infections.

By McCormack K, Rabindranath K, Kilonzo M, Vale L, Fraser C, McIntyre L, et al.

\section{No. 24}

The clinical effectiveness and cost of repetitive transcranial magnetic stimulation versus electroconvulsive therapy in severe depression: a multicentre pragmatic randomised controlled trial and economic analysis.

By McLoughlin DM, Mogg A, Eranti S, Pluck G, Purvis R, Edwards D, et al.

\section{No. 25}

A randomised controlled trial and economic evaluation of direct versus indirect and individual versus group modes of speech and language therapy for children with primary language impairment.

By Boyle J, McCartney E, Forbes J, O'Hare A.

No. 26

Hormonal therapies for early breast cancer: systematic review and economic evaluation.

By Hind D, Ward S, De Nigris E, Simpson E, Carroll C, Wyld L.

No. 27

Cardioprotection against the toxic effects of anthracyclines given to children with cancer: a systematic review.

By Bryant J, Picot J, Levitt G, Sullivan I, Baxter L, Clegg A.

\section{No. 28}

Adalimumab, etanercept and infliximab for the treatment of ankylosing spondylitis: a systematic review and economic evaluation.

By McLeod C, Bagust A, Boland A, Dagenais P, Dickson R, Dundar Y, et al. 
No. 29

Prenatal screening and treatment strategies to prevent group B streptococcal and other bacterial infections in early infancy: costeffectiveness and expected value of information analyses.

By Colbourn T, Asseburg C, Bojke L, Philips Z, Claxton K, Ades AE, et al.

No. 30

Clinical effectiveness and costeffectiveness of bone morphogenetic proteins in the non-healing of fractures and spinal fusion: a systematic review.

By Garrison KR, Donell S, Ryder J, Shemilt I, Mugford M, Harvey I, et al.

\section{No. 31}

A randomised controlled trial of postoperative radiotherapy following breast-conserving surgery in a minimum-risk older population. The PRIME trial.

By Prescott RJ, Kunkler IH, Williams LJ, King CC, Jack W, van der Pol M, et al.

\section{No. 32}

Current practice, accuracy, effectiveness and cost-effectiveness of the school entry hearing screen.

By Bamford J, Fortnum H, Bristow K, Smith J, Vamvakas G, Davies L, et al.

\section{No. 33}

The clinical effectiveness and cost-effectiveness of inhaled insulin in diabetes mellitus: a systematic review and economic evaluation.

By Black C, Cummins E, Royle P, Philip S, Waugh N.

\section{No. 34}

Surveillance of cirrhosis for hepatocellular carcinoma: systematic review and economic analysis.

By Thompson Coon J, Rogers G, Hewson P, Wright D, Anderson R, Cramp M, et al.

\section{No. 35}

The Birmingham Rehabilitation Uptake Maximisation Study (BRUM). Homebased compared with hospital-based cardiac rehabilitation in a multi-ethnic population: cost-effectiveness and patient adherence.

By Jolly K, Taylor R, Lip GYH, Greenfield S, Raftery J, Mant J, et al.

\section{No. 36}

A systematic review of the clinical, public health and cost-effectiveness of rapid diagnostic tests for the detection and identification of bacterial intestinal pathogens in faeces and food.

By Abubakar I, Irvine L, Aldus CF, Wyatt GM, Fordham R, Schelenz S, et al.

\section{No. 37}

A randomised controlled trial

examining the longer-term outcomes of standard versus new antiepileptic drugs. The SANAD trial.

By Marson AG, Appleton R, Baker GA, Chadwick DW, Doughty J, Eaton B, et al.

\section{No. 38}

Clinical effectiveness and cost-

effectiveness of different models

of managing long-term oral

anticoagulation therapy: a systematic

review and economic modelling.

By Connock M, Stevens C, Fry-Smith A, Jowett S, Fitzmaurice D, Moore D, et al.

\section{No. 39}

A systematic review and economic model of the clinical effectiveness and cost-effectiveness of interventions for preventing relapse in people with bipolar disorder.

By Soares-Weiser K, Bravo Vergel Y, Beynon S, Dunn G, Barbieri M, Duffy S, et al.

\section{No. 40}

Taxanes for the adjuvant treatment of early breast cancer: systematic review and economic evaluation.

By Ward S, Simpson E, Davis S, Hind D, Rees A, Wilkinson A.

\section{No. 41}

The clinical effectiveness and costeffectiveness of screening for open angle glaucoma: a systematic review and economic evaluation.

By Burr JM, Mowatt G, Hernández R, Siddiqui MAR, Cook J, Lourenco T, et al.

\section{No. 42}

Acceptability, benefit and costs of early screening for hearing disability: a study of potential screening tests and models.

By Davis A, Smith P, Ferguson M, Stephens D, Gianopoulos I.

No. 43

Contamination in trials of educational interventions.

By Keogh-Brown MR, Bachmann MO, Shepstone L, Hewitt C, Howe A, Ramsay CR, et al.

\section{No. 44}

Overview of the clinical effectiveness of positron emission tomography imaging in selected cancers

By Facey K, Bradbury I, Laking G, Payne E.

\section{No. 45}

The effectiveness and cost-effectiveness of carmustine implants and temozolomide for the treatment of newly diagnosed high-grade glioma: a systematic review and economic evaluation.

By Garside R, Pitt M, Anderson R, Rogers G, Dyer M, Mealing S, et al.
No. 46

Drug-eluting stents: a systematic review and economic evaluation.

By Hill RA, Boland A, Dickson R, Dündar Y, Haycox A, McLeod C, et al.

No. 47

The clinical effectiveness and costeffectiveness of cardiac resynchronisation (biventricular pacing) for heart failure: systematic review and economic model

By Fox M, Mealing S, Anderson R, Dean J, Stein K, Price A, et al.

\section{No. 48}

Recruitment to randomised trials: strategies for trial enrolment and participation study. The STEPS study.

By Campbell MK, Snowdon C, Francis D, Elbourne D, McDonald AM, Knight R, et al.

No. 49

Cost-effectiveness of functional cardiac testing in the diagnosis and management of coronary artery disease: a randomised controlled trial.

The CECaT trial.

By Sharples L, Hughes V, Crean A, Dyer M, Buxton M, Goldsmith K, et al.

\section{No. 50}

Evaluation of diagnostic tests when there is no gold standard. A review of methods.

By Rutjes AWS, Reitsma JB,

Coomarasamy A, Khan KS, Bossuyt PMM.

No. 51

Systematic reviews of the clinical effectiveness and cost-effectiveness of proton pump inhibitors in acute upper gastrointestinal bleeding.

By Leontiadis GI, Sreedharan A Dorward S, Barton P, Delaney B. Howden CW, et al.

No. 52

A review and critique of modelling in prioritising and designing screening programmes.

By Karnon J, Goyder E, Tappenden P, McPhie S, Towers I, Brazier J, et al.

No. 53

An assessment of the impact of the NHS Health Technology Assessment Programme.

By Hanney S, Buxton M, Green C, Coulson D, Raftery J.

\section{Volume 12, 2008}

No. 1

A systematic review and economic model of switching from nonglycopeptide to glycopeptide antibiotic prophylaxis for surgery.

By Cranny G, Elliott R, Weatherly H, Chambers D, Hawkins N, Myers L, et al. 
No. 2

'Cut down to quit' with nicotine replacement therapies in smoking cessation: a systematic review of effectiveness and economic analysis.

By Wang D, Connock M, Barton P, Fry-Smith A, Aveyard P, Moore D.

\section{No. 3}

A systematic review of the effectiveness of strategies for reducing fracture risk in children with juvenile idiopathic arthritis with additional data on longterm risk of fracture and cost of disease management

By Thornton J, Ashcroft D,

O'Neill T, Elliott R, Adams J, Roberts C, et al.

No. 4

Does befriending by trained lay workers improve psychological well-being and quality of life for carers of people with dementia, and at what cost? A randomised controlled trial.

By Charlesworth G, Shepstone L, Wilson E, Thalanany M, Mugford M, Poland F.

No. 5

A multi-centre retrospective cohort study comparing the efficacy, safety and costeffectiveness of hysterectomy and uterine artery embolisation for the treatment of symptomatic uterine fibroids. The HOPEFUL study.

By Hirst A, Dutton S, Wu O, Briggs A, Edwards C, Waldenmaier L, et al.

\section{No. 6}

Methods of prediction and prevention of pre-eclampsia: systematic reviews of accuracy and effectiveness literature with economic modelling.

By Meads CA, Cnossen JS, Meher S, Juarez-Garcia A, ter Riet G, Duley L, et al.

No. 7

The use of economic evaluations in NHS decision-making: a review and empirical investigation.

By Williams I, McIver S, Moore D, Bryan S.

\section{No. 8}

Stapled haemorrhoidectomy (haemorrhoidopexy) for the treatment of haemorrhoids: a systematic review and economic evaluation.

By Burch J, Epstein D, Baba-Akbari A, Weatherly H, Fox D, Golder S, et al.

No. 9

The clinical effectiveness of diabetes education models for Type 2 diabetes: a systematic review.

By Loveman E, Frampton GK, Clegg AJ

\section{No. 10}

Payment to healthcare professionals for patient recruitment to trials: systematic review and qualitative study.

By Raftery J, Bryant J, Powell J, Kerr C, Hawker S.

\section{No. 11}

Cyclooxygenase-2 selective non-steroidal anti-inflammatory drugs (etodolac, meloxicam, celecoxib, rofecoxib, etoricoxib, valdecoxib and lumiracoxib) for osteoarthritis and rheumatoid arthritis: a systematic review and economic evaluation.

By Chen Y-F, Jobanputra P, Barton P, Bryan S, Fry-Smith A, Harris G, et al.

\section{No. 12}

The clinical effectiveness and costeffectiveness of central venous catheters treated with anti-infective agents in preventing bloodstream infections: a systematic review and economic evaluation.

By Hockenhull JC, Dwan K, Boland A, Smith G, Bagust A, Dündar Y, et al.

\section{No. 13}

Stepped treatment of older adults on laxatives. The STOOL trial.

By Mihaylov S, Stark C, McColl E, Steen N, Vanoli A, Rubin G, et al.

\section{No. 14}

A randomised controlled trial of cognitive behaviour therapy in adolescents with major depression treated by selective serotonin reuptake inhibitors. The ADAPT trial.

By Goodyer IM, Dubicka B,

Wilkinson P, Kelvin R, Roberts C, Byford S, et al.

\section{No. 15}

The use of irinotecan, oxaliplatin and raltitrexed for the treatment of advanced colorectal cancer: systematic review and economic evaluation.

By Hind D, Tappenden P, Tumur I Eggington E, Sutcliffe P, Ryan A.

\section{No. 16}

Ranibizumab and pegaptanib for the treatment of age-related macular degeneration: a systematic review and economic evaluation.

By Colquitt JL, Jones J, Tan SC, Takeda A, Clegg AJ, Price A.

\section{No. 17}

Systematic review of the clinical effectiveness and cost-effectiveness of 64-slice or higher computed tomography angiography as an alternative to invasive coronary angiography in the investigation of coronary artery disease.

By Mowatt G, Cummins E, Waugh N, Walker S, Cook J, Jia X, et al.
No. 18

Structural neuroimaging in psychosis: a systematic review and economic evaluation.

By Albon E, Tsourapas A, Frew E, Davenport C, Oyebode F, Bayliss S, et al.

\section{No. 19}

Systematic review and economic analysis of the comparative effectiveness of different inhaled corticosteroids and their usage with long-acting beta ${ }_{2}$ agonists for the treatment of chronic asthma in adults and children aged 12 years and over.

By Shepherd J, Rogers G, Anderson R, Main C, Thompson-Coon J, Hartwell D, et al.

No. 20

Systematic review and economic analysis of the comparative effectiveness of different inhaled corticosteroids and their usage with long-acting beta 2 agonists for the treatment of chronic asthma in children under the age of 12 years.

By Main C, Shepherd J, Anderson R, Rogers G, Thompson-Coon J, Liu Z, et al.

\section{No. 21}

Ezetimibe for the treatment of hypercholesterolaemia: a systematic review and economic evaluation.

By Ara R, Tumur I, Pandor A, Duenas A, Williams R, Wilkinson A, et al.

No. 22

Topical or oral ibuprofen for chronic knee pain in older people. The TOIB study.

By Underwood M, Ashby D, Carnes D, Castelnuovo E, Cross P, Harding G, et al.

No. 23

A prospective randomised comparison of minor surgery in primary and secondary care. The MiSTIC trial.

By George S, Pockney P, Primrose J, Smith H, Little P, Kinley $\mathrm{H}$, et al.

No. 24

A review and critical appraisal of measures of therapist-patient interactions in mental health settings.

By Cahill J, Barkham M, Hardy G, Gilbody S, Richards D, Bower P, et al.

No. 25

The clinical effectiveness and costeffectiveness of screening programmes for amblyopia and strabismus in children up to the age of $4-5$ years: a systematic review and economic evaluation.

By Carlton J, Karnon J, Czoski-Murray C, Smith KJ, Marr J. 
No. 26

A systematic review of the clinical effectiveness and cost-effectiveness and economic modelling of minimal incision total hip replacement approaches in the management of arthritic disease of the hip.

By de Verteuil R, Imamura M, Zhu S, Glazener C, Fraser C, Munro N, et al.

\section{No. 27}

A preliminary model-based assessment of the cost-utility of a screening programme for early age-related macular degeneration.

By Karnon J, Czoski-Murray C, Smith K, Brand C, Chakravarthy U, Davis $\mathrm{S}$, et al.
No. 28

Intravenous magnesium sulphate and sotalol for prevention of atrial fibrillation after coronary artery bypass surgery: a systematic review and economic evaluation.

By Shepherd J, Jones J,

Frampton GK, Tanajewski L, Turner D, Price A. 



\section{Health Technology Assessment Programme}

\begin{tabular}{|c|c|c|c|}
\hline \multirow[b]{2}{*}{ Members } & $\begin{array}{l}\text { Director, } \\
\text { Professor Tom Walley, } \\
\text { Director, NHS HTA Programme, } \\
\text { Department of Pharmacology \& } \\
\text { Therapeutics, } \\
\text { University of Liverpool }\end{array}$ & $\begin{array}{l}\text { Deputy Director, } \\
\text { Professor Jon Nicholl, } \\
\text { Director, Medical Care Research } \\
\text { Unit, University of Sheffield, } \\
\text { School of Health and Related } \\
\text { Research }\end{array}$ & \\
\hline & & & \\
\hline $\begin{array}{l}\text { Chair, } \\
\text { Professor Tom Walley, } \\
\text { Director, NHS HTA Programme, } \\
\text { Department of Pharmacology \& } \\
\text { Therapeutics, } \\
\text { University of Liverpool }\end{array}$ & $\begin{array}{l}\text { Professor Bruce Campbell, } \\
\text { Consultant Vascular \& General } \\
\text { Surgeon, Royal Devon \& Exeter } \\
\text { Hospital } \\
\text { Professor Robin E Ferner, } \\
\text { Consultant Physician and } \\
\text { Director, West Midlands Centre } \\
\text { for Adverse Drug Reactions, } \\
\text { City Hospital NHS Trust, } \\
\text { Birmingham }\end{array}$ & $\begin{array}{l}\text { Dr Edmund Jessop, Medical } \\
\text { Adviser, National Specialist, } \\
\text { Commissioning Advisory Group } \\
\text { (NSCAG), Department of } \\
\text { Health, London } \\
\text { Professor Jon Nicholl, Director, } \\
\text { Medical Care Research Unit, } \\
\text { University of Sheffield, } \\
\text { School of Health and } \\
\text { Related Research }\end{array}$ & $\begin{array}{l}\text { Dr Ron Zimmern, Director, } \\
\text { Public Health Genetics Unit, } \\
\text { Strangeways Research } \\
\text { Laboratories, Cambridge }\end{array}$ \\
\hline
\end{tabular}

\section{HTA Commissioning Board}

Members

\section{Programme Director,}

Professor Tom Walley,

Director, NHS HTA Programme,

Department of Pharmacology \&

Therapeutics,

University of Liverpool

Chair,

Professor Jon Nicholl,

Director, Medical Care Research

Unit, University of Sheffield,

School of Health and Related

Research

\section{Deputy Chair,}

Dr Andrew Farmer,

University Lecturer in General

Practice, Department of

Primary Health Care,

University of Oxford

Dr Jeffrey Aronson,

Reader in Clinical

Pharmacology, Department of

Clinical Pharmacology,

Radcliffe Infirmary, Oxford
Professor Deborah Ashby,

Professor of Medical Statistics,

Department of Environmental

and Preventative Medicine,

Queen Mary University of

London

Professor Ann Bowling,

Professor of Health Services

Research, Primary Care and

Population Studies,

University College London

Professor John Cairns,

Professor of Health Economics,

Public Health Policy,

London School of Hygiene

and Tropical Medicine,

London

Professor Nicky Cullum,

Director of Centre for Evidence

Based Nursing, Department of

Health Sciences, University of

York

Professor Jon Deeks,

Professor of Health Statistics,

University of Birmingham
Professor Jenny Donovan,

Professor of Social Medicine,

Department of Social Medicine,

University of Bristol

Professor Freddie Hamdy,

Professor of Urology,

University of Sheffield

Professor Allan House,

Professor of Liaison Psychiatry,

University of Leeds

Professor Sallie Lamb, Director,

Warwick Clinical Trials Unit,

University of Warwick

Professor Stuart Logan,

Director of Health \& Social

Care Research, The Peninsula

Medical School, Universities of

Exeter \& Plymouth

Professor Miranda Mugford,

Professor of Health Economics,

University of East Anglia

Dr Linda Patterson,

Consultant Physician,

Department of Medicine,

Burnley General Hospital
Professor Ian Roberts,

Professor of Epidemiology \&

Public Health, Intervention

Research Unit, London School

of Hygiene and Tropical

Medicine

Professor Mark Sculpher,

Professor of Health Economics,

Centre for Health Economics,

Institute for Research in the

Social Services,

University of York

Professor Kate Thomas,

Professor of Complementary

and Alternative Medicine,

University of Leeds

Professor David John Torgerson, Director of York Trial Unit,

Department of Health Sciences,

University of York

Professor Hywel Williams,

Professor of

Dermato-Epidemiology,

University of Nottingham 


\section{Diagnostic Technologies \& Screening Panel}

Members

\section{Chair,}

Dr Ron Zimmern, Director of the Public Health Genetics Unit, Strangeways Research Laboratories, Cambridge

Ms Norma Armston, Freelance Consumer Advocate, Bolton

Professor Max Bachmann, Professor of Health Care Interfaces, Department of Health Policy and Practice, University of East Anglia

Professor Rudy Bilous Professor of Clinical Medicine \& Consultant Physician,

The Academic Centre,

South Tees Hospitals NHS Trust

Ms Dea Birkett, Service User Representative, London
Dr Paul Cockcroft, Consultant Medical Microbiologist and Clinical Director of Pathology, Department of Clinical Microbiology, St Mary's Hospital, Portsmouth

Professor Adrian K Dixon, Professor of Radiology, University Department of Radiology, University of Cambridge Clinical School

Dr David Elliman, Consultant in Community Child Health, Islington PCT \& Great Ormond Street Hospital, London

Professor Glyn Elwyn, Research Chair, Centre for Health Sciences Research, Cardiff University, Department of General Practice, Cardiff

Professor Paul Glasziou, Director, Centre for Evidence-Based Practice, University of Oxford
Dr Jennifer J Kurinczuk, Consultant Clinical Epidemiologist, National Perinatal Epidemiology Unit, Oxford

Dr Susanne M Ludgate, Clinical Director, Medicines \& Healthcare Products Regulatory Agency, London

Mr Stephen Pilling, Director, Centre for Outcomes, Research \& Effectiveness, Joint Director, National Collaborating Centre for Mental Health, University College London

Mrs Una Rennard,

Service User Representative,

Oxford

Dr Phil Shackley, Senior Lecturer in Health Economics, Academic Vascular Unit, University of Sheffield
Dr Margaret Somerville, Director of Public Health Learning, Peninsula Medical School, University of Plymouth

Dr Graham Taylor, Scientific Director \& Senior Lecturer, Regional DNA Laboratory, The Leeds Teaching Hospitals

Professor Lindsay Wilson Turnbull, Scientific Director, Centre for MR Investigations \& YCR Professor of Radiology, University of Hul

Professor Martin J Whittle, Clinical Co-director, National Co-ordinating Centre for Women's and Childhealth

Dr Dennis Wright, Consultant Biochemist \& Clinical Director, The North West London Hospitals NHS Trust, Middlesex

\section{Pharmaceuticals Panel}

\section{Chair,}

Professor Robin Ferner,

Consultant Physician and Director, West Midlands Centre for Adverse Drug Reactions, City Hospital NHS Trust, Birmingham

Ms Anne Baileff, Consultant Nurse in First Contact Care, Southampton City Primary Care Trust, University of Southampton
Professor Imti Choonara, Professor in Child Health, Academic Division of Child Health, University of Nottingham

Professor John Geddes, Professor of Epidemiological Psychiatry, University of Oxford

Mrs Barbara Greggains, Non-Executive Director, Greggains Management Ltd

Dr Bill Gutteridge, Medical Adviser, National Specialist Commissioning Advisory Group (NSCAG), London

Mrs Sharon Hart, Consultant Pharmaceutical Adviser, Reading
Dr Jonathan Karnon, Senior Research Fellow, Health Economics and Decision Science, University of Sheffield

Dr Yoon Loke, Senior Lecturer in Clinical Pharmacology, University of East Anglia

Ms Barbara Meredith, Lay Member, Epsom

Dr Andrew Prentice, Senior Lecturer and Consultant Obstetrician \& Gynaecologist, Department of Obstetrics \& Gynaecology, University of Cambridge

Dr Frances Rotblat, CPMP Delegate, Medicines \& Healthcare Products Regulatory Agency, London

\section{Dr Martin Shelly, General Practitioner, Leeds}

Mrs Katrina Simister, Assistant Director New Medicines, National Prescribing Centre, Liverpool

Dr Richard Tiner, Medical Director, Medical Department, Association of the British Pharmaceutical Industry, London 


\section{Therapeutic Procedures Panel}

Members

\section{Chair,}

Professor Bruce Campbell,

Consultant Vascular and General Surgeon, Department of Surgery, Royal Devon \& Exeter Hospital

Dr Mahmood Adil, Deputy Regional Director of Public Health, Department of Health, Manchester

Dr Aileen Clarke, Consultant in Public Health, Public Health Resource Unit, Oxford
Professor Matthew Cooke,

Professor of Emergency

Medicine, Warwick Emergency

Care and Rehabilitation,

University of Warwick

Mr Mark Emberton, Senior Lecturer in Oncological Urology, Institute of Urology, University College Hospital

Professor Paul Gregg, Professor of Orthopaedic Surgical Science, Department of General Practice and Primary Care, South Tees Hospital NHS

Trust, Middlesbrough

Ms Maryann L Hardy, Lecturer, Division of Radiography, University of Bradford
Dr Simon de Lusignan, Senior Lecturer, Primary Care Informatics, Department of Community Health Sciences, St George's Hospital Medical School, London

Dr Peter Martin, Consultant Neurologist, Addenbrooke's Hospital, Cambridge

Professor Neil McIntosh, Edward Clark Professor of Child Life \& Health, Department of Child Life \& Health, University of Edinburgh

Professor Jim Neilson, Professor of Obstetrics and Gynaecology, Department of Obstetrics and Gynaecology, University of Liverpool
Dr John C Pounsford,

Consultant Physician,

Directorate of Medical Services, North Bristol NHS Trust

Dr Karen Roberts, Nurse Consultant, Queen Elizabeth Hospital, Gateshead

Dr Vimal Sharma, Consultant Psychiatrist/Hon. Senior Lecturer, Mental Health Resource Centre, Cheshire and Wirral Partnership NHS Trust, Wallasey

Professor Scott Weich, Professor of Psychiatry, Division of Health in the Community, University of Warwick

Members

\section{Chair, \\ Dr Edmund Jessop, Medical} Adviser, National Specialist Commissioning Advisory Group (NSCAG), London

Mrs Sheila Clark, Chief Executive, St James's Hospital, Portsmouth

Mr Richard Copeland Lead Pharmacist: Clinical Economy/Interface, Wansbeck General Hospital, Northumberland
Dr Elizabeth Fellow-Smith, Medical Director, West London Mental Health Trust, Middlesex

Mr Ian Flack, Director PPI Forum Support, Council of Ethnic Minority Voluntary Sector Organisations, Stratford

Dr John Jackson, General Practitioner, Newcastle upon Tyne

Mrs Veronica James, Chief Officer, Horsham District Age Concern, Horsham

Professor Mike Kelly, Director, Centre for Public Health Excellence,

National Institute for Health and Clinical Excellence, London
Professor Yi Mien Koh, Director of Public Health and Medical Director, London NHS (North West London Strategic Health Authority), London

Ms Jeanett Martin, Director of Clinical Leadership \& Quality, Lewisham PCT, London

Dr Chris McCall, General Practitioner, Dorset

Dr David Pencheon, Director, Eastern Region Public Health Observatory, Cambridge

Dr Ken Stein, Senior Clinical Lecturer in Public Health, Director, Peninsula Technology

Assessment Group,

University of Exeter,

Exeter
Dr Carol Tannahill, Director, Glasgow Centre for Population Health, Glasgow

Professor Margaret Thorogood, Professor of Epidemiology, University of Warwick, Coventry

Dr Ewan Wilkinson, Consultant in Public Health, Royal Liverpool University Hospital, Liverpool 


\section{Expert Advisory Network}

\section{Members}

Professor Douglas Altman, Professor of Statistics in Medicine, Centre for Statistics in Medicine, University of Oxford

Professor John Bond, Director, Centre for Health Services Research, University of Newcastle upon Tyne, School of Population \& Health Sciences, Newcastle upon Tyne

Professor Andrew Bradbury, Professor of Vascular Surgery, Solihull Hospital, Birmingham

Mr Shaun Brogan,

Chief Executive, Ridgeway

Primary Care Group, Aylesbury

Mrs Stella Burnside OBE

Chief Executive,

Regulation and Improvement

Authority, Belfast

Ms Tracy Bury,

Project Manager, World

Confederation for Physical

Therapy, London

Professor Iain T Cameron, Professor of Obstetrics and Gynaecology and Head of the School of Medicine, University of Southampton

Dr Christine Clark, Medical Writer \& Consultant Pharmacist, Rossendale

Professor Collette Clifford, Professor of Nursing \& Head of Research, School of Health Sciences, University of Birmingham, Edgbaston, Birmingham

Professor Barry Cookson, Director, Laboratory of Healthcare Associated Infection, Health Protection Agency, London

Dr Carl Counsell, Clinical Senior Lecturer in Neurology, Department of Medicine \& Therapeutics, University of Aberdeen

Professor Howard Cuckle, Professor of Reproductive Epidemiology, Department of Paediatrics, Obstetrics \& Gynaecology, University of Leeds

Dr Katherine Darton, Information Unit, MIND The Mental Health Charity, London
Professor Carol Dezateux, Professor of Paediatric Epidemiology, London

Dr Keith Dodd, Consultant Paediatrician, Derby

Mr John Dunning, Consultant Cardiothoracic Surgeon, Cardiothoracic Surgical Unit, Papworth Hospital NHS Trust, Cambridge

Mr Jonothan Earnshaw, Consultant Vascular Surgeon, Gloucestershire Royal Hospital, Gloucester

Professor Martin Eccles, Professor of Clinical

Effectiveness, Centre for Health Services Research, University of Newcastle upon Tyne

Professor Pam Enderby, Professor of Community Rehabilitation, Institute of General Practice and Primary Care, University of Sheffield

Professor Gene Feder, Professor of Primary Care Research \& Development, Centre for Health Sciences, Barts \& The London Queen Mary's School of Medicine \& Dentistry, London

Mr Leonard R Fenwick,

Chief Executive, Newcastle upon Tyne Hospitals NHS Trust

Mrs Gillian Fletcher,

Antenatal Teacher \& Tutor and President, National Childbirth Trust, Henfield

Professor Jayne Franklyn, Professor of Medicine,

Department of Medicine, University of Birmingham, Queen Elizabeth Hospital,

Edgbaston, Birmingham

Dr Neville Goodman,

Consultant Anaesthetist, Southmead Hospital, Bristol

Professor Robert E Hawkins, CRC Professor and Director of Medical Oncology, Christie CRC Research Centre, Christie Hospital NHS Trust, Manchester

Professor Allen Hutchinson, Director of Public Health \& Deputy Dean of ScHARR, Department of Public Health, University of Sheffield

Professor Peter Jones, Professor of Psychiatry, University of Cambridge, Cambridge
Professor Stan Kave, Cancer Research UK Professor of Medical Oncology, Section of Medicine, Royal Marsden Hospital \& Institute of Cancer Research, Surrey

Dr Duncan Keeley, General Practitioner (Dr Burch \& Ptnrs), The Health Centre, Thame

Dr Donna Lamping, Research Degrees Programme Director \& Reader in Psychology, Health Services Research Unit, London School of Hygiene and Tropical Medicine, London

Mr George Levvy,

Chief Executive, Motor

Neurone Disease Association, Northampton

Professor James Lindesay, Professor of Psychiatry for the Elderly, University of Leicester, Leicester General Hospital

Professor Julian Little, Professor of Human Genome Epidemiology, Department of Epidemiology \& Community Medicine, University of Ottawa

Professor Rajan Madhok, Consultant in Public Health, South Manchester Primary Care Trust, Manchester

Professor Alexander Markham, Director, Molecular Medicine Unit, St James's University Hospital, Leeds

Professor Alistaire McGuire, Professor of Health Economics, London School of Economics

Dr Peter Moore,

Freelance Science Writer, Ashtead

Dr Andrew Mortimore, Public Health Director, Southampton City Primary Care Trust, Southampton

Dr Sue Moss, Associate Director Cancer Screening Evaluation Unit, Institute of Cancer Research, Sutton

Mrs Julietta Patnick, Director, NHS Cancer Screening Programmes, Sheffield

Professor Robert Peveler, Professor of Liaison Psychiatry, Royal South Hants Hospital, Southampton
Professor Chris Price,

Visiting Professor in Clinica Biochemistry, University of Oxford

Professor William Rosenberg, Professor of Hepatology and Consultant Physician, University of Southampton, Southampton

Professor Peter Sandercock, Professor of Medical Neurology, Department of Clinical Neurosciences, University of Edinburgh

Dr Susan Schonfield, Consultant in Public Health, Hillingdon PCT, Middlesex

Dr Eamonn Sheridan,

Consultant in Clinical Genetics, Genetics Department, St James's University Hospital, Leeds

Professor Sarah Stewart-Brown, Professor of Public Health, University of Warwick, Division of Health in the Community Warwick Medical School, LWMS, Coventry

Professor Ala Szczepura, Professor of Health Service Research, Centre for Health Services Studies, University of Warwick

Dr Ross Taylor, Senior Lecturer, Department of General Practice and Primary Care, University of Aberdeen

Mrs Joan Webster, Consumer member, HTA Expert Advisory Network 



\section{Feedback}

The HTA Programme and the authors would like to know your views about this report.

The Correspondence Page on the HTA website (http://www.hta.ac.uk) is a convenient way to publish your comments. If you prefer, you can send your comments

to the address below, telling us whether you would like us to transfer them to the website.

We look forward to hearing from you.

The National Coordinating Centre for Health Technology Assessment,

Alpha House, Enterprise Road

Southampton Science Park

Chilworth

Southampton SO 16 7NS, UK.

Fax: +44 (0) $2380595639 \quad$ Email: hta@hta.ac.uk

http://www.hta.ac.uk 